$8 / 1 F, E 350, B 21 \% N 8$

\title{
Non-Aqueous Electrolyte Solutions in Chemistry and Modern Technology
}

Josef Barthel, Heiner-J. Gores, Georg Schmeer, and Rudolf Wachter

Institut für Physikalische und Theoretische Chemie der Universität Regensburg, FRG

Table of Contents

\section{Part A}

Fundamentals of Chemistry and Physical Chemistry of Non-Aqueous Electrolyte Solutions

I Introduction . . . . . . . . . . . . . . . . . . . . . . . . . . 37

II Classification of Solvents and Electrolytes. . . . . . . . . . . . . . 38

III Thermodynamics of Electrolyte Solutions . . . . . . . . . . . . . . 40

IV Short and Long-Range Forces in Dilute Electrolyte Solutions . . . . . . 43

4.1 Distribution Functions and Mean-Force Potentials . . . . . . . 43

4.2 The Basic Chemical Model of Electrolyte Solutions . . . . . . . 44

4.3 The Ion-Pair Concept. . . . . . . . . . . . . . . . . . . . 46

V Thermodynamic Properties of Electrolyte Solutions . . . . . . . . . . 48

5.1 Generalities . . . . . . . . . . . . . . . . . . . . . 48

5.2 Solution and Dilution Experiments . . . . . . . . . . . . . . 49

5.3 EMF-Measurements .. . . . . . . . . . . . . . . . . . 52

5.4 Some Remarks on Thermodynamic Investigations . . . . . . . 53

5.5 Ion Solvation . . . . . . . . . . . . . . . . . . . . 54

5.6 Concentrated Solutions . . . . . . . . . . . . . . . . . . . 56

5.7 Water at Extreme External Conditions . . . . . . . . . . . . 57

VI Transport Properties. . . . . . . . . . . . . . . . . . . . . . . 57

6.1 Dilute Solutions . . . . . . . . . . . . . . . . . . . . 57

6.2 Concentrated Solutions . . . . . . . . . . . . . . . . . . . 61

6.3 Ion Aggregates and their Role in Conductance . . . . . . . . . 62 
Josef Barthel et al.

VII Spectroscopic and Relaxation Methods . . . . . . . . . . . . . . . 64

7.1 Introduction. . . . . . . . . . . . . . . . . 64

7.2 Diffraction Methods . . . . . . . . . . . . . . . . . 65

7.3 Absorption Spectroscopy . . . . . . . . . . . . . . . . . . 67

7.4 NMR and Related Methods . . . . . . . . . . . . . . . . . 70

7.5 ESR-Spectroscopy . . . . . . . . . . . . . . . . . . . . . 71

7.6 Relaxation Methods . . . . . . . . . . . . . . . 71

VIII Chemical Reactions in Organic Solvents . . . . . . . . . . . . . . 74

8.1 Ions and Ion Pairs in Chemical Reactions . . . . . . . . . . . 74

8.2 Kinetic Solvent Effects . . . . . . . . . . . . . . . . . . . 75

8.3 The Use of Correlation Functions . . . . . . . . . . . . . . 80)

8.4 Phase-Transfer Reactions . . . . . . . . . . . . . . . . 82

\section{Part B}

\section{Technical Applications and Applied Research}

Univ. Bibliothek Regensburro
IX

Introduction

$\mathbf{X}$

High-Energy Batteries . . . . . . . . . . . . . . . . . . . . . . 85

10.1 Background . . . . . . . . . . . . . . . . . . 85

10.2 Non-Aqueous Electrolyte Solutions in Lithium Batteries. . . . . 87

10.3 Stability of Electrolyte Solutions with Lithium . . . . . . . . . 90

10.4 Non-Aqueous Primary Cells . . . . . . . . . . . . . . . . . 91

10.4.1 Commercial Cells with Solid Cathodes and Organic Solvents 91

10.4.2 Commercial Cells with Liquid Cathodic Materials . . . . 91

10.4.3 Recent Developments. . . . . . . . . . . . . . . . . 92

10.5 Secondary Batteries. . . . . . . . . . . . . . . . . . . . . 93

10.5.1 Improvements of the Cycling Efficiency of the Anode. . . 9.3

10.5.2 Cathode Materials for Secondary Lithium Batteries. . . . 95

XI Non-Emissive Electro-Optic Displays. . . . . . . . . . . . . . . . 96

11.1 Comparison of Methods. . . . . . . . . . . . . . . . . . . 96

11.2 Displays with Non-Aqueous Electrolyte Solutions . . . . . . . 97

XII Photo-Electrochemical Cells. . . . . . . . . . . . . . . . . . . 98

12.1 Introduction. . . . . . . . . . . . . . . . . . . . . . . . 98

12.2 Liquid-Junction Cells . . . . . . . . . . . . . . . . . . . . 94

12.3 Non-Aqueous Solutions in Liquid-Junction Cells . . . . . . . . 10()

XIII Electrodeposition . . . . . . . . . . . . . . . . . 102

13.1 Introduction. . . . . . . . . . . . . . . . . . . . . . . . 102

13.2 Selected Examples . . . . . . . . . . . . . . . . . . . . . 103

XIV Wet Electrolytic Capacitors. . . . . . . . . . . . . . . . 104 
XV Electro-Organic Synthesis . . . . . . . . . . . . . . 105

15.1 Disappointments and Advantages. . . . . . . . . . . . . 105

15.2 The Influence of Electrolyte Solutions on Reactions. . . . . . . 107

15.3 Selected Examples from Actual Investigations . . . . . . . . 108

XVI Further Promising Fields of Application. . . . . . . . . . . . . . . 110

16.1 Processes Based on Solvating Properties. . . . . . . . . . . . 110

16.2 Electropolishing . . . . . . . . . . . . . . . 111

16.3 Anodic Oxidation of Semiconductors . . . . . . . . . . 111

XVII Acknowledgements. . . . . . . . . . . . . . 111

XVIII Appendices . . . . . . . . . . . . . . . . . . . . . . . . . . 111

A Solvent and Electrolyte Data. . . . . . . . . . . 111

A.1 Properties of Organic Solvents . . . . . . . . . . 111

A.2 Ion Distance Parameters . . . . . . . . . . . . . 116

B Electrostatic Potential around a Particle with

an Arbitrary Charge Distribution. . . . . . . . . . . . . 116

C Electrostatic Potential around a Polarisable Apolar Particle . . . 119

D Symbols and Abbreviations . . . . . . . . . . . . . . . 121

D.1 Fundamental Constants . . . . . . . . . . . 121

D.2 Generally Used Superscripts and Subscripts . . . . . . . 121

D.2.1 Superscripts . . . . . . . . . . . . . . . 121

D.2.2 Subscripts . . . . . . . . . . . . . 121

D.3 Symbols . . . . . . . . . . . . . . 122

XIX References (Part A and B) . . . . . . . . . . . . . 123

XX References (Appendices A, B, C and D) . . . . . . . . . 141

In this paper a brief survey is given of the properties of non-atpueous electrolyte solutions and their applications in chemistry and technology without going into the details of theory. Specilic solvent-solute interactions and the role of the solvent beyond its function as a homogenous isotropic medium are stressed. Taking into account Parker's statement " "Scicmtists now'culats are under increasing pressure to consider the relevance of their rescurch. and rightly so" we have included examples showing the increasing industrial interest in non-aqueous electrolyte solutions.

The concepts and results are arranged in two parts. Part A concerns the fundamentals of thermodynamics, transport processes, spectroscopy and chemical kinetics of non-ilyueous solutions and some applications in these fields. Part B describes their use in various technologies such ats high-energy hatteries, non-emissive electro-optic displays, photoelectrochemical cells. clectrodeposition. electrolytic capacitors, electro-organic synthesis, metallurgic processes and others.

Four Appendices are added. Appendix A gives a survey on the most important non-alyucous sotvents, their physical properties and correlation parameters. and the commonly used abbreviations. Appendices $B$ and $($ show the mathematical background of the general chemical model. The symbols and abbreviations of the text are listed and explained in Appendix $D$. 


$$
-
$$




\section{Part A}

\section{Fundamentals of Chemistry and Physical Chemistry of Non-Aqueous Electrolyte Solutions}

\section{Introduction}

The systematic investigation of non-aqueous solutions is guided by the progress of our knowledge on solute-solute and solute-solvent interactions. By combination with chemical models of the solution, valuable results can be obtained which assist the understanding of the properties of these solutions.

For Dilute Electrolyte Solutions consistent and reliable equations are based on the modern conception of electrochemistry which takes into account both long and short-range forces between the solute and solvent particles in the framework of the McMillan-Mayer-Friedman approaches to theory ${ }^{2)}$. Solution chemists usually think of short-range interactions in terms of ion-pair formation. A chemical model of electrolyte solutions as developed and used in our laboratory ${ }^{3.4)}$ is the basis of the fundamentals given in part A of this survey. It allows the use of the classical association concept initially introduced by Bjerrum ${ }^{5)}$ after some refinements concerning the spatial extension and structure of ion pairs and the mean-force potentials. Classical thermodynamics and transport phenomena are unable to distinguish between ion pairs and undissociated electrolyte molecules, both proving their presence in the solutions as neutral particles in equilibrium with the 'free' ions. However, in favourable cases ion pairs may be detected separately from undissociated electrolyte molecules by spectroscopic methods. The ions in an ion pair retain their individual ionic characters and are linked only by Coulombic and short-range forces, including $\mathrm{H}$-bonding.

Modern developments of the statistical-mechanical theory of solutions provide valuable results, but no satisfactory answer can yet be found to fundamental questions such as the effect of ions on the permittivity of the solvent or on the structures in solution ${ }^{2)}$. Computer simulations may be helpful in understanding how some fundamental properties of the solutions are derived from fundamental laws. However, the actual limitation to a set of a few hundred particles in a box of about $20 \AA$ of length, a time scale of the order of picoseconds, and pair potentials based on classical mechanics usually prevent the deduction of useful relationships for the properties of real electrolyte solutions.

The treatment of Electrolyte Solutions from Moderate to Saturated Concentrations either rationalizes the effects from ion-ion and ion-solvent interactions in terms of the parameters characterizing the behaviour of electrolytes in dilute solutions or uses correlation methods based on empirical interaction scales ${ }^{6-211}$. Examples of both procedures will be given. 


\section{Classification of Soblvents and Electrolytes}

Any attempt to set up a complete theory which takes into account all types of interaction energy between the ions and molecules of an electrolyte solution with the aim of determining the properties of the solution by means of statistical thermodynamic methods must be unsuccessful as a result of insuperable mathematical difficulties. The approaches to the problem which have been used were outlined in Section I.

Two aspects determine the role of the solvent: its bulk properties and its electron donor or acceptor abilities. The Debye-Hückel theory ${ }^{22)}$ which is valid at infinitcly low concentrations, recognizes solvents only by their bulk properties, i.c. relative permittivity $\varepsilon$, viscosity $\eta$, and density $\varrho$. However, the Debye-Hückel range of validity is often experimentally unattainable (Ref. ${ }^{4)}$, cf. also Figs. 4 and 6). The importance of bulk properties decreases with increasing electrolyte concentration.

Donor and acceptor properties are the main factors which govern processes on the molecular scale, i.e. solvation and association. Theoretical and semiphenomenological approaches use molecular properties, dipole and quadrupole moments, polarizability etc., or mean-force potentials for taking these effects into consideration. Applied solution chemistry takes account of them with the help of the $\mathrm{cm}$ pirical scales previously mentioned ${ }^{6-211}$.

Various attempts have been made to classify solvents, e.g. according to bulk and molecular properties ${ }^{20}$, empirical solvent parameter scales ${ }^{6-211}$, hydrogen-bonding ability ${ }^{23.24)}$. and miscibility ${ }^{25}$. In table I solvents are divided into classes on the basis of their acid-base properties ${ }^{26-29}$ ) which can be used as a general chemical measure of their ability to interact with other species. Detailed information on these and other solvents, their symbols, fusion and boiling points $\left(\theta_{1}\right.$ and $\left.\theta_{13}\right)$, bulk properties $(\varepsilon, \eta, \varrho)$, and currently-used correlation parameters DN (donor number). $\mathrm{E}_{\mathrm{T}}$-value, and $\mathrm{AN}$ (acceptor number) is given in Appendix A-1.

Table I Classification of organic solvents (for detailed information see: Appendix A-1)

\begin{tabular}{|c|c|}
\hline Solvent class & Examples \\
\hline 1. amphiprotic hydroxylic & $\begin{array}{l}\text { methanol (MeOH): ethanol (EtOH): l-propanol } \\
(\mathrm{PrOH}) \text { : diethylene glycol (DF:G): glycerol: }\end{array}$ \\
\hline 2. amphiprotic protogenic & acetic acid \\
\hline 3. protophilic $\mathrm{H}$-bond donor & $\begin{array}{l}\text { formamide (FA); N-methylformamide (NMF): } \\
\text { diaminoethane; }\end{array}$ \\
\hline 4. aprotic protophilic & $\begin{array}{l}\text { dimethylformamide (DMF); 1-methyl-2-pyroli- } \\
\text { done (NMP); hexamethylphosphoric triamide } \\
\text { (HMPT); dimethylsulfoxide (DMSO) }\end{array}$ \\
\hline 5. aprotic protophobic & $\begin{array}{l}\text { acetonitrile }(\mathrm{AN}) \text {; sulfolane (TMS): propylene } \\
\text { carbonate }(\mathrm{PC}) ; \gamma \text {-butyrolactonc }(\gamma \text {-BL }) \text { : acetic } \\
\text { anhydride }\end{array}$ \\
\hline 6. Wow promittivity electron donor & 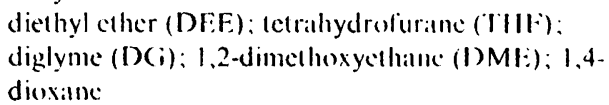 \\
\hline 7. incri & 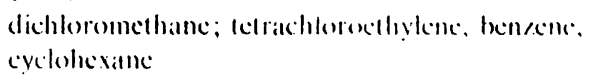 \\
\hline
\end{tabular}


The symbols quoted there, e.g. MeOH, THF, DME etc., are used in this text. No classification is universally applicable. Overlapping of the solvent classes is inevitable and some specific solute-solvent interactions evade classification. Specific interactions, however, are often sought in connexion with technological problems and have led to a search for appropriate solvent mixtures which are gaining importance in many fields of applied research. In spite of all its limitations, the classification of solvents is useful for rationalizing the choice of appropriate solvents and solvent mixtures for particular investigations.

Electrolytes can be classified in two categories, ionophores ${ }^{30)}$ (true electrolytes ${ }^{31}{ }^{11}$ ) and ionogenes ${ }^{301}$ (potential electrolytes ${ }^{31)}$ ). Ionophores are substances which, in the pure state, already exist as ionic crystals, e.g. alkali metal halides. lonogenes, such as carboxylic acids, form ions only by chemical reactions with solvent molecules. Amphiprotic solvents themselves behave as ionogenes in producing their lyonium ions (anions) and lyate ions (cations) by autoprotolysis reactions. Ionophores are initially completely dissociated in solution and their ions are solvated. However, almost all solvents allow ion-association to ion pairs and higher ion aggregates, both with and without inclusion of solvent molecules, to occur. When electrically neutral these species cannot transport current. The following examples are given for illustration:

(a) ionophores:

(b) ionogenes:

$$
\begin{aligned}
& \mathrm{NaCl} \text { (cryst) } \underset{\text { acetonitrile }}{\longrightarrow} \mathrm{Na}^{+}+\mathrm{Cl}^{-} \stackrel{\mathrm{K}_{A}}{\rightleftarrows}\left[\mathrm{Na}^{+} \mathrm{Cl}^{-}\right]^{0} \\
& \mathrm{LiBF}_{4} \text { (cryst) } \underset{\text { dimethoxyethane }}{\longrightarrow} \mathrm{Li}^{+}+\mathrm{BF}_{4}^{-} \stackrel{\mathrm{K}_{\mathrm{A}}}{\rightleftarrows}\left[\mathrm{Li}^{+} \mathrm{BF}_{4}^{-}\right]^{0} \\
& \text { and further asspciation to }\left[\mathrm{Li}^{+}\left(\mathrm{BF}_{4}^{-}\right)_{2}\right]^{-} \text {etc. }
\end{aligned}
$$

$$
\begin{aligned}
& \mathrm{HClO}_{4}+\mathrm{CH}_{3} \mathrm{COOH} \stackrel{\mathrm{K}_{1}}{\rightleftarrows}\left[\mathrm{CH}_{3} \mathrm{COOH}_{2}^{+} \mathrm{ClO}_{4}^{-}\right]^{0} \stackrel{\mathrm{K}_{\mathrm{D}}}{\rightleftarrows} \begin{array}{c}
\mathrm{CH}_{3} \mathrm{COOH}_{2}^{+}+ \\
+\mathrm{ClO}_{4}^{-}
\end{array} \\
& \mathrm{CH}_{3} \mathrm{OH}+\mathrm{CH}_{3} \mathrm{OH} \stackrel{\mathrm{KS}_{\mathrm{S}}}{\rightleftarrows} \mathrm{CH}_{3} \mathrm{OH}_{2}^{+}+\mathrm{CH}_{3} \mathrm{O}^{-} .
\end{aligned}
$$

These association and dissociation reactions do not usually proceed to completion. Both processes are described by the thermodynamic equilibrium constants $\mathrm{K}_{\mathrm{A}}$ (association constant) or $\mathrm{K}_{\mathrm{D}}$ (dissociation constant). The dissolution of perchloric acid in glacial acetic acid ${ }^{32-34}$ ) shows the typical ionisation equilibrium (equilibrium constant, $\mathrm{K}_{1}$ ) preceding the dissociation process in the case of ionogenes. The overall constant $\mathrm{K}$ is given by

$$
K=\frac{K_{1} K_{0}}{1+K_{1}} .
$$

for streng acids and bases, where $k_{1} s$. cepliation (1) reduces to $k=k_{1}$, whereals for weak ones, where $K_{1} \ll 1, K \ldots K_{1} K_{1}$. The sequence of basicitics cain change with changing solvent; the $K_{1}$-values are more significant for the discussion of ionogenes than are the $\mathrm{K}$-values. Ionisation constants, however, will not be discussed in this article. It is sufficient to note that the dissolution of acids or bases 
in amphiprotic solvents is generally followed by a protolysis reaction (partial neutralisation) as a consequence of the following equilibria:

$$
\begin{aligned}
& \mathrm{AH}+\mathrm{SH} \rightleftarrows \mathrm{A}^{-}+\mathrm{SH}_{2}^{+} \\
& \mathrm{B}+\mathrm{SH} \rightleftarrows \mathrm{BH}^{+}+\mathrm{S}^{-}
\end{aligned}
$$

where $\mathrm{SH}$ represents the amphiprotic solvent, $\mathrm{AH}$ the acid and $\mathrm{B}$ the base. When these equilibria are shifted markedly towards ionisation, a levelling effect ${ }^{35)}$ occurs which almost completely replaces the acids or bases with the lyate or lyonium ions of the solvent, irrespective of the initial strong acid or base. A typical example of this is the behaviour of the mineral acids in water.

The series of simultaneous equilibria including $K_{1}, K_{D}$ (or $K_{A}$ ) and the autoprotolysis constant $\mathrm{K}_{\mathrm{S}}$ limits the quantitative discussion of electrolyte solutions to simple cases. However, the appropriate choice of such cases will give valuable insight into the properties of electrolyte solutions, especially those of ionophores where the ionisation step need not be considered.

Finally, a classification of the individual ions is only possible in a rough and incomplete way. Monoatomic cations can be arranged according to the number of electrons and are referred to as " $\mathrm{d}^{\mathrm{n}}$-cations" (e.g. alkali metal cations then are $\mathrm{d}^{\text {" - }}$ cations). Cations such as $\left[\mathrm{R}_{4} \mathrm{~N}\right]^{+},\left[\mathrm{R}_{4} \mathrm{P}\right]^{+}$, or $\left[\mathrm{R}_{3} \mathrm{~S}\right]^{+}$have their charges shielded by alkyl or aryl groups. They are almost non-polarizable and are referred to as inert cations. Cations of type $\left[\mathrm{R}_{4-n} \mathrm{H}_{n} \mathrm{~N}\right]^{+}$or $\left[(\mathrm{ROH})_{4} \mathrm{~N}\right]^{+}$are protic cations, capable of forming $\mathrm{H}$-bonds with anions or solvent molecules. The distinction between "hard" and "soft" cations has no significant relevance here, but for anions it is useful. A detailed discussion of the properties of electrolyte solutions as a function of ion classes and solvents is given in Ref. ${ }^{36)}$.

It should be mentioned that experimental investigations, especially in dilute non-aqueous solutions, require highly purified solvents and solutes. Impurities can change the properties of the solution drastically. A water content of $20 \mathrm{pmm}$ is equivalent to the total amount of solute in a $10^{-3}$ molar solution. For checking the purity of solvents UV cut-off, conductivity, chromatography as well as thermal and electrochemical methods are recommended ${ }^{37-41)}$. The control of the purity of electrolytes is more difficult; for details see Refs. ${ }^{37-42)}$.

\section{Thermodynamics of Electrolyte Solutions}

The thermodynamic properties of an electrolyte solution can be derived from the chemical potentials $\mu_{i}$ of its components which are given by the relationships ${ }^{43}$. (if. also 301

$$
\begin{aligned}
& \mu_{s}(p, T)=\mu_{s}^{*}(p, T)+R T \ln x_{s} f_{s}: \\
& \mu_{s}^{*}(p, T)=\lim _{x_{s} \rightarrow 1} \mu_{s}(p, T) ; \quad \lim _{x_{s} \rightarrow 1} f_{s}=1
\end{aligned}
$$


for the solvent $\mathrm{S}$, and

$$
\begin{aligned}
& \mu_{i}(p, T)=\mu_{i}^{\infty(c)}(p, T)+v_{i} R T \ln c_{ \pm}^{(i)} y_{ \pm}^{(i)} ; \quad i=1,2, \ldots \\
& \mu_{i}^{\infty(c)}(p, T)=\lim _{x_{s} \rightarrow 1}\left[\mu_{i}(p, T)-v_{i} R T \ln c_{ \pm}^{(i)}\right] ; \quad \lim _{x_{s} \rightarrow 1} y_{ \pm}^{(i)}=1
\end{aligned}
$$

for the electrolyte components $Y_{i}=\left(X_{1}^{z_{1}}\right)_{v_{1}^{i}}\left(X_{2}^{z_{2}}\right)_{v_{2}^{i}}\left(X_{3}^{z_{3}}\right)_{v_{3}^{i}} \ldots \quad$ which dissociate into their ions $X_{m}^{z_{m}}$ according to the scheme $Y_{i} \rightarrow \sum_{m} v_{m}^{i} X_{m}^{z_{m}}$.

In these equations, $x_{s}$ and $c_{ \pm}^{(i)}$ are the mole fraction of the solvent, $S$, and the mean concentrations $\left[\mathrm{mol} / \mathrm{dm}^{3}\right.$ of solution] of the electrolytes, $Y_{i} ; f_{s}$ and $y_{ \pm}^{(i)}$ are the appropriate activity coefficients

$$
c_{ \pm}^{(i)}=\prod_{m} c_{m}^{v_{m}^{i} / v_{i}} ; \quad y_{ \pm}^{(i)}=\prod_{m} y_{m}^{v_{m}^{i} / v_{i}} ; \quad v_{i}=\sum_{m} v_{m}^{i} .
$$

Eqs. (4a) are replaced by an equivalent set of equations

$$
\mu_{i}(p, T)=\mu_{i}^{\infty o(m)}+v_{i} R T \ln m_{ \pm}^{(i)} \gamma_{ \pm}^{(i)} ; \quad i=1,2, \ldots
$$

if mean molalities, $\mathrm{m}_{ \pm}^{(\mathrm{i})}[\mathrm{mol} / \mathrm{kg}$ of solvent] are chosen as the concentration scale with $\gamma_{ \pm}^{(i)}$ as the appropriate activity coefficients. Eqs. ( $\left.4 \mathrm{~b}-\mathrm{f}\right)$ then must be appropriately changed. Conversion formulae for the reference chemical potentials, concentration scales and activity coefficients are given in Refs. ${ }^{31,36,43,44)}$.

The relationships 3 and 4 , or 3 and 5 , respectively, form a complete set of equations on which a general discussion of the thermodynamic properties of the electrolyte solution can be based.

As only some fundamental ideas can be illustrated in this article, the following discussion is restricted to solutions of a solvent $\mathrm{S}$ and a symmetrical electrolyte $\mathrm{Y}=\mathrm{C}^{z^{+}} \mathrm{A}^{z^{-}}$yielding $\mathrm{z}_{+}$-valent cations $\mathrm{C}^{z^{+}}$and $\mathrm{z}_{-}$-valent anions $\mathrm{A}^{\mathrm{z}^{-}}$. The chemical potential of the solute is then given by the relationships

$$
\begin{aligned}
& \mu_{\mathrm{Y}}(\mathrm{p}, \mathrm{T})=\mu_{\mathrm{Y}}^{\infty(\mathrm{c})}(\mathrm{p}, \mathrm{T})+2 \mathrm{RT} \ln \mathrm{c}_{ \pm} \mathrm{y}_{ \pm} \\
& \mathrm{c}_{ \pm}=\left[\mathrm{c}_{+} \mathrm{c}_{-}\right]^{1 / 2}=\mathrm{c}_{\mathrm{Y}}=\mathrm{c} ; \quad \mathrm{y}_{ \pm}=\left[\mathrm{y}_{+} \mathrm{y}_{-}\right]^{1 / 2}
\end{aligned}
$$

or by a similar set of equations derived from eq. (5).

Eq. (6a) is valid for both completely and partially dissociated (or associated) electrolytes if the activity coefficient is written as follows

$$
y_{ \pm}=\alpha y_{ \pm}^{\prime}
$$

with $\alpha$ as the degree of dissociation and $y_{ \pm}^{\prime}$ as the activity coeflicient of the dissociated part (free ions) of the electrolyte component of the solution ${ }^{4.36 .44)}$. For completely dissociated clectrolytes $\alpha$ is equal to 1 . The ion pairs of ionophoric electrolytes and the molecules of ionogenic electrolytes are in equilibrium with the free ions. The 
Josef Barthel et al.

equilibrium condition yields the equilibrium constant as an association $\left(\mathrm{K}_{\mathrm{A}}\right)$ or dissociation $\left(\mathrm{K}_{\mathrm{D}}\right)$ constant

$$
K_{A}=K_{D}^{-1}=\frac{1-\alpha}{\alpha^{2} c y_{ \pm}^{\prime 2}}
$$

The solution process of $n_{Y}$ mol of electrolyte $Y$ in $n_{s}$ mol of solvent $S$ is accompanied by a change in Gibbs energy

$$
\Delta_{\text {sol }} \mathrm{G}=\mathrm{n}_{\mathrm{s}}\left(\mu_{\mathrm{s}}-\mu_{\mathrm{s}}^{*}\right)+\mathrm{n}_{\mathrm{Y}}\left(\mu_{\mathrm{Y}}-\mu_{\mathrm{Y}}^{*}\right) .
$$

Analogous equations are obtained for every other extensive thermodynamic property $\mathrm{Z}$, i.e.

$$
\Delta_{\text {sol }} Z=n_{s}\left(Z_{s}-Z_{s}^{*}\right)+n_{Y}\left(Z_{Y}-Z_{Y}^{*}\right)
$$

where $Z_{i}$ and $Z_{i}^{*}$ are the partial molar quantities of the solvent or the electrolyte in the solution $\left(Z_{i}\right)$ and in the pure phase $\left(Z_{i}^{*}\right)$. Another useful formulation of $\Delta_{\text {sol }} Z$ is based on the definition of apparent molar quantities $\Phi_{Z}$ of the solute

$$
\mathrm{Z}=\mathrm{n}_{\mathrm{s}} \mathrm{Z}_{\mathrm{s}}^{*}+\mathrm{n}_{\mathrm{Y}} \Phi_{\mathrm{Z}}
$$

yielding the relationship

$$
\frac{\Delta_{\text {sol }} Z}{n_{Y}}=\Delta_{\text {sol }} Z_{Y}^{\infty}+\left(\Phi_{Z}-\Phi_{Z}^{\infty}\right) ; \quad \Delta_{\text {sol }} Z_{Y}^{\infty}=Z_{Y}^{\infty}-Z_{Y}^{*}
$$

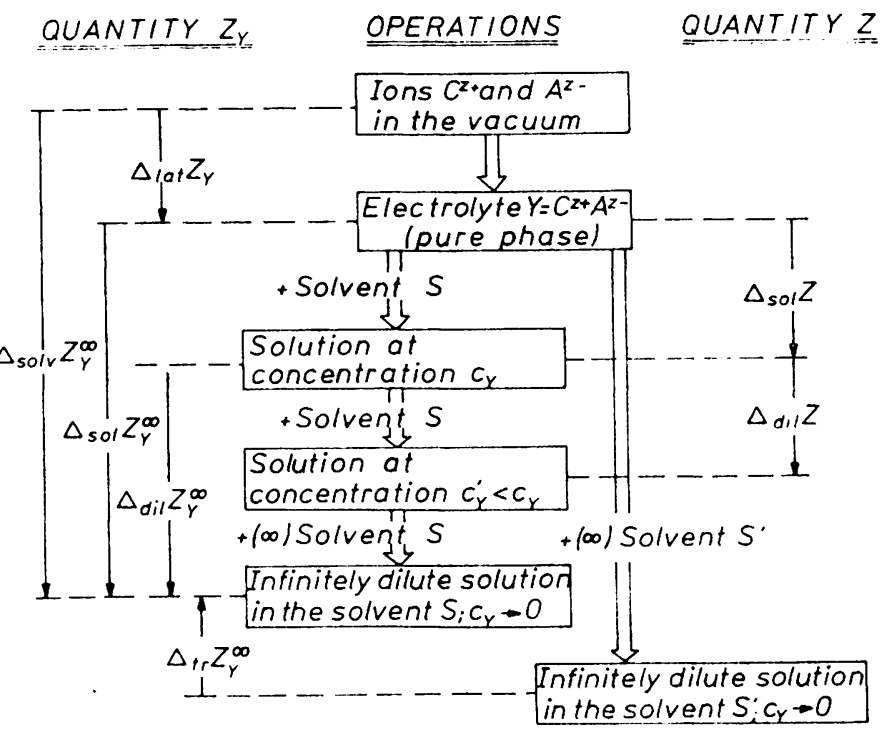

Fig. 1. Operations on electrolyte solutions at constant pressure and temperature and their appropriate translation into thermodynamic quantities:

$$
\Delta Z=Z_{\text {fin. }} \cdots Z_{\text {init. }}
$$

lat: lattice; solv: solvation; sol: solution; dil: dilution; tr: transfer from solvent $S^{\prime}$ to solvent $S$. $Z=V$ (volume): $S$ (entropy); $C_{n}$ (heat capacity); $H$ (enthalpy); $G$ (Gibbs energy) 
if the thermodynamic relation $\Phi_{Z}^{\infty}=Z_{Y}^{\infty}$ is taken into account. The molar quantity $\Delta_{\mathrm{sul}} Z_{\mathrm{Y}}$ corresponds to the transfer of $1 \mathrm{~mol}$ electrolyte compound from its pure state to infinite dilution in the solvent $S$.

Figure I summarizes the operations and notions used in solution chemistry.

\section{Short and Long-Range Forces in Dilute Electrolyte Solutions}

\subsection{Distribution Functions and Mean-Force Potentials}

The statistical theory of electrolyte solutions is built up around the distribution functions of the ions, $\mathrm{cf}^{30,44-49)}$. Electrolytes in solution give ions of the types $\mathrm{X}_{1}^{\mathrm{z}_{1}}, \mathrm{X}_{2}^{\mathrm{z}_{2}}, \ldots$ in the analytical concentrations $\mathrm{N}_{1}, \mathrm{~N}_{2}, \ldots$ ions $/ \mathrm{cm}^{3}$. The distribution of the ions in the solution depends on the forces acting between all the particles, ions and solvent molecules. External forces are also involved in the description of transport properties.

The analytical concentrations, $\mathrm{N}_{\mathrm{i}}$, are one-particle molecular distribution functions and do not provide any information on particle interactions. Two-particle molecular distribution functions

$$
f_{i j}\left(\vec{r}_{1}, \vec{r}_{2}\right)=N_{i} N_{j} g_{i j}\left(\vec{r}_{1}, \vec{r}_{2}\right)=N_{j} N_{i j} g_{j i}\left(\vec{r}_{2}, \vec{r}_{1}\right)=f_{j i}\left(\vec{r}_{2}, \vec{r}_{1}\right)
$$

indicate the probability of finding two ions, $X_{i}$ and $X_{j}$, simultaneously at points $P_{1}\left(\vec{r}_{1}\right)$ and $P_{2}\left(\vec{r}_{2}\right)$ in the solution, regardless of the position of the remaining ions and regardless of the velocities of all the particles, see Fig. 2. The pair-correlation

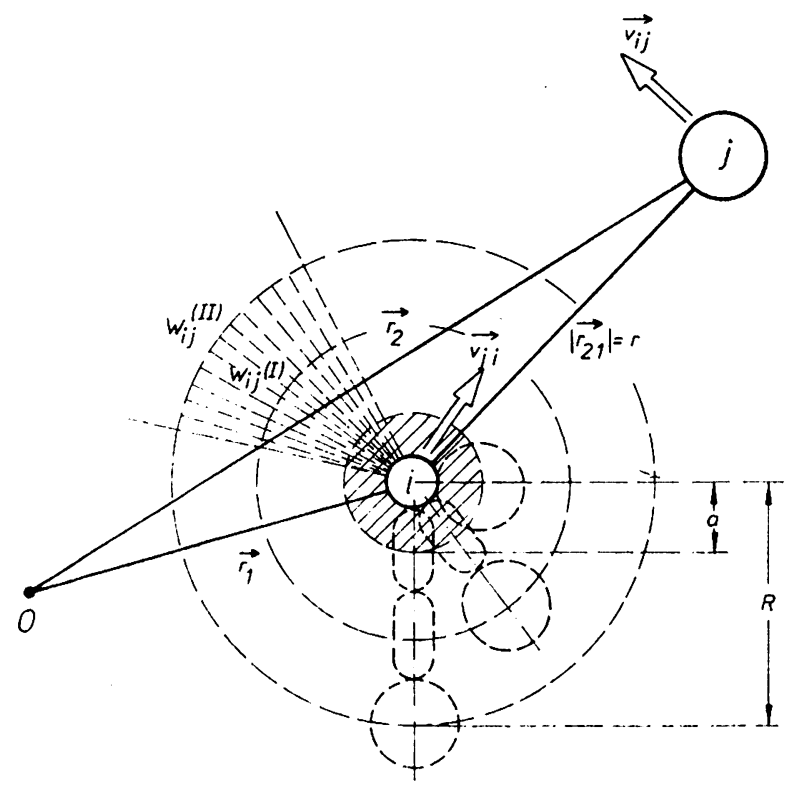

Fig. 2. The chemical model of electrolyte solutions. $\mathrm{O}$ : observer, $\mathrm{i}$ : ion $\mathrm{X}_{\mathrm{i}}$ : $\mathrm{j}$ : ion $\mathrm{X}_{\mathrm{j}}$ in an arbitrary position, $\vec{r}_{21}$, with regard to the ion $\mathrm{X}_{\mathrm{i}}$; special positions (contact, separation by one or two orientated solvent molecules) are sketched with broken lines. $r$, a, $R$ : distance parameters; $W_{i j}$ : mein-force potentials; $\dot{v}_{i j}$ and $\dot{v}_{j i}$ : relative velocitics of ions $X_{i}$ and $X_{j}$ 
Josef Barthel et al.

functions, $g_{i j}\left(\vec{r}_{1}, \vec{r}_{2}\right)$, are related to the mean-force potentials $W_{i j}\left(\vec{r}_{1}, \vec{r}_{2}\right)$ between the ions $X_{i}$ and $X_{j}$ by the relationship

$$
\mathrm{W}_{\mathrm{ij}}\left(\overrightarrow{\mathrm{r}}_{1}, \overrightarrow{\mathrm{r}}_{2}\right)=-\mathrm{kT} \ln \mathrm{g}_{\mathrm{ij}}\left(\overrightarrow{\mathrm{r}}_{1}, \overrightarrow{\mathrm{r}}_{2}\right) .
$$

In addition they can be used to determine the local concentrations $N_{i j}$ of ions $X_{j}$ at a distance $\vec{r}_{21}\left(\vec{r}_{21}=\vec{r}_{2}-\vec{r}_{1}\right)$ from an ion $X_{1}$ situated at $\vec{r}_{1}$

$$
N_{i j}\left(\vec{r}_{1}, \vec{r}_{21}\right)=N_{j} g_{i j}\left(\vec{r}_{1}, \vec{r}_{21}\right) \text {. }
$$

The relative velocities (see Fig. 2) of ions $X_{i}$ and $X_{j}, \vec{v}_{i j}\left(\vec{r}_{1}, \vec{r}_{21}\right)$ and $\vec{v}_{j i}\left(\vec{r}_{2}, \vec{r}_{12}\right)$, and the two-particle molecular distribution functions are linked by Onsager's continuity equation ${ }^{45)}$ :

$$
--\frac{\partial f_{i j}}{\partial t}=\operatorname{div}_{1}\left[f_{i j} \vec{v}_{i j}\right]+\operatorname{div}_{2}\left[f_{j i} \vec{v}_{j i}\right]=-\frac{\partial f_{j i}}{\partial t}
$$

where the differential operators are applied with regard to the coordinates in $\vec{r}_{1}$ and $\vec{r}_{2}$. A general treatment yielding Eq. (16) starts from Liouville's theorem and uses the BBGKY hierarchy of equations ${ }^{48,52)}$.

For basic information on electrolyte theory see Refs. ${ }^{2-4,22,30,36,44-70)}$.

\subsection{The Basic Chemical Model of Electrolyte Solutions}

In order to obtain a framework which allows the development of appropriate equations for the properties of solutions at low electrolyte concentrations, a model of the ions and their surroundings must be used which takes into account both short and long-range forces. For this purpose the space around an ion is subdivided into three regions (see Fig. 2).

i) $\mathrm{r} \leqq \mathrm{a}$, a being the minimum distance of two oppositely-charged ions which is assumed to be the sum of effective cation and anion radii, $a=a_{+}+a_{-}$.

ii) $\mathrm{a} \leqq \mathrm{r} \leqq \mathrm{R}$, within which a paired state of oppositely-charged ions, the so-called ion pair, suppresses long-range interactions with other ions in the solution. In dilute solutions the occupation of the region $\mathrm{a} \leqq \mathrm{r} \leqq \mathrm{R}$ by ions of the same sign or by more than two ions can usually be neglected.

iii) $r \geqq R$, the region of long-range ion-ion Coulombic interactions.

Table II shows the mean-force potentials for a dilute solution of the electrolyte compound $\mathrm{Y}=\mathrm{C}^{\mathbf{z}} \mathrm{A}^{\mathbf{z}^{-}}$.

The model is a McMillan-Mayer (MM)-level Hamiltonian model. Friedman ${ }^{21}$ characterizes models of this type as follows: "With MM-models it is interesting to see whether one can get a model that economically and elegantly agrees with all of the relevant experimental data for a given system: success would mean that we can understand all of the observations in terms of solvent-averaged forces between the ions. However, it must be noted that there is no reason to expect the MM potential function to be nearly pairwise additive. There is an upper bound on the ion concentration range within which it is sensible to compare the model with data for real systems if the pairwise addition approximation is made." 
Table II Mean-force potential $\mathrm{W}_{\mathrm{ij}}(\mathrm{r})$ of ion-ion interaction in dilute solutions of symmetrical electrolytes

The mean-force potentials of this table are special formulae of the general charge distribution. Appendix $B$, for a single charge (ion).

$$
x^{2}(\text { SI-units })=\frac{1000 \mathrm{~N}_{\mathrm{A}} \mathrm{e}_{0}^{2}}{\varepsilon_{0} \varepsilon \mathrm{kT}} \times \Gamma ; \Gamma \text { (ional concentration) }=\sum_{j}\left(\alpha c_{j}\right) z_{j}^{2}
$$

$\varepsilon_{0}$ : permittivity of vacuum; $\mathrm{k}$ : Boltzmann constant; $\mathrm{e}_{0}$ : charge of proton; $\mathrm{N}_{\mathrm{A}}$ : Avogadro number; $\mathrm{W}_{i j}^{*}$ mean-force potential of the short-range forces.

\begin{tabular}{ll}
\hline Region & Mean-force potential \\
\hline $\mathrm{r} \leqq \mathrm{a}$ & $\infty$ \\
$\mathrm{a} \leqq \mathrm{r} \leqq \mathrm{R}$ & $\frac{\mathrm{e}_{0}^{2} z_{i} z_{j}}{4 \pi \varepsilon_{0} \varepsilon} \times \frac{1}{\mathrm{r}}-\frac{\mathrm{e}_{0}^{2} z_{\mathrm{i}} z_{j}}{4 \pi \varepsilon_{0} \varepsilon} \frac{x}{1+x \mathrm{R}}+\mathrm{W}_{\mathrm{ij}}^{*}$ \\
$\mathrm{r} \geqq \mathrm{R}$ & $\frac{\mathrm{e}_{0}^{2} z_{\mathrm{i}} \mathrm{z}_{\mathrm{j}}}{4 \pi \varepsilon_{0} \varepsilon} \times \frac{1}{\mathrm{r}} \times \frac{\exp [x(\mathrm{R}-\mathrm{r})]}{1+x \mathrm{R}}$
\end{tabular}

A multitude of MM-level Hamiltonian models can be found for the same system. The features of our chemical model are given in Refs. ${ }^{3,4,72)}$.

i) The distance parameters a (minimum distance of two ions) and $\mathrm{R}$ (upper limit of the structured region around an ion) are fixed by chemical evidence.

ix) The lower distance is fixed as a hard-core radius by the center-to-center distance of the ions where these exist (e.g. alkali halides) or else is calculated from bond lengths or van der Waals volumes (e.g. tetraalkylammonium salts). For unsymmetrical ions like $\mathrm{Me}_{2} \mathrm{Bu}_{2} \mathrm{~N}^{+}$or $\mathrm{C}_{2} \mathrm{H}_{5} \mathrm{O}^{-}$the shortest possible distance is taken to be the distance of closest approach. Some ions, e.g. $\mathrm{Li}^{+}$in water or protic solvents, require the inclusion of a functional group of the solvent molecule (here: $\mathrm{OH}$ ) into the distance of closest approach. This leads to structures like $\mathrm{Li}^{+}(\mathrm{ROH}) \mathrm{Cl}^{-}$with $\mathrm{a}=\mathrm{a}_{\text {cryst }}+\mathrm{d}_{\mathrm{OH}}$.

iß) The upper distance $R$ is obtained by adding the length of one or more orientated solvent molecules to the distance of closest approach: $R=a+n s, n=1,2, \ldots$ Values $a$ and $s$ are quoted in Appendix A-2.

ii) The mean-force potentials of $\mathrm{W}_{\mathrm{ij}}$ (Eq. 14) are split into two parts representing Coulombic ion-ion interaction, $\mathrm{W}_{\mathrm{ij}}^{\mathrm{el}}$, and short-range interactions, $\mathrm{W}_{\mathrm{ij}}^{*} \mathrm{~A}$ further subdivision of the $\mathrm{W}_{\mathrm{ij}}^{*}$ 's which specifies contributions from induction, dispersion and chemical forces (e.g. $\mathrm{H}$-bonding) is possible. At the current stage of investigation, the contributions $\mathrm{W}_{\mathrm{ij}}^{\mathrm{el}}$ for every region are obtained from the resolution of a set of Poisson-equations and appropriate boundary conditions and the $\mathrm{W}_{\mathrm{ij}}^{*}$ are chosen as step potentials.

iii) Extensions

iiix) A subdivision of the region $a \leqq r \leqq R$ is useful when more than one shell of solvent molecules is orientated.

iiiß) The introduction of local permittivities is possible. 
Josef Barthel et al.

iii $)$ The spherical charge symmetry can be replaced by an arbitrary charge distribution leading to angular-dependent potentials. Appendix B gives a summary of the appropriate potentials. Chemical kinetics makes use of this type of extension when kinetic salt, solvent, and substituent effects are treated for reactions between particles with complex charge distributions (see Sect. VIII).

\subsection{The Ion-Pair Concept}

Models of the electrolyte solution allow the introduction of the association concept if a critical distance around the central ion can be defined within which pair configurations of oppositely charged ions are considered as ion pairs. The link between the model and the experimentally determined thermodynamic property of the solution is an integral expression which can be subdivided in various ways

$$
\int_{0}^{\infty} r^{2} g_{i j} d r=\int_{a}^{R} r^{2} \exp \left[-\frac{W_{i j}^{(l)}}{k T}\right] d r+\int_{R}^{\infty} r^{2} \exp \left[-\frac{W_{i j}^{(I)}}{k T}\right] d r .
$$

The choice of $R$ is arbitrary within reasonable limits and then divides up the thermodynamic excess function, $\mu_{\mathrm{Y}}^{\mathrm{E}}=v R T \ln \mathrm{y}_{ \pm}$, into contributions from the sodefined ion pair (degree of dissociation, $\alpha$ ) and from the 'free' ions (activity coefficient of the free ions, $y_{ \pm}^{\prime}$ ), cf. Eq. (7). Onsager characterized the situation as follows ${ }^{73)}$ : "The distinction between free ions and associated pairs depends on an arbitrary convention. Bjerrum's choice is good, but we could vary it within reason. In a complete theory this would not matter; what we remove from one page of the ledger would be entered elsewhere with the same effect."

Theory alone cannot provide a criterion for the best association constant. However, the variety of solution models leads usually to more or less satisfactory association constants when all of the relevant experimental data including their dependence on temperature and pressure are considered. Once more, chemical evidence is a good criterion for the selection of the appropriate model. It will be shown in the following sections that the identification of the "critical distance of association" with the cut-off distance of the short-range forces, $\mathrm{R}$, in our chemical model yields association constants which are almost independent of the experimental method of their determination.

The association concept is based on the equilibrium of 'free' ions and ion pairs in the solution

$$
\mathrm{C}^{\mathbf{z}^{+}}+\mathrm{A}^{\mathbf{z}-} \rightleftarrows\left[\mathrm{C}^{\mathbf{z}+} \mathrm{A}^{\mathbf{z}^{-}}\right]^{0} .
$$

The concentration equilibrium constant of ion-pair formation, $\mathrm{K}_{\mathrm{c}}=\mathrm{K}_{\mathrm{A}} \mathrm{y}_{ \pm}^{\prime 2}$ (sec Eq. (8)), can be written ${ }^{4}$ as shown in the first equation of Fig. 3 when using the reduced partition functions $Q_{p}, Q_{+}$, and $Q_{-}$of ion pairs, free cations and free anions.

As a first approximation the free cations and anions are considered as charged spheres of masses $m_{+}$and $m_{-}$. The ion pair is represented by an uncharged 


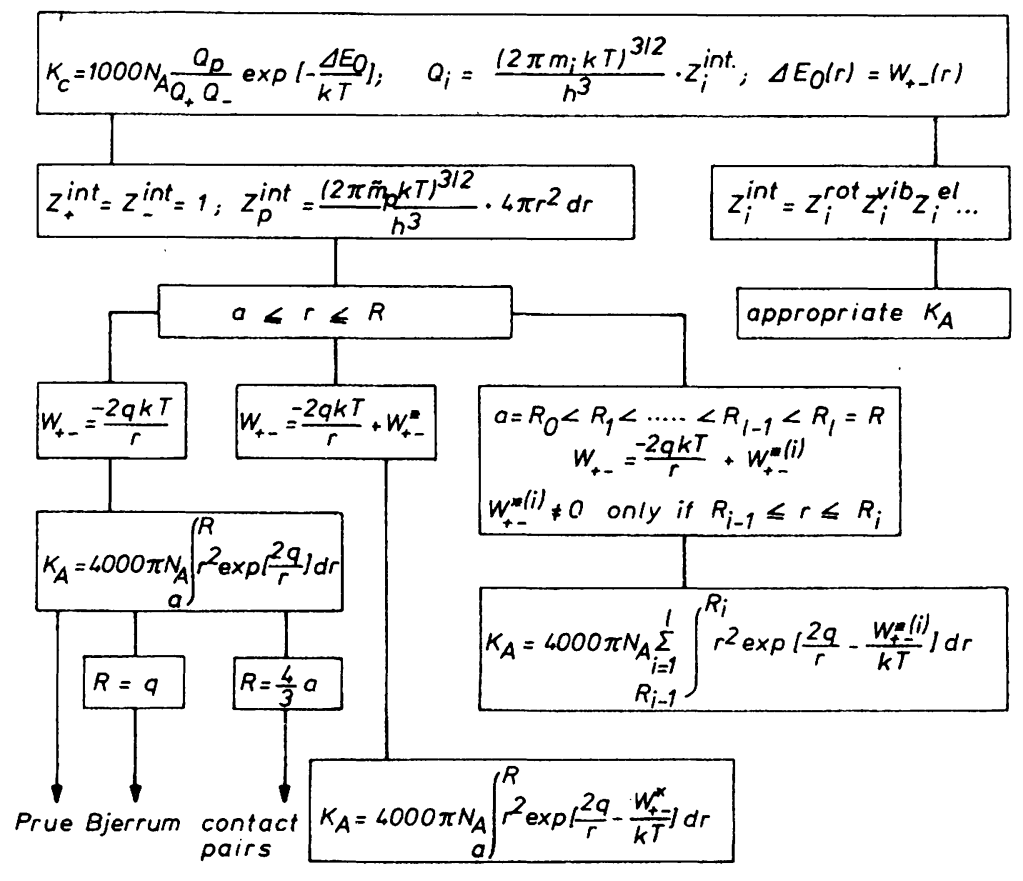

Fig. 3. The family tree of association constants

particle of reduced mass, $\tilde{\mathrm{m}}_{\mathrm{p}}\left(\tilde{\mathrm{m}}_{\mathrm{p}}^{-1}=\mathrm{m}_{+}^{-1}+\mathrm{m}_{-}^{-1}\right)$, in a spherical box of radius $\mathrm{R}$, meaning that an ion pair is formed if two oppositely-charged ions have approached to within a distance smaller than $R$. The difference in energies of the reacting species, $\Delta \mathrm{E}_{0}$, can be identified with the mean-force potential $\mathrm{W}_{+_{-}}(\mathrm{a} \leqq \mathrm{r} \leqq \mathrm{R})$, Table II.

Finally, cf. Fig. 3, the equation

$$
K_{A}=4000 \pi N_{A} \int_{a}^{R} r^{2} \exp \left[\frac{2 q}{r}-\frac{W_{+-}^{*}}{k T}\right] d r ; \quad q=\frac{e_{0}^{2}\left|z_{+} z_{-}\right|}{8 \pi \varepsilon_{0} \varepsilon k T}
$$

is obtained by this approximation. The activity coefficient of the dissociated part of the electrolyte, $y_{ \pm}^{\prime}$, is given by the relationship ${ }^{3,65)}$

$$
y_{ \pm}^{\prime}=\exp \left[-\frac{x q}{1+x R}\right] \text {. }
$$

Figure 3 shows the family tree of some association constants which can be found in the literature and indicates the presuppositions for deducing them from the initial equation. For example, Bjerrum's association constant ${ }^{5)}$ and its appropriate activity coefficient are obtained from Eqs. (19) by setting $R=q$ and $\mathrm{W}_{+-}^{*}=0$. As a further 
example, the subdivision of the region $a \leqq r \leqq R$ into $a<R_{1}<\ldots<R_{n-1}<R$ is straightforward ${ }^{4)}$. A current application is the case of stepwise ion-pair formation $^{74-76)}$, e.g.

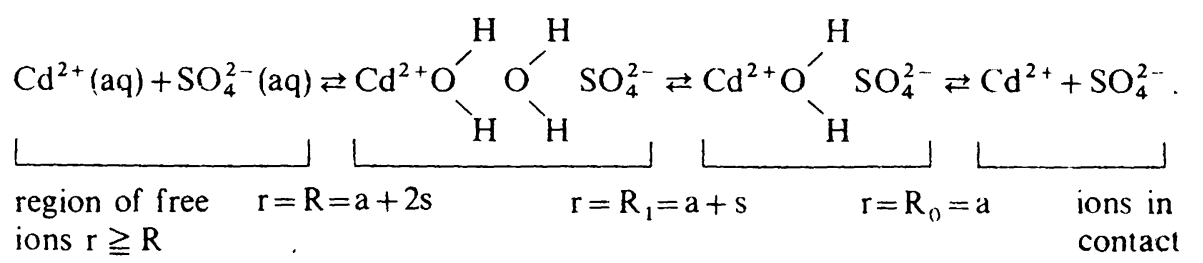

The distance parameter $\mathrm{a}=\mathrm{a}_{+}+\mathrm{a}_{-}$has its usual meaning, $\mathrm{s}$ is the length of an orientated solvent molecule.

Association constants, as determined by thermodynamic or transport process mesurements, are the basis for determining the short-range forces around the ions and mean-force potentials in dilute solutions. These experiments provide distance parameters, $\mathrm{R}$, as well as $\mathrm{K}_{\mathrm{A}}$-values and thus permit determination of short-range interaction potentials, $W_{+-}^{*}$, via Eq. (19a), or an equivalent expression from Fig. $3^{3.4 .72 .}$ 74-81). On the other hand, molar quantities $\Delta G_{A}^{*}=N_{A} W_{+}^{*}$.. can be interpreted as the non-Coulombic part of the Gibbs energy of the ion-pair formation reaction $3,4,74.75$ ). In addition, calorimetric measurements and studies of the temperature-dependence of conductance provide enthalpies and entropies of ion-pair formation which yield valuable information. For example, alkali metal, alkaline earth and other divalent cation salts in protic solvents yield positive $\Delta \mathrm{H}_{\mathrm{A}}^{*}$ and highly positive $\Delta \mathrm{S}_{\mathrm{A}}^{*}$ values in contrast to tetraalkylammonium salts which show $\Delta H_{A}^{*}<0$ and small entropies, $\Delta S_{A}^{* 4,74-77)}$. Ion-pair formation within the former groups of salts involves the rearrangement of the solvation shells whereas that of the latter one scarcely docs at all. For more details on comprehensive series of measurements see Refs. ${ }^{4.771}$.

\section{Thermodynamic Properties of Electrolyte Solutions}

\subsection{Generalities}

Properties E $(\mathrm{c} ; \mathrm{p}, \mathrm{T})$ of dilute and moderately concentrated electrolyte solutions (concentration range $x \mathrm{q}<0.5 ; x$ (Table II), q (Eq. 19b)), e.g. thermodynamic properties $\mathrm{Z}$, can be represented by a set of equations ${ }^{72)}$

$$
\begin{aligned}
& E(c ; p, T)=E^{\infty}(p, T)+E^{\prime}(\alpha c, R ; p, T) \\
& K_{\wedge} \therefore \begin{array}{ccc}
1-\alpha & 1 \\
\alpha^{2} c & y_{1}^{\prime}
\end{array} ; \quad y_{1}^{\prime}=\exp \left[\begin{array}{c}
4 x \\
1+x R
\end{array}\right]
\end{aligned}
$$

where $\mathrm{E}^{\mathrm{r}}(\mathrm{p}, \mathrm{T})$ is the corresponding property of the infinitcly dilute solution. The other symbols have the meaning given in the preceding sections. Transport properties are controlled by a similar set of equations, sec Section VI. 
The chemical model allows the determination of both values of $E^{\infty}(p, T)$ by a wellfounded extrapolation method and values of $R$ and $W_{i j}^{*}$ independently of the special thermodynamic or transport property which is being investigated and thus provides data for other ones ${ }^{3,72,77,81-83}$. This fact can be used for computer methods which require the storing of a minimum of basic data to make these properties available. The data bank ELDAR ${ }^{83)}$ works on this principle. Spectroscopic or kinetic investigations do not necessarily furnish the complete set of parameters for establishing function $E^{\prime}$, Eq. (21 a), see Sections VII and VIII.

\subsection{Solution and Dilution Experiments}

The basic equations of type Eq. (21 a) needed for solution and dilution experiments are obtained from Eqs. $(12 \mathrm{a}, \mathrm{b})$. The apparent molar quantity $\Phi_{\mathrm{z}}$ may be split into two parts, one for the 'free' ions of the chemical model, $\Phi_{Z}(F I)=\Phi_{Z}(r>R)$, the other one for the ion pairs, $\Phi_{\mathrm{z}}(\mathrm{IP})=\Phi_{\mathrm{z}}(\mathrm{a} \leqq \mathrm{r} \leqq \mathrm{R})$. This assumption leads to the relationship

$$
\Phi_{\mathrm{Z}}-\Phi_{\mathrm{Z}}^{\infty}=\Phi_{\mathrm{Z}}^{\mathrm{rel}}=\left[\alpha \Phi_{\mathrm{Z}}(\mathrm{FI})+(1-\alpha) \Phi_{\mathrm{Z}}(\mathrm{IP})\right]-\Phi_{\mathrm{Z}}^{\infty}
$$

which is introduced into Eq. (12a) yielding the equation

$$
\frac{\Delta_{\text {sol }} Z}{n_{Y}}=\Delta_{\text {sol }} Z_{Y}^{\infty}+\alpha \Phi_{Z}^{\text {rel }}(F I)+(1-\alpha) \Delta Z_{A}^{0} .
$$

$\Phi_{Z}^{\text {rel }}$ is the corresponding relative apparent molar quantity. For symmetrical electrolytes at moderate and low concentrations the quantity $\Phi_{Z}^{\text {rel }}$ (IP) equals $\Delta Z_{A}^{0}=$ $\Phi_{Z}\left(\right.$ IP) $-\Phi_{Z}^{\infty}$, i.e. the molar quantity for the formation of an ion pair from its cation and anion which are initially infinitely separated.

As an example, heat of dilution experiments and the information they provide about solution properties will be discussed. A comparison of Eqs. $(12 a, 22)$ and Fig. 1 shows that $\Phi_{\mathrm{H}}^{\text {rel }}$ (in the literature sometimes called $\Phi_{\mathrm{L}}$ ) and the measured negative heat of dilution are identical, i.e.

$$
\Phi_{\mathrm{H}}^{\mathrm{rel}}=-\Delta_{\mathrm{dil}} \mathrm{H}^{\infty}
$$

Hence, when diluting an electrolyte solution at molality $\mathrm{m}$ to a molality $\mathrm{m}$ ' by adding an appropriate amount of solvent, the accompanying heat of process is

$$
\Delta \Phi_{\mathrm{H}}^{\mathrm{rel}}=\Phi_{\mathrm{H}}^{\mathrm{rel}}\left(\mathrm{m}^{\prime}\right)-\Phi_{\mathrm{H}}^{\mathrm{rel}}(\mathrm{m})=\alpha^{\prime} \Phi_{\mathrm{H}}^{\mathrm{rel}}(\mathrm{FI}) \cdots \alpha \Phi_{\mathrm{H}}^{\mathrm{rel}}(\mathrm{FI})+\left(\alpha-\alpha^{\prime}\right) \Delta \mathrm{H}_{\mathrm{A}}^{0} .
$$

Using the well-known thermodynamic relationship

$$
\Phi_{H}^{\mathrm{rel}}(\mathrm{Fl})=-v \mathrm{RT}^{2} \frac{1}{\mathrm{~m}} \int_{0}^{\mathrm{m}}\left(\frac{\partial \ln \gamma_{ \pm}^{\prime}}{\partial \mathrm{T}}\right)_{\mathrm{p}} \mathrm{dm}
$$


and the activity coefficient of the free ions required by the chemical model, $\gamma_{ \pm}^{\prime}$, after conversion of $y_{ \pm}^{\prime}$ (Eq. 7) into the molal scale, the following theoretical expression ${ }^{77}$ ) is obtained

$$
\Phi_{H}^{\text {rel }}(\mathrm{FI})=-v \mathrm{RT}^{2}\left\{\left[\left(\frac{\partial \ln \varepsilon}{\partial \mathrm{T}}\right)_{\mathrm{p}}+\frac{1}{\mathrm{~T}}\right] \frac{x \mathrm{q}}{1+x \mathrm{R}}+\frac{\bar{\alpha} x \mathrm{q}}{3} \sigma(x \mathrm{R})\right\}
$$

where the function $\sigma(x R)$ is given by the relationship

$$
\sigma(x \mathrm{R})=\frac{3}{(x \mathrm{R})^{3}}\left[1+x \mathrm{R}-\frac{1}{1+x \mathrm{R}}-2 \ln (1+x \mathrm{R})\right] .
$$

$\bar{\alpha}$ is the cubic expansion coefficient of the solvent; the other symbols where already defined in the preceding text.

The data analysis of dilution measurements with the set of Eqs. (25) yields the basic quantities $\mathrm{K}_{\mathrm{A}}$ and $\mathrm{R}$ of the chemical model and $\Delta \mathrm{H}_{\mathrm{A}}^{0}$ (heat of ion-pair formation). The entropy of ion-pair formation, $\Delta S_{A}^{0}$, can be calculated from $K_{A}$ and $\Delta H_{A}^{0}$ in the usual way. Table III shows examples of a simultaneous determination of $\mathrm{K}_{\mathrm{A}}$, $\mathrm{R}_{\text {exp }}$ and $\Delta \mathrm{H}_{\mathrm{A}}^{0}$.

The association constants of table III can be compared with those from conductance measurements, $\mathrm{K}_{A}^{(\Lambda)}$, and are found to be in perfect agreement, e.g. $\mathrm{K}_{A}^{(\Lambda)}\left(\mathrm{MgSO}_{4} / \mathrm{H}_{2} \mathrm{O}\right)$ $=160 \mathrm{dm}^{3} \mathrm{~mol}^{-1}$. The agreement of the $\mathrm{R}_{\text {exp }}$-values of Table III for aqueous solutions with those of the ion-pair model, Eq. (20), should be stressed as an important result. The calculated values, $R_{\text {calc }}$, correspond to $R=a+2 s$ (here $s=d_{O H}$, dimension of $\mathrm{OH}$ ) according to this model. The agreement of $\mathbf{R}_{\exp }$ with Bjerrum's distance parameter q, which is often used as the upper limit of association and which depends only on the permittivity of the solvent [cf. Eq. (19b)], is less satisfactory. For aqueous solutions of 2,2-electrolytes at $25^{\circ} \mathrm{C}$ q equals $1.43 \mathrm{~nm}$, independent of the ionic radii.

The same situation is given for non-aqueous solutions, e.g. propanol solutions in Table III. The association constants from calorimetric and conductance measurements

Table III Thermodynamic quantities of ion-pair formation in water and propanol $\left(25^{\circ} \mathrm{C}\right.$ ) from

\begin{tabular}{|c|c|c|c|c|c|c|c|}
\hline \multirow[t]{2}{*}{ Solvent } & \multirow[t]{2}{*}{ Electrolyte } & \multirow{2}{*}{$\frac{\mathrm{K}_{\mathrm{A}}}{\mathrm{dm}^{3} \mathrm{~mol}^{-1}}$} & \multirow{2}{*}{$\frac{\Delta \mathrm{H}_{\mathrm{A}}^{0}}{\mathrm{~J} \mathrm{~mol}^{-1}}$} & \multirow{2}{*}{$\frac{R_{\text {exp }}}{n m}$} & \multicolumn{3}{|l|}{$\mathrm{R}_{\text {calc/nm }}$} \\
\hline & & & & & $a+2 d_{o H}$ & $a+s$ & $q$ \\
\hline $\mathrm{H}_{2} \mathrm{O}$ & $\begin{array}{l}\mathrm{MgSO}_{4} \\
\mathrm{CaSO}_{4} \\
\mathrm{CdSO}_{4} \\
\mathrm{NiSO}_{4}\end{array}$ & $\begin{array}{l}161 \\
192 \\
239 \\
210\end{array}$ & $\begin{array}{l}5780 \\
6670 \\
8390 \\
5440\end{array}$ & $\begin{array}{l}0.93 \\
0.95 \\
0.96 \\
0.91\end{array}$ & $\begin{array}{l}0.88 \\
0.91 \\
0.91 \\
0.88\end{array}$ & & 1.43 \\
\hline $\mathrm{C}_{3} \mathrm{H}_{7} \mathrm{OH}$ & $\begin{array}{l}\mathrm{Nal} \\
\mathrm{KI} \\
\mathrm{RbI}\end{array}$ & $\begin{array}{l}206 . \\
374 \\
527\end{array}$ & $\begin{array}{l}18930 \\
19060 \\
17550\end{array}$ & $\begin{array}{l}0.97 \\
0.99 \\
0.95\end{array}$ & $\begin{array}{l}0.88 \\
0.91 \\
0.93\end{array}$ & $\begin{array}{l}1.01 \\
1.04 \\
1.06\end{array}$ & 1.37 \\
\hline
\end{tabular}
measurements of heats of dilution ${ }^{77}$ 
agree satisfactorily ${ }^{77}$. The experimentally determined distances, $R_{\text {exp }}$, differ distinctly from q, which equals $1.37 \mathrm{~nm}$ for all propanol solutions of 1,1 -electrolytes at $25^{\circ} \mathrm{C}$. Two values of $R_{\text {calc }}$ are quoted in Table III, one for the configuration $\mathrm{C}^{+}(\mathrm{OH})(\mathrm{OH}) \mathrm{A}^{-}$, i.e. $\mathrm{R}_{\text {calc }}=\mathrm{a}+2 \mathrm{~d}_{\mathrm{OH}}$, the other for $\mathrm{C}^{+}$(propanol)A , i.e. $\mathrm{R}_{\text {calc }}$ $=\mathrm{a}+\mathrm{s}$ (cf. Appendix A-2). Both values $\mathrm{R}_{\text {calc }}$ are compatible with the experimental value, $R_{\text {exp }}$.

Comparing Table III with the results of conductance data at various temperatures shows a further important feature. The temperature-dependence of conductance data yields $\Delta \mathrm{H}_{\mathrm{A}}^{0}$-values via the relationship

$$
\left(\frac{\mathrm{d} \ln \mathrm{K}_{\mathrm{A}}}{\mathrm{dT}}\right)_{\mathrm{p}}=\frac{\Delta \mathrm{H}_{\mathrm{A}}^{0}}{\mathrm{RT}^{2}}
$$

which agree with the $\Delta \mathrm{H}_{\mathrm{A}}^{0}$-values from calorimetric measurements, i.e. from conduct-. ance measurements on solutions of $\mathrm{NaI}$ in propanol a value of $\Delta \mathrm{H}_{\mathrm{A}}^{0}=18800 \mathrm{~J} \mathrm{~mol}^{-1}$ is determined.

The second example concerning heat of solution measurements was chosen to stress a crucial problem in non-aqueous electrochemistry. This is the proper extrapolation to infinite dilution when association of the electrolyte occurs ${ }^{84-87}$. Figure 4 shows that the validity range of the limiting law is attained only at very low concentrations (here $<10^{-5} \mathrm{M}$ ), generally inaccessible to measurements. Hence, extrapolation from measured values $\left(>5 \cdot 10^{-3} \mathrm{M}\right)$ yields erroneous data. Reliable

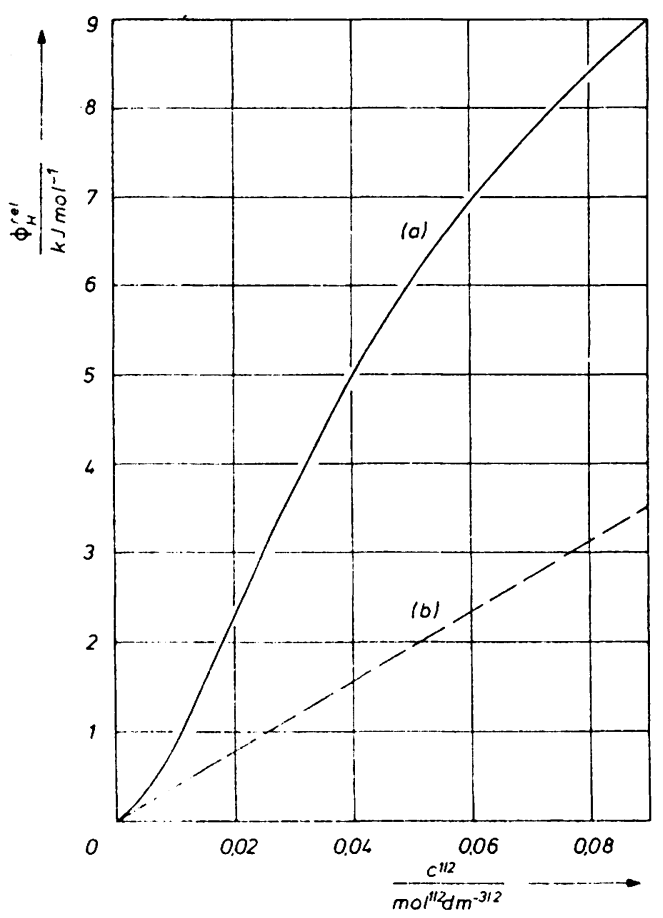

Fig. 4. Relative apparent molar enthalpy of $\mathrm{KI}$ in propanol $\left(25^{\circ} \mathrm{C}\right)$ from heat of dilution measurements. (a) measured curve (b) limiting law; for explanation see text 
Josef Barthel et al.

Table IV Heat of solution data of $\mathrm{NaI}$ in 1-propanol at $25^{\circ} \mathrm{C}^{84}$ )

\begin{tabular}{lccc}
$\frac{\mathrm{m} \cdot 10^{3}}{\mathrm{~mol} \mathrm{~kg}}$ & $\frac{\Delta_{\text {sol }} \mathrm{H}_{\mathrm{Y}}}{\mathrm{J} \mathrm{mol}}$ & $\frac{\Phi_{\mathrm{H}}^{\text {rel }}}{\mathrm{J} \mathrm{mol}^{-1}}$ & $\frac{\Delta_{\text {sol }} \mathrm{H}_{\mathrm{Y}}^{\text {o }}}{\mathrm{J} \mathrm{mol}}$ \\
\hline 20.56 & -19090 & 8898 & -27988 \\
21.70 & -18850 & 9024 & -27874 \\
22.44 & -18840 & 9103 & -27943 \\
22.64 & -18780 & 9123 & -27903 \\
23.70 & -18700 & 9250 & -27950 \\
& & & Mean: -27932 \\
\hline
\end{tabular}

extrapolations require the use of Eq. (23) and an appropriate model. The DebyeHückel limiting law and its empirical extensions are generally insufficient.

Table IV shows $\Delta_{\text {sol }} H_{Y}, \Phi_{H}^{\text {rel }}$ and extrapolated $\Delta_{\text {sol }} H_{Y}^{\infty}$-values as a function of molality for solutions of $\mathrm{NaI}$ in $\mathrm{n}$-propanol ${ }^{84)}$. The $\Phi_{\mathrm{H}}^{\text {rel }}$-values were determined from the dilution measurements of Table III. Taking into account that $\Phi_{\mathrm{H}}^{\text {rel }}$ contributes about $50 \%$ of $\Delta_{\text {sol }} H_{Y}$, it is obvious that reliable $\Delta_{\text {sol }} \mathrm{H}_{\mathrm{Y}}^{\infty}$-values can only be obtained from theoretically sound extrapolation methods. For comparison, Abraham et al. ${ }^{85}$ ) estimated a value of $\Delta_{\mathrm{sol}} \mathrm{H}_{\mathrm{Y}}^{\infty}=-23510 \mathrm{~J} \mathrm{~mol}^{-1}$ from their measurements on solutions of $\mathrm{NaI}$ in propanol. A re-evaluation of these measurements based on the chemical model and Eq. (23) yields $\Delta_{\text {sol }} \mathrm{H}_{\mathrm{Y}}^{\infty}=-27200 \pm 180 \mathrm{~J} \mathrm{~mol}^{-1}$, in satisfactory agreement with our values in Table IV.

An example of Eq. (23) for determining molar volumes is given in Ref. ${ }^{81)}$. Comparing the results of molar volume measurements with the pressure dependence of the association constant from conductance experiments shows satisfactory agreement, i.e. the equation

$$
\left(\frac{\mathrm{d} \ln \mathrm{K}_{\mathrm{A}}}{\mathrm{dp}}\right)_{\mathrm{T}}=-\frac{\Delta \mathrm{V}_{\mathrm{A}}}{\mathrm{RT}}
$$

is fulfilled when $K_{A}$-values from pressure-dependent conductance and $\Delta V_{A}$-values from density measurements are combined.

\subsection{EMF-Measurements}

For $\Delta$ G-measurements, emf or solubility products, the chemical potential, Eqs. $(6,7)$, is an appropriate form of the basic Eqs. (21). For example, the emf of the galvanic cell without liquid junction

$$
\left.\mathrm{Ag} / \mathrm{AgCl}(\mathrm{s}) / \mathrm{K}^{+} \mathrm{Cl}^{-} \text {(sol ; concentration } \mathrm{c} \mathrm{mol} \mathrm{dm}{ }^{-3}\right) /(\mathrm{K}, \mathrm{Hg})
$$

is given by the set of equations

$$
\begin{aligned}
& \mathrm{E}=\mathrm{E}^{0} \ldots \frac{2 \mathrm{RT}}{\mathrm{F}} \ln \left(\alpha \mathrm{y}_{t}^{\prime} \mathrm{c}\right)
\end{aligned}
$$

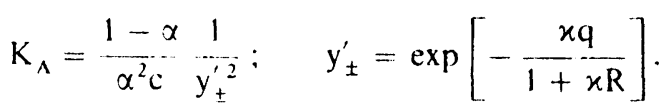


Emf measurements yield reliable standard potentials $\mathrm{E}^{0}$ only when data analysis uses well-founded extrapolation methods which take into account association of the electrolyte compounds ${ }^{88}$. A knowledge of reliable standard potentials is important for electrochemistry in non-aqueous solutions, especially for solvation studies and technological investigations. A comprehensive survey of these questions is in preparation. Data analysis with the help of Eqs. (28) gives $\mathrm{K}_{\mathrm{A}}$ and $\mathrm{R}$ values which are compatible with those from other methods. Table $\mathrm{V}$ illustrates the satisfactory agreement of activity coefficients from emf measurements, $\mathrm{y}_{ \pm}(\mathrm{emf})$, and heats of dilution, $\mathrm{y}_{ \pm}\left(\Phi_{\mathrm{H}}^{\text {rel }}\right)$, both evaluated by appropriate methods.

Table $\mathrm{V}$ Activity coefficients of aqueous $\mathrm{CdSO}_{4}$ solutions at $25^{\circ} \mathrm{C}$

\begin{tabular}{lllll}
\hline$\frac{10^{4} \mathrm{c}}{\mathrm{mol} \mathrm{dm}^{-3}}$ & 10.0 & 30.0 & 50.0 & 100.0 \\
\hline$y_{+}\left(\Phi_{\mathrm{H}}^{\text {rel }}\right)$ & & & & \\
$\mathrm{y}_{ \pm}(\mathrm{cml})$ & 0.699 & 0.551 & 0.476 & 0.383 \\
\hline
\end{tabular}

\subsection{Some Remarks on Thermodynamic Investigations}

- The possibility of determining the quantities $\mathrm{K}_{\mathrm{A}}, \Delta \mathrm{Z}_{\mathrm{A}}^{0}$ and $\mathrm{R}$ controlling association as well as the values of $\mu_{\mathrm{Y}}^{\infty}$ and $\Delta_{\text {sol }} Z_{\mathrm{Y}}^{\infty}$ relevant for solvation gives a convincing reason for making comprehensive measurements on the properties of dilute solutions. Temperature- and pressure-dependent data in particular are needed at the present time. The determination of thermodynamic quantities has been the object of numerous investigations. However, the examples given illustrate the difficulties in getting standard values for the thermodynamic properties of partially associated electrolytes. This may be the reason why most of the work on the thermodynamic properties of electrolyte solutions, such as measurement of the apparent molal volumes $^{89-96)}$, apparent molal heat capacities ${ }^{89.90 .97)}$ and heats of solution ${ }^{98-100)}$, has been concerned with solutions of non-associated electrolytes. In this case the extrapolation to infinite dilution is carried out with the help of Eq. (12a) in combination with the Debye-Hückel activity coefficient or its extended forms ${ }^{101-104)}$.

The features of the chemical model are well-founded extrapolations towards $Z_{Y}^{\infty}$ and related quantities on the one hand and the gtneration of a basic set of model parameters $\mathrm{R}$ and $\mathrm{W}_{\mathrm{ij}}$ (via $\mathrm{K}_{\mathrm{A}}$ ) independent of the special experimental method on the other hand. Moreover, the distance parameter $\mathrm{R}$ is always found to be in accordance with the dimensions of a configuration of ions and orientated adjacent solvent molecules which is compatible with general chemical evidence. As far as chemical models are McMillan-Mayer-level Hamiltonian models, they permit the use of statistical thermodynamic relationships for calculating the solvent properties in a well-founded manner.

It should be mentioned in this context that investigations on dilute solutions, from which reliable information is expected, require precise measurements down to very 
low concentrations $\left(\mathrm{c} \sim 10^{-4} \mathrm{~mol} \mathrm{dm}^{-3}\right)$. Very sensitive and precise apparatus is needed, see Refs. ${ }^{4,77,79,81,105-107)}$, and purification of solvents and solutes together with the purity control of solvents, solutes and solutions are often the major part of these investigations.

\subsection{Ion Solvation}

Ion solvation is the transfer process of the separated ions of a pure electrolyte compound $Y$ from the vacuum to the infinitely dilute solution in a solvent $S$. In the case of ionophoric electrolytes the solvation quantities $\Delta_{\mathrm{solv}} Z_{\mathrm{Y}}^{\alpha}$ are related to the corresponding solution quantities, $\Delta_{\text {sol }} Z_{Y}^{\infty}(E q .(12 b)$ ), via lattice quantities, $\Delta_{\text {lat }} Z_{Y}$ according to Fig. 1.

Lattice energies of many electrolytes are known ${ }^{108-111)}$ and in combination with the experimentally determined solution energies yield the solvation energies and related quantities $\Delta_{\text {solv }} Z_{\mathbf{Y}}^{\infty}$. For tables of solution data see Refs. ${ }^{36,112,113)}$.

Besides the solvation quantities, transfer quantities, $\Delta_{\mathrm{tr}} Z_{\mathrm{Y}}^{\infty}$, can be advantageously used, cf. Fig. 1. They give an account of the change in $Z$ when the electrolyte $Y$ is transferred from solvent $S^{\prime}$ to solvent $S$. With water as the reference solvent, $S^{\prime}$, the transfer activity coefficients, ${ }_{m} \gamma_{Y}{ }^{114-116)}$, are obtained from the Gibbs transfer energy, $\Delta_{\mathrm{tr}} G_{\mathbf{Y}}^{\infty}$, by the relationship

$$
\Delta_{\mathrm{tr}} G_{Y}^{\infty}=\Delta_{\text {solv }} G_{Y}^{\infty}(S)-\Delta_{\text {solv }} G_{Y}^{\infty}(W)=R T \ln _{m} \gamma_{Y}
$$

The choice of the appropriate concentration scale for standard thermodynamic functions of transfer was extensively discussed by Ben-Naim ${ }^{117}$ who showed that the molarity scale has a number of advantages over the others.

Separation into ionic transfer activity coefficients for the electrolyte $C^{x^{+}} A^{x-}$ is executed with the help of the equation

$$
{ }_{m} \gamma_{Y}^{2}=\left({ }_{m} \gamma_{+}\right)\left({ }_{m} \gamma_{-}\right)
$$

The interest of theory and technology in single ion solvation and transfer quantities originates in their importance for solution structure, kinetic, analytical or surface problems, i.e. for all problems involving the solvation shell or its rearrangement. For example, transfer proton activity coefficients ${ }_{m} \gamma_{\mathrm{H}}+$ are used for transferring the $\mathrm{pH}$-scale from water to other solvents:

$$
\mathrm{pH}(\mathrm{S})=\mathrm{pH}(\mathrm{W})+\log _{\mathrm{m}} \gamma_{\mathrm{H}^{+}} \text {. }
$$

Further examples of technical importance are found in the field of extraction processes ${ }^{118)}$, ionic equilibria and emf measurements ${ }^{119}$, and analytical applications 120.1211.

The requirements of theory both for solvation and transfer data of single ions are similar. A complete theory would require the knowledge of all molecular distribution functions and mean-force potentials between the ions and the solvent molecules. As already stressed in Section II such a theory is unavailable with the present state of knowledge. In the endeavour to represent solvation by models, the 
ion-solvent interactions are split into electrostatic, non-electrostatic, and chemical contributions.

Dielectric continuum models like the Born model ${ }^{122)}$ and its extensions taking into account local permittivity ${ }^{123,124)}$ or introducing 'effective ionic radii' ${ }^{125,126}$ ) consider the solvent as a structureless shielding continuum. More satisfactory results are obtained with the help of an electrodynamic theory of condensed media which takes into consideration the structure of polar solvents ${ }^{127}$, but the prediction of equal free energies of hydration for cations and anions of equal size and charge is rather unrealistic. These quantities should differ by twice the ion-quadrupole interaction energy.

Ion-solvent interaction causes orientation of the neighbouring inner solvent molecules and extends with greater or less attenuation into the bulk solution ${ }^{128-131}$. Primary, and in some cases also secondary, solvation shells are chosen as the basis of models. Solvent mixtures introduce the possibility of preferential ion solvation ${ }^{132-137) \text {. }}$

The energy content of the primary solvation shell depends on the short-range interactions of the types of ion-dipole, ion-quadrupole, ion-induced dipole, dipoledipole and dispersion and repulsion forces ${ }^{138-140)}$. For non-aqueous electrolyte solutions, however, most of the molecular and structural data needed for the calculation of the formation energy of the primary solvation shell are unknown. In addition, calculations of solvation energies must include an estimation of the energy content of the region outside the primary solvation shell. Whereas the electrostatic part may be approximated by the Born model, using the solvated ion as a hard sphere, the non-electrostatic parts resulting from cavity formation and structure breaking in the secondary solvation shell are generally unknown. Therefore, ab initio calculations have not so far been very successful for non-aqueous solvation. Present information has been obtained from semi-empirical methods and/or extrathermodynamic assumptions.

The basis of the extrapolation methods ${ }^{141-143)}$ is the representation of the electrostatic contributions to ion-solvent interactions by a series expansion of type $a_{j} r^{-j}$ where $r$ is the ionic radius. For example, in a series of electrolytes with common cation and varying anions (anion radius, $r_{-}$) a set-up

$$
\Delta_{\mathrm{sol}} Z_{\mathrm{Y}}^{\infty}=\Delta_{\mathrm{sol}} Z_{+}^{\infty}+\sum_{j=1}^{\mathrm{n}} \frac{\mathrm{a}_{\mathrm{j}}}{\mathrm{r}_{-}^{\mathrm{j}}}+\Delta_{\mathrm{sol}} Z_{-}^{\infty}(\text { neutral) }
$$

is used for determining single cation solvation quantities from the measured $\Delta_{\mathrm{sol}} Z_{\mathrm{Y}}^{\infty}$ values. A variety of methods differ in the number of terms in the power series and in the corrections, $\Delta_{\text {soo }} Z^{\infty}$-(neutral), for non-electrostatic contributions ${ }^{144-146)}$. A drawback of all extrapolation methods is the uncertainty of the extrapolation $(r \rightarrow \infty)$ from the very small range of ionic radii available.

Reference ions ${ }^{147}$. , reference ion/molecule pairs ${ }^{148-150)}$, and reference clectrolytes $91,136,150-156)$, are the basis of further methods. The assumption that the rubidium ion would have a constant potential in all solvents as a consequence of its low electrical lield and polarizability ${ }^{147}, i . c^{\prime} . \gamma_{\mathrm{Rb}^{+}}=1$, as well as similar hypotheses involving large (ransition state anions ${ }^{149}$ are only of historical interest. More realistic are the determinations of solvation quantities based on the assumption that 
Josef Barthel et al.

large ions and their corresponding uncharged molecules, like the ion/molecule pair ferrocinium/ferrocene ${ }^{148}$ ) or similar ones ${ }^{149,150)}$, show equal solvation in each solvent. The disadvantage of the reference ion and reference ion/molecule methods, both of which neglect the electrostatic contributions of the ionic species, is assumed to be overcome ${ }^{151)}$ by the reference electrolyte method proposing the partition of measured electrolyte solvation quantities equally between its ions. The criteria for reference electrolytes are the same as for reference ion/molecule pairs. The difference in the short-range electrostatic ion-molecule interactions is neglected if the cation and the anion of the reference electrolyte are structural analogues of equal size, e.g. $\left(\mathrm{Ph}_{4} \mathrm{As}\right)^{+}\left(\mathrm{BPh}_{4}\right)^{-151)}$ or $\left(\mathrm{i}-\mathrm{Am}_{3} \mathrm{BuN}\right)^{+}\left(\mathrm{BPh}_{4}\right)^{-150)}$. Reference electrolytes were widely used to determine transfer activity coefficients and solvation enthalpies ${ }^{111,112,131,150,153)}$ and partial molar volumes ${ }^{91,154)}$ of single ions. Criticisms of the reference electrolyte method are based on spectroscopic investigations ${ }^{157)}$ and calculations ${ }^{158)}$ using the scaled-particle theory ${ }^{159)}$. Kim et al. ${ }^{155.156)}$ propose an unequal partition of the standard free energy of transfer between $\left(\mathrm{Ph}_{4} \mathrm{As}\right)^{+}$and $\left(\mathrm{BPh}_{4}\right)^{-}$as the result of a comprehensive investigation. However, the consequences of these corrections for the equipartition principle are still a matter of debate. In a recent review Marcus ${ }^{119)}$ gives a critical evaluation of the $\left(\mathrm{Ph}_{4} \mathrm{As}\right)^{+}\left(\mathrm{BPh}_{4}\right)^{-}$problem.

A rapid experimental method to determine transfer activity coefficients uses galvanic cells with transference but negligible liquid-junction potentials ${ }^{149,160-162)}$, e.g. the cell

\begin{tabular}{l|l|l|l|}
$\mathrm{Ag}$ & $\begin{array}{l}\mathrm{AgClO}_{4}(0.01 \mathrm{M}) \\
\text { reference } \\
\text { solvent }\end{array}$ & $\begin{array}{l}\mathrm{Et}_{4} \mathrm{NPi}(0.1 \mathrm{M}) \\
\text { reference solvent } \\
\text { or solvent } S\end{array}$ & $\begin{array}{l}\mathrm{AgClO}_{4}(0.01 \mathrm{M}) \\
\text { solvent } S\end{array}$
\end{tabular}

where the reference solvent is either acetonitrile or methanol and the bridge electrolyte tetraethylammonium picrate dissolved in the weaker solvating solvent for the $\mathrm{Ag}^{+}$ions. The results from the application of this method differ by about one unit in $\log _{m} \gamma_{Y}$ from those obtained by the reference electrolyte assumption which Popovych ${ }^{114}$ considers to be the more reliable one.

All these methods do not satisfactorily take into account such specific interactions like $\mathrm{H}$-bonding of small anions with protic solvents ${ }^{163)}$ or those of $\mathrm{Cu}^{+}, \mathrm{Ag}^{+}, \mathrm{Au}^{+}$ with some dipolar aprotic solvents, as well as the structural contributions of strongly structured solvents, e.g. water, alcohols, amides, to the solvation energy. This drawback of actual solvation theory is one of the reasons motivating practical chemists to restrict themselves to qualitative classification ${ }^{164,165)}$ according to solvent scales or classes, cf. also Section 8.3.

\subsection{Concentrated Solutions}

Information in the field of thermodynamic properties of concentrated non-aqueous electrolyte solutions is rather poor at present, in spite of increasing technological interest. No reliable theory is available. Aqueous solutions have been better investigated. Pitzer et al. ${ }^{166-171)}$, and Cruz and Renon ${ }^{172-174)}$ extended the DebyeHückel concept and obtained empirical equations for the osmotic coefficient and 
ionic activity coefficients from Gibbs excess enthalpy which in Pitzer's theory is presented as a sum of cationic and anionic contributions with an unlimited number ${ }^{174)}$ of adjustable parameters. The Cruz-Renon extension contains a Debye-McAulay term to correct for the change of dielectric constant of the solvent due to the presence of ions in the solution and a term taking into account short-range forces. Both theories are of great help for practising engineers in the prediction of solubility data, treatment of vapour-liquid equilibria, and further technical problems ${ }^{174)}$

\subsection{Water at Extreme External Conditions}

Application of high pressures and temperatures changes the bulk properties of a solvent to a considerable extent. There is a continuous transition of these properties going through the critical point ${ }^{175)}$. As emphasized by Franck ${ }^{176)}$, under extreme conditions water substance loses its typical properties and behaves as a high polar "non-aqueous, water-like" solvent. The consequences for electrolyte solutions are considerable changes in the ion-ion and ion-solvent interactions. Thus it is not surprising that 1,1-electrolytes form ion pairs in aqueous solutions at high temperatures, e.g. aqueous $\mathrm{NaCl}$ solutions with densities below $0.75 \mathrm{~g} \mathrm{~cm}^{-3}$ exhibit ion-pairing, increasing with decreasing density ${ }^{177)}$. For further information on this technically important solvent and its "non-aqueous" electrolyte solutions, including conductance and dielectric properties see Refs. ${ }^{178-188)}$.

\section{Transport Properties}

\subsection{Dilute Solutions}

Transport equations of electrolyte and single ion conductance, self- and mutualdiffusion, and transference numbers can be obtained either from Onsager's continuity equation or from Onsager's fundamental equations of irreversible processes. Many publications deal with this matter, especially with electrolyte conductance. For monographs, review articles, surveys of results and recent contributions in this

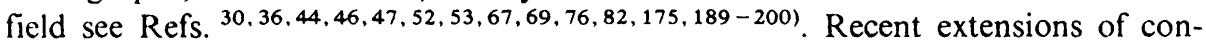
ductance theory concern electrolyte mixtures of any type ${ }^{201-204)}$. A discussion of former papers is given in Refs. ${ }^{36,76,189-1911}$.

Electrolyte conductance, $\Lambda$, and transference numbers, $\mathrm{t}_{\mathrm{i}}$, are required for a proper understanding of the transport of charge by ions in electrolyte solutions.

Conductance equations for completely dissociated electrolytes are obtained in the form

$$
\Lambda=\Lambda^{* x} \cdots \Lambda^{r} \cdots \Lambda^{*}
$$

with $\Lambda^{\text {*n }}$ as the limiting electrolyte conductance at infinite dilution, a concentrationdependent relaxation term, $\Lambda^{\prime}$, and a concentration-dependent electrophoretic term, 
Josef Barthel et al.

$\Lambda^{\mathrm{e}}$, both of which are due to effects inhibiting the conductance as the electrolyte concentration increases. Alternatively, series expansions

$$
\Lambda=\Lambda^{\infty}-\mathrm{Sc}^{1 / 2}+\mathrm{Ec} \log \mathrm{c}+\mathrm{J}_{1} \mathrm{c}+\mathrm{J}_{2} \mathrm{c}^{3 / 2}+\ldots
$$

in which the coefficients $S, E, J_{1}$, and $J_{2}$ contain contributions due both to the relaxation and electrophoretic effects can be used. Summarizing tables of the coefficients as obtained from various theories are given in Refs. ${ }^{36,191)}$. Eq. (34) contains the well-known square-root law

$$
\Lambda=\Lambda^{\infty}-\mathrm{S} \sqrt{c}
$$

as the limiting law. The limiting law has been the object of various empirical extensions (see ${ }^{44,47.191)}$ ) since Onsager derived it as the first exact and statistically well-founded conductance equation ${ }^{45,205 \text { ). }}$.

Only the free ions in the solution are supposed to transport charges in the applied external field. For associating electrolytes Eq. (34) is transformed into the set of equations

$$
\begin{aligned}
& \Lambda=\alpha\left[\Lambda^{\infty}-\mathrm{S}(\alpha \mathrm{c})^{1 / 2}+\mathrm{E}(\alpha \mathrm{c}) \log (\alpha \mathrm{c})+\mathrm{J}_{1}(\alpha \mathrm{c})+\mathrm{J}_{2}(\alpha \mathrm{c})^{3: 2}+\ldots\right] \\
& \mathrm{K}_{\mathrm{A}}=\frac{1-\alpha}{\alpha^{2} \mathrm{c}} \times \frac{1}{\mathrm{y}_{ \pm}^{\prime 2}} ; \quad \mathrm{y}_{ \pm}^{\prime}=\exp \left[-\frac{x \mathrm{q}}{1+x \mathrm{R}}\right]
\end{aligned}
$$

which is of the type of Eqs. (21). Then the introduction of the chenical model as the base for electrolyte conductance is straightforward $4.74-76)$. Discussion and comparison of conductance equations of electrolytes and single ions and their use for determining transport and structure parameters of a multitude of solutions can be found in recent surveys $4,67,75,76,189-192,194)$. Fig. 6 shows the generally observed dependence on concentration of equivalent conductance of partially associated electrolytes. The validity range $\left(<10^{-5} \mathrm{M}\right)$ of Onsager's limiting law, Eq. (35), is indicated. The deviations from the limiting law are caused both by the complete transport equation of type (36) (here from Ref. ${ }^{195}$ ) ) and by association.

Conductance measurements on dilute solutions are of special interest for electrolyte theory. These measurements can be carried out at high precision for almost all electrolytes in almost all solvents at various temperatures and pressures and thus provide an efficient method for determining the basic data of electrolyte solutions, i.e. $\Lambda^{x}, \mathrm{~K}_{\mathrm{A}}$ and $\mathrm{R}$, under various conditions. Values of $\mathrm{K}_{\mathrm{A}}$ and $\mathrm{R}$ are found to be compatible with the values obtained from thermodynamic methods. The enthalpies and volumes of ion-pair formation, $\Delta H_{A}^{0}$ and $\Delta V_{A}$, as determined from temperature- and pressure-dependence of conductance, are compatible with the corresponding relative apparent molar quantities, $\Phi_{11}^{\text {(el }}(I P)$ and $\left(D_{v}^{\text {rel }}(I P)\right.$, from ther. modynamic meatsurements, ef. Section 5.2.; R-values ate lound to he almost independent of temperature.

Transference numbers, $t_{i}$, and single ion conductances, $\Lambda_{i}=t_{i} \Lambda$, deduced from them are of theoretical and technical interest. Several attempts have been made to replace the experimentally difficult and time-consuming measurement of transference numbers 
by methods based on empirical assumptions, such as splitting the equivalent conductance $\Lambda$ of standard electrolytes into equal contributions from cation and anion (cf. Sect. 5.5.), e.g. $\left(\mathrm{Bu}_{4} \mathrm{~N}\right)^{+}\left(\mathrm{BPh}_{4}\right)^{-206,207)}$ or $\left(\mathrm{i}-\mathrm{Am}_{4} \mathrm{~N}\right)^{+}\left(\mathrm{i}-\mathrm{Am}_{4} \mathrm{~B}\right)^{\left.-{ }^{-208}\right)}$, or calculating the ionic conductance in one solvent from that in another by the help of Walden's rule ${ }^{209)}$. The temperature-dependence of transference numbers was also calculated on the basis of rules of this type ${ }^{210}$.

Electrolyte theory relates transport numbers to the chemical model through the following set of equations ${ }^{82,194)}$

$$
\begin{aligned}
& \frac{\mathrm{t}_{\mathrm{i}}-0.5}{\mathrm{t}_{\mathrm{i}}^{\infty}-0.5}=\Lambda^{\infty}\left[\Lambda^{\infty}-\frac{1}{\Xi} \frac{\mathrm{e}_{0}^{2} \mathrm{~N}_{\mathrm{A}}}{3 \pi \eta} \frac{x}{1+\chi \mathrm{R}}\right]^{-1}+\mathrm{B}(\alpha \mathrm{c}) \\
& \mathrm{K}_{\mathrm{A}}=\frac{1-\alpha}{\alpha^{2} \mathrm{c}} \times \frac{1}{\mathrm{y}_{ \pm}^{\prime 2}} ; \quad \mathrm{y}_{ \pm}^{\prime}=\exp \left[-\frac{\chi \mathrm{q}}{1+\chi \mathrm{R}}\right]
\end{aligned}
$$

where $e_{0}$ is the charge of proton, $N_{A}$ Avogadro's number, $\eta$ the viscosity of the solvent and $\Xi$ a conversion factor ( $\Xi=1$ for SI units). The other symbols have their usual meaning.

Among the experimental methods for determining transference numbers, the moving boundary method (cf. ${ }^{82,190,194.211)}$ ) allows their determination with a precision close to that of conductances. Figure 5 gives an example ${ }^{82)}$.

Figure 5 shows transference numbers decreasing with increasing concentration and decreasing temperature when $t_{+}^{\alpha}<0.5$ and increasing when $t_{+}^{\infty}>0.5$, in accordance with theory. The possibility of reversing the sign of temperature- and concentration-

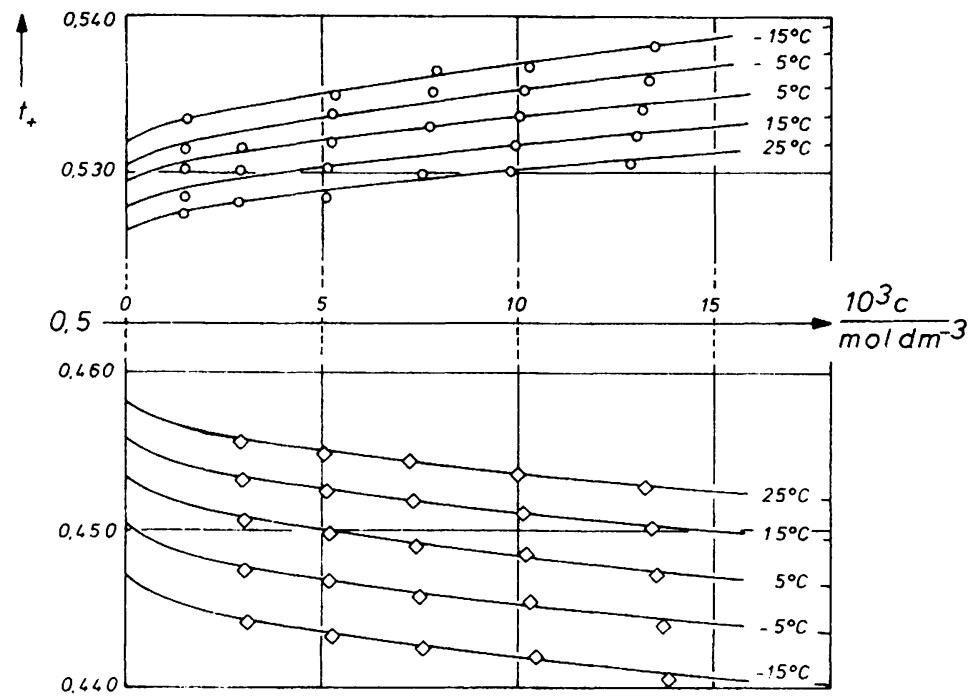

lig. 5. Temperature- and concentration-dependence of cationic transference numbers of meihathol solutions of $\mathrm{Me}_{4} \mathrm{NSCN}(0)$ and $\mathrm{KSCN}(\diamond)^{82}$. The full lines are computer plots acrording to the set of Eqs. (37) 
Josef Barthel et al.

dependence by the choice of appropriate electrolytes can be used in battery research when battery electrolytes with a high mobility of the active ion at low temperature are sought as well as in other technological applications which require specific charge transport properties, cf. Part B.

Table VI shows the limiting anion conductances determined from the measurements underlying Fig. 5. Extrapolations were made by taking into account the association of the electrolyte compounds $\mathrm{KSCN}$ and $\mathrm{Me}_{4} \mathrm{NSCN}$ in methanol via Eqs. (37). As a result, the theoretical requirement of equal limiting anion conductances $\lambda_{\mathrm{SCN}}^{\infty}$ - is fulfilled within the limits of experimental error.

For further information on transport phenomena in dilute solutions reference should be made to the recent literature; the literature up to 1975 is quoted in Refs. ${ }^{36,55,113)}$.

The current state of knowledge in the field of dilute electrolyte solutions is illustrated by Fig. $6^{72)}$.

The conductance functions for $\mathrm{Pr}_{4} \mathrm{NI}$ and $\mathrm{i}-\mathrm{Am}_{4} \mathrm{NI}$ in propanol, Fig. 6, are computer plots which were calculated entirely without use of conductance data for

Table VI Single anion conductance from independent measurements of transference numbers in $\mathrm{KSCN}$ and $\mathrm{Me}_{4} \mathrm{NSCN}$ in methanol ${ }^{82}$ )

\begin{tabular}{lll}
\hline Temp. & $\lambda_{\mathrm{SCN}}^{\alpha}-/\left[\mathrm{S} \mathrm{cm}^{2} \mathrm{~mol}^{-1}\right]$ & $\lambda_{\mathrm{SCN}}^{\infty} /\left[\mathrm{S} \mathrm{cm}^{2} \mathrm{~mol}^{-1}\right]$ \\
${ }^{0} \mathrm{C}$ & from KSCN & 33.61 \\
-15 & 33.65 & 39.82 \\
-5 & 39.84 & 46.60 \\
+5 & 46.57 & 53.97 \\
+15 & 53.93 & 61.95 \\
+25 & 61.87 & $\mathrm{Me}_{4} \mathrm{NSCN}$ \\
\hline
\end{tabular}

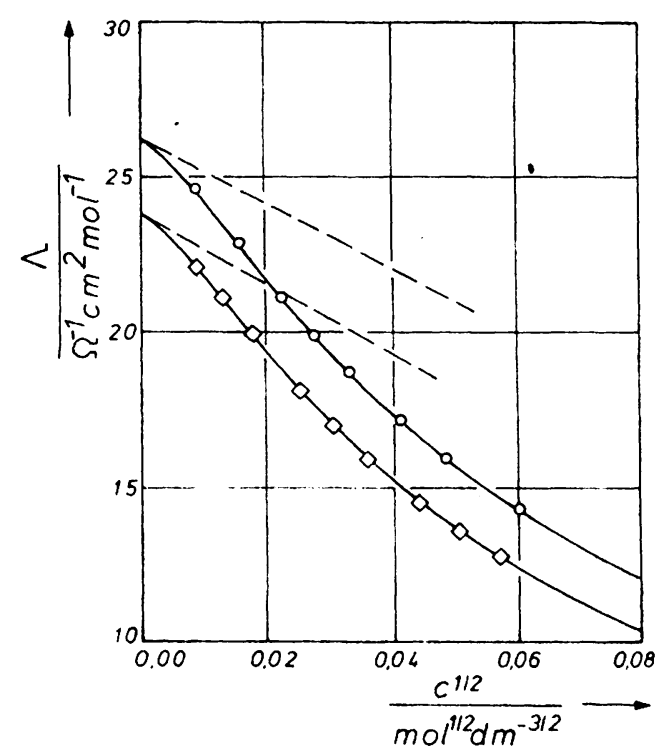

Fig. 6. Conductance of propanol solutions of $\mathrm{Pr}_{4} \mathrm{NI}(\mathrm{O})$ and $\mathrm{i}-\mathrm{Am}_{4} \mathrm{NI}(0)$ at $25^{\circ} \mathrm{C}^{72)}$. The full lines are calculated with the help of Eqs. (36) using $\lambda_{i}^{\alpha^{\prime}}$-values from transference numbers, and $K_{1}$ and $R$ values from calorimetric meatsurenients. Values (o) and (o) from conductance measurements were added for comparison. The broken lines represent the Onsager limiting law of conductance 
the electrolyte solutions investigated. Calculation was based on the set of Eqs. (36). Association constants, $\mathrm{K}_{\mathrm{A}}$, and distance parameters, $\mathrm{R}$, were determined from calorimetric measurements on solutions of $\mathrm{Pr}_{4} \mathrm{NI}$ and $\mathrm{i}-\mathrm{Am}_{4} \mathrm{NI}$ in propanol ${ }^{77}$ ); $\Lambda^{\infty}$-values were obtained via transport numbers $t_{i}^{\infty}$ of $\mathrm{KSCN}^{82)}$ and single-ion limiting conductances $\lambda_{i}^{\infty}$ based on these. The measured points of independent conductance measurements are added to prove the validity of the method. Agreement is better than $0.1 \%$.

\subsection{Concentrated Solutions}

Theoretically well-founded equations for transport data of highly concentrated electrolyte solutions are not available at present. Three classes of transport equations can be found in the literature ${ }^{76)}$; molten salt approaches, empirical extensions of equations for dilute solutions, and empirical equations for fitting measured data.

The temperature-dependence of transport properties $W(T)$, of glassforming liquids and of fused salts ${ }^{212}$ can be interpreted with the help of a modified Vogel-Fulcher-Tammann equation

$$
W(T)=A T^{-1 / 2} \exp \left[-\frac{B}{T-T_{0}}\right]
$$

where $\mathrm{A}$ and $\mathrm{B}$ are constants for a given transport property, conductance, diffusion or fluidity. The theoretical significance of the ideal ${ }^{213)}$ or theoretical ${ }^{214)}$ glass transition temperature $T_{0}$ is given in Refs. ${ }^{215)}$ and ${ }^{216}$. Application of Eq. (38) to experimental results usually yields temperatures $T_{0}$ which are lower than the glass transition points $\mathrm{T}_{\mathrm{g}}$ determined by thermal methods. Thermal methods, e.g. DSC or DTA, yield values of $T_{0}$ which depend on the cooling rate ${ }^{217,218)}$ and which cannot be attributed to internally equilibrated liquids. Angell ${ }^{213}$ ) transformed Eq. (38) into a relationship for the isothermal concentration-dependence of transport properties predicting a maximum of specific conductance at each temperature, e.g. for aqueous $\mathrm{Ca}\left(\mathrm{NO}_{3}\right)_{2}$ solutions ${ }^{213,218)}$. Bruno and Della Monica ${ }^{219,220)}$ have applied Angell's model to non-aqueous solutions. Further information can be found in comprehensive reviews ${ }^{175,22 i-224)}$.

Extensions of the conductance equations for dilute solutions using empirical correction factors, e.g. viscosity functions ${ }^{225}{ }^{226)}$, can be found in the literature. However, although viscosity is the most important parameter influencing the conductance ${ }^{227}$, equations of this type are doubtful. The mean-force potentials of dilute solutions are based on approximations which cannot really be corrected for by viscosity functions. A noteworthy extension is given in Ref. ${ }^{228)}$.

Comprehensive experimental data which provide an insight into the competitive effects of solvent viscosity, ion-ion, and ion-solvent interactions are only available at present for a few non-aqueous systems. A survey is given in Refs. ${ }^{76,229,230 \text { ). }}$

Fig. 7 shows the typical concentration-dependence of the specific conductance, $x\left[\Omega^{-1} \mathrm{~cm}^{-1}\right]$, of $\mathrm{LiClO}_{4}$ at various temperatures in propylene carbonate ${ }^{232)}$ and propylene carbonate-dimethoxyethane mixtures ${ }^{227)}$.

Lacking a reliable theory, an empirical equation ${ }^{231}$ ) was used to reproduce the 


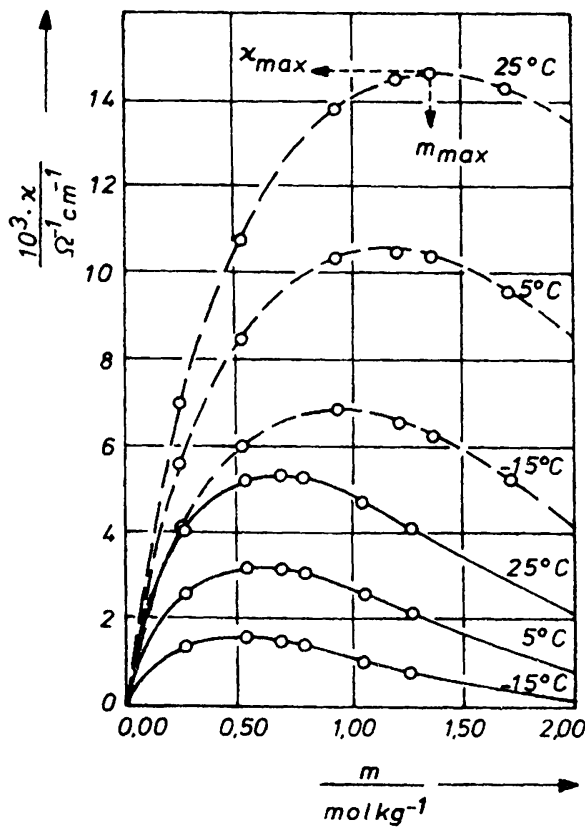

Fig. 7. Specific conductance of $\mathrm{LiClO}_{4}$ solutions in propylene carbonate (full lines) and propylene carbonate - dimethoxyethane (42 weight \% of PC) mixtures (broken lines) at various temperatures

conductance data. The concentration, $m_{\max }$, at maximum conductance, $\boldsymbol{x}_{\max }$, decreases with decreasing temperature, i.e. with increasing viscosity of the solvent. A decrease of viscosity at constant temperature resulting from a change in solvent composition produces an increase in $\mathrm{m}_{\max }$, also proving that viscosity is the most important factor determining the conductance. It is of technical interest that the specific conductance of solutions in polar solvents, here PC, can be considerably increased by the addition of suitable solvents with low permittivity, here DME. Ion-ion and specific ion-solvent interactions, e.g. association and solvation, are second-order effects ${ }^{227)}$.

Investigations on various salts in these solvents show that competition between ion-ion and ion-solvent interactions with increasing salt concentration leads to comparable states of the different solutions at their respective maximum conductance 227 . ${ }^{232)}$, i.e. the maximum specific conductance for every solution is obtained when the conductance-determining effects have established a critical energy barrier which depends almost exclusively on solvent and temperature and not on the solute. As an important consequence, in spite of large ion-ion association constants, the maximum specific conductance can be found at unexpectedly high $x_{\max }$-values in solvents of low permittivity ${ }^{227,230)}$. This feature can be used advantageously for technical applications.

\subsection{Ion Aggregates and their Role in Conductance}

Many 1,1-electrolytes show association to aggregates higher than ion pairs in pure solvents of classes 6 and 7 of Table I and in their mixtures of low permittivity, also in mixtures with solvents of other classes, e.g. $\mathrm{PC}, \mathrm{H}_{2} \mathrm{O}, \mathrm{ROH}$. The dependence of the 


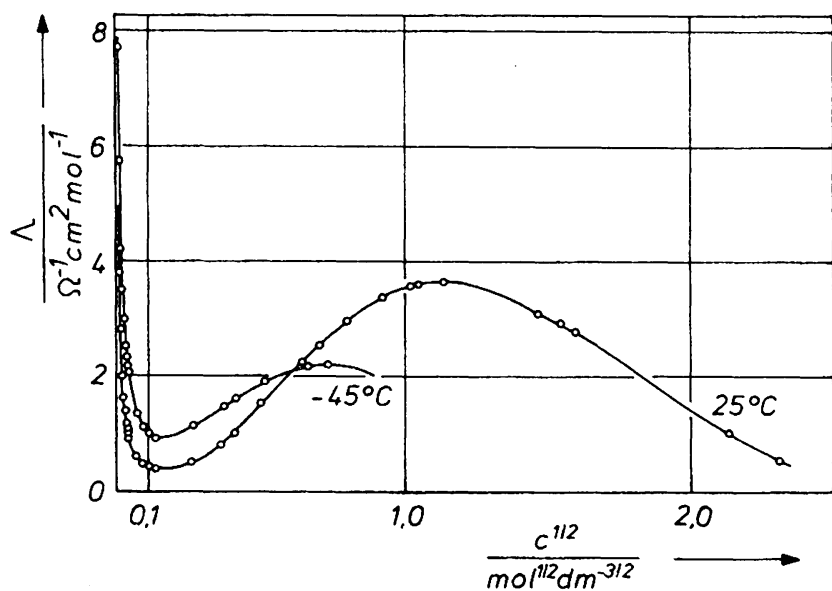

Fig. 8. Equivalent conductance of $\mathrm{LiBF}_{4}$ in dimethoxyethane solutions at $+25^{\circ} \mathrm{C}$ and $-45^{\circ} \mathrm{C}^{233}$

electrolyte conductance of these solutions upon the concentration and temperature is a suitable probe for this effect. Fig. 8 shows a minimum of equivalent conductance followed by a maximum for DME solutions of $\mathrm{LiBF}_{4}$ at $25^{\circ} \mathrm{C}$ as a typical proof for the coexistence of free ions, ion pairs, triple ions and possibly higher aggregates in the solution ${ }^{233)}$. The use of appropriate conductance equations ${ }^{30,234)}$ for data analysis yields the equilibrium constants $\mathrm{K}_{\mathrm{A}}$ (ion pairs) and $\mathrm{K}_{\mathrm{T}}$ (triple ions).

The ion-pair constant $\mathrm{K}_{\mathrm{A}}$ increases strongly with increasing temperature whereas the triple ion constant $\mathrm{K}_{\mathrm{T}}$ decreases slightly. Taking into consideration the resulting change in the charge density and the weakly temperature-dependent viscosity of the solvent (cf. Fig. 18), the observed inversions of the temperature coefficient of equivalent conductance in the range of low and moderate concentrations can be predicted without the need for further assumptions ${ }^{233)}$.

The range of high concentrations of such solutions, especially of those with solvents of class 7 , shows examples of an increase of conductance up to five orders of magnitude which cannot be explained by the usual transport equations. On the basis of conductance ${ }^{235}{ }^{236}$ ), viscosity ${ }^{235)}$, transference numbers ${ }^{237}$ ) and cryoscopic ${ }^{238)}$ measurements Gileadi et al. considered a "hopping mechanism" 235 . ${ }^{236)}$ quite similar to the Grotthuss mechanism for the proton in aqueous solutions

$$
\mathrm{C}^{+}+\left(\mathrm{C}^{+} \mathrm{A}^{-}\right)_{\mathrm{n}} \rightarrow \mathrm{C}^{+} \ldots \mathrm{A}^{-}\left(\mathrm{C}^{+} \mathrm{A}^{-}\right)_{\mathrm{n}-1} \ldots \mathrm{C}^{+} \rightarrow\left(\mathrm{C}^{+} \mathrm{A}^{-}\right)_{\mathrm{n}}+\mathrm{C}^{+}
$$

which predicts an increase of conductance with increasing number $n$, i.e. with increasing ion aggregation in the solution. The role of both cluster formation and the "hopping mechanism" for solutions of low dielectric constant is also illustrated by the system $\mathrm{NMF} / \mathrm{Br}_{2}{ }^{239}$ ) in which dissociation occurs according to

$$
\mathrm{NMF}+\mathrm{Br}_{2} \rightarrow\left(\mathrm{NMFBr}^{+}\right) \mathrm{Br}^{-} \stackrel{\mathrm{Br}_{2}}{\longrightarrow} \mathrm{NMFBr}^{+}+\mathrm{Br}_{3}^{-}
$$

Ion aggregates of quite another type must be considered for polyvalent ions in non-aqueous solvents, even in protic solvents (class 1), e.g. $\mathrm{CdCl}_{2}$ in methanol ${ }^{240)}$. The concentration-dependence of equivalent conductance down to $10^{-5} \mathrm{M}$ solutions as well as the temperature-dependence require this electrolyte to be treated as a 1,1-electrolyte, $\mathrm{CdCl}^{+} \mathrm{Cl}^{-}$, forming ion pairs of type $\left[\mathrm{CdCl}^{+}\left(\mathrm{ROH}^{-} \mathrm{Cl}^{-}\right]\right.$. 


\section{Spectroscopic and Relaxation Methods}

\subsection{Introduction}

The information on the structure of electrolyte solutions provided by thermodynamic and transport properties on the one hand and by spectroscopic, relaxation and kinetic investigations on the other, complement one another with regard to the chemical model. Thermodynamic and transport properties provide the distance parameter $\mathrm{R}$, the overall association constant $\mathrm{K}_{\mathrm{A}}$, and the activity coefficient $\mathrm{y}_{ \pm}$linked to it. No direct information can be achieved on the structure of the region $\mathrm{a} \leqq \mathrm{r} \leqq \mathrm{R}$ and possible regions $\mathrm{a} \leqq \mathrm{R}_{1} \leqq \mathrm{R}_{2} \ldots \leqq \mathrm{R}$. This problem, however, can be solved by modern spectroscopic and relaxation methods.

An appropriate subdivision of the region $a \leqq r \leqq R$ (cf. Sect. 4.2.) within the framework of an equilibrium concept is accompanied by the assumption of a suite of equilibria ${ }^{74,75)}$

$$
\mathrm{C}^{\mathrm{z}}+\mathrm{A}^{\mathrm{z}-} \stackrel{\mathrm{K}_{1}}{\rightleftarrows}\left[\mathrm{C}^{\mathrm{z}+} \mathrm{A}^{\mathrm{z}-}\right]_{1}^{0} \stackrel{\mathrm{K}_{2}}{\rightleftarrows} \stackrel{\mathrm{K}_{\mathrm{n}}}{\rightleftarrows}\left[\mathrm{C}^{\mathrm{z}+} \mathrm{A}^{\mathrm{z}-}\right]_{\mathrm{n}}^{0}
$$

Equation (20) gives an example. Every "ion pair" $\left[\mathrm{C}^{z+} \mathrm{A}^{\mathrm{z}-}\right]_{i}^{0}$ differs as a chemical species by its energy content from its neighbours in the suite as a consequence of the distance-dependent interaction forces between the ions. Individual equilibrium constants are given by the relationships

$$
\mathrm{K}_{1}=\frac{\mathrm{a}_{1}}{\mathrm{a}_{+} \mathrm{a}_{-}} ; \quad \mathrm{K}_{\mathrm{i}}=\frac{\mathrm{a}_{\mathrm{i}}}{\mathrm{a}_{\mathrm{i}-1}} \quad(\mathrm{i}=1 \ldots \mathrm{n})
$$

$a_{+}$and $a_{-}$being the activities of the free ions and $a_{i}$ those of the ion pairs.

Actually the link between spectroscopic, on the one hand, and thermodynamic or transport process results on the other, is not yet completely established. The concentration ranges of the methods differ greatly. Spectroscopy requires moderately or highly concentrated solutions with the exception of a few methods which have recently been developed for the low concentration range. Hence, the use of activity coefficients $y_{ \pm}^{\prime}$ of dilute solutions is doubtful. The overall association constant

$$
\mathrm{K}_{\mathrm{A}}=\mathrm{K}_{1}+\mathrm{K}_{1} \mathrm{~K}_{2}+\mathrm{K}_{1} \mathrm{~K}_{2} \mathrm{~K}_{3}+\ldots+\prod_{\mathrm{i}=1}^{\mathrm{n}} \mathrm{K}_{\mathrm{i}}
$$

considers exclusively free ions and ion pairs $\left[\mathrm{C}^{+} \mathrm{A}^{-}\right]_{i}^{0}$. Only in dilute solutions the activities of the ion pairs can be set equal to their concentrations.

The overall constant of the chemical model (see Fig. 3)

$$
K_{A}=4000 \pi N_{A} \sum_{i=1}^{n} \int_{R_{i}-1}^{R_{i}} r^{2} \exp \left[\frac{2 q}{r}-\frac{W_{+}^{*(i)}}{k T}\right] d r
$$


when compared with Eq. (41) enables the partial association constants to be expressed in terms of $R_{i}$ and $W_{+-}^{(i)}{ }^{3)}$. Hence, distance parameters $R_{i}$ and ion-pair configurations $\left[\mathrm{C}^{+} \mathrm{A}^{-}\right]_{\mathrm{i}}^{0}$ from spectroscopic evidence as well as information on ionion and ion-solvent interaction in moderately and highly concentrated solutions are actually the crucial contributions to electrochemistry.

Relaxation methods can provide information on some of the equilibria of Eq. (39) or all of them, depending on the frequency range of the method used, and can then establish a criterion for an appropriate subdivision of the region $a \leqq r \leqq R$.

Diffraction methods yield direct information on the pair-correlation functions, $\mathrm{g}_{\mathrm{ij}}\left(\overrightarrow{\mathrm{r}}_{1}, \overrightarrow{\mathrm{r}}_{21}\right)$, cf. Section 4.1.

Absorption methods give evidence on ion pairs but do not necessarily yield the overall association constants required by the thermodynamic excess functions. However, they furnish essential contributions to the elucidation of solvent-solvent and ion-solvent interactions and are the basis for most of the semi-empirical interaction scales usually applied.

\subsection{Diffraction Methods}

$\mathrm{X}$-ray and neutron scattering experiments yield direct information on the atomic pair-correlation functions, $\mathrm{g}_{\mathrm{ij}}\left(\overrightarrow{\mathrm{r}}_{1}, \overrightarrow{\mathrm{r}}_{12}\right)$, by the help of the scattering cross-section $\mathrm{do} / \mathrm{d} \Omega$ ${ }^{241.242)}$ or the reduced intensity $I{ }^{243)}$ both of which depend on the scattering angle $\theta$, which is expressed as the scattering vector $k=[4 \pi \sin (\theta / 2)] / \lambda . \lambda$ is the wavelength of the incident radiation. The intensity of the radiation scattered by each atom $i$ depends on its scattering factor $f_{i}$.

$\mathrm{X}$-rays are scattered at the inner electrons of an atom. The scattering factor (also called form factor) decreases with increasing $\mathrm{k}$ and increases linearly with the atomic number. The positions and interactions of light particles like hydrogen atoms or protons cannot be determined directly. Thermal neutrons, in contrast, are scattered on the spherical atomic nuclei and therefore the scattering factor (in this case also called coherent scattering length) is independent of angle but shows marked, unsystematic dependence on the atomic mass for all nuclei. The elimination of systematic errors due to absorption, polarisation, sample geometry, Compton scattering, multiple scattering at many atoms, incoherent and inelastic scattering, is a difficult but necessary task.

The mean cross-section is a function of the total structure factor $F_{T}(k)$

$$
\frac{d \sigma}{d \Omega}=N \times\left[F_{T}(k)+\Sigma c_{i} f_{i}^{2}\right],
$$

which itself is expressed by the partial structure factors $S_{i j}(k)$

$$
F_{T}(k)=\sum_{i} \sum_{j} N c_{i} c_{j} f_{i} f_{j}\left[S_{i j}(k)-1\right]
$$

with

$$
\mathrm{S}_{\mathrm{ij}}(\mathrm{k})=\mathrm{a}+\frac{4 \mathrm{~N}}{\mathrm{kV}} \int_{0}^{\infty}\left(\mathrm{g}_{\mathrm{ij}}(\mathrm{r})-1\right) \times \mathrm{r} \times \sin (\mathrm{kr}) \mathrm{dr} ; \quad \sum \mathrm{c}_{\mathrm{i}}=1
$$

$\mathrm{N}$ is the total number of all particles $\mathrm{i}$ with concentration $\mathrm{c}_{\mathrm{i}}$ in the volume $\mathrm{V}$. 
Josef Barthel et al

The total structure factor $\mathrm{F}_{\mathrm{T}}(\mathrm{k})$ contains the simultaneous information on all correlation functions of adjacent atoms, intermolecular as well as intramolecular. As a consequence, reports in the literature have been limited to solvents with few atoms, e.g. $\mathrm{H}_{2} \mathrm{O}$. Furthermore, the measured signal is very insensitive towards changes in solvent structure so that only highly concentrated solutions can be examined. The important results obtained from diffraction methods are the $\mathrm{M}^{\mathrm{Z}+} \ldots \mathrm{OH}_{2}$ distances, the tilt angles between the $\mathrm{M}^{\mathrm{Z}+} \ldots \mathrm{O}$ axis and the plane of the water molecule and hydration numbers ${ }^{241,242)}$. The configuration of $\mathrm{CdI}_{4-n}^{(n-2)} \cdot \mathrm{S}_{\mathrm{n}}$ complexes $\left(\mathrm{S}=\mathrm{H}_{2} \mathrm{O}\right.$ or dimethylsulfoxide) were investigated recently ${ }^{243)}$.

The extended X-ray absorption fine structure (EXAFS) in the high energy vicinity of the $\mathrm{K}$-edge (in some cases also L-edge) of atoms ${ }^{244.245)}$, e.g. $\mathrm{Cu}, \mathrm{Ni}, \mathrm{Fe}, \mathrm{Br}$, results from the backscattering of the excited photo-electron at the electron shells of the nearest neighboured atoms. The distance-dependent interference between the outgoing and the back-scattered wave function of the photo-electron changes the interaction between the incident $\mathrm{X}$-ray radiation and the excited photo-electron and causes the fine structure of the transmitted radiation. The selectivity of the absorption edge, the dependence of the shape of the fine structure on the atomic number of the backscattering atom, the absence of multiple scattering, and the ability to measure the phase and amplitude of the back-scattered radiation allow a rather simple and straightforward interpretation of EXAFS ${ }^{244}$. Data analysis via Fourier transformation provides very exact ion-solvent and ion-ion distances in moderately concentrated as well as in dilute solutions. The main advantage, but also the main experimental difficulty, is the need for continuous synchrotron radiation with high energy flux.

Until now most of the investigations have been made on aqueous solutions, e.g. $\mathrm{CuBr}_{2}{ }^{246.247)}, \mathrm{NiCl}_{2}{ }^{248)}, \mathrm{Ni}\left(\mathrm{NO}_{3}\right)_{2}{ }^{249}$ ). The chemical behaviour of these metal

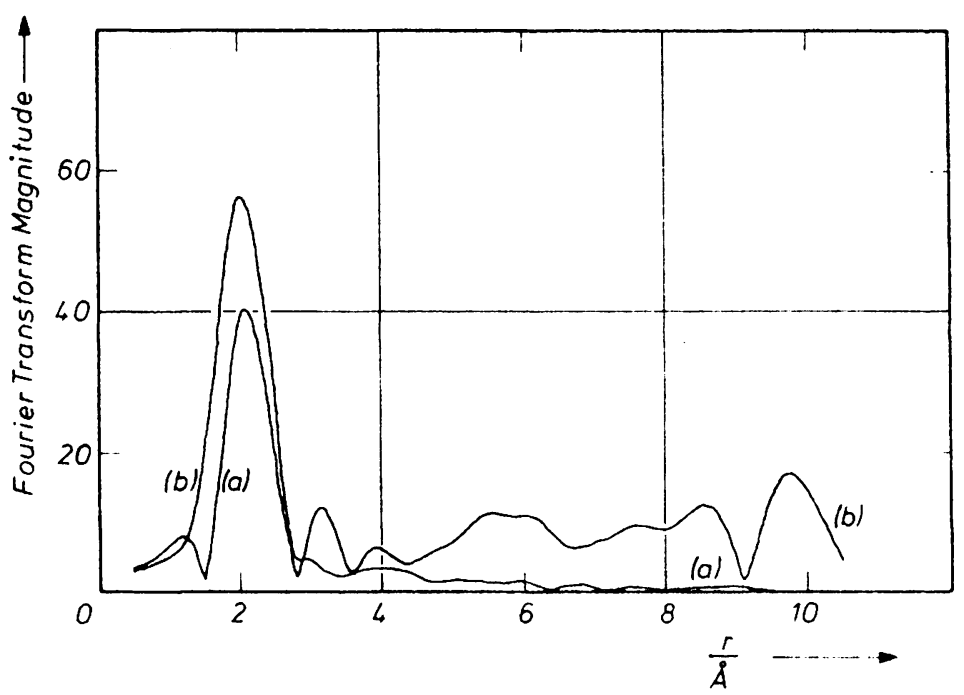

Fig. 9. Fourier transform EXAFS of $\mathrm{Ni}\left(\mathrm{NO}_{3}\right)_{2} \cdot 6 \mathrm{H}_{2} \mathrm{O}$ (a) solid salt: (b) $0.1 \mathrm{M}$ aqueous solution (with kind permission of the authors ${ }^{249)}$ ) 
cations in forming stable metal-solvent complexes is clearly shown by the investigations on $\mathrm{Ni}\left(\mathrm{NO}_{3}\right)_{2}$ for which the distances and the coordination number are the same in $0.1 \mathrm{M}$ aqueous solutions and in $\mathrm{Ni}\left(\mathrm{NO}_{3}\right)_{2} \cdot 6 \mathrm{H}_{2} \mathrm{O}$ crystals ${ }^{249}$ ) as shown in Fig. 9.

Investigations on moderately concentrated solutions $(0.1 \mathrm{M})$ of $\mathrm{NiCl}_{2}{ }^{248)}$ reveal outer-sphere complexes; the existence of $\mathrm{CuBr}_{4}^{2-246)}$ or $\mathrm{NiCl}_{4}^{2-}{ }^{248)}$ could not be verified by this method. An example in non-aqueous solution, $\mathrm{LiBr}$ in diethyl ether, has recently been published ${ }^{250,251)}$.

The consistency and the accuracy of the data for intermolecular distances and coordination numbers are the main features of these three methods. Their wide application, however, is prevented by the very expensive and time-consuming nature of the experiments.

\subsection{Absorption Spectroscopy}

In contrast to diffraction methods, yielding the position variables and quantities related to them, absorption spectroscopy also furnishes information about the population density of energy levels via Beer's law.

Electronic spectroscopy (180-750 nm) of organic compounds with mesomicric systems, e.g. $\mathrm{CH}_{3}-\mathrm{CO}-\mathrm{CH}=\mathrm{C}\left(\mathrm{CH}_{3}\right)_{2}{ }^{252)}$, or appropriate inorganic metal complexes, e.g. $\mathrm{CoCl}_{2}\left(\mathrm{C}_{5} \mathrm{H}_{5} \mathrm{~N}\right)_{\mathrm{n}}{ }^{253)}$, shows marked solvent effects from $\pi \rightarrow \pi^{*}, \mathrm{n} \rightarrow \pi^{*}, \mathrm{~d} \rightarrow \pi^{*}$ transitions or charge-transfer absorptions. Organic ions without mesomeric systems, simple inorganic ions and most of the solvents in Table I are generally unsuited for investigations in this frequency range. Halogen ions are an exception to this rule. They show $p \rightarrow s$ and $p \rightarrow d$ transitions in the UV-range which are shifted to lower energies for the higher homologues thus making iodide the most convenient ion for such measurements ${ }^{254}$. The absorption bands, which are strongly solventdependent, represent charge transfer to solvent (CTTS) spectra.

Investigations on carbanions with delocalized electrons are an interesting field of application ${ }^{255}, 256$ ). Their spectra in solvents of low permittivity suggest equilibria between tight and solvent-separated ion pairs and higher aggregates. For example, ion pairs formed from the alkali salts of isomeric vinyl pyridine carbanions ${ }^{257)}$ show the marked influence of the solvent and the structure of the anion as a consequence of charge delocalization in the isomeric pyridine rings. The properties of such carbanioncation pairs, which serve as catalysts in non-radical polymerization, determine to a large extent the stereospecificy of the chain growth and the stereoregularity of the polymer ${ }^{258)}$.

UV and VIS spectroscopy provide a handy and efficient tool for the generation of semi-empirical scales of solute-solute and solute-solvent interaction parameters which are currently used for correlations. Table VII gives a survey.

Excitcd states of ketones (compound I) and positive solvatochromic dyes, e.g. diethylamino p-nitrobenzene (compound II of table VII) or related compounds are more strongly solvated by polar solvents when compared with apolar ones. The shift of the $\pi \rightarrow \pi^{*}$ transition of substituted p-nitrophenoles ${ }^{260)}$ as well as the $\mathrm{n} \rightarrow \pi^{*}$ transition of ketones ${ }^{259)}$ are used as empirical polarity scales, $\pi^{* 260)}$ and $\Phi 259$. of a solvent. The energy shifts of the $\pi \rightarrow \pi^{*}$ transition of substituted pyridinium-N-phenolate betaines (compound III) and the charge-transfer absorption 
Josef Barthel et al.

Table VII Selected compounds for UV/VIS-solvent parameters

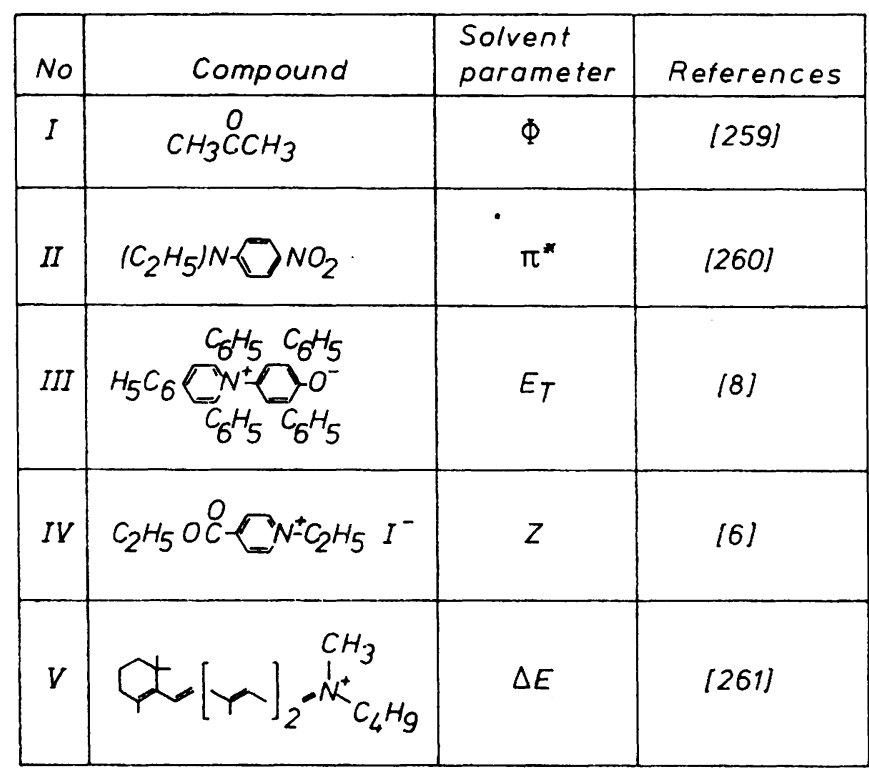

of the pyridinium iodide complex (compound IV) are the basis of the $E_{T}{ }^{8)}$ and $Z^{6)}$ scales. All these polarity scales represent the ability of solvents to solvate negative charges. An attempt was also made to classify the nucleophilic behaviour of solvents by the shift of the absorption band of $\mathrm{N}$-retinylidenemethyl-n-butylammonium iodide ${ }^{261)}$ (compound V).

Molecular vibrations in solvent molecules and multiatomic ions, as investigated by IR and Raman spectroscopy ${ }^{262)}$, are sensitive to changes in the surroundings of the molecule or ion. The measureable effects are band shifts, removal of degeneracy, variation of band intensity and shape, and the occurence and disappearance of bands. The resolution of the bands which are often overlapping requires highly developed computer-aided techniques ${ }^{263-268}$. The measured effects are not very sensitive to concentration; so far only concentrated solutions, $0.1 \mathrm{M}$ to saturation, have been studied. The use of Fourier-transform IR spectrometers and multiplexing techniques ${ }^{269-271)}$ will surely permit the use of lower concentrations and improve the accuracy of data.

IR and Raman-active intramolecular motions of ions or solvent molecules, giving evidence of solute-solute interactions, have been reported for many electrolytes in appropriate solvents, e.g. acetonitrile ${ }^{272-280)}$, dimethylsulfoxide $272.281-283$ ), liquid ammonia ${ }^{284-289)}$, methanol ${ }^{290)}$, formamide 291.292 ).

Both IR and NMR data indicate that in methanol solutions solvation of both cations and anions occurs by primary solvent molecules which are strongly hydrogenbonded to those in the bulk solvent ${ }^{290}$ ). This result has been confirmed and extended to other protic solvents through microwave investigations on alkali metal halides and salts of divalent cations in methanol, ethanol and formamide ${ }^{293,294)}$. Alkali salt ion pairs in protic solvents show cation-anion distances, as found by calori- 


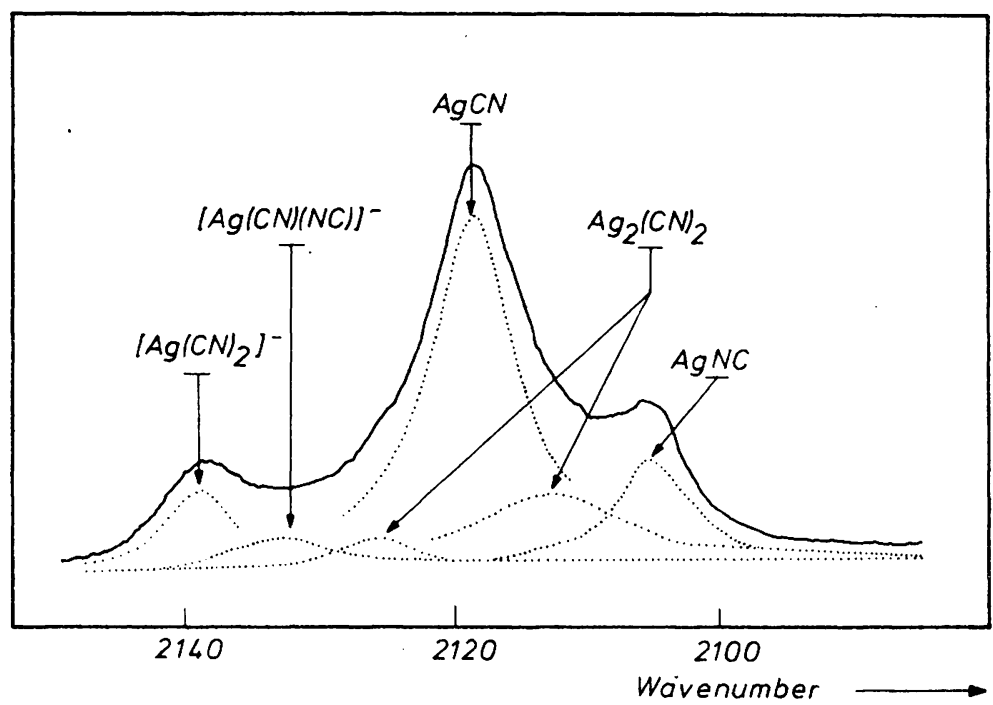

Fig. 10. Raman spectrum of silver cyanide in liquid ammonia and its decomposition into component bands. (with kind permission of the authors ${ }^{289}$ )

metric and conductance measurements, which require the inclusion of solvent molecules, and are in agreement with the spectroscopic evidence.

In his comprehensive investigation on Raman spectra of liquid ammonia solutions 288. 289) Gill found multicomponent bands of multiatomic anions. The system $\mathrm{AgCN} /$ $\mathrm{NH}_{3}$, Fig. 10, is given as an example. The positions and variations of relative intensities of component bands with changing cation, concentration and temperature indicate that a range of discrete ion pairs and higher aggregates coexist in equilibrium.

Association constants of electrolytes in organic solvents obtained from Raman and IR measurements are known, e.g. for $\mathrm{NaI}$ and $\mathrm{KI}$ in $\mathrm{AN}^{275)}, \mathrm{AgNO}_{3}$ in $\mathrm{AN}^{279)}$, LiSCN in polar solvents and ethers ${ }^{282,295,296)}, \mathrm{NaCo}(\mathrm{CO})_{4}$ in polar aprotic solvents ${ }^{297.298)}$ and $\left(\mathrm{C}_{4} \mathrm{H}_{9}\right)_{4} \mathrm{NCl}$ in benzene ${ }^{299)}$. The equilibrium concentrations of ions and ion pairs, needed for the calculation of association constants, are determined by integrating the appropriate bands and comparing the areas with reference areas which are related to known concentrations. This procedure furnishes 'apparent association constants' sometimes referred to without characterising them as such ${ }^{275)}$. The drawbacks of this method of calculation are the uncertainty in the area determination and the lack of reliable activity coefficients in concentrated solutions.

The approximations of the theory for dilute electrolyte solutions cannot be used without ambiguity. In particular the assumption cannot be maintained that the activity coefficient of the uncharged ion pairs equals one. Irish ${ }^{300)}$ suggested a way to account for the activity coefficient of the ion pair by assuming its behaviour to be similar to that of a structured dipole molecule, e.g. glycine. The quantitative comparison of the spectroscopically-determined association constants with those determined by conductivity, which is seldom found in the literature, also suffers from 
Josef Barthel et al.

the fact that in vibrational spectroscopy only short-range interactions can be observed. As a consequence of the last statement Janz et al. pointed out ${ }^{279)}$ that in acetonitrile $\mathrm{AgNO}_{3}$ forms only contact ion pairs; they draw the conclusion from the rather satisfactory agreement between $\mathrm{K}_{A}(\operatorname{Raman})$ and $\mathrm{K}_{A}(\Lambda)$.

The influence of cation-complexing agents like crown ethers ${ }^{281)}$, cryptands ${ }^{283}$. 298) or biological macrocyclic systems ${ }^{3011}$ on the structure of ion pairs is very marked and can easily be seen in vibrational spectroscopy.

Most spectroscopic investigations have been made with polyvalent electrolytes which show marked association and solvation effects but for which almost no reliable information exists from conductance measurements.

\subsection{NMR and Related Methods}

Nuclear magnetic resonance is a sensitive probe of the immediate chemical environment of ions in solution ${ }^{302,303)}$. The use of the Fourier transform technique combined with high resolution spectrometers permits measurements on nuclei with spins $I \geqq 1 / 2$ down to $10^{-3} \mathrm{M}$ solutions ${ }^{304)}$. Besides the classical nuclei with $\mathrm{I}={ }^{1} / 2\left({ }^{1} \mathrm{H},{ }^{13} \mathrm{C},{ }^{15} \mathrm{~N},{ }^{19} \mathrm{~F},{ }^{31} \mathrm{P},{ }^{205} \mathrm{Tl}\right.$ etc. $)$ there exist $\mathrm{NMR}$-active isotopes with $\mathrm{I} \geqq 1$ of almost all elements of the periodic system ${ }^{305)}\left({ }^{2} \mathrm{H},{ }^{7} \mathrm{Li},{ }^{11} \mathrm{~B},{ }^{14} \mathrm{~N},{ }^{23} \mathrm{Na}\right.$, ${ }^{25} \mathrm{Mg},{ }^{27} \mathrm{Al},{ }^{35} \mathrm{Cl},{ }^{39} \mathrm{~K},{ }^{43} \mathrm{Ca},{ }^{81} \mathrm{Ba},{ }^{87} \mathrm{Rb},{ }^{133} \mathrm{Cs}$ etc.). For nuclei with $\mathrm{I}={ }^{1} / 2$ the position and the multiplicity of the chemical shift, $\delta$, is due to spin-spin and spinlattice coupling and to magnetic shielding. Nuclear spins of $I \geqq 1$ yield electrical quadrupole moments which interact with the electrical field gradient resulting from the charge distribution of the adjacent molecules. In this case an electrical field of non-spherical symmetry is required but this is caused even by thermal fluctuations. Magnetic dipoles give sharp signals but quadrupoles show band broadening.

The maximum value of the chemical shift increases with increasing atomic number. A 2000-fold augmentation of $\delta$ is observed when going from ${ }^{1} \mathrm{H}$ to ${ }^{205} \mathrm{Tl}$, making thallium salts very sensitive probes for NMR investigations ${ }^{306,307)}$. ' $\mathrm{H}-\mathrm{NMR}$ spectroscopy is used mainly for investigation on hydrogen-bonding systems in aqueous and alcoholic solutions ${ }^{290,300)}$. The interaction between acceptor and hydroxyl group was examined in systems which are highly diluted with an inert solvent ${ }^{308}$ ) The chemical shift of ${ }^{31} \mathrm{P}$ of $\left(\mathrm{C}_{2} \mathrm{H}_{5}\right)_{3} \mathrm{PO}$ is the basis of the acceptor numbers, AN ${ }^{11 !}$.

Popov's comprehensive multinuclear NMR studies of alkali ions in non-aqueous solvents ${ }^{304.309-316)}$, encompassing concentration-dependence of chemical shifts, ionpair formation, influence of the solvent and correlation with donor numbers, and the role of macrocyclic polyethers and cryptands, are evidence of the powerful tool provided by NMR methods for the investigation of non-aqueous electrolyte solutions.

With respect to the exchange-time of ionic processes, the frequency of the NMR signal is generally low. Consequently, only a population-averaged resonance signal indicates the equilibrium between free ions and ion pairs. The concentrationdependent chemical shift can be expressed by

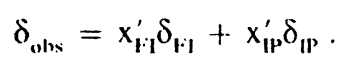


The mole fractions of free ions, $\mathrm{x}_{\mathrm{Fl}}^{\prime}$, and ion pairs, $\mathrm{x}_{\mathrm{IP}}^{\prime}$, are linked as usual to the association constant, $\mathrm{K}_{\mathrm{A}}{ }^{311}$,

$$
\mathrm{K}_{\mathrm{A}}=\frac{\mathrm{c}-\mathrm{c}_{\mathrm{FI}}^{\prime}}{\left(\mathrm{c}_{\mathrm{FI}}^{\prime}\right)^{2} \cdot \mathrm{y}_{ \pm}^{\prime 2}} ; \quad \mathrm{x}_{\mathrm{FI}}^{\prime}=\frac{\mathrm{c}_{\mathrm{FI}}^{\prime}}{\mathrm{c}}
$$

$\delta_{\mathrm{FI}}$ can be obtained by extrapolation to infinite dilution, $\mathrm{K}_{\mathrm{A}}$ and $\delta_{\mathrm{IP}}$ by nonlinear least-squares fitting ${ }^{311}$. The attempt ${ }^{280.317)}$ to correlate association constants from NMR measurements with those deduced from electrical conductance is not very meaningful because the two methods look at different populations of the ionic surroundings.

Macrocyclic complexing agents produce chemical shifts of the complexed cations, which are independent of the solvent. The occurence of distinct signals demonstrates the stability of such complexes ${ }^{318}$.

The determination of spin-lattice relaxation ${ }^{319-321)}$ gives the possibility of investigating dynamic properties of the electrolyte and the solvent in the solution. Attempts have been made to measure diffusion coefficients ${ }^{322}$ and transport numbers ${ }^{323)}$.

\subsection{ESR-Spectroscopy}

ESR-spectroscopy of radical anions and cations uses the coupling of electron and nuclear spin as the probe for ion-ion and ion-solvent interactions. Information is obtained from analyzing band shifts and band broadening and determining $\mathrm{g}$-values in various solvents ${ }^{324}$.

\subsection{Relaxation Methods}

The frequency range of microwave (MW) and far infrared (FIR) investigations extends between $5 \cdot 10^{8}$ and $10^{13} \mathrm{~Hz}\left(0.01\right.$ to $\left.200 \mathrm{~cm}^{-1}\right)$. Different names are used as a consequence of different measuring techniques ${ }^{294)}$ but all methods study the response of the solution to changing electromagnetic fields.

The microwave response both of polar solvents and electrolyte solutions is usually represented with the help of its frequency-dependent complex relative permittivity, $\varepsilon(\omega)=\varepsilon^{\prime}(\omega)+j \varepsilon^{\prime \prime}(\omega)$, cf. Ref. ${ }^{325)}$. The characteristic parameters of such investigations are the relaxation times or relaxation time distributions of molecular processes and the extrapolated 'real' permittivities of zero $\left(\varepsilon_{0}\right)$ and inifinite $\left(\varepsilon_{\infty}\right)$ frequencies of one or more relaxation regions.

Figure 11 shows a representation of $\varepsilon^{\prime \prime}(\omega)=f\left(\varepsilon^{\prime}(\omega)\right)$. called an Argand diagram, for $0.48 \mathrm{M} \mathrm{NaClO}_{4}$ in a PC-DME mixture (20 weight \% PC). Data analysis of the precedingly determined frequency-dependent permittivities of the solvent mixture without $\mathrm{NaClO}_{4}$ yielded two relaxation regions, one attributable to DME (relaxation time $\tau=4.7 \mathrm{ps}$ ) the other to $\mathrm{PC}$ (relaxation time $\tau=22 \mathrm{ps}$ ). The shifts of solvent relaxation times with reference to those of the two pure solvents, $\tau(D M E)=3.6 \mathrm{ps}$ and $\tau(P C)=39 \mathrm{ps}$, is correlated to the change in viscosity. Addition of the 


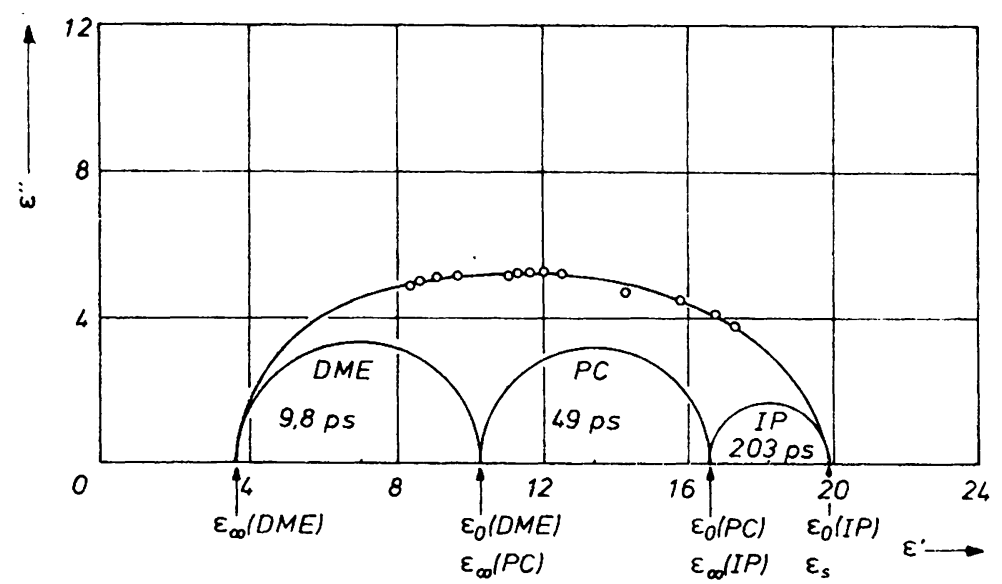

Fig. 11. Argand diagram $\varepsilon^{\prime \prime}$ vs. $\varepsilon^{\prime}$ of a $0.48 \mathrm{M} \mathrm{NaClO}_{4}$ solution in propylene carbonate-dimethoxyethane ( 20 weight $\%$ of $\mathrm{PC}$ ) at $25^{\circ} \mathrm{C}$ (upper curve with measured points) ${ }^{326)}$. Data analysis yields three relaxation times and appropriate Debye circles

electrolyte, Fig. 11, yields a third relaxation region (relaxation time $\tau(\mathrm{IP})=203 \mathrm{ps}$ ) due to ion-pair movements and shifting of the solvent relaxation times to higher values, $\tau(\mathrm{DME})=9.8 \mathrm{ps}$ and $\tau(\mathrm{PC})=49 \mathrm{ps}^{326}$. The static permittivity of the solution, $\varepsilon_{0}$ increases with increasing salt concentration ${ }^{326)}$.

Separate relaxation regions attributable to ion pairs ${ }^{294,326.327)}$ and higher aggregates ${ }^{328}$ ) cannot be observed in all solvents. Free ions contribute to $\varepsilon^{\prime \prime}(\omega)$ through their conductances. A survey is given in Ref. ${ }^{36)}$. As a rule, 1,1-electrolytes in protic solvents or solvents of high permittivity cannot be identified by separate regions. They yield decreasing $\varepsilon_{0}$-values (static permittivity of the solution) ${ }^{293}$, 329. 330) with increasing electrolyte concentration which depend specifically on the ions, e.g. $\mathrm{Li}>\mathrm{Na}>\mathrm{K}>\mathrm{Rb}>\mathrm{Cs}$ in water and alcohol solutions. Figure 12 gives a survey on $\mathrm{LiNO}_{3}$ solutions in various solvents ${ }^{293}$.

Both broadening and shifting of the relaxation time distribution of these solutions are also ion-specific ${ }^{329-331)}$. E.g. in methanol as solvent $\mathrm{NaClO}_{4}$ shifts relaxation times to higher, $\mathrm{Bu}_{4} \mathrm{NClO}_{4}$ to lower frequencies indicating 'structure making' or 'breaking' by the added salt ${ }^{331)}$, cf. Fig. 13 .

The FIR response $\left(0.1 \mathrm{~cm}^{-1}\right.$ to $\left.100 \mathrm{~cm}^{-1}\right)$ of polar dielectrics is related to inertial effects and the libration of dipoles ${ }^{294)}$. Ions in polar media contribute in a complex manner. Information is provided by Lambert-Beer's law related to the complex relative permittivity containing the conductance contribution to $\varepsilon^{\prime \prime}$ when electrolytc solutions are investigated. The rotational motion of polar molecules gives rise to a broad-band absorption with a maximum in the FIR region ${ }^{3321}$. Models proposing the libration of each molecule in the cage of its neighbours are used to explain the excess absorption observed ${ }^{294.332 .333}$. Ions in the solution interact specifically. For alkali salts a typical cation-band (about $400 \mathrm{~cm}^{-1}$ for $\mathrm{Li}^{1}, 110 \mathrm{~cm}^{-1}$ for $\mathrm{Cs}^{+}$) is observed arising from cation-solvent vibrations ${ }^{334-336)}$. The non-visible contribution of the anion mass excludes ion-pair vibrations, in contrast to tetraalkylammonium 
Non-Aqueous Electrolyte Solutions in Chemistry and Modern Technology

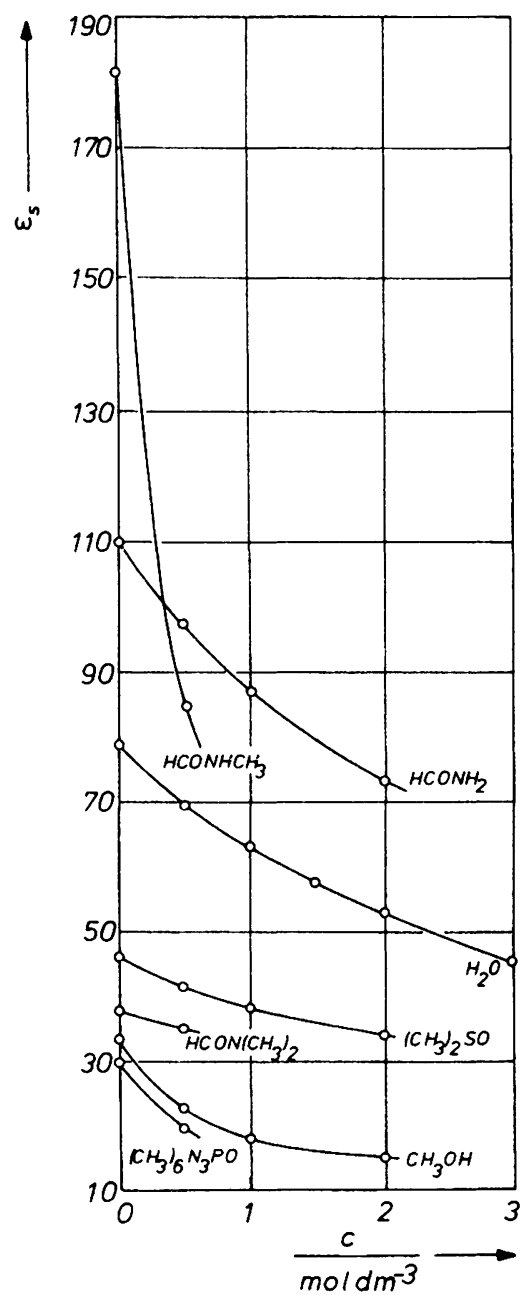

Fig. 12. Decrease of permittivity of various solvents by addition of $\mathrm{LiNO}_{3}$ at $25^{\circ} \mathrm{C}^{293)}$

salts in solvents of low permittivity where a broad, strong and asymmetrical absorption band, e.g. at $80 \mathrm{~cm}^{-1}$ for $\mathrm{Bu}_{4} \mathrm{NBr}$, is attributed to the libration of ion-pair dipoles ${ }^{294)}$. Lestrade, Badiali and Cachet have stressed the compatibility of FIR results and the chemical model ${ }^{294}$.

The region of radiowaves and still lower frequencies provides information on the relaxation of the ion cloud ${ }^{337-339)}$ in electrolyte solutions.

In connexion with dielectric and other spectroscopic relaxation methods, e.g. NMR, the group of ultrasonic relaxation, temperature-and pressure-jump methods ${ }^{51}$. $340-342)$ must be mentioned. These yield information on the processes in electrolyte solution and confirm the basic chemical model of free ions and ion pairs in the solution ${ }^{342)}$. 


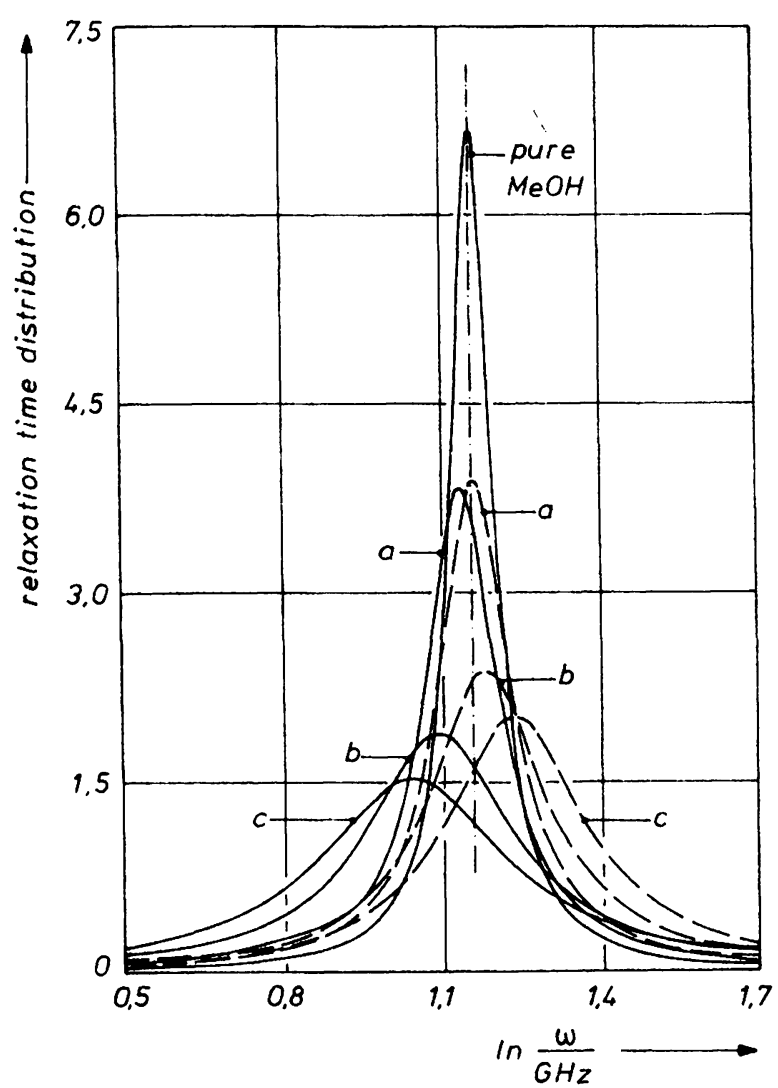

Fig. 13. Structure making and breaking effects in methanol solutions $\left(25^{\circ} \mathrm{C}\right)$ by tetrabutylammonium (full lines) and sodium (broken lines) iodide at concentrations $0.064 \mathrm{M}$ (a); $0.250 \mathrm{M}$ (b); and $0.535 \mathrm{M}$ (c). This figure shows the shift and broadening of relaxation time distributions. For further details reference is made to Ref. ${ }^{329)}$

\section{Chemical Reactions in Organic Solvents}

The rate constants of chemical reactions ${ }^{343)}$, the yield ${ }^{344)}$ and the selectivity ${ }^{345}$ ) a reaction, as well as the conditions for refining or recycling ${ }^{346)}$ of products can be optimized by the choice of appropriate solvents. Discussion in this section is restricted to reaction mechanisms involving electrolytes or single ions. The role of electrolyte solutions in primary and secondary kinetic salt effects is not considered. For this problem see Refs. ${ }^{78,347-349)}$.

\subsection{Ions and Ion Pairs in Chemical Reactions}

The ions and ion pairs of an electrolyte compound $\mathrm{Y}=\mathrm{C}^{+} \mathrm{A}^{-}$, which is involved in a chemical reaction yielding an overall rate constant $k_{\text {obs }}$

$$
\mathrm{B}+\mathrm{Y} \stackrel{\mathrm{k}_{\mathrm{obs}}}{\longrightarrow} \text { Products }
$$


may react by different reaction paths to yield the same reaction products ${ }^{350-357)}$, e.g.

$$
\mathrm{B}+-\left[\begin{array}{l}
\mathrm{C}^{+} \text {or } \mathrm{A}^{-} \stackrel{\mathrm{k}_{\mathrm{FI}}}{ } \\
{\left[\mathrm{C}^{+} \mathrm{A}^{-}\right]_{\mathrm{i}}^{0} \stackrel{\mathrm{k}_{\mathrm{IP}}^{(\mathrm{i})}}{ }}
\end{array}\right] \longrightarrow \text { Products . }
$$

The ion pairs $\left[\mathrm{C}^{+} \mathrm{A}^{-}\right]_{i}^{0}$ are those which were introduced through Eq. (39), $k_{\mathrm{F} 1}$ and $k_{\mathrm{IP}}^{(i)}$ are the appropriate individual rate constants. Then the overall rate constant is given by the relationship

$$
\mathrm{k}_{\mathrm{obs}}=\frac{\mathrm{k}_{\mathrm{Fl}} \mathrm{c}_{\mathrm{FI}}^{\prime}+\sum_{\mathrm{i}=1}^{\mathrm{n}} \mathrm{k}_{\mathrm{IP}}^{(\mathrm{i}) \mathrm{c}_{\mathrm{IP}}^{\prime(i)}}}{\mathrm{c}_{\mathrm{Y}}} ; \quad \mathrm{c}_{\mathrm{Y}}=\mathrm{c}_{\mathrm{FI}}^{\prime}+\sum_{\mathrm{i}=1}^{\mathrm{n}} \mathrm{c}_{\mathrm{lP}}^{\prime(i)}
$$

and is strongly dependent upon the electrolyte concentration, $c_{\mathrm{Y}}$. A simple case is given when data analysis can be executed with the help of an empirical set-up of equations of type of Eqs. (21)

$$
\begin{aligned}
& \mathrm{k}_{\mathrm{obs}}=\alpha \mathrm{k}_{\mathrm{FI}}+(1-\alpha) \mathrm{k}_{\mathrm{IP}} \\
& \mathrm{K}_{\mathrm{A}}=\frac{1-\alpha}{\alpha^{2} \mathrm{c}} \frac{1}{\mathrm{y}_{ \pm}^{\prime 2}} ; \quad \mathrm{y}_{ \pm}^{\prime}=\exp \left[-\frac{x \mathrm{q}}{1+\chi \mathrm{R}}\right] .
\end{aligned}
$$

Figure 14 shows an example in which $\mathrm{k}_{\mathrm{FI}}$ and $\mathrm{k}_{\mathrm{IP}}$ are obtained from linear functions of the type $k_{\text {obs }} /(1-\alpha)$ vs. $\alpha /(1-\alpha)$.

Values of $\mathrm{K}_{\mathrm{A}}$ from conductance measurements can often be used for calculating the degree of dissociation. Significant deviations, however, may also occur in this case, especially in mixed solvents, indicating that not all the pair configurations which are counted as ion pairs by the thermodynamic overall association constant, $\mathrm{K}_{\mathrm{A}}$, are reacting species ${ }^{177)}$.

Depending on the reaction mechanism various cases are observed, e.g.

(i) $\mathrm{k}_{\mathrm{Fl}}>\mathrm{k}_{\mathrm{IP}}$ for the solvolysis of alkyl halides in ethanol ${ }^{350,353)}$.

(ii) $\mathrm{k}_{\mathrm{Fi}}<\mathrm{k}_{\mathrm{iP}}$ cf. Fig. $14^{354)}$.

(iii) $\mathrm{k}_{\mathrm{tP}} \sim 0$ for the reaction of alkali phenoxides with methyl iodide in alcoholic solutions ${ }^{352}$,

(iv) $\mathrm{k}_{\mathrm{FI}} \sim 0$ for cyclic condensation reactions (Dieckmann condensation) ${ }^{351)}$.

\subsection{Kinetic Solvent Effects}

Comparison of reaction rates $\mathrm{k}^{\mathrm{s}}$ in a solvent $\mathrm{S}$ and $\mathrm{k}^{\circ}$ in a reference solvent (index o) yields

$$
\ln \frac{\mathrm{k}^{\mathrm{s}}}{\mathrm{k}^{\mathrm{o}}}=-\frac{1}{\mathrm{RT}}\left[\Delta \mathrm{G}_{\mathrm{c}}^{\neq s}-\Delta \mathrm{G}_{\mathrm{c}}^{\neq \mathrm{o}}\right]
$$

or related relationships, e.g. Ref. ${ }^{358 .}{ }^{359}$. 
Josef Barthel et al

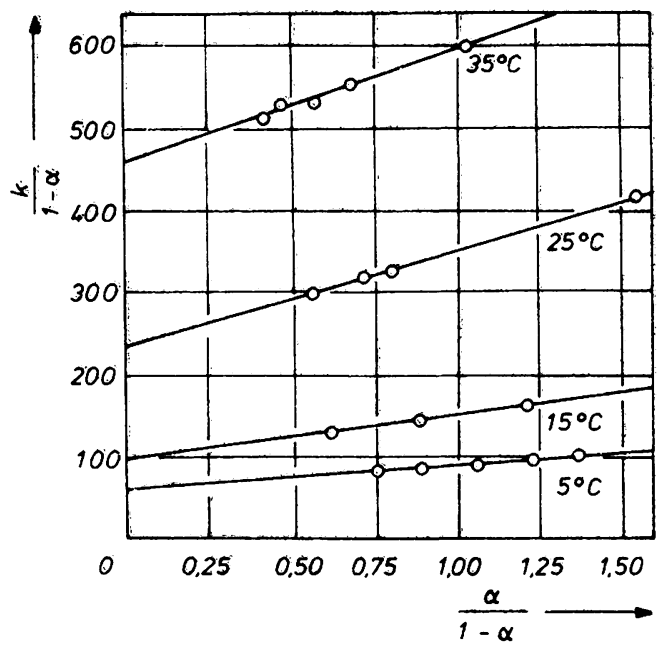

Fig. 14. Reactivity of ions and ion pairs in the reesterification reaction

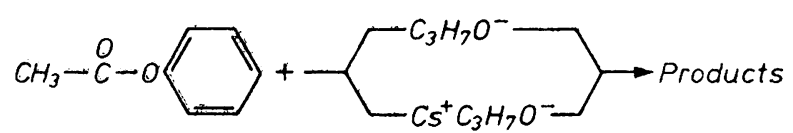

at various temperatures in propanol as the solvent ${ }^{354 !}$. Data analysis was executed with the help of Eqs. (23). Association constants of $\mathrm{C}_{3} \mathrm{H}_{7} \mathrm{OCs} / \mathrm{PrOH}$ were determined by conductance measurements.

\begin{tabular}{lllll}
\hline Temperature $\left({ }^{\circ} \mathrm{C}\right)$ & 5 & 15 & 25 & 35 \\
\hline $\mathrm{k}_{\mathrm{Fl}} /\left(\mathrm{dm}^{3} \mathrm{~mol}^{-1} \mathrm{~s}^{-1}\right)$ & 0.52 & 0.88 & 1.78 & 2.47 \\
\hline $\mathrm{k}_{\mathrm{IP}} /\left(\mathrm{dm}^{3} \mathrm{~mol}^{-1} \mathrm{~s}^{-1}\right)$ & 1.07 & 2.12 & 4.0 & 7.68
\end{tabular}

The energies $\Delta G^{*}$ based on the particle densities of the reacting species represent the maximum reversible work to build the activated complex $\mathrm{X}^{*}$, from the initial products in the reference solvent and in the solvent $S$, respectively. Eq. (49) is obtained from the theory of absolute reaction rates by assuming that the reaction mechanism is not affected by transferring the reaction from one solvent into the other. Change in the reaction mechanism is reported when the transfer is followed by a change of the charge distribution of the activated complex, e.g. ${ }^{360}$ ).

Studies of substitution, addition-elimination, elimination, and addition reactions involving ions or charge-bearing activated complexes are the usual means of investigation of solvent effects. Table VIII gives a survey of these reactions.

Generally valid equations for a quantitative discussion of solvent effects cannot normally be obtained. The use of models in kinetic investigations is based on presumptive evidence. Experimental rate constants or activation energies are compared with the prediction of possible configurations of the activated complex. For this purpose models containing detailed charge distributions for calculating activation energies. $\Delta \mathrm{G}^{*}$, and their dependence on solvent parameters are available from the 
Table VIII Appropriate classes of reactions for the investigation of solvent effects.

$\mathrm{Y}^{\mathrm{Z}} \mathrm{Y}$ : nucleophile of charge $-1 \leqq \mathrm{z}_{\mathrm{Y}} \leqq 0$

$E^{z_{E}}$ : electrophile of charge $0 \leqq z_{E} \leqq+1$.

$\mathrm{R}$ : general organic group; X: leaving group;

$\mathrm{L}$ : nucleophilic ligand;

Transition state formulae are in brackets

\begin{tabular}{|c|c|c|c|}
\hline \multicolumn{2}{|l|}{ Reaction and reaction type } & \multicolumn{2}{|l|}{ Examples and References } \\
\hline $\begin{array}{l}\text { I. Substitution } \\
\text { I.1. } R-X \longrightarrow\left[\delta^{+} \cdots \cdot \bar{\delta}\right] \rightarrow \text { Products } \\
\begin{aligned} \text { I.2. } Y^{Z_{Y}}+R-X & \rightarrow\left[Y \cdots R \cdots X I^{z_{Y}}\right. \\
& \longrightarrow \text { Products }\end{aligned}\end{array}$ & $\begin{array}{l}S_{N^{1}} \\
S_{N^{2}}\end{array}$ & 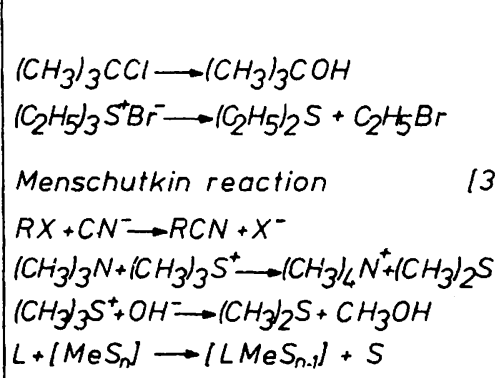 & $\begin{array}{l}{[361]} \\
{[362]} \\
3][364] \\
{[365]} \\
{[366]} \\
{[367]} \\
{[368]}\end{array}$ \\
\hline 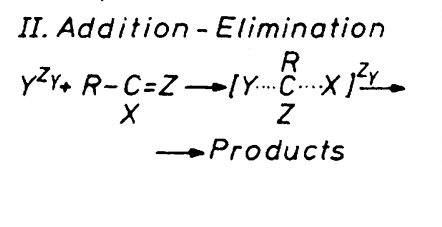 & $\begin{array}{l}A_{A C^{2}} \\
B_{A C^{2}}\end{array}$ & $\begin{array}{l}\text { acid ester solvolysis } \\
\text { neutral ester solvolysis } \\
\text { alkaline ester solvolysis }\end{array}$ & $\begin{array}{l}{[369]} \\
{[370]} \\
{[371]}\end{array}$ \\
\hline 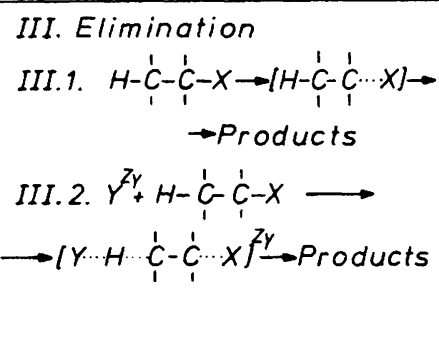 & $E_{1}$ & $\begin{array}{rl} & \stackrel{H}{\mathrm{C}}-\mathrm{H} \\
\mathrm{H} & \mathrm{H}-\mathrm{Br}+\mathrm{C}_{2} \mathrm{H}_{5} \mathrm{OH} \\
\longrightarrow & \square-\mathrm{H}=\mathrm{CH}_{2}\end{array}$ & [372] \\
\hline 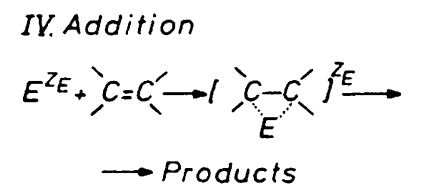 & & 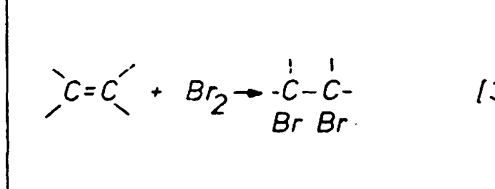 & $4][375]$ \\
\hline
\end{tabular}

litcrature ${ }^{78.376 \cdots 280)}$. Appendices B and C contain the fundamentals of the extended chemical model (see Sect. IV) for these calculations.

The (iiths encegy of activation, $\Lambda G^{\prime}$, caln be related to the mean-force pertential of the pair distribution function $W_{1 j}$ of the reactants which is written for this purpose in the following form

$$
W_{i j}=\left[e_{0} z_{j} \psi_{i}(P)+\mu_{j} \nabla \psi_{i}(P)+\theta_{j} \nabla \nabla \psi_{i}(P)\right]+W^{*}(P)
$$


where $e_{0} z_{j}, \mu_{j}$ and $\theta_{j}$ are the charge, dipole moment and quadrupole tensor of particle $j$, $\Psi_{i}(\mathrm{P})=\Psi_{i}(r, \theta, \varphi)$ the potential of the electric field of particle $i$ at point $P$, and $W^{*}$ a possible specific contribution from solvent-particle interactions.

Only a few simple examples of applications will be given. For ion-ion reactions the solvent effect, Eq. (49), is controlled by the relationship

$$
\ln \frac{k^{s}}{k^{0}}=\frac{e_{0}^{2} z_{i} z_{j}}{4 \pi \varepsilon_{0} k T} \frac{1}{r_{0}}\left[\frac{1}{\varepsilon^{0}}-\frac{1}{\varepsilon^{s}}\right]+\frac{W^{* 0}-W^{* s}}{k T}
$$

and for ion-dipole molecule reactions by

$$
\ln \frac{k^{s}}{k^{0}}=\frac{e_{0} z_{j}}{4 \pi \varepsilon_{0} k T} \frac{6\left(\varepsilon^{s}-\varepsilon^{0}\right)}{\left(2 \varepsilon^{0}+1\right)\left(2 \varepsilon^{s}+1\right)} \frac{\mu_{i}}{r_{0}^{2}} \cos \vartheta_{0}+\frac{W^{* 0}-W^{* s}}{k T} .
$$

Both equations are obtained from the general equations, appendix $B$ when the reacting ions are represented as single charges and the reacting dipole-molecules as point-dipoles in the spheres of radius a. Quantities $r_{0}$ (Eq. (51)) and $r_{0}, \vartheta_{0}$ (Eq. (52)) are the coordinates of particle $\mathrm{j}$ which characterize the configuration of the activated complex in the coordinate system of particle $i$.

By careful selection of a series of solvents or solvent mixtures the term due to specific interactions, $W^{* 0}-W^{* s}$, may be eliminated and then the well-known equations of the literature ${ }^{376-380)}$ are obtained. At an early stage of the research on solvent effects, Hughes and Ingold ${ }^{381)}$ established useful qualitative rules for nucleophilic substitution and addition-elimination reactions based on the permittivity of the solvent. Examples of changing the permittivity in the vicinity of reactants as a consequence of hydrophobic and hydrophilic interactions were given recently ${ }^{382}$ ). The important variation of the rate constant for the addition reaction of halogen to olefines ${ }^{374,375)}$ in polar solvents is a further example of interest. A good conformity between the chemical model and the experiment is obtained when an interaction of a halide cation and a non-polar but polarizable molecule (olefine) can be assumed ${ }^{376)}$. The basic equations for calculating interactions between ions and polarizable molecules are given in Appendix $C$. The discussion of solvent effects in the framework of these models has been limited to series of solvents with similar structures or to solvent mixtures where one of the solvent components changes the permittivity of the bulk solvent but is inert in the solvation of the reactants and the activated complex.

The suppression of the interaction term, $W^{* 0}-W^{* s}$, means the neglect of changing specific solvation when changing the solvent. The influence of solvents belonging to different solvent classes (Table I) which change the rate constant of some reactions by many powers of ten, reveals the contribution of short-range, specific solvation predominating the Coulombic interactions.

Medium activity coefficients, cf. Section 5.5, can be used to discuss these effects. Fig. 15 provides a summary of the changes in solvation energy of ions and neutral molecules of various types in solvents which are representative for the solvent classes of Table I. The energy scale, RT $\ln _{\mathrm{MeOH}} \gamma_{3}$, with methanol as the reference solvent is taken from Ref. ${ }^{359}$ ). The non-measurable medium activity coefficient of the activated complex can be estimated from similar stable molecules or ịons. 


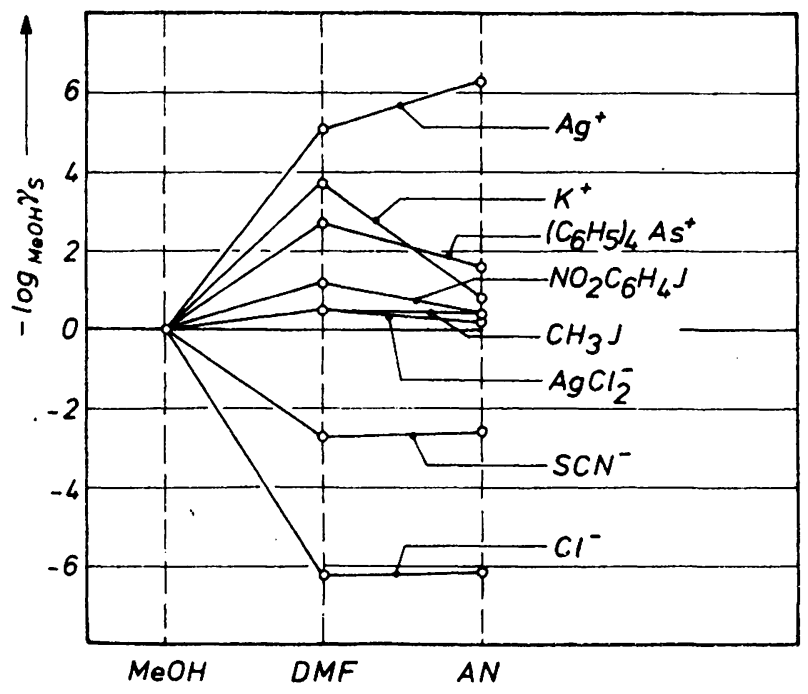

Fig. 15. Solvent activity coefficients for various ions and molecules with respect to $\mathrm{MeOH}$ as the reference solvent

In a comprehensive investigation Parker ${ }^{359)}$ tested the consistency of the model calculation through the conformity between the estimated values and the experimental values from kinetic measurements. The extra-thermodynamic equi-partition assumption, e.g. using $\left(\mathrm{AsPh}_{4}\right)^{+}\left(\mathrm{BPh}_{4}\right)^{-}$as the reference electrolyte, was adopted for all particles, thus vanishing in the final equations.

Table IX shows six examples of reactions in almost isodielectric solvents. The increase of up to six orders of magnitude in the rate constant of the reactions 1) to 3) is the result of drastically decreasing anion solvation and weakly increasing solvation of the activated complex in the dipolar aprotic solvents with a minimum effect for the soft anion, $\mathrm{SCN}^{-}$, which is better solvated in AN or DMSO than hard anions. The stronger solvation of the polar activated complex in dipolar aprotic solvents and

Table IX Solvent effect $\ln \left(\mathbf{k}^{3} / \mathbf{k}^{0}\right)$ in isodielectric solvents. $k^{0}:$ rate constant in methanol as the reference solvent

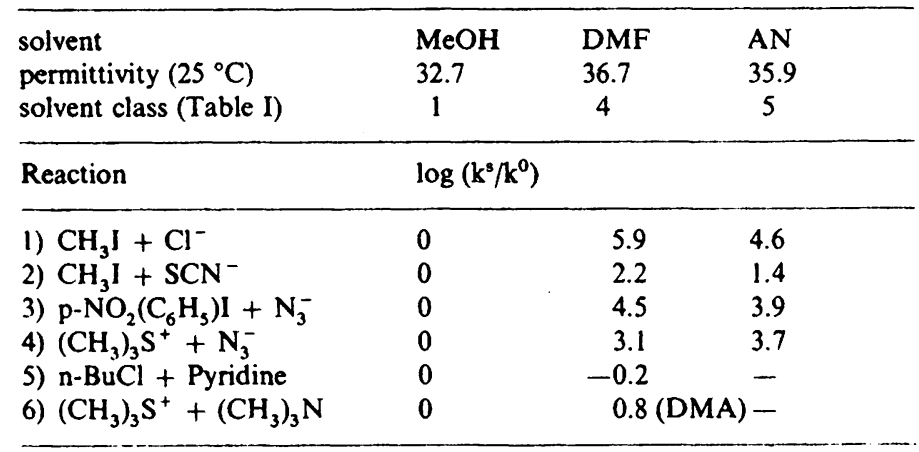


competition between decreasing anion and increasing cation ion-solvent interactions are observed in reaction 4). Reactions between molecules forming an uncharged activated complex, reaction 5), or reactions in which the charged species are a cation and an activated complex of equal charge, reaction 6), are only weakly affected by the transfer from polar protic to aprotic solvents. The solvation of the reactants in reaction 5) increases in DMF and $\mathrm{AN}$, rendering the reaction slower in aprotic media. For further discussion of specific solvent effects see Refs. ${ }^{383}{ }^{384}$ ).

It is not possible to transfer hydroxyl ions into dry aprotic dipolar solvents. Therefore the alkaline hydrolysis of esters, which is one of the most investigated secondorder model reactions in water and aqueous mixtures, is unsuited for the investigation of specific solvent effects despite many efforts ${ }^{385-388}$.

Most inorganic reactions of solvolysis and nucleophilic substitution of transition metal complexes are rather insensitive towards a change from protic to aprotic dipolar solvents ${ }^{368}$ ). Since the maximum coordination number of the complexes cannot be exceeded, in most cases the rate-determining step is a dissociation leaving a transition state with a positive charge almost one unit higher than the initial complex and an anion or, in few cases, a molecule. Thus the decreasing solvation of anions by dipolar solvents is counteracted by the increasing solvation of the cationic transition state.

The solvent effect on proton-transfer reactions is determined by two effects ${ }^{389)}$. In cases of slow proton transfers, which are not diffusion-controlled, e.g. reactions between carbon acids and weak bases ${ }^{390}$ ), the solvent effect is determined by hydrogen-bonding and formation of ion pairs whereas the viscosity of the solvent prevails in very fast diffusion-controlled reactions.

\subsection{The Use of Correlation Functions}

The tight link between kinetic solvent effects and the theory of solvation, suggests the correlation of kinetic data with parameters quoted in Section II when quantitative information from the theory of solvation is not available.

Nucleophilic effects (solvation of Lewis acids) can be correlated with Gutmann's DN-values ${ }^{11)}$ or with Palm's B-coefficient ${ }^{391)}$. The two coefficients are positively correlated but show marked deviations for hydrogen bonding systems. Electrophilic effects (solvation of Lewis bases) are represented by the $E_{\mathrm{T}}$-values of Dimroth and Reichardt ${ }^{8)}$, Kosower's Z-scale ${ }^{6,7)}$ or the AN-number of Gutmann and Mayer ${ }^{15}$. The $E_{T}$ and $Z$ parameters show a strong positive correlation which can be understood from the similar basis of both scales (cf. Sect. VII). The correlation between $E_{T}$ and AN-numbers is also positive ${ }^{15)}$. Inasmuch as these parameters are based on enthalpy effects the simultaneous correlation of protic and aprotic solvent properties yields usually two functions - one for protic and the other one for aprotic solvents --. when entropy is the determining factor, as in hydrogen bonding systems.

The correlation of kinetic data with empirical parameters is based on the principle of Linear Free Energy Relationships (LFER) and Quantitative Analogy Models (QAM) ${ }^{392.393)}$.

In a general way, correlation functions link a measurable quantity $Z_{k}$ of a system, 
the $\mathrm{i}$-th influence of the environment, $\xi_{\mathrm{ik}}$, and the response of the system toward this influence, $\beta_{i}$, by a linear expression

$$
Z_{k}=Z_{0}+\sum_{i} \beta_{i} \xi_{i k}
$$

which is the result of Taylor-series linearisation of the quantity $Z_{k} \cdot Z_{0}$ is the quantity $Z_{k}$ under normalized conditions. Today this method is widely used in computerassisted research.

Application to kinetic solvent effects consists in choosing $\ln k_{s}$ as the property $Z_{k}$ and the above quoted correlation parameters as the quantities $\xi_{\mathrm{ik}}$.

In the simplest case Eq. (53) can be represented by a one-parameter correlation

$$
\ln \mathrm{k}^{\mathrm{s}}=\alpha+\beta \xi_{\mathrm{s}},
$$

where $\alpha=\ln \mathrm{k}^{0}$ and $\xi_{\mathrm{s}}=\mathrm{DN}, \mathrm{E}_{\mathrm{T}}$, or AN etc. In many cases such one-parameter correlations yield satisfactory linear functions when solvents of the same class or related classes are considered ${ }^{12,394-398)}$.

Multiparameter correlations of the type

$$
\ln k^{s}=\alpha+\sum_{i} \beta_{i} \xi_{i s}
$$

are of increasing interest because of the improved computer techniques of multiple correlation.

Koppel and Palm used an equation with four parameters ${ }^{3911}$.

$$
\ln \mathrm{k}^{\mathrm{s}}=\ln \mathrm{k}^{0}+\mathrm{eE}+\mathrm{bB}+\mathrm{pP}+\mathrm{yY} .
$$

The equations of Fawcett and Krygowski ${ }^{399,400)}$

$$
\ln \mathrm{k}^{\mathrm{s}}=\alpha+\beta_{1} \mathrm{E}_{\mathrm{T}}+\beta_{2} \mathrm{DN}
$$

and of Mayer ${ }^{401)}$

$$
\ln \mathrm{k}^{\mathrm{s}}=\alpha+\beta_{1} \Delta \mathrm{DN}+\beta_{2} \Delta \mathrm{AN}-\beta_{3} \frac{\Delta\left[\Delta_{\mathrm{vap}} \mathrm{G}\right]}{\mathrm{RT}}
$$

yield good correlation encompassing many solvent classes.

Taft, Kamlet and coworkers ${ }^{261)}$ separate the solvent polarity from hydrogen bond donor $(\mathrm{HBD})$ and hydrogen bond acceptor (HBA) effects by the relationship

$$
\ln k^{s}=\ln k^{0}+n \pi^{*}+a \alpha+b \beta
$$

$\pi^{*}$ is the frequency shift of p-nitrophenyl dyes, for which hydrogen bonding is excluded, and $\alpha$ and $\beta$ are HBD and HBA-properties of the solvent respectively. The polarity scale $\pi^{*}$ is correlated with the dipole moment of the solvent, corrected with respect to the average reaction field ${ }^{402)}$. The HBA-coefficient $\beta$ is correlated with the proton affinity in the gas phase ${ }^{403)}$. 
Josef Barthel et al.

For nonpolar solutes, e.g. n-octane, it has been shown that the Gibb's energy of solution in different solvents is linearly correlated with Hildebrand's solubility parameter $\delta_{\mathbf{H}}{ }^{404}$, which takes into account the van der Waals and dispersion forces. In Eq. (58) these forces are considered by the change of the Gibbs energy of evaporation of the solvent.

A new generation of multiparameter correlations of high technological importance is presented in the comprehensive work of Dubois on the DARC system ${ }^{405,406)}$ and of Fredenslund and Rasmussen ${ }^{407.408)}$ and others on the UNIFAC method. These permit the advanced calculation of reactivity and solution properties on the basis of topological treatments of the molecules and their vicinity from a minimum of experimentally-determined supporting data. These methods form the basis of comprehensive data banks ${ }^{409-412)}$.

\subsection{Phase-Transfer Reactions}

The principle of phase-transfer reactions - advantageously used for substitution, alkylation, acylation, elimination, and redox reactions of organic compounds, RQ, - is the transfer of an ion from aqueous solution into an apolar phase where the chemical reaction

$$
\left[\mathrm{C}^{+} \mathrm{A}^{-}\right]_{\text {org }}^{o}+\mathrm{RQ} \rightarrow \mathrm{RA}+\left[\mathrm{C}^{+} \mathrm{Q}^{-}\right]_{\text {org }}^{o}
$$

takes place 413-416). Two features previously shown for solvent effects are thus used, the very high reaction rate of nucleophilic reactions in aprotic solvents and the reactivity of ions and ion pairs in chemical reactions. The problems of water transfer are minimized by the choice of apolar solvents, immiscible with water and suitable lipophilic counterions of the reacting ion.

The ionic co-reactant is usually an anion $\mathrm{A}^{-}\left(\mathrm{Cl}^{-}, \mathrm{N}_{3}^{-}, \mathrm{OH}^{-}, \mathrm{CN}^{-}, \mathrm{NO}_{2}^{-}, \mathrm{F}^{-}\right.$, $\mathrm{RCO}_{2}^{-}, \mathrm{RO}^{-}, \mathrm{BH}_{4}^{-}, \mathrm{MnO}_{4}^{-}, \mathrm{ClO}_{4}^{-}$) which is transferred into the apolar phase (benzene, toluene, pentane, $\mathrm{CH}_{2} \mathrm{Cl}_{2}, \mathrm{CHCl}_{3}, \mathrm{CCl}_{4}$ ) by the help of a 'catalytic' cation $\mathrm{C}^{+}\left(\mathrm{R}_{4} \mathrm{~N}^{+}, \mathrm{R}_{\mathbf{4}} \mathbf{P}^{+}, \mathrm{R}_{4} \mathrm{As}^{+}\right.$, metal cation complexed with crown ethers or cryptates) suitable for forming an ion pair, $\left[\mathrm{C}^{+} \mathrm{A}^{-}\right]^{0}$, in the apolar solvent.

The reaction, Eq. (60), is controlled by the heterogeneous equilibrium

$$
\mathrm{A}_{\mathrm{aq}}^{-}+\left[\mathrm{C}^{+} \mathrm{Q}^{-}\right]_{\mathrm{org}}^{\mathrm{o}} \rightleftarrows \mathrm{Q}_{\mathrm{aq}}^{-}+\left[\mathrm{C}^{+} \mathrm{A}^{-}\right]_{\mathrm{org}}^{\mathrm{o}}
$$

with the equilibrium constant

$$
\mathrm{K}=\frac{\left[\mathrm{C}^{+} \mathrm{A}^{-}\right]_{\mathrm{org}}^{0} \times\left[\mathrm{Q}^{-}\right]_{\mathrm{aq}}}{\left[\mathrm{C}^{+} \mathrm{Q}-\right]_{\mathrm{org}}^{0} \times\left[\mathrm{A}^{-}\right]_{\mathrm{aq}}}
$$

Thus the ion-pair concentration $\left[\mathrm{C}^{+} \mathrm{A}\right]_{\text {org }}^{o}$ can be controlled via the concentration of $\mathrm{A}^{-}$in the aqueous phase. The appropriate choice of electrolyte concentration, solvent and the catalyst are the conditions for optimizing the process. Tetraalkylammonium salts are commonly used and the number of carbon atoms should be at least 16 . Unsymmetrical ions with one long alkyl chain tend to form 
micelles and should be avoided ${ }^{417}$ ). Appropriate catalysts are $\mathrm{Bu}_{4} \mathrm{~N}^{+}, \mathrm{TEBA}^{\circledR}=$ $=\mathrm{N}+\left(\mathrm{C}_{6} \mathrm{H}_{5} \mathrm{CH}_{2}\right)\left(\mathrm{C}_{2} \mathrm{H}_{5}\right)_{3}$, and ALIQUAT $336^{\circledR}$ which is a mixture of trialkylammonium salts with 15 to 30 carbon atoms; $\mathrm{Bu}_{4} \mathrm{NHSO}_{4}$ is very suitable because of its cheapness and the ease of recovering it from the organic phase by treatment with sulfuric acid. In the anion sequence $\mathrm{F}^{-}>\mathrm{OH}^{-}>\mathrm{HSO}_{4}^{-}>\mathrm{Cl}^{-}>\mathrm{CN}^{-}>$ $>\mathrm{Br}^{-}>\mathrm{I}^{-}>\mathrm{ClO}_{4}^{-}$the exchange equilibrium of the phase-transfer catalyst decreases from left to right and hence also its catalytic activity.

Phase-transfer catalysts are used to extract organic or pharmaceutical products from waste water ${ }^{418)}$ and to transfer hydrophilic dyes from water into hydrophobic polymers ${ }^{419}$.

A convincing example used in organic and pharmaceutical synthesis ${ }^{418.420}$ is the alkylation of $\mathrm{CH}, \mathrm{OH}$ or $\mathrm{NH}$-acids by alkylating agents with $\mathrm{NaOH}$ under mild conditions. The potential Hoffmann degradation of the transfer-catalyst ion ${ }^{421)}$ when tetraalkylammonium salts are chosen can be avoided by the use of the more expensive alkali crown complexing agents. For comparison, in non-aqueous homogenous phase reactions the alkylation takes place only with strong bases, like $\mathrm{NaNH}_{2}, \mathrm{NaOR}$, $\mathrm{LiOC}_{4} \mathrm{H}_{9}$ etc.

The use of chiral catalysts introduces the possibility of synthesizing stereospecific products ${ }^{422)}$ with only minor formation of racemates.

\section{Part B}

\section{Technical Applications and Applied Research}

\section{Introduction}

A perusal of recent literature shows an increasing interest in technical applications and applied research based on non-aqueous electrolyte properties. The assortment of solvents with widely varying properties, an almost unlimited number of solvent mixtures and soluble electrolyte compounds provides flexibility in tackling a given problem. The unique properties of non-aqueous solutions can be the key in solving special technical problems.

Primary batteries (Sect. X) of high energy density, very low self-discharge (long shelf life) and good low-temperature performance make use of the large liquid range of organic solvents and of the kinetic stability of lithium metal in non-aqueous solutions. They are commercially available and have replaced conventional systems in some fields, e.g. cardiac pacemaker batteries and military applications. Good solubilities for some technically important electrolytes and many non-electrolytes, large liquid range, solution stability, enhanced stability of the solvent against oxidation and reduction are factors which recommend non-aqueous electrolyte solutions for use in the electrodeposition of metals (Sect. XIII), the production of wet capacitors (Sect. XIV), and various fields of electro-organic synthesis (Sect. XV). Flat non-emissive electrode displays (Sect. XI) and liquid junction solar cells (Sect. XII) 
Josef Barthel et al.

are further fields which are developing fast and where non-aqueous electrolyte solutions are successfully competing with solid state ionics and aqueous electrolyte solutions. Here the non-aqueous solutions may be superior to aqueous solutions because of increased corrosion resistance of the electrodes. Other built-in advantages when compared to solid state electrolytes are the better levelling properties both for temperature and concentration discontinuities and the good permanent contacts between electrodes and ionic conductors which are not interrupted by temperature and pressure changes or volume changes occuring from chemical reactions (high energy batteries, electrochromic displays, liquid junction solar cells).

Drawbacks of non-aqueous electrolyte solutions include the appreciately higher costs of the solvent and, in some cases, its toxicity or flammability. Until now some promising fields of application have been blocked because of existing alternative production units and by the technological problems of scaling up the electrochemical processes. The flexibility in the choice of appropriate electrolyte solutions is linked to an increased number of variables and may involve time-consuming optimisation

Table X Conductivities of several technically important ion-conducting systems

\begin{tabular}{|c|c|c|c|}
\hline System & $\begin{array}{l}\text { Temperature } \\
\frac{\theta}{{ }^{\circ} \mathrm{C}}\end{array}$ & $\begin{array}{l}\text { Conductivity } \\
\frac{10^{4} x}{\Omega^{-1} \mathrm{~cm}^{-1}}\end{array}$ & Ref. \\
\hline $\begin{array}{l}* 5.68 \mathrm{M} \mathrm{HCl} / \mathrm{H}_{2} \mathrm{O} \\
* 6.80 \mathrm{M}\end{array}$ & $\begin{array}{l}+25 \\
-20\end{array}$ & $\begin{array}{l}8490 \\
3529\end{array}$ & 4231 \\
\hline $\begin{array}{l}2.81 \mathrm{M} \mathrm{LiClO} \\
2.84 \mathrm{M}\end{array}$ & $\begin{array}{r}+25 \\
0\end{array}$ & $\begin{array}{l}1517 \\
878.4\end{array}$ & 424) \\
\hline $\begin{array}{l}* 3.92 \mathrm{M} \mathrm{LiClO}_{4} / \mathrm{MeOH} \\
* 2.68 \mathrm{M}\end{array}$ & $\begin{array}{l}+25 \\
-45\end{array}$ & $\begin{array}{l}498.1 \\
123.7\end{array}$ & 4251 \\
\hline $\begin{array}{l}* 0.66 \mathrm{M} \mathrm{LiClO} \\
* 0.34 \mathrm{M}\end{array}$ & $\begin{array}{r}+25 \\
\cdot-45\end{array}$ & $\begin{array}{r}54.20 \\
2.75\end{array}$ & 2321 \\
\hline $\begin{array}{l}\text { *1.39 } \mathrm{M} \mathrm{LiClO}_{4} / \mathrm{PC}, \mathrm{DME} \\
42 \text { weight } \% \text { of PC } \\
\text { *0.74 } \mathrm{M} \mathrm{LiClO} / \mathrm{PC}, \mathrm{DME} \\
28 \text { weight } \% \text { of PC }\end{array}$ & $\begin{array}{l}+25 \\
-45\end{array}$ & $\begin{array}{r}145.9 \\
33.1\end{array}$ & 2271 \\
\hline $\begin{array}{l}\mathrm{LiCl} \text { (liquid) } \\
\mathrm{LiCl} / \mathrm{KCl} \text { (eutectic) } \\
\quad 58.5 \mathrm{~mol} \% \text { of } \mathrm{LiCl} \\
\text { Ethylpyridinium bromide/ }\end{array}$ & $\begin{array}{l}+637 \\
+475\end{array}$ & $\begin{array}{l}58540 \\
16150\end{array}$ & $\begin{array}{l}426) \\
426)\end{array}$ \\
\hline $\mathrm{AlCl}_{3}, 1: 2$, melt & +25 & 84.3 & 4271 \\
\hline $\begin{array}{l}\mathrm{LiO}_{2} \mathrm{C}_{2} \mathrm{~F}_{3} \text {-polyethyleneoxide } \\
\text { complex } \\
\mathrm{Lil}(\mathrm{s}) \\
\mathrm{Lil} / \mathrm{Al}_{2} \mathrm{O}_{3} \\
\mathrm{Lil} / \mathrm{Al}_{2} \mathrm{O}_{3} \\
\mathrm{Li}{ }_{3} \mathrm{~N}\end{array}$ & $\begin{array}{r}+25 \\
+25 \\
+37 \\
+300 \\
+25\end{array}$ & $\begin{array}{l}10^{-4} \\
10^{-3} \\
1 \\
50 \text { to } 100 \\
10\end{array}$ & $\begin{array}{l}4281 \\
429.4301 \\
429.4311 \\
4291 \\
4321\end{array}$ \\
\hline
\end{tabular}


studies. When compared to aqueous electrolyte solutions or salt melts, the non-aqueous solutions show distinctly lower conductivities, but their accessible temperature range is more favourable for many applications. Tàble $X$ gives a comparison of some ionic conductors which have been used technically. The asterisk $\left(^{*}\right)$ means that the concentration variables were chosen to yield the maximum conductivity of the system, $x_{\max }$, cf. Fig. 7.

In various fields the use of non-aqueous electrolyte solutions has reached the stage of commercialisation and offers the possibility of introducing both new products and procedures. The following seven sections provide information on the current state of knowledge in some of them. Advantages of the non-aqueous electrolyte solutions are best demonstrated by quoting numerical values proving the degree of optimization. We also felt that it was necessary to demonstrate the reasons which led to the selection of particular non-aqueous electrolyte solutions by including a short description of the competing technological alternatives. Preference has been given to the most recent publications in our choice of examples. For the earlier literature, reference is generally made to monographs and reviews.

Technology considers electrochemical systems, i.e. heterogeneous systems with conducting liquid and solid phases, surface layers, membranes, etc. The fields of research which were discussed in the preceding eight sections concern almost exclusively the electrochemical properties of homogeneous liquid systems. Solvent structure, ion solvation, and association and their competition turn out to be the governing factors for the understanding of electrolyte solutions. In many cases an understanding of the role of the electrolyte solution in electrochemical systems also requires consideration of the neighbouring phases of the solution.

It is satisfactory to state that modern electrolyte theory can be helpful for optimizing forthcoming technologies. On the other hand, exciting new problems arise from technological investigations which then stimulate the theory to search for new approaches.

\section{High-Energy Batteries}

\subsection{Background}

High energy batteries ${ }^{229)}$ work with distinctly higher (1.5 to 10 times) ${ }^{433)}$ energy densities and higher open-circuit and working voltages than conventional systems. They may be operated even at low temperatures, e.g. $-50^{\circ} \mathrm{C}$. Furthermore, they exhibit appreciably lower self-discharge rates (down to $<1 \%$ /a) which in the case of lithium batteries are mainly due to film formation on the Li-electrode. Lithium is the most favoured anode material because of its low equivalent weight but $\mathrm{Na}^{434,435}$, $\mathrm{K}^{436)}, \mathrm{Mg}^{229.437-439)}, \mathrm{Al}^{229.439-441)}$, and $\mathrm{Ca}^{438.442 .820)}$ have been considered as possible substitutes. The reasons are the natural abundance of aluminium, magnesium or calcium, their higher electronic conductivity ${ }^{442)}$, and the higher security (higher melting points) provided by these metals.

Batteries can be divided into two classes, the non-rechargeable primary and the rechargeable secondary batteries. Various types of small primary batteries have been 
commercially available since the early seventies. Secondary batteries are now the object of increased research. Some success has already been gained by the invention of reversible cathode materials which, in conjunction with lithium. anodes and appropriate electrolyte solutions, allow an increased number of charge-discharge cycles.

High-energy batteries with a lithium anode are classified ${ }^{443,444)}$ with regard to the type of their ionic conductor. This can be a fast solid $\mathrm{Li}^{+}$-ion conductor, a fused lithium salt, a lithium-potassium-salt eutectic mixture, or a non-aqueous lithium salt solution. If inorganic solvents are used, e.g. $\mathrm{SO}_{2}, \mathrm{SOCl}_{2}, \mathrm{SO}_{2} \mathrm{Cl}_{2}$, the solvent itself is the depolarizer and then a solid catalytic electrode is needed, e.g. carbon. The type of ionic conductor determines the internal resistance of the cell and the working temperature range and hence the possible technical applications.

Systems which work only at elevated temperatures, e.g. $\mathrm{Na} / \mathrm{\beta}$-alumina/S or Li/salt melt $/ \mathrm{FeS}$, have a potential for traction and load-levelling purposes. The reader is referred to reviews ${ }^{426,434,445-451 \text { ). }}$

Solid-state cells for operation at ambient temperatures are mentioned for comparison with the wet cells. The low conductivities of fast solid ion conductors at ambient temperatures, cf. $\mathrm{Li}_{3} \mathrm{~N}$ and $\mathrm{LiI}$ (Table $\mathrm{X}$ ) limit their use to fields where low discharge currents can be tolerated, e.g. batteries for cardiac pacemakers.

An example is the $\mathrm{Li} / \mathrm{LiI} / \mathrm{I}_{2} \cdot \mathrm{PVP}\left(\mathrm{PVP}=\right.$ poly-2-vinylpyridine) cell ${ }^{433.444 .452 .4531}$ which is commercially available. The cell reaction $14 \mathrm{Li}+\mathrm{PVP} \cdot 8 \mathrm{I}_{2} \rightarrow 14 \mathrm{Lil}+$ + PVP $\cdot \mathrm{I}_{2}{ }^{431)}$ entails an increase of the internal resistance during discharge (specific resistances ${ }^{431)} 10^{3} \Omega \mathrm{cm}\left(\mathrm{PVP} \cdot 8 \mathrm{I}_{2}\right) ; 10^{7} \Omega \mathrm{cm}\left(\mathrm{PVP} \cdot \mathrm{I}_{2}\right)$ ). Typical characteristics are: open-circuit voltage ${ }^{453)}: 2.8 \mathrm{~V}$; energy density ${ }^{453)}: 200 \mathrm{~W} \mathrm{~h} / \mathrm{kg}$ or $0.7 \mathrm{~W} \mathrm{~h} / \mathrm{cm}^{3}$; self-discharge ${ }^{431,453)}<10 \%$ in 10 years; capacity ${ }^{431)}$ : $2 \mathrm{~A}$ h; current drain ${ }^{431)}$ : $25 \mu \mathrm{A}$. About 500,000 cells ${ }^{452)}$ (Cardiac Pacemakers Inc.; Catalyst Research Corp.; Medtronic Inc.; Wilson Greatbach Ltd) were implanted in the period 1972-80. A

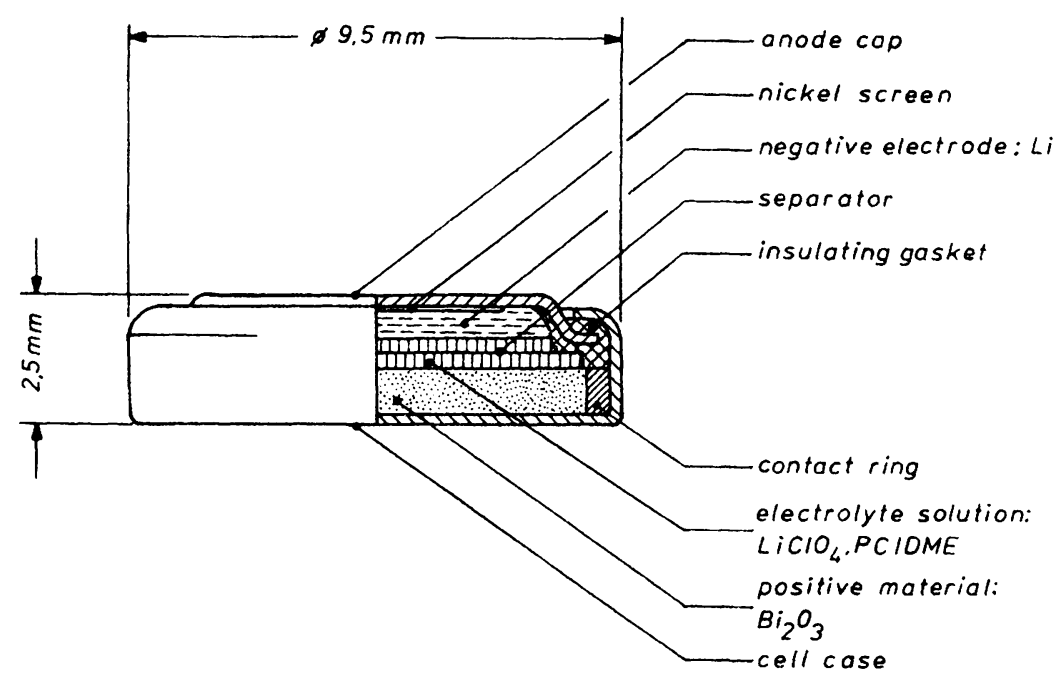

Fig. 16. Structure of a $\mathrm{Li} / \mathrm{Bi}_{2} \mathrm{O}_{3}$ cell (VARTA) (with kind permission of VARTA) 
promising new solid state-cell ${ }^{428}$ ) uses $\mathrm{LiO}_{2} \mathrm{C}_{2} \mathrm{~F}_{3}$ in polyethylene oxide with a $\mathrm{Li}_{\mathrm{x}} \mathrm{TiS}_{2}$ intercalation electrode (cf. also Sect. 10.5.2.). For further information see Refs. ${ }^{431,454-456)}$.

Lithium batteries with non-aqueous solutions are also available $443.444,453,457)$ commercially. Energy density, $300 \mathrm{~W} \mathrm{~h} / \mathrm{kg}^{444)}$ or 0.35 to $0.5 \mathrm{~W} \mathrm{~h} / \mathrm{cm}^{3458)}$, and self-discharge, $<2 \%$ per year ${ }^{443,444)}$ are comparable to those of commercial solidstate cells. The $\mathrm{Li} / \mathrm{LiClO}_{4}(\mathrm{PC}) / \mathrm{Ag}_{2} \mathrm{CrO}_{4}$ cell has found extensive use in pacemakers, more than 350,000 being manufactured up to $1980^{452}$ ). A diagram of a battery with a non-aqueous electrolyte solution is given in Fig. 16. Further information is given in Section 10.4 .

Solid-state and wet lithium cells have replaced ${ }^{453)}$ the conventional Rubin-Mallory zinc/mercury pacemaker battery using aqueous $\mathrm{NaOH}$ solutions. Both types of lithium cell exhibit higher energy densities than conventional cells, e.g. $\mathrm{Zn} / \mathrm{HgO}$ with $100 \mathrm{~W} \mathrm{~h} / \mathrm{kg}^{444)}$ or $0.35 \mathrm{~W} \mathrm{~h} / \mathrm{cm}^{3457)}$ or $\mathrm{Zn} / \mathrm{MnO}_{2}$ with 0.1 to $0.2 \mathrm{~W} \mathrm{~h} / \mathrm{cm}^{3}{ }^{358}$ ), and a far longer shelf-life, e.g. a lead-acid battery exhibits a self-discharge rate of $1 \%$ per day ${ }^{444)}$, the $\mathrm{Zn} / \mathrm{MnO}_{2}$-cell of $20 \%$ per year ${ }^{444)}$.

\subsection{Non-Aqueous Electrolyte Solutions in Lithium Batteries}

The requirements concerning non-aqueous battery electrolyte solutions are high specific conductance of the solution $\left(>5 \times 10^{-3} \mathrm{~S} \mathrm{~cm}^{-1}\right)$ and high mobility of the active ion over a large temperature range $\left(-50^{\circ} \mathrm{C}\right.$ to $\left.+50^{\circ} \mathrm{C}\right)$, sufficiently high solubility of the electrolyte compound $\left(>0.3 \mathrm{~mol} \mathrm{dm}^{-3}\right)$ at all temperatures, compatibility both with the lithium anode and the positive material (cathode) and, in the case of rechargeable batteries, stability over a sufficiently large voltage range.

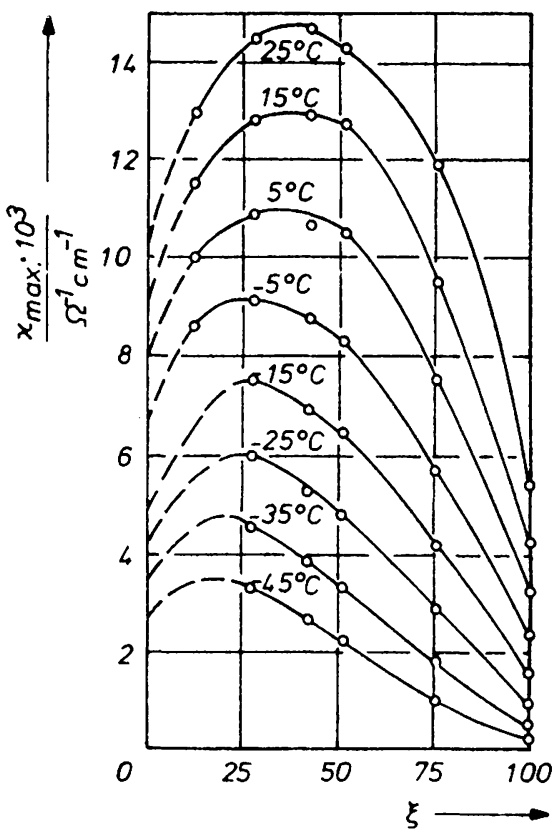

Fig. 17. Plot of maximum specific conductance of non-aqueous $\mathrm{LiClO}_{4}$ solutions $\left(x_{\text {max }}\right)$ vs. solvent composition $(\xi)$ of the mixed solvent propylene carbonate-dimethoxyethane at temperatures $\left.\left(-45^{\circ} \mathrm{C} \leqq \theta \leqq+25^{\circ} \mathrm{C}\right)^{227}\right)$ 
Josef Barthel et al.

Hence the optimum solvent for a battery would be a solvent of low viscosity, high permittivity, and low vapour pressure fulfilling all compatibility and stability conditions. Solvents of classes 6 or 7 in Appendix A-1, have low viscosities accompanied, however, by low permittivities and high vapour pressures, whereas those of classes 4 and 5 have high permittivities and low vapour pressures, but large temperature coefficients of viscosity yielding low conductances at low temperatures, cf. DME (class 6) and PC (class 5) in Figs. 17 and 18. Solvents of the other classes are unsuitable with regard to the stability and compatibility conditions. Solvent mixtures can improve both the solubility of the electrolyte and the conductivity of the solution and may reduce the temperature coefficient of conductivity and viscosity.

An example is $\mathrm{LiClO}_{4}$ in $\mathrm{PC} / \mathrm{DME}$ mixtures which is widely used as an electrolyte solution in commercial primary batteries. The complete information about the specific conductance of this battery electrolyte in the temperature range $-45^{\circ} \mathrm{C} \leqq \theta$ $\leqq+25^{\circ} \mathrm{C}$ is given in Fig. $17^{227.232)}$. The viscosity and the relative permittivity of the mixed solvent over the same temperature range are shown in Figs. $18 \mathrm{a}^{460}$ ) and $18 \mathrm{~b}^{326)}$.

Figure 17 is based on series of conductance measurements on $\mathrm{LiClO}_{4}$ in $\mathrm{PC} / \mathrm{DME}$ mixtures as a function of solvent composition (weight $\%$ of $\mathrm{PC}=\xi$ ), electrolyte concentration $\mathrm{m}$, and temperature $\theta$. For every solvent composition $\xi$, a $x$-m-function. see Fig. 7, was established by a least-squares procedure. The maximum specific conductances from these functions, $x_{\max }$, are then plotted in Fig. 17 as a function of solvent composition and temperature. Figures $18 \mathrm{a}$ and $\mathrm{b}$ show the viscosity and the relative permittivity of the mixed solvent as a function of the same parameters. The conductance behaviour of the $\mathrm{LiClO}_{4} / \mathrm{PC} / \mathrm{DME}$-system can be understood from the competition between the solvent viscosity, ion solvation and ion aggregation to ion pairs, triple ions and higher aggregates ${ }^{233)}$. A comprehensive study of this

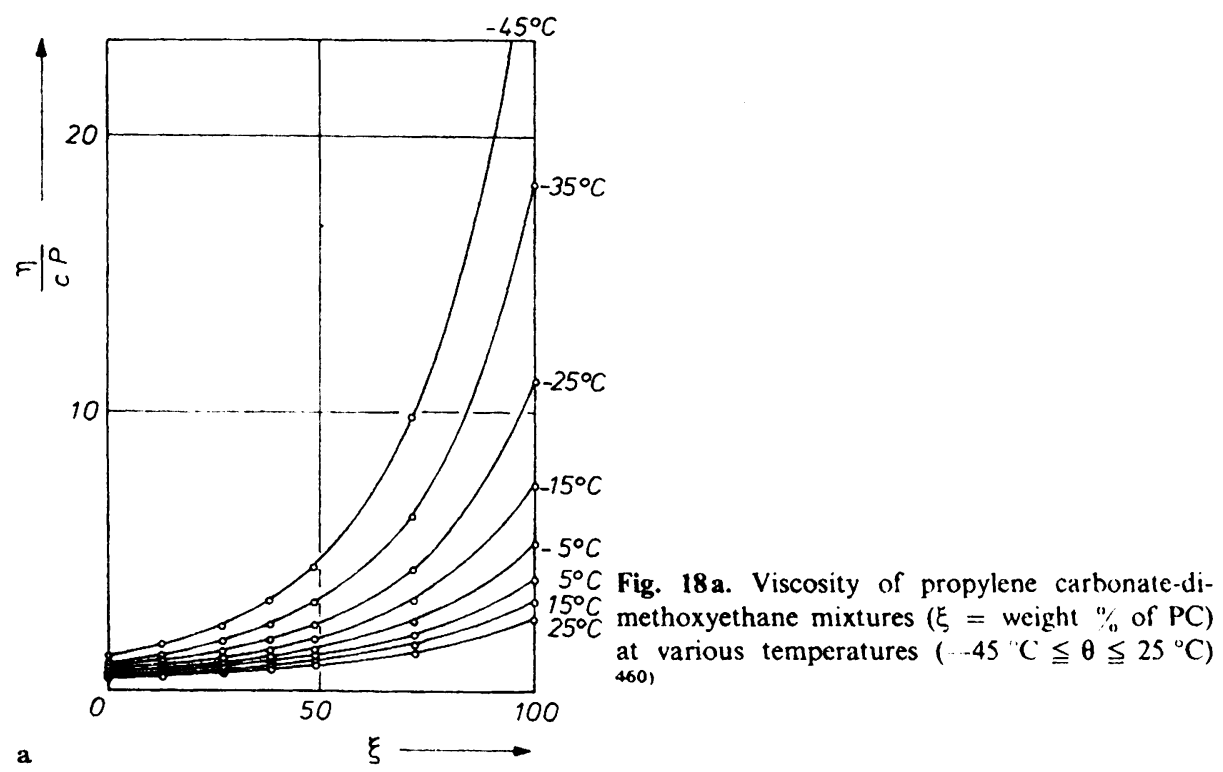




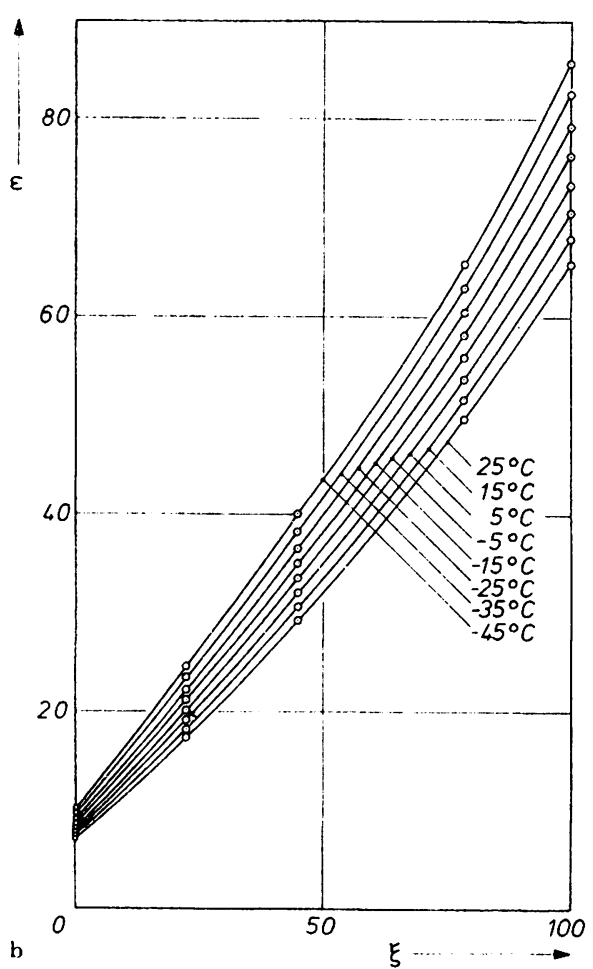

Fig. 18b. Relative permittivity of propylene carbonate-dimethoxyethane mixtures $(\xi=$ weight $\%$ of $\mathrm{PC}$ ) at various temperatures $\left(-45^{\circ} \mathrm{C} \leqq \theta \leqq 25^{\circ} \mathrm{C}\right)^{326}$

type on 12 further electrolyte compounds in $\mathrm{PC}, \mathrm{DME}$ and $\mathrm{PC} / \mathrm{DME}$ mixtures from infinitely dilution to saturation provides useful rules for the choice of battery electrolytes, see Section 6.2.

Competition of solvation and association affects conductance strongly. Conductivity enhancements up to a factor of 300 were observed when DME, triglyme, DMSO, HMTT, PC, AN or 12-crown-4 ether were added to 1,3-dioxolane solutions of Lil, LiSCN and $\mathrm{LiBPh}_{4}{ }^{461,463)}$. Increase of ion mobilities up to a factor of 5 is reported for additions of 12-crown-4 ether to THF solutions of $\mathrm{LiBF}_{4}{ }^{464}$. Margalit et al. ${ }^{466)}$ compared the conductance behaviour of $\mathrm{LiAsF}_{6}$ in $\gamma-\mathrm{BL} / \mathrm{PC}$ and $\mathrm{DME} / \mathrm{PC}$ mixtures. Like us, ${ }^{227,232)}$, Venkatasetty et al. ${ }^{467)}$ stressed the possibility of rationalizing the discussion of concentrated electrolyte solutions in terms of dilute solutions, their example being $\mathrm{LiAsF}_{6}$ in THF, NM, and dimethylsulfite. The use of multicomponent organic solvent mixtures is illustrated by the following examples: $\mathrm{LiBF}_{4}, \mathrm{LiPF}_{6}$, or LiAsF 6 in mixtures of 3-methyl-2-isoxazolidone/dioxolane/THF/ $\mathrm{EGS}^{468)}$ and $\mathrm{LiClO}_{4}$ in THF/PC/DME ${ }^{469}$ ).

The relative mobility of the active ion, $\mathrm{Li}^{+}$, in lithium batteries can be improved by the choice of appropriate counterions, (see transference numbers, Sect. 6.1.) Lithium salts with large organic anions like $\mathrm{Li}\left[\mathrm{B}\left(\mathrm{C}_{2} \mathrm{H}_{5}\right)_{3}\left(\mathrm{C}_{4} \mathrm{H}_{4} \mathrm{~N}\right)\right]^{470)}$, or halo-organic metal salt complexes like $\mathrm{Li}\left[\mathrm{B}\left(\mathrm{C}_{6} \mathrm{~F}_{5}\right)_{3} \mathrm{CF}_{3}\right] \cdot \mathrm{DEE}{ }^{471)}$ are suitable candidates. Such salts have the further advantages of high solubility, low ion association, and replacement of $\left(\mathrm{CO}_{4}\right.$ which might be hazardous ${ }^{472,473)}$. Further information may be found in Refs. ${ }^{230.457 .462 .465 .474 * 477)}$. 
Josef Barthel et al.

\subsection{Stability of Electrolyte Solutions with Lithium}

The most important condition for the use of non-aqueous electrolyte solutions in lithium batteries is their stability in contact with lithium. At least kinetic stability is required. Of the many solvents which are claimed to be stable with lithium ${ }^{438)}$ few if any ${ }^{478,479)}$ seem to be thermodynamically stable.

Propylene carbonate, the solvent used most widely in commercial batteries, decomposes ${ }^{480,481)}$ cathodically on graphite at potentials of $>0.6 \mathrm{~V}$ against a lithium reference electrode: $2 \mathrm{Li}^{+}+\mathrm{PC}+2 \mathrm{e}^{--} \rightarrow \mathrm{CH}_{3}-\mathrm{CH}=\mathrm{CH}_{2}+\mathrm{Li}_{2} \mathrm{CO}_{3}$. This reaction is also found with lithium amalgam ${ }^{482}$. Kinetic stability is supposed to result from a passivating film on the substrate which protects the lithium from further reaction with PC. This film could be $\mathrm{Li}_{2} \mathrm{CO}_{3}$, cf. Refs. ${ }^{480-483)}$, or a polymerisation product of propylene, cf. Ref. ${ }^{484}$ ). Epelboin et al. ${ }^{484)}$ observed both $\mathrm{Li}_{2} \mathrm{CO}_{3}$ in the pores of the substrate and a plastic layer which they consider to be the passivating film. Despite the importance of these results, for batteries and electrodeposition (Sect. XIII), only a few solvents have been comprehensively investigated with regard to their reactivity. Further examples are $A N^{230,485,486)}, D^{2} F^{485)}, N^{485}$, and $\gamma$-BL ${ }^{487)}$. Caiola et al. pointed out rules ${ }^{488,489)}$ for the apparent stability of organic solvents with lithium. Cyclic molecules were found to have greater stability than open-chained ones; molecules with short alkyl chains are more stable than those with long ones.

Dey and Holmes reported ${ }^{486,490}$ ) the reactivity of organic solvents (AN, $\gamma$-BL, $\mathrm{MF}, \mathrm{PC}, \mathrm{DME})$, their mixtures, and of further additives $\left(\mathrm{CCl}_{4}\right.$, diglyme, THF, bromobenzene, pyridine and others), using DTA. DME and PC exhibited the highest exothermic initiation temperatures, $425^{\circ} \mathrm{C}$ and $244^{\circ} \mathrm{C}$ respectively. Selim and Bro stated ${ }^{479)}$ that "any polar solvent is intrinsically reactive toward lithium". This may possibly be undetectable by static experiments but is crucial in deposition and reanodization experiments (see Sect. 10.5.). Either lithium or aluminium can be plated from non-aqueous mixed lithium-aluminium electrolyte solutions, depending only on the composition of the solution; this amazing fact led Peled ${ }^{491}$ ' to suggest that alkaline and alkaline earth metals are always protected by a film formed by reaction with the electrolyte controlling corrosion and deposition-dissolution processes.

It is now generally accepted that the success of lithium batteries is mainly due to the formation of a protective film ${ }^{492)}$. The strategy for improving compatibility which, above all, is essential for secondary batteries is the search for stable solvents or additives which form appropriate films. It should be stressed that these investigations require highly pure solutions ${ }^{492)}$.

The positive material (anode) may induce unwanted film formation on lithium. This is observed ${ }^{483)}$ for cells with THF as the solvent and $\mathrm{V}_{2} \mathrm{O}_{5}$ or $\mathrm{Ag}_{2} \mathrm{CrO}_{4}$ as the positive materials. THF may be oxidized at $\mathrm{V}_{2} \mathrm{O}_{5}$ reacting to form a living polymer, which diffuses to the lithium electrode and reacts there to give an insoluble gel. Further problems arise from insufficient compatihility with the anode. e.g. solubilization of the positive materials by complexation 229.230 .493 ) and from the lack of compatibility of electrolyte compound and solvent, e.g. exchange reactions of inorganic acid esters with the anion of the electrolyte ${ }^{488.494)}$. 


\subsection{Non-Aqueous Primary Cells}

\subsubsection{Commercial Cells with Solid Cathodes and Organic Solvents}

This topic has been comprehensively reviewed by Scrosati ${ }^{443)}$, Dey ${ }^{483)}$, Besenhard ${ }^{44)}$, and Kronenberg and Blomgren ${ }^{457)}$. From the numerous systems investigated the following are produced commercially for use in portable electronic devices ${ }^{458}$. 495-498).

$$
\begin{aligned}
& \mathrm{Li} / \mathrm{LiClO}_{4}(\mathrm{THF} / \mathrm{DME}) / \mathrm{CuS} \\
& \mathrm{Li} / \mathrm{LiBF}_{4}(\gamma-\mathrm{BL}) /\left(\mathrm{CF}_{\mathrm{x}}\right)_{\mathrm{n}} ; \mathrm{x} \approx 1 \\
& \mathrm{Li} / \mathrm{LiClO}_{4}(\mathrm{PC}) / \mathrm{Ag}_{2} \mathrm{CrO}_{4} \\
& \text { SAFT (F); Dupont (USA) } \\
& \text { Matsushita (J) } \\
& \text { SAFT (F); Mallory (USA) } \\
& \mathrm{Li} / \mathrm{LiClO}_{4}(\mathrm{PC} / \mathrm{DME}) / \mathrm{MnO}_{2} \\
& \mathrm{Li} / \mathrm{LiClO}_{4}(\mathrm{PC} / \mathrm{THF}) \text { or } \\
& \text { Hitachi (J); Sanyo (J); Varta (G) } \\
& \mathrm{LiAsF}_{6}(\mathrm{MF}) / \mathrm{V}_{2} \mathrm{O}_{5} \\
& \mathrm{Li} / \mathrm{LiClO}_{4} \text { (THF or dioxolane)/CuO SAFT (F) } \\
& \mathrm{Li} / \mathrm{LiClO}_{4}(\mathrm{PC} / \mathrm{DME}) / \mathrm{Bi}_{2} \mathrm{O}_{3} \quad \text { Varta }(\mathrm{G}) \text {; see Fig. } 16 \\
& 2 \mathrm{Li}+2 \mathrm{CuS} \rightarrow \mathrm{Li}_{2} \mathrm{~S}+\mathrm{Cu}_{2} \mathrm{~S} ; 2 \mathrm{Li}+\mathrm{Cu}_{2} \mathrm{~S} \rightarrow \mathrm{Li}_{2} \mathrm{~S}+2 \mathrm{Cu} \\
& \mathrm{n} \mathrm{Li}+(\mathrm{CF})_{\mathrm{n}} \rightarrow \mathrm{n} \mathrm{LiF}+\mathrm{n} \mathrm{C} \\
& 2 \mathrm{Li}+\mathrm{Ag}_{2} \mathrm{CrO}_{4} \rightarrow \mathrm{Li}_{2} \mathrm{CrO}_{4}+2 \mathrm{Ag} \\
& \mathrm{Li}+\mathrm{MnO}_{2} \rightarrow \mathrm{LiMnO}_{2} \\
& 4 \mathrm{Li}+\mathrm{V}_{2} \mathrm{O}_{5} \rightarrow \mathrm{V}_{2} \mathrm{O}_{3}+2 \mathrm{Li}_{2} \mathrm{O} ; \mathrm{Li}+\mathrm{V}_{2} \mathrm{O}_{5} \rightarrow \mathrm{LiV}_{2} \mathrm{O}_{5} \\
& 12 \mathrm{Li}+\mathrm{Bi}_{2} \mathrm{O}_{3} \rightarrow 2 \mathrm{Li}_{3} \mathrm{Bi}+3 \mathrm{Li}_{2} \mathrm{O} \text {. }
\end{aligned}
$$

Up to 1980 more than $350,000 \mathrm{Li} / \mathrm{Ag}_{2} \mathrm{CrO}_{4}$ cells and more than $100,000 \mathrm{Li} / \mathrm{CuS}$ cells have been produced ${ }^{452}$ ). Some characteristic data: open-circuit voltages 2 to $3 \mathrm{~V}$; energy densities 160 to $200 \mathrm{~W} \mathrm{~h} / \mathrm{kg}$; Li/CuS has a zero self-discharge in seven years ${ }^{452)}: \mathrm{Li} / \mathrm{MnO}_{2}$ (Varta) is available in sizes ranging from 30 to $1000 \mathrm{~mA} \mathrm{~h}^{499}$ ).

For some further commercial systems ${ }^{458)}$ the battery electrolyte cannot be quoted: $\mathrm{Li} / \mathrm{MnO}_{2}$ (Toshiba (J); UCC (USA); SAFT (F); Ray-o-Vac (USA)); Li/(CF $)_{n}$ (Eagle Pitcher (USA); Yardney (USA)); $\mathrm{Li} / \mathrm{Bi}_{2} \mathrm{PbO}_{5}$ and $\mathrm{Li} / \mathrm{CuO}$ (SAFT (F)); $\mathrm{Li} / \mathrm{FeS}_{2}$ (UCC (USA)); open-circuit voltages: $\sim 3 \mathrm{~V}\left(\mathrm{Li} / \mathrm{MnO}_{2}\right.$ and $\left.\mathrm{Li} /\left(\mathrm{CF}_{\mathrm{x}}\right)_{\mathrm{n}}\right)$; $\sim 1.5 \mathrm{~V}$ (all others).

\subsubsection{Commerical Cells with Liquid Cathodic Materials}

The cells of this type generally use $\mathrm{SO}_{2}$ or $\mathrm{SOCl}_{2}$ as the depolarizers. The schemes of cell reaction are

$$
\begin{aligned}
& 2 \mathrm{Li}+2 \mathrm{SO}_{2} \rightarrow \mathrm{Li}_{2} \mathrm{~S}_{2} \mathrm{O}_{4} \quad \text { Ref. }{ }^{500)} \\
& 4 \mathrm{Li}+2 \mathrm{SOCl}_{2} \rightarrow \mathrm{S}+\mathrm{SO}_{2}+4 \mathrm{LiCl} \text { Refs. }{ }^{501.502)} .
\end{aligned}
$$

These cells exhibit the highest energy and power densities down to low temperatures among the primary cells as a consequence of high conductivity, fast-reacting liquid depolarizer, large surface area of carbon electrodes ${ }^{483}$ ) and low temperature coeffi- 
Josef Barthel et al.

cients of conductivity and viscosity. Hazardous currents up to $100 \mathrm{~A}$ were reported for these cells ${ }^{483}$.

The Li/SO ${ }_{2}$ battery (Mallory (USA) ${ }^{443)}$; Duracell (USA) ${ }^{443)}$; Power Conversion Inc. (USA) ${ }^{483,503)}$; Honeywell (USA) ${ }^{4831}$ ) uses electrolytes which typically contain 1.8 $\mathrm{M} \mathrm{LiBr}$ in a mixture $23: 10: 3$ of $\mathrm{SO}_{2}, \mathrm{AN}$, and $\mathrm{PC}$. The system is under pressure and has a safety vent ${ }^{483}$. The base electrolyte solution, $\mathrm{LiBr} / \mathrm{AN} / \mathrm{SO}_{2}$ shows high conductivity with a low temperature coefficient (specific conductance ${ }^{483}$ ): $\sim 5 \times 10^{-2}$ $\left.\Omega^{-1} \mathrm{~cm}^{-1}\left(25^{\circ} \mathrm{C}\right) ; \sim 2.4 \times 10^{-2} \Omega^{-1} \mathrm{~cm}^{-1}\left(-50{ }^{\circ} \mathrm{C}\right)\right)$; the open-circuit voltage is about $2.9 \mathrm{~V}^{503)}$ capacities range from 0.5 to $30 \mathrm{~A} \mathrm{~h}^{500,503)}$ at energy densities of about $290 \mathrm{~W} \mathrm{~h} / \mathrm{kg}\left(0.4 \mathrm{~W} \mathrm{~h} / \mathrm{cm}^{3}\right)^{483,505)}$. Linden and McDonald ${ }^{500)}$ published a review about this battery which also summarizes the fields of possible applications.

A detailed study of the reaction mechanism ${ }^{506,507)}$ shows a remarkably high rate constant for the electron-transfer reaction, $1.0 \pm 0.2 \mathrm{~cm} / \mathrm{s}$ in $\mathrm{DMF}^{506)}$, and the strong influence ${ }^{507)}$ of both the supporting electrolyte and the solvent on the reduction which is explained by ion-pairing. Safety studies $486,490,508-510$ ) show the importance of the composition of the electrolyte solution. The exothermic reaction of lithium with $\mathrm{AN}$ is retarded by $\mathrm{SO}_{2}$ and $\mathrm{PC} ; \mathrm{SO}_{2}$ did not react with lithium at $320{ }^{\circ} \mathrm{C}^{508)}$. Dey and Holmes ${ }^{486)}$ published a list of eight electrolyte solutions which have higher conductivity than the standard $\mathrm{LiBr} / \mathrm{AN} / \mathrm{SO}_{2}$ solution and increased stability with lithium.

The $\mathrm{Li} / \mathrm{SOCl}_{2}$ cells ${ }^{511-513)}$ (Mallory (USA), GTE (USA), Honeywell (USA) ${ }^{483)}$ ) use $\mathrm{LiAlCl}_{4} / \mathrm{SOCl}_{2}$ as the electrolyte solution; the open-circuit voltage is $3.6 \mathrm{~V}$; available capacities range from 0.8 to $10.8 \mathrm{~A} \mathrm{~h}^{514)}$ at energy densities of about $660 \mathrm{~W} \mathrm{~h} / \mathrm{kg}^{483,492)}$. Studies on the cell reaction and further aspects of the chemistry in the $\mathrm{Li} / \mathrm{SOCl}_{2}$ cell are found in Refs. ${ }^{483.501 .502,515-517)}$, conductivity and viscosity studies on $\mathrm{LiAlCl}_{4} / \mathrm{SOCl}_{2}$ in Refs. ${ }^{518.519)}$.

$\mathrm{Li} / \mathrm{SOCl}_{2}$ cells may be operated at high discharge currents. Cells with discharge rates up to $300 \mathrm{~mA} / \mathrm{cm}^{2}$ are reported in an investigation on the cell performance ${ }^{520)}$. The most effective discharge characteristics were obtained with $1.5 \mathrm{M} \mathrm{LiAlCl}_{4}$ and $4.5 \mathrm{M} \mathrm{AlCl}_{3}$ solutions ${ }^{520}$, the highest average voltages with cells containing only $\mathrm{AlCl}_{3}$ or an excess of $\mathrm{AlCl}_{3}$ which dissolves the protective $\mathrm{LiCl}$ film of the cathode and thus limits the use of this solution to reserve cells. Reserve cells (Sonnenschein (Tadiran/GTE)) ${ }^{514)}$ work without voltage delay. Another way to circumvent voltage delays is to use lithium closoboranes, $\mathrm{Li}_{2} \mathrm{~B}_{10} \mathrm{Cl}_{10}, \mathrm{Li}_{2} \mathrm{~B}_{12} \mathrm{Cl}_{12}$, or other appropriate electrolytes ${ }^{521}$.

\subsubsection{Recent Developments}

Some types of cell which introduce new principles should be mentioned. An organic material, pyromellitic dianhydride/pyromellitic acid, is used as the cathode material in a lithium battery ${ }^{522)}$ with $1 \mathrm{M} \mathrm{LiClO}_{4} / \mathrm{PC}$ electrolyte solution and yields an energy density of about $1300 \mathrm{~W} \mathrm{~h} / \mathrm{kg}$. The open-circuit voltage is reported to be $3.1-3.2 \mathrm{~V}$.

$\mathrm{SO}_{2} \mathrm{Cl}_{2}$ is used as a promising depolarizer in the cell $\mathrm{Li} / \mathrm{LiAlCl}{ }_{4}, \mathrm{SO}_{2}\left(\mathrm{Cl}_{2} / \mathrm{C}^{4 \times 3.52 .31)}\right.$ The suggested cell reaction is $2 \mathrm{Li}+\mathrm{SO}_{2} \mathrm{Cl}_{2} \rightarrow 2 \mathrm{LiCl}+\mathrm{SO}_{2}$. The cell characteristics are comparable to those of $\mathrm{Li} / \mathrm{SOCl}_{2}$-cells.

The cell $1 . i / 5$ M $\&$ (as $L i_{2} S_{11}$ ), I M LiAsti (THF)/C ${ }^{524)}$ contains $S_{n}^{2}$ als the depolarizer: energy density $300 \mathrm{~W} \mathrm{~h} / \mathrm{kg}$. The solubility of polysulfides in aprotic solvents is controlled by the solvent basicity ${ }^{525}$. 


\subsection{Secondary Batteries}

In contrast to primary cells, no secondary cell has yet reached the commercial stage. Only one secondary battery, $\mathrm{Li} / \mathrm{TiS}_{2}{ }^{526)}$, gives a warranty for a minimum of five charge-discharge cycles ${ }^{444}$ ). The battery was introduced ${ }^{492,527)}$ by Exxon. The reason for this far less successful situation is mainly due to the poor cycling behaviour of the lithium anode.

Lithium may be plated at $\sim 100 \%$ efficiency from several non-aqueous solutions ${ }^{479}$. 492.528 .529 ) but is stripped anodically with much lower efficiency ${ }^{492,528,530)}$. Brummer et al. ${ }^{492)}$ gave an explanation of this fact: The formation of protective films isolates lithium grains from the substrate which cannot then be discharged. This causes increasing irregularities during the following cycles by making more and more lithium electro-inaccessible $530-533$.

\subsubsection{Improvements of the Cycling Efficiency of the Anode}

With regard to their model Brummer et al. proposed ${ }^{492,528)}$ :

i) the use of surface active additives as "levelling agents" or the use of "precursors"

ii) the use of alloying substrates,

iii) the use of scavengers generated internally,

iv) rigorous purification of electrolytes and solvents,

v) modification of solvent reactivity.

From these suggestions only those concerning the electrolyte solution, i) and v), will be discussed here, for further information the reader is referred to the comprehensive reviews of Brummer et al. ${ }^{492,528)}$.

Brummer et al. ${ }^{492)}$ quote Rhodamin B sodium salt and disodium fluorescein as examples of levelling agents. When added to $\mathrm{LiAlCl}_{4} / \mathrm{PC}$ solutions the adherence of lithium is improved. Alkyl aryl polyethers or alkyl aryl polyethyleneglycol ethers serve the same purpose ${ }^{534)}$. Addition of tetraglyme $(1-2 \%)$ to a $1 \mathrm{M} \mathrm{LiClO}_{4}$ solution in $\mathrm{PC}$ containing $\mathrm{Bu}_{4} \mathrm{NI}(0.6 \mathrm{M})$ results in a significantly better cycling behaviour ${ }^{535)}$. Macroheterocyclic compounds as additives reduce the solvent decomposition as shown by Soffer ${ }^{536)}$ for the reaction of lithium amalgam with solutions of $\mathrm{LiClO}_{4}$ in PC. Precursors ${ }^{492,530,533)}$ are oxidizing agents which produce, in a faster reaction with the substrate than the solvent does ${ }^{492)}$, an appropriate type of film which must be highly permeable for $\mathrm{Li}^{+}$but impermeable for the solvent. Brummer et al. recently reviewed ${ }^{492}$ their investigations on precursors in $1 \mathrm{M} \mathrm{LiClO}_{4} / \mathrm{PC}$ ${ }^{530.532)}, 1 \mathrm{M} \mathrm{LiAsF}_{6} / \mathrm{MA}$, and $1 \mathrm{M} \mathrm{LiClO}_{4} / \mathrm{MA}^{531,533)}$ solutions. In $1 \mathrm{M} \mathrm{LiClO}_{4} / \mathrm{PC}$ solutions. $0.1 \mathrm{M} \mathrm{PSBr}_{3}$ and $0.01 \mathrm{MPOBr}_{3}$ yielded average cycling efficiency of $85 \%$ in comparison to $40 \%$ for the precursor-free solutions ${ }^{492)}$. Koch and Young ${ }^{537)}$, who used highly purified THF as the solvent, found that $\mathrm{LiAsF}_{6}$ is the electrolyte which is least reactive with lithium. Bubbling $\mathrm{N}_{2}$ or $\mathrm{O}_{2}$ through the solution enhanced the cycling efficiency for about 10 cycles, in contrast to bubbling argon, $\mathrm{CO}_{2}$ or to non-gased solutions. The effect of $\mathrm{N}_{2}$ wals explained by $\mathrm{Li}_{3} \mathrm{~N}$ formation which is a good $\mathrm{Li}^{\prime}$-ion conductor ${ }^{432)}$. The $\mathrm{AsF}_{6}$ ion itsclf fulfils the conditions for being a precursor ${ }^{+02)}$ by forming brown films of $(\ldots \text { As - ( ) . As - }-)_{n}$ polymer and 1.iF 5.38 ) in $\mathrm{THF}$, but slower in the presence of $\mathrm{N}_{2}$ and $\mathrm{O}_{2}$. The cycling efficiency is reported 
Josef Barthel et al.

to be $85.2 \%$ in agreement with the result from $\mathrm{POBr}_{3}{ }^{492)}$. These examples also illustrate the necessity for highly pure solutions.

"Modification of the solvent reactivity" aims at the search for polar solvents which are less reactive with lithium. Actually, substitutions are introduced into the solvent molecule to lower its polarity. The fact that the $(\mathrm{C}-\mathrm{O})$ group (ethers) is less polar than $(C=O)(P C, M A)$ or $(S=O)(D M S O)$ and that cyclic molecules are more stable with lithium than open-chained ones ${ }^{488,489)}$ suggests that cyclic ethers should be the most suitable solvents for rechargeable lithium batteries ${ }^{492)}$. A comprehensive investigation on THF and its alkylated analogues $527,539,540)$ yielded important information. In static tests 2-Me-THF and 2,5-di-Me-THF proved to be more stable with lithium at elevated temperatures than THF and 3-Me-THF. Solutions of 2-Me-THF containing $\mathrm{LiAsF}_{6}$ were stable over a period of 13 months, THF solutions reacted after 25 days and THF solutions without the precursor, $\mathrm{AsF}_{6}^{-}$, even reacted within 3 days. Conductivities of $1 \mathrm{M} \mathrm{LiAsF}_{6}$ solutions with THF $\left(13.7 \times 10^{-3}\right.$ $\left.\Omega^{-1} \mathrm{~cm}^{-1}\right)$ and 2-Me-THF $\left(3.0 \times 10^{-3} \Omega^{-1} \mathrm{~cm}^{-1}\right)$ as the solvents differ considerably ${ }^{527)}$ in spite of almost equal solvent viscosities $\left(0.461 \mathrm{cP}\right.$ (THF) ${ }^{541)} ; 0.457 \mathrm{cP}$ $\left.(2-\mathrm{Me}-\mathrm{THF})^{542)}\right)$, probably due to ion association $\left(\mathrm{K}_{\mathrm{D}}\left(\mathrm{LiBPh}_{4} / \mathrm{THF}\right) / \mathrm{K}_{\mathrm{D}}\left(\mathrm{LiBPh}_{4} /\right.\right.$ $2-\mathrm{Me}-\mathrm{THF})=4.4$ at $\left.25^{\circ} \mathrm{C}\right)^{541,542)}$. The cycling efficiency of these solutions is compared in Fig. 19.

Using $1.1 \mathrm{C} / \mathrm{cm}^{2}$ plating and stripping cycles on $\mathrm{Ni}$, in $1 \mathrm{M} \mathrm{LiAsF}$ solutions only $7 \%$ of the lithium is encapsulated on the 10 th cycle when $2-\mathrm{Me}-\mathrm{THF}$ is the solvent, but $80 \%$ when THF ${ }^{540}$.

Using the $\mathrm{LiAsF}_{6} / 2-\mathrm{Me}$-THF solution Brummer et al. ${ }^{528}$ ) have investigated three promising secondary lithium anode/intercalation cathode cells (cf. Fig. 20); the cathode materials are $\mathrm{TiS}_{2}, \mathrm{Cr}_{\mathrm{x}} \mathrm{V}_{1-\mathrm{x}} \mathrm{S}_{2}$ and $\mathrm{V}_{6} \mathrm{O}_{13}$. It is claimed that such cells working for 100 to 200 cycles at attractive energy densities are feasible. Additional information can be found in a recent publication ${ }^{543)}$.

Koch et al. disclosed ${ }^{544,545)}$ a DEE-based electrolyte solution, $2.5 \mathrm{M} \mathrm{LiAsF}_{6}$ in DEE/THF (9:1), which enables bright lithium deposits up to $10 \mathrm{C} / \mathrm{cm}^{2}$ by plating. This non-aqueous electrolyte solution exhibits the best cycling efficiency $(>98 \%)$

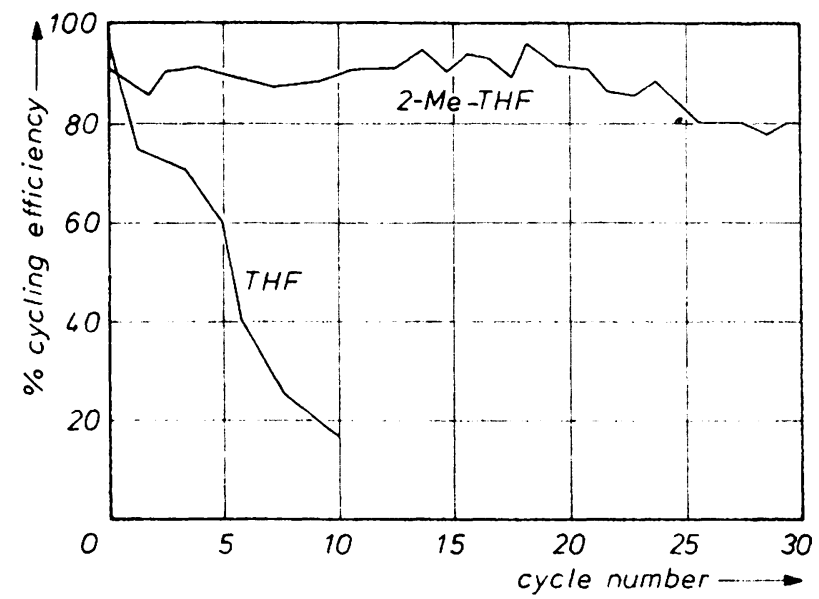

Fig. 19. Efficiency of cycling lithium on a nickel substrate from $1 \mathrm{M} \mathrm{LiAsF}$ solutions in cyclic ethers. Anodic and cathodic current densities: $1 \mathrm{~mA} / \mathrm{cm}^{2}$ (with kind permission of the authors ${ }^{5401}$ ) 


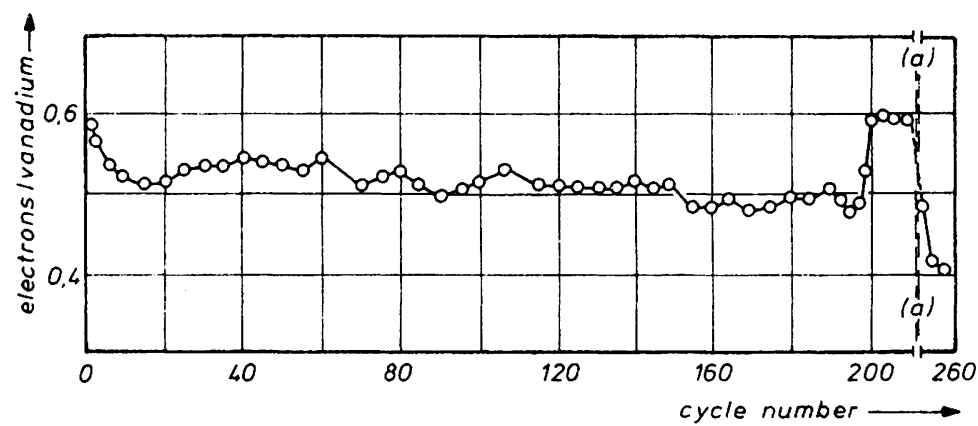

Fig. 20. Cathode utilization vs. cycle number for a hermetic laboratory test cell: $\mathrm{Li} / 2-\mathrm{Me}-\mathrm{THF}, \mathrm{LiAsF}_{6} /$ V-oxide, C. Curent density: $1 \mathrm{~mA} / \mathrm{cm}^{2}$; cathode capacity: $500 \mathrm{~mA} \mathrm{~h}$ (based on 1 electron/vanadium); current reduced to $0.5 \mathrm{~mA} / \mathrm{cm}^{2}$ after about 200 cycles; (a): interrupted scale. (with kind permission of the authors ${ }^{543)}$ )

so far reported. The authors assume that the excellent stability with lithium is due to lithium ethoxide film formation.

\subsubsection{Cathode Materials for Secondary Lithium Batteries}

With regard to the importance for reversible lithium batteries and looking at the possible applications of reversible cathode materials in electrochromic (Sect. XI) and photo-electrochemical (Sect. XII) cells some significant results of this rapidly growing field should be presented. Both inorganic and organic materials are investigated.

Inorganic Materials with a host lattice structure can reversibly intercalate $\mathrm{Li}^{+}$ ions, e.g.

$$
\mathrm{xLi}^{+}+\mathrm{TiS}_{2}+\mathrm{xe}^{-} \rightarrow \mathrm{Li}_{\mathbf{x}} \mathrm{TiS}_{2} ; 0<\mathrm{x} \leqq 1 .
$$

The thermodynamic and kinetic aspects of intercalation processes were recently reviewed ${ }^{546,547)}$. Materials which exhibit both good electronic and $\mathrm{Li}^{+}$-ion conductivity, no phase change, and negligible volume effects at the intercalation process are possible candidates for new cathode materials. Scrosati ${ }^{443)}$ recently reviewed $\mathrm{TiS}_{2}, \mathrm{~V}_{6} \mathrm{O}_{13}, \mathrm{NbSe}_{3}, \mathrm{Mo}_{8} \mathrm{O}_{13}$, and $\mathrm{Li}_{\mathrm{x}} \mathrm{CoO}_{2}$. For further recent information including cyclabilities in non-aqueous cells with lithium anodes, diffusion coefficients, and structure determinations see: $\mathrm{TiS}_{2}{ }^{526,548-550)} ; \mathrm{TiS}_{3}{ }^{548)} ; \mathrm{V}_{6} \mathrm{O}_{13}{ }^{551-553)} ; \mathrm{WO}_{3}{ }^{553)}$; $\mathrm{MoO}_{3}{ }^{553)} ; \mathrm{V}_{2} \mathrm{O}_{5}{ }^{553,554)} ; \mathrm{MoO}_{\mathrm{n}}$ with $2 \leqq \mathrm{n} \leqq 3^{555)} ; \mathrm{Li}_{\mathrm{x}} \mathrm{CoO}_{2}{ }^{556)} ; \mathrm{NbSe}_{3}{ }^{554,557)}$; $\mathrm{Na}_{\mathrm{x}} \mathrm{CrS}_{2}$ with $\mathrm{x} \geqq 0.1^{558)} ; \mathrm{FeV}_{3} \mathrm{O}_{8}{ }^{559)} ; \mathrm{CuCoS}_{4}{ }^{560-562)} ; \mathrm{V}_{2} \mathrm{~S}_{5}{ }^{563)} ; \mathrm{MoS}_{2}{ }^{564)}$; $\mathrm{MoS}_{3}{ }^{565)}$; and $\mathrm{KFeS}_{2}{ }^{566)}$.

Some remarkable results must be mentioned in connection with non-aqueous electrolyte solutions. The use of melts of LiI-glyme solvates as the electrolyte solution in the $\mathrm{Li} / \mathrm{TiS}_{2}$ cell prohibits its rechargeability ${ }^{550}$, in contrast to $\mathrm{LiClO}_{4} /$ dioxolane solutions: The solvation of $\mathrm{Li}^{+}$is supposed to be sufficiently strong to entail glyme co-intercalation. The cell of lithium/low temperature amorphous molybdenum disulfide is highly reversible with $\mathrm{LiClO}_{4}$ /dioxolane as the electrolyte solution: after 244 cycles the capacity still exceeds $50 \%$ of the second discharge step ${ }^{564)}$. Dioxolane/DME mixtures are the most favourable and THF/DME mixtures the 
Josef Barthel et al

poorest solvents with regard to the performance of the cell $\mathrm{Li} / \mathrm{LiClO}_{4}$ (mixed solvent)/ $\mathrm{CuCoS}_{4}{ }^{561)}$. The expectation that cyclability would be improved by the use of two intercalation electrodes with different chemical potentials of the $\mathrm{Li}^{+}$ion as the electrodes was confirmed by Lazzari and Scrosati ${ }^{567)}$ : With a cell $\mathrm{Li}_{\mathbf{x}} \mathrm{WO}_{2} / \mathrm{LiClO}_{4}$ $(\mathrm{PC}) / \mathrm{TiS}_{2}$, open circuit voltage $2.0 \mathrm{~V}$, they did not find cell deterioration upon prolonged cycling.

Organic Materials are new in this field of application. Polyacetylene, $(\mathrm{CH})_{n}$, may be chemically doped either $p$ - or n-type ${ }^{568-570)}$ and electric conductivity can be varied over 12 orders of magnitude up to $10^{3} \Omega^{-1} \mathrm{~cm}^{-1}$. Golden films of composition $\left[\mathrm{CHI}_{0.07}\right]_{\mathrm{n}},\left[\mathrm{CH}\left(\mathrm{ClO}_{4}\right)_{0.0645}\right]_{n}$, and $\left[\mathrm{CH}\left(\mathrm{AsF}_{4}\right)_{0.059}\right]_{\mathrm{n}}$ with conductivities of 9.7, 970, and $260 \Omega^{-1} \mathrm{~cm}^{-1}$ are obtained by the oxidation of $(\mathrm{CH})_{\mathrm{n}}$ in $\mathrm{KI} / \mathrm{H}_{2} \mathrm{O}, \mathrm{Bu}_{4} \mathrm{NClO}_{4} /$ $\mathrm{CH}_{2} \mathrm{Cl}_{2}$, and $\mathrm{Bu}_{4} \mathrm{NAsF}_{6} / \mathrm{CH}_{2} \mathrm{Cl}_{2}$ solutions, respectively ${ }^{571)}$. Polyacetylene is believed to exist as the polycarbonium ion, $\left(\mathrm{CH}^{\mathrm{z}}\right)_{n}$, stabilized by monovalent anions $\mathrm{A}^{-}$to give $\left[\left(\mathrm{CH}^{\mathrm{z}}\right) \mathrm{A}_{\mathrm{z}}^{-}\right]_{n}$.

A non-optimized cell ${ }^{571)}$ with lithium anode and $\mathrm{LiClO}_{4} / \mathrm{PC}$ electrolyte solution showed no change in its open circuit voltage $(4.1 \mathrm{~V})$ after 326 successive constantcurrent cycles. The cell with $\left[\mathrm{CH}^{+0.06}\left(\mathrm{ClO}_{4}\right)_{0.06}^{-}\right]_{\mathrm{n}}$ cathode, energy density $176 \mathrm{~W} \mathrm{~h} / \mathrm{kg}$. is expected to give the possibility of producing inexpensive lightweight batteries with a variety of applications ${ }^{571)}$.

For further information on non-aqueous lithium batteries the reader is referred to conference reports $462,476,504,572,573$ ), reviews $230,438,443-445,457,483,574,575$ ), books 229.576, 577), and compilations of the patent literature $434,578,579$ ).

\section{Non-Emissive Electro-Optic Displays}

\subsection{Comparison of Methods}

The common features of flat non-emissive electro-optic displays actually under investigation are unrestricted viewing angle, open-circuit memory (at least transient) and hence low power consumption $\left(30 \mathrm{~mJ} \mathrm{~cm}^{-2580)}\right.$ to $\left.3 \mu \mathrm{J} \mathrm{cm}^{-2}{ }^{581)}\right)$, operation at low voltages and improved optical contrast, suitable threshold ${ }^{580)}$ and switching voltage levels, fast response time $\left(<10 \mathrm{~ms}^{581.582)} ;<80 \mathrm{~ms}^{580)}\right)$ and long lifetime $\left(>10^{7}\right.$ cycles) ${ }^{583)}$. The underlying controlling effects are the electrochromic effect, the electrophoretic effect, or reversible thin-layer electrodeposition.

In Electrochromic Displays the electrochemically induced reversible colour change. electrochromism, is accomplished either by reduction or oxidation. The extensivelystudied coloration mechanism of $\mathrm{WO}_{3}{ }^{584-600)}$ can be sketched out as a simultaneous injection of cations and electrons, e.g. ne ${ }^{-}+\mathrm{nX}^{+}+\mathrm{WO}_{3} \rightleftarrows \mathrm{X}_{\mathrm{n}} \mathrm{WO}_{3} ; \mathrm{X}=\mathrm{H}^{+}$, $\mathrm{Li}^{+}, \mathrm{Na}^{+} ; \mathrm{n} \sim 0.1-0.2^{599)}$. The colour of the resulting tungsten bronze is blue, independent of the cation.

Mixed conductivity, ionic and electronic, is a feature of clectrochromics. Both transport rates affect the kinetics of the electrochromic reaction ${ }^{6011}$. The coloration kinetics and the stability of the electrode are strongly influenced both by the elect rolyte solution and the preparation of the electrode material.

Other inorganic electrochromic materials studied include $\mathrm{MoO}_{3}{ }^{586.600)}, \mathrm{MoO}_{3} /$ $\mathrm{WO}_{3}{ }^{590)}, \mathrm{V}_{2} \mathrm{O}_{5}{ }^{602)}, \mathrm{RhO}_{2}{ }^{603)}, \mathrm{Nb}_{2} \mathrm{O}_{5}{ }^{604)}$, and iridium oxides ${ }^{580,601.605-608)}$; orga- 
nic electrochromics include the rare-earth diphthalocyanine complexes ${ }^{609.610)}$ and the viologen derivatives ${ }^{586,611,612)}$ and other heterocyclic compounds.

Both solid-state ${ }^{613,614)}$ and wet cells are studied.

Electrochromic displays were claimed to be fundamentally unsuited ${ }^{615)}$ for matrix addressing. However, in his "Theory of Electrochemical Memory" Beni ${ }^{616)}$ stressed that matrix addressing of electrochromic displays should be possible by the choice of appropriate electrolytes which control both threshold and short-circuit memory. The number of lines which can be matrix addressed sequentially is shown to be in the range 10 to $10^{5}$.

The Electrophoretic Displays make use of the migration of charged pigment particles, suspended in an inert solvent (generally a solvent of class 7) which contains a contrasting dye ${ }^{581,617-619)}$. Application of a high intensity electric field drives the particles $\left(\mathrm{TiO}_{2}\right.$, anatase) carrying adsorbed ionic species (from added $\mathrm{Na}$ laurylsulfate, e.g. $\left.{ }^{620}\right)$ to the oppositely charged electrode. The electrolyte also acts as a dispersant.

Displays based on Electroplating Reactions are seldom found in the literature 582. 617.621). In these devices, reversible plating on to transparent electrodes is used.

A comparison of electro-optic displays by Pankove ${ }^{622)}$ includes systems such as light-emitting diodes (LED) and liquid crystal displays (LCD).

\subsection{Displays with Non-Aqueous Electrolyte Solutions}

Investigations on the $\mathrm{XWO} / \mathrm{WO}_{3}$ system in non-aqueous solutions were made with the aim of avoiding corrosion of the electrode by dissolution ${ }^{591-594)}$ as was observed in aqueous sulfuric acid solutions. Systems exhibiting $\mathrm{Li}^{+}$insertion from non-aqueous electrolyte solutions, e.g. $\mathrm{LiClO}_{4}$ in $\mathrm{AN}^{592)}$ or $\mathrm{PC}^{591)}$ were found to be irreversible ${ }^{592)}$ or very slow ${ }^{591)}$, the response times being up to $40 \mathrm{~s}^{5911}$. The advantages of nonaqueous electrolyte solutions are a large liquid range and the better memory ${ }^{591)}$ of the oxygen-insensitive product accessible in these solvents, namely $\mathrm{Li}_{\mathrm{x}} \mathrm{WO}_{3}$. Only a few attempts managed to obtain the advantage of high stability provided by the non-aqueous electrolyte solutions and to avoid at the same time the drawback of slow response. The evaporated $\mathrm{WO}_{3}$ film electrode was found to be very stable in $\mathrm{H}_{2} \mathrm{SO}_{4}$ /glycerol $(1: 10)$ for more than $5 \times 10^{6}$ cycles at $0.5 \mathrm{~Hz}$ over 6 months ${ }^{592)}$. More than $10^{7}$ cycles and a response time of about $0.5 \mathrm{~s}$ were obtained with a highly porous $\mathrm{WO}_{3}$-film and $1 \mathrm{M} \mathrm{LiClO}_{4} / \mathrm{PC}$ solutions ${ }^{623)}$. High $\mathrm{Li}^{+}$-ion diffusion coefficients $\left(10^{-7} \mathrm{~cm}^{-2} \mathrm{~s}^{-1}\right)$ in $\mathrm{Li}_{y} \mathrm{M}_{x} \mathrm{WO}_{3}(\mathrm{M}=\mathrm{Na}, \mathrm{K}: \mathrm{x} \sim 0.6)$ were determined ${ }^{624)}$ from measurements on the cell $\mathrm{Li} / \mathrm{LiAsF}_{6}$ (non-aqueous solvent) $/ \mathrm{Li}_{\mathrm{y}} \mathrm{M}_{\mathrm{x}} \mathrm{WO}_{3}$ showing the influence of structure when compared to those $\left(2.8 \times 10^{-11}\right.$ to $2.4 \times 10^{-12} \mathrm{~cm}^{2} \mathrm{~s}^{-1}$, varying with $\mathrm{x}$ ) for $\mathrm{Li}^{+}$in $\mathrm{Li}_{x} \mathrm{WO}_{3}{ }^{595)}$.

Iridium oxide is a new electrode material with promising properties: good opencircuit memory (loss $\sim 10^{\circ} \%$ in $5 \mathrm{~h}$ ) ${ }^{607)}$, very fast response at ambient temperatures $(<40 \mathrm{~ms})^{606.607 .625)}$ and still a suitable one at low temperature $\left(<1 \mathrm{~s} ; \ldots-25^{\circ} \mathrm{C}\right)^{625}$. This electrochromic was mainly investigated with aqueous electrolyte solutions 580. 605-607.(026) and solid electrolytes ${ }^{627)}$. Non-aqueous electrolyte solutions, LiAsF 6 / 2-Me-THF and $\mathrm{NaAsF}_{6} / \mathrm{PC}$, were used for the insertion of $\mathrm{Ii}^{+}$and $\mathrm{Na}^{+}$by McIntyre et al. ${ }^{(01)}$; the reported response times are 10 to $20 \mathrm{~s}$. 
Josef Barthel et al.

Reichmann and Bard ${ }^{604)}$ recently reported studies on the $\mathrm{Nb}_{2} \mathrm{O}_{5}$ electrode. Using a $0.8 \mathrm{M} \mathrm{LiClO}_{4} / \mathrm{AN}$ solution $\mathrm{Nb}_{2} \mathrm{O}_{5}$ could be coloured and bleached over three days without deterioration of the electrode at a response time of 1-2 s, in contrast to an aqueous $1 \mathrm{M} \mathrm{H}_{2} \mathrm{SO}_{4}$ solution where hydrogen evolution was observed. Organic electrochromics, e.g. the viologen derivatives, exhibit a remarkable stability also in organic solvents. For example, a $0.1 \mathrm{M}$ solution of $\mathrm{N}, \mathrm{N}^{\prime}$-diheptyl-4,4'bipyridinium dibromide in a mixture of PC and EG $(9: 1)$ containing suspended $\mathrm{TiO}_{2}$ is claimed to be stable for $7 \times 10^{7}$ cycles at $0.3 \mathrm{~Hz}$ at a contrast ratio of $20: 1^{612)}$.

Further information on electrochromics can be found in a recent review article by Beni ${ }^{583)}$.

Electrophoretic Displays with response times of $10 \mathrm{~ms}$, electrical resistivities of $10^{10} \Omega \mathrm{cm}$ and switching energies of $3 \mu \mathrm{J} / \mathrm{cm}^{2}$ at an applied field of $10^{4} \mathrm{~V} / \mathrm{cm}$ were obtained with $\mathrm{TiO}_{2} /$ xylene suspensions. Improvements can probably be made by an appropriate choice of the charge controlling electrolyte (ionic surfactant) ${ }^{581}{ }^{5}$ which stabilizes the suspension. Basic information on the conductance behaviour of these large ions in solvents with a very low dielectric constant is given by an investigation on sodium lauryl sulfate and sodium di-2-ethylhexylsulfosuccinate (degree of association $\sim 10^{7}$ ). The transient current is strongly dependent on the applied voltage conditions; the steady-state current exhibits non-ohmic behaviour, ionic dissociation and recombination processes being the controlling factors ${ }^{620}$ ). Further information on the state of technology is given in the reviews ${ }^{618,619)}$ by Dalisa. The low cost of fabrication and the high contrast over a wide range of viewing angles make electrophoretic displays promising for flat large-scale devices.

Reversible Electrodeposition of a silver iodide complex from a solution of $0.3 \mathrm{M}$ $\mathrm{AgI}$ and $\mathrm{KI}$ or $\mathrm{RbI}$, and $\mathrm{I}_{2}$ in DMSO or diethyl malonate is an example for the third class of wet non-emissive electro-optic displays ${ }^{582}$. As long as the silver content of the solution is high enough the solvent did not deteriorate when pulses of $50 \mathrm{~V}$ were passed through. The addition of $\mathrm{Al}_{2} \mathrm{O}_{3}$, for preventing $\mathrm{TiO}_{2}$ from agglomeration, and the use of $\mathrm{RbAg}_{4} \mathrm{I}_{5}$ in DMSO as the solid ion-conductor established a cell which survived more than $10^{7}$ cycles when operated at $<2 \mathrm{~V}$ drive, the realized response times were $<10 \mathrm{~ms}$.

\section{Photo-Electrochemical Cells}

\subsection{Introduction}

The application of the photovoltaic effect for the generation of electrical energy using sunlight as the energy source has reached the stage of commercialisation.

Investigations of non-aqueous electrolyte solutions for application in photo-clectrochemical liquid junction cells have only just begun and no predictions concerning their use in commercial cells can be made at present. The betterdeveloped ${ }^{\text {(28) }}$ solid-state technologies have resulted in three lines of approach, based on different photovoltaic materials. These were described recently by Johnston ${ }^{629)}$ in his monograph "Solar Voltaic Cells" as "established technologies" for different 
requirements: single or semi-crystal Si cells, single crystal GaAs cells and $\mathrm{CdS} / \mathrm{Cu}_{2} \mathrm{~S}$ cells; the attained efficiencies and fill factors $\left(\left(\mathrm{I}_{\mathrm{m}} \times \mathrm{V}_{\mathrm{m}}\right) /\left(\mathrm{I}_{\mathrm{sc}} \times \mathrm{V}_{\mathrm{oc}}\right)<1 ; \mathrm{I}_{\mathrm{m}}, \mathrm{V}_{\mathrm{m}}\right.$ : current and voltage at point $\mathrm{m}$ of the I vs. V-diagram for which $\mathrm{I} \times \mathrm{V}$ is maximum; $\mathrm{I}_{\mathrm{sc}}$ : short circuit current, $\mathrm{V}_{\mathrm{oc}}$ : open circuit voltage) are: $15.5,0.76(\mathrm{Si}) ; 20.5,0.81$ (GaAs); and 8.6, $0.71\left(\mathrm{CdS} / \mathrm{Cu}_{2} \mathrm{~S}\right)$, respectively ${ }^{630)}$.

\subsection{Liquid-Junction Cells}

Two possible configurations are currently being investigated ${ }^{631-634)}$, the regenerative and the storage cell. The regenerative cell, where no net overall reaction occurs in the undivided liquid junction containing a redox couple, is used for the direct conversion of solar energy to electricity. The storage cell, where a membrane separates the catholyte and anolyte, converts the solar energy via electrochemical redox reactions and stores it as chemical energy. A new approach is energy storage by photo-intercalation ${ }^{635)}$ using layer-type compounds, e.g. p- $\mathrm{ZrSe}_{2}$, in analogy to those in secondary lithium batteries (cf. Sect. 10.5.2). A variant of the storage cell can be used for producing desired chemicals by photo-electrosynthesis 628.636 )

The regenerative cell contains a narrow band-gap semiconductor, generally of $\mathrm{n}$-type in aqueous cells, and a metal counter-electrode. p-Type semiconductors cannot be stabilized in aqueous solutions by redox couples ${ }^{634)}$, because the highly negative redox potentials neided would entail the reaction with water. The liquid junction is an electrolyte solution of high conductivity which contains the redox couple, e.g. $\mathrm{S}^{2-} / \mathrm{S}_{2}^{2-}, \mathrm{Se}_{2}^{2-} / \mathrm{Se}^{2-}$, or $\left[\mathrm{Fe}(\mathrm{CN})_{6}\right]^{3-/ 4-}$. The illuminated electrode drives the majority carriers, $\mathrm{e}^{-}$for $\mathrm{n}$-type, through the semiconductor and the external lead to the counter-electrode where reduction occurs. The minority carriers, $\mathrm{h}^{+}$for $\mathrm{n}$-type, move towards the semiconductor-electrolyte interface where oxidation at the photo-anode takes place. We are not aware of any investigations on storage cells with non-aqueous electrolyte solutions. So the following discussion is limited to regenerative cells.

The attractive feature of regenerative cells are the perfect phase contact by the liquid junction ${ }^{628.637)}$ and the elimination of the energy loss due to absorption in the semiconductor of solid-state cells (electrolyte solutions are transparent to the major part of the solar spectrum ${ }^{636,637)}$ ). High purity of electrode materials is less important in liquid cells ${ }^{632.636)}$; polycrystals and thin films may be used ${ }^{628,636)}$; the formation of the Schottky-like barrier is technically simpler and hence cheaper than in solidstate cells 628,632 .

As efficiencies of power conversion are begining to catch up those of dry photovoltaics, several authors have claimed that economically viable liquid-junction cells which challenge solid-state cells ${ }^{632,636)}$ will become feasible. An economic analysis based on standardized procedures was published recently ${ }^{638}$ ). It is claimed that liquid-junction cells have already at the time being the potential to meet and exceed the goal required for 1986 by the U.S. National Photovoltaic Program of a cost of $50 \varnothing$ per peak watt, cf. Ref. ${ }^{629)}$.

Some problems have to be solved relating to the stability of the photo-anode (photo-degradation) ${ }^{628,633,639.640)}$ and to the cell performance ${ }^{638)}$. Stability criteria for the choice of appropriate redox couples ${ }^{64:-643)}$ were recently discussed by 
Josef Barthel et al.

Gerischer ${ }^{633)}$. Non-aqueous solutions provide the advantage of great flexibility for the choice of suitable redox pairs $\left.{ }^{644}, 645\right)$, wide anodic and cathodic stability ranges ${ }^{646)}$, and change of attackability ${ }^{635,636)}$. The stabilization ratio (= redox current/corrosion current) varies in the order of magnitude of $10^{3}$ and depends strongly on the organic solvent for the stabilization of $\mathrm{n}$-CdTe with ferrocene ${ }^{647}$. For further aspects see Refs. ${ }^{635,648-657)}$, especially for the use of the more stable transition metal dichalcogenides which exhibit d-d-phototransitions without splitting chemical bonds of the semiconductor.

\subsection{Non-Aqueous Solution in Liquid-Junction Cells}

In aqueous cells the best performances of n-type $\mathrm{CdS}, \mathrm{CdSe}, \mathrm{CdTe}$ and GaAs photoanodes were obtained by stabilization with chalcogenide/polychalcogenide redox couples. Noufi and Tench ${ }^{658)}$ reported an efficiency of $12 \%-14 \%$ using $n / n^{+}$GaAs in selenide/polyselenide solutions for polycrystalline and single crystals of GaAs; the fill factors were 0.67 and 0.8 respectively. The photocurrents in these systems, however, deteriorate with time, especially at high light intensities ${ }^{659)}$. Strong specific adsorption of the chalcogenide and the slow two-electron transfer are considered to be reasons for the limited stability ${ }^{659}$ ).

The main advantages of non-aqueous cells are the flexibility for choosing suitable ${ }^{644)}$ and less noxious ${ }^{645)}$ redox pairs, changed attackability, and wider stability ranges (e.g. $\mathrm{AN}: 5 \mathrm{~V} ; \mathrm{H}_{2} \mathrm{O}: 1.5 \mathrm{~V}$ ) ${ }^{646)}$ as already mentioned. Many one-electron redox couples can be photo-oxidized on $\mathrm{n}-\mathrm{GaAs}$ or photoreduced on $\mathrm{p}-\mathrm{GaA}$ s at less negative potentials than on $\mathrm{Pt}^{644)}$. The search for the new and promising intercalation electrodes for storage cells ${ }^{635)}$ is facilitated by the multitude of possible solvents.

A drawback is the lower conductance of non-aqueous solutions entailing lower fill factors. The investigation of non-aqueous electrolyte solutions for applications in photoelectrochemical cells is still in its swaddling cloths. Only few aspects can be discussed.

The resistance of $\mathrm{n}$-CdSe to photodecomposition varies with solvent in the following order: $\mathrm{AN} \approx \mathrm{PC}>\mathrm{DMF}>\mathrm{EtOH} \approx \mathrm{MeOH} \gg \mathrm{H}_{2} \mathrm{O}^{659)}$. Methanol/ $\left[\mathrm{Fe}(\mathrm{CN})_{6}\right]^{3-/ 4-}$ was chosen for subsequent stability tests because of the high rates of electron transfer and its transparence to most of the solar spectrum. The conversion efficiency for the photo-anode at $85 \mathrm{~mW} / \mathrm{cm}^{2}$ (tungsten-halogen illumination) is reported to be $3.5 \%$ at a constant current density of $6 \mathrm{~mA} / \mathrm{cm}^{2}$ and the fill factor is $0.56^{659)}$. The anode was completely stabilized by the redox couple and no deterioration of the surface or degradation of the photoresponse were observed ${ }^{659)}$. Specific adsorption at the electrode surface and ion pairs in the bulk solution limit the maximum short-circuit current to $17.5 \mathrm{~mA} / \mathrm{cm}^{2}$ in stirred and $7.5 \mathrm{~mA} / \mathrm{cm}^{2}$ in unstirred solutions ${ }^{60(0)}$. Purity of the solvent is essential ${ }^{654)}$.

Langmuir et al. studied the stabilization of n-GaAs photo-anodes by some redox couples $\left(\mathrm{Br}_{2} / \mathrm{Br}^{-}, \mathrm{I}_{2} / \mathrm{I}_{3}, \mathrm{I}_{3}^{-} / \mathrm{I}^{-}\right.$, and ferrocene, acetyl ferrocene, $\mathrm{N}, \mathrm{N}^{\prime}$-tetramethyl-pphenylenediamine with their appropriate oxidated species) in $0.01 \mathrm{M} \mathrm{LiAsF}_{6}$ solutions of $\mathrm{PC}{ }^{645)}$. With the exception of $\mathrm{Br}_{2} / \mathrm{Br}^{-}$, which corroded GaAs even in the dark, these redox couples proved to be suitable. The low efficiencics (up to $7 \%$ ) 
obtained are related to low redox-pair solubilities and low conductivities of the solution. Anthraquinone, p-benzoquinone, ferrocene, dimethylferrocene, hydroxymethylferrocene, and $\mathrm{N}, \mathrm{N}^{\prime}$-tetramethyl-p-phenylenediamine were used as depolarizers in $n-G a A s / 0.2 \mathrm{M} \mathrm{Bu}_{4} \mathrm{NClO}_{4}(\mathrm{AN}) / \mathrm{Pt}$ liquid-junction cells ${ }^{644)}$. The $\mathrm{n}-\mathrm{GaAs}$ was operated at potentials $(0.1$ to $-0.6 \mathrm{~V}$ vs. SCE) where photodissolution would occur in water: $\mathrm{GaAs}+6 \mathrm{~h}^{+} \rightarrow \mathrm{Ga}^{3+}+\mathrm{As}^{3+644)}$. Using the ferrocene/ferrocinium couple and $0.52 \mathrm{~mW} / \mathrm{cm}^{2}$ of $720-800 \mathrm{~nm}$ radiation a maximum energy conversion of $14 \%$ (with solar radiation at $9 \mathrm{~mA} / \mathrm{cm}$ and $0.2 \mathrm{~V}$ only $2.4 \%$ ) was obtained ${ }^{644)}$. The complete removal of water is necessary to yield sufficiently high electrode stability. For information about decreased photo-dissolution of photoconductors in AN see the papers of Bard et al. on $\mathrm{n}$ - and $\mathrm{p}-\mathrm{Si}^{661)}$, $\mathrm{n}$ - and $\mathrm{p}$-GaAs ${ }^{662)}$. n-CdS, n-GaP, $\mathrm{n}-\mathrm{ZnO}^{663)}, \mathrm{n}$ - and $\mathrm{p}-\mathrm{InP}{ }^{646)}$.

The photo-electrochemical generation ${ }^{664-665)}$ of a conducting film on the photoanode is a new way to prevent photo-anodes from photodegradation. For example, an insoluble and conducting polypyrrole film $\left(10-100 \Omega^{-1} \mathrm{~cm}^{-1}\right)$ was produced on the $n-G a A s$ anode from a $0.1 \mathrm{M} \mathrm{Et}_{4} \mathrm{NBF}_{4}$ acetonitrile solution containing $0.1 \mathrm{M}$ pyrrole at $0.45 \mathrm{~V}$ vs. SCE with the help of a tungsten-halogen lamp operating at $50 \mathrm{~mW} / \mathrm{cm}^{2664)}$. The unprotected anode deteriorated in less than 1 min whereas the protected one was operated for $100 \mathrm{~h}$ without deterioration, see Fig. $2^{66.5)}$. Recently this method was also applied to n-CdTe, n-CdSe, n-CdS and n-Si electrodes which were studied in aqueous and non-aqueous systems ${ }^{665)}$.

For further aspects and information the reader is referred to monographs and reviews, Refs. ${ }^{628.631,657.666-671)}$.

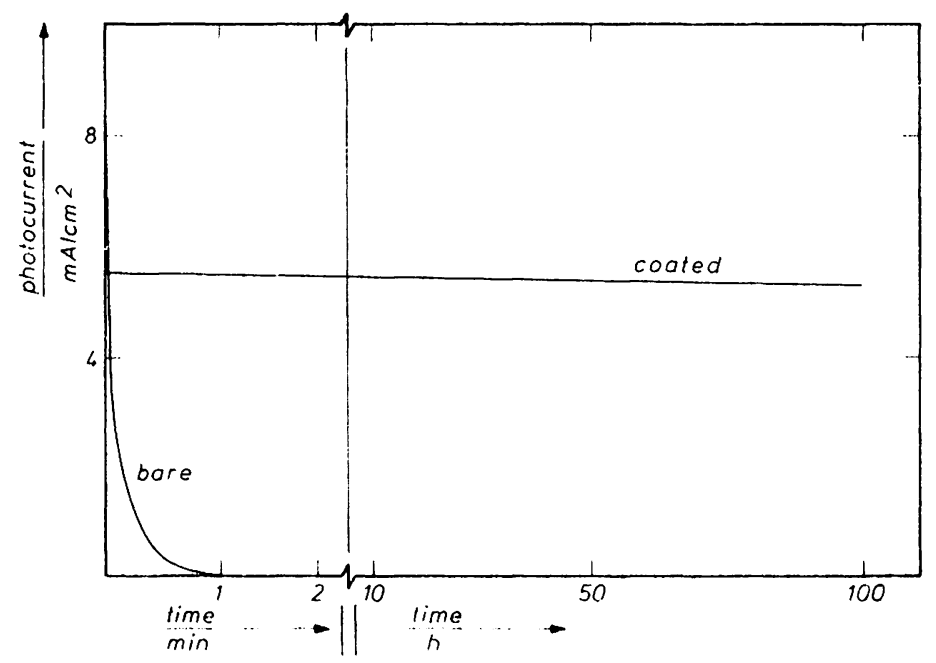

Fig. 21. Short-circuit photocurrent vs. time for bare and polypvrrol-coated $n$-GaAs electrodes in methanol $/ 0.2 \mathrm{M} \mathrm{Fe}(\mathrm{CN})_{6}^{3 \cdot 14-}, 0.1 \mathrm{M} \mathrm{Et}_{4} \mathrm{NBF}_{4}$ solution ${ }^{6651}$.

(reprinted by permission of the publisher, The Electrochemical Society, Inc.) 


\section{Electrodeposition}

\subsection{Introduction}

At first sight, non-aqueous electrolyte solutions are not suitable for the electrodeposition of metals and compounds for many reasons:

- the high costs of solvent and solute combined with high purity requirement;

- complex operating conditions caused by toxicity and flammability;

- poor conductivity (cf. table X);

- low current efficiencies as a frequent consequence of unwanted side reactions such as the decomposition or polymerisation of the solvent which also causes impure metal deposits.

Nevertheless, numerous publications with promising contributions to this field of application show the increasing interest in non-aqueous solutions. Many metals of technological importance cannot be electrodeposited from aqueous solutions because the potentials are so negative that hydrogen evolution would occur instead of metal deposition ${ }^{672-674)}$ : alkali and earth alkali metals, B, Al, (Ga), Si, the lanthanides, and some of the transition metals $(\mathrm{Ti}, \mathrm{Zr}, \mathrm{Hf}, \mathrm{V}, \mathrm{Nb}$, and $\mathrm{Ta}$ which are referred to as valve or refractory metals). Some metals, for which deposition from aqueous solutions is thermodynamically favourable, cannot be obtained as pure deposits: $\mathrm{W}^{577.672,673)}$, Mo ${ }^{577,672,673)}$, and Ge ${ }^{577,672)}$.

Attempts to electroplate the valve metals have so far not been very successful. Takei ${ }^{674)}$ classifies them as metals which cannot be electrodeposited from either aqueous or non-aqueous solutions because their inner d-orbitals are not filled. They are believed to form strong covalent bonds with ligands. As a consequence metal deposits contain carbon, oxygen or halides.

One commercial application is the deposition of Li from non-aqueous solutions for the use in high energy-density batteries (cf. Sect. X). Coating, especially with Al. was proposed for uranium fuel elements ${ }^{675.676)}$, steel ${ }^{673.677)}$, production of wave guides ${ }^{6721}$, high surface-area deposits for electrolytic capacitors ${ }^{678)}$, and mirrors ${ }^{679)}$. Protective coatings with aluminium are considered to be more efficient than zinc coatings and even cheaper ${ }^{673)}$. Electrorefining of $\mathrm{Al}$ in non-aqueous solutions may use up to $85 \%$ less energy than the fused-salt electrolysis ${ }^{672.680)}$ commonly used. The electrodeposition of Be has appealing aspects for the atomic energy industry ${ }^{681}$. A new and intensively researched field is the electrodeposition of scmiconducting materials for the production of inexpensive large terrestrial solar cells ${ }^{682)}$. This application includes the electrodeposition as thin films of both pure semiconducting metals, such as $\mathrm{Ge}$ or $\mathrm{Si}$, and compounds, e.g. CdS and CdSe. A further field of research is the codeposition of metals as alloys by making use of the potential shifts relative to water.

Even metals being depositable from aqueous solutions may be advantageously plated from non-aqueous solutions when special surface properties are wanted. e.g greater coat thickness or higher cathodic efficiencies ${ }^{68.31}$. 
Non-Aqueous Electrolyte Solutions in Chemistry and Modern Technology

\subsection{Selected Examples}

The electrodeposition which is commercially most important ${ }^{577,673)}$ is that of $\mathrm{Al}$ by the NBS process ${ }^{684,685}$. The plating bath is a mixed electrolyte solution of $\mathrm{LiAlH}_{4}(0.2-0.4 \mathrm{M})$ and $\mathrm{AlCl}_{3}(3 \mathrm{M})$ in anhydrous DEE. Attempts have been made to reduce the volatility of solvent (flammability), to improve the operating life of the bath, to increase the current density, and to find substitutes for $\mathrm{LiAlH}_{4}$.

The Etmac bath ${ }^{676,686)}$ consisting of a solution of $\mathrm{AlCl}_{3}, \mathrm{AlHCl}_{2}$, and 2-ethoxyethyl trimethylammonium chloride in DEE shows reduced volatility and, furthermore, avoids the restriction through the initial aluminium content of the bath. Aluminium films up to $130 \mu \mathrm{m}$ thick were obtained with current densities of 0.5 to $15.5 \mathrm{~A} / \mathrm{dm}^{2}$.

Commercial baths using THF solutions $\left(\mathrm{AlCl}_{3}: \mathrm{LiAlH}_{4}=5: 1\right)^{677)}$ are now available ${ }^{681)}$ and smooth and coherent deposits were obtained with high current densities (up to $18 \mathrm{~A} / \mathrm{dm}^{2}$ without stirring). Additions of benzene were investigated. A THF/ benzene bath $\left(\mathrm{AlCl}_{3}: \mathrm{LiAlH}_{4}=3 \text { to } 1\right)^{687)}$ with a total aluminium concentration $\geqq 0.7 \mathrm{M}$ shows advantages with regard to volatility, stability, and operating life when compared to the NBS-bath. Deposits were obtained at current densities of up to $10 \mathrm{~A} / \mathrm{dm}^{2}$ with stirring and the bath is applicable to aluminium refining. In the range of 0 to $50 \mathrm{Vol} \%$ of benzene, the specific conductance of these baths is almost independent of solvent composition at high aluminium contents (equimolar $\mathrm{LiAlH}_{4} / \mathrm{AlCl}_{3}$ mixtures, both concentrations at $0.7 \mathrm{M}$; specific conductance $4 \times 10^{-3}$ $\Omega^{-1} \mathrm{~cm}^{-1}$ ). For further information on solvent mixtures of THF see ${ }^{688}$, for other solute mixtures in THF yielding conductivities up to $10^{-2} \Omega^{-1} \mathrm{~cm}^{-1} \mathrm{see}^{439.689 .690)}$.

Investigations on $\mathrm{Al}_{2} \mathrm{Br}_{6}$ as the source for aluminium exhibit some interesting features for the system $\mathrm{KBr}$ (or $\mathrm{LiBr}$ ) $/ \mathrm{Al}_{2} \mathrm{Br}_{6}$ toluene ${ }^{235,237,691-696)}$ ). The analysis of transference numbers and e.m.f. data exhibits triple ions, $\left(\mathrm{K}_{2}\left[\mathrm{Al}_{2} \mathrm{Br}_{7}\right]\right)^{+}$and $\left(\mathrm{K}\left[\mathrm{Al}_{2} \mathrm{Br}_{7}\right]_{2}\right)^{-}$in equilibrium with $\mathrm{KBr}$ and $\mathrm{Al}_{2} \mathrm{Br}_{6}$ as the predominant ionic species ${ }^{237)}$; the observed high conductance of $1 \mathrm{M} \mathrm{Al}_{2} \mathrm{Br}_{6} / 0.8 \mathrm{KBr}\left(6 \times 10^{-3} \Omega^{-1} \times\right.$ $\times \mathrm{cm}^{-1}$ ) in an inert solvent (toluene), suggests a non-Stokesian (hopping, $\mathrm{cf}$. Sect. 6.3) conductance mechanism ${ }^{235)}$.

Another way of replacing the expensive hydrides of the Etmac bath was reported by Yoshio et al. ${ }^{697)}$. Using $\mathrm{DEE}$ solutions of $\mathrm{Al}_{2} \mathrm{Br}_{6}$ and $\mathrm{LiCl}$ with conductivities of 6 to $10 \times 10^{-3} \Omega^{-1} \mathrm{~cm}^{-1}$, current densities of 20 to $100 \mathrm{~mA} / \mathrm{cm}^{2}$ were obtained at efficiencies of essentially $100 \%$ giving bright and adherent aluminium coatings. Takei ${ }^{6811}$ reports a bath containing $\mathrm{Al}\left(\mathrm{CF}_{3} \mathrm{COO}\right)_{3}, 400 \mathrm{~g} / \mathrm{dm}^{-3}$, in $\mathrm{MeOH}$ for $31 \%$ cathode efficiency. Thin and uniform $\mathrm{Be}$ films are obtained from $\mathrm{Be}\left(\mathrm{CF}_{3} \mathrm{COO}\right)_{2} /$ $\mathrm{CF}_{3} \mathrm{COOH} / \mathrm{Na}_{2} \mathrm{SO}_{4} / \mathrm{AN}$ baths ${ }^{681}$ )

Phosphotungstic acid in THF, DMF and FA with $\mathrm{H}_{3} \mathrm{BO}_{3}, \mathrm{NH}_{4} \mathrm{Cl}, \mathrm{H}_{2} \mathrm{O}_{2}$, and citric acid as additives were investigated for tungsten deposition ${ }^{681)}$; $\mathrm{X}$-ray analysis showed tungsten and tungsten oxides as the components of the deposits from FA solutions. From phosphomolybdic acid in FA an analogous result, Mo and Mo-oxides, was obtained ${ }^{6811}$.

Titanium is generally produced by the Kroll or Hunter process and recently also by energy saving deposition from high-temperature salt baths as known for coatting (9)8. ${ }^{699)}$. Many attempts have been made ${ }^{672,700.701)}$ to replace the high-temperature process with a low-temperature electroplating process. Brenner et al. ${ }^{7011}$ listed more 
Josef Barthel et al.

than 50 solvents, but did not succeed in plating $\mathrm{Ti}$ as a pure metal. Only $\mathrm{Ti} / \mathrm{Al}$ deposits containing up to $6 \% \mathrm{Ti}$ were obtained from a bath containing hydrides and borohydrides. Biallozor and Lisowska ${ }^{700)}$ obtained layers about $15 \mu \mathrm{m}$ thick with a titanium content of $37 \%$ by electroreduction of $\mathrm{TiCl}_{4}$ in acetonitrile solutions containing $\mathrm{LiBF}_{4}$. The carbon content of the deposit is $60 \%$. Santons and Dyment ${ }^{702}$ ) electrolysed $\mathrm{TiCl}_{3}$ in $\mathrm{HCl} / \mathrm{DMSO}$ solutions and obtained adhesive and homogeneous films up to $75 \mu \mathrm{m}$ thickness. They claimed the method to be also successful for some other valve metals $(\mathrm{Zr}, \mathrm{Hf}, \mathrm{Nb})$.

Tantalum coatings are of great technical importance as a consequence of their good high-temperature properties $\left(\mathrm{T}_{\mathrm{F}} \approx 3000^{\circ} \mathrm{C}\right)$, excellent corrosion resistance, and high thermal conductivity. Matching surfaces with Ta sheets is used technically despite the high cost, poor heat conduction and resulting material stress ${ }^{703}$ ). Electrodeposition from salt melts wastes energy and imposes technical problems ${ }^{703)}$. Fischer and Schwabe ${ }^{703)}$ investigated deposition from $\mathrm{TaCl}_{5} / \mathrm{PC}$ solutions as a function of conductivity, temperature, electrolyte concentration, and current density. They obtained compact Ta coatings containing traces of $\mathrm{Cl}$.

Electrodeposition of silicon can be achieved from PC baths containing tetraalkylammonium chlorides and $\mathrm{SiHCl}_{3}$ as the Si source ${ }^{704}$. Deposits on a variety of materials including low-cost substrates such as the Ti-6 Al-4 V alloy or coated fused silica were made. Both surface morphology and current decay resulting from the increase of electrical resistance of the growing $\mathrm{Si}$ film can be controlled by the cation size of the supporting electrolyte, $\mathrm{R}_{4} \mathrm{NCl}$. Bound hydrogen $\left(\mathrm{SiH}_{2}\right.$ or $\left.\mathrm{SiH}\right)$ can be driven off at $470{ }^{\circ} \mathrm{C}$. The amorphous $\mathrm{Si}$ film exhibits photoconduction and photovoltaic properties and offers an inexpensive route for solar cell applications.

Recently, the electrodeposition of amorphous silicon was achieved using EG and FA/EG solutions of HF and tetraethyl orthosilicate or silicic acid as the silicon sources ${ }^{705)}$. The conductivity changes from $\mathrm{p}$ - to n-type, when doping with phosphorous. This is possible by the addition of triethyl phosphate to an EG solution of HF containing $10^{-2} \mathrm{M}$ tetraethyl orthosilicate ${ }^{705}$ )

For details of the deposition of other semiconducting materials, e.g. CdS, CdSe, $\mathrm{Ge}$, from molten salts and organic solvents the reader is referred to a recent comprehensive review by Elwell ${ }^{682)}$.

\section{Wet Electrolytic Capacitors}

Electrolytic capacitors contain $\mathrm{Al}, \mathrm{Ta}, \mathrm{Nb}, \mathrm{Ti}$, or $\mathrm{Zr}$ foil electrodes which arc electrolytically oxidized in a dielectric formation process ${ }^{617,706 * 710)}$. The oxide films are $\leqq 100 \mathrm{~nm}$ thick ${ }^{617}$ ). The most important electrode metals are $\mathrm{Al}$, $\mathrm{Ta}$ and $\mathrm{Nb}$ with the electrolytically-formed oxides ${ }^{706.711-713)} \mathrm{Al}_{2} \mathrm{O}_{3}, \mathrm{Ta}_{2} \mathrm{O}_{5}$ and $\mathrm{Nb}_{2} \mathrm{O}_{5}$ of static permittivities up to $10^{617)}, 28^{617.714)}$ and $41^{714)}$, respectively. Aqueous as well as non-aqueous electrolyte solutions are used to establish the contact between the oxide film and the counter-electrode (cathode), especially in $\mathrm{Al}_{2} \mathrm{O}_{3}$ capacitors "17). $\mathrm{\Gamma a}_{2} \mathrm{O}_{5}$ capacitors are almost always constructed from solid electrolytes ${ }^{617)}$.

The characteristics of electrolytic capacitors are their high specific capacitance (up to $\left.400 \mu \mathrm{F} / \mathrm{cm}^{2}\right)^{711}$ ) and the dielectric oxide layers withstanding the intense electric field (up to $10^{7} \mathrm{~V} / \mathrm{cm}$ ) ${ }^{617,706}$ ). The main drawback is the high dissipation 
factor, especially at high frequencies and low temperatures. The electrolyte is the controlling factor which determines dissipation ${ }^{706)}$ and shelf life ${ }^{715}$ ). Wet capacitors with non-aqueous electrolyte solutions exhibit wider temperature ranges and higher corrosion resistances than those with aqueous solutions.

The general requirements for the electrolyte solution are almost the same as those for HEBs, i.e. low resistivity $(300<\mathrm{Q} /(\Omega \mathrm{cm})<2000)^{707)}$ over a large temperature range, low vapour pressure of the solvent, and sufficient solubility of the electrolyte. Specific compatibility conditions must be fulfilled. The electrolyte should act as a good oxide-forming agent, maintaining the electrochemical state of repair of the oxide layer during the life time of the capacitor ${ }^{617,708)}$. Glycol and glycerol with appropriate additives for reducing the water content and for stabilizing the oxide layer, and borates as the solutes are well-known capacitor electrolytes ${ }^{708}, 715,716$ ). Their disadvantages are very high viscosity and temperature coefficient of viscosity which reduce the usable temperature range. Furthermore, the oxide layer is not resistant to this electrolyte at higher temperatures ${ }^{715}$.

Improvements in capacitor electrolytes are obtained by optimizing binary and ternary solvent mixtures and using appropriate additives. Some examples may illustrate this field of application. Capacitors using $\mathrm{N}$-methylformamide and $\mathrm{N}$ ethylformamide solutions of triethylammonium maleate and monomethylammonium maleate were studied over a large temperature range $\left(-65^{\circ} \mathrm{C}<\theta<85^{\circ} \mathrm{C}\right)^{717}$. Solvent mixtures of PC (35.5-43.5 weight $\%$ ), $\gamma$-BL (35.5-43\%), and NMA (1.4 to $16.2 \%$ ) with tetramethylguanidine, picric acid, and citric acid as the electrolytes ${ }^{718}$ ) show increased lifetime. Low specific resistance $\left(140 \Omega \mathrm{cm} ; 50^{\circ} \mathrm{C}\right)$ was found for glycol/DMF solutions of p-nitrobenzoic acid, neutralized by diethylamine in the temperature range $-40{ }^{\circ} \mathrm{C} \leqq \theta \leqq 100{ }^{\circ} \mathrm{C}^{719}$. Capacitors using DMF or one of its homologues and the azeotropic mixture of $\mathrm{Et}_{3} \mathrm{~N}$ and acetic acid show a long shelflife and improved low-temperature performance ${ }^{720)} . \mathrm{P}_{2} \mathrm{O}_{5}{ }^{715}$, 720) and $\mathrm{H}_{3} \mathrm{PO}_{4}{ }^{721}$ ) were proposed as deterioriation inhibitors. For further information concerning the use of non-aqueous solutions see $617,709,710,712,716,722-724)$. Information on the electric breakdown in wet electrolytic capacitors can be found in Refs. ${ }^{725-730)}$.

A new promising type of electrolyte capacitor making use of the double-layer capacitance at large surface electrodes was recently proposed ${ }^{731},{ }^{732}$ ). Only capacitors with aqueous electrolyte solutions have so far been investigated. They can attain capacities up to $1 \mathrm{~F} / \mathrm{cm}^{2}$ and energy densities up to $25 \mathrm{~W}$ h/l. They may be used to protect memories during brief circuit interruptions instead of batteries. Because of water decomposition only voltages up to $0.9 \mathrm{~V}$ can be applied. Consideration should be given to the use of non-aqueous electrolyte solutions which would permit the application of higher voltages, cf. Ref. ${ }^{731}$.

\section{Electro-Organic Synthesis}

\subsection{Disappointments and Advantages}

Swann's "Bibliography of Electro-Organic Synthesis 1801-1975" contains about 12,000 citations involving electro-synthesis reactions ${ }^{733-735)}$. Only a handful have reached large-scale commercialization ${ }^{733.736)}$. Based on Swann's work, Beck, Alkire 
Josef Barthel et al.

and Weinberg compared the energy requirements of further possible candidates for electrochemical synthesis on the large tonnage scale $\left(>10^{4} t /\right.$ year) with the conventional routes ${ }^{737}$ ).

Despite this disappointing situation, numerous examples in open and patent literature indicate continuous research activity in both the academic and industrial field. "Fossil fuels for energy and feedstocks are dwindling rapidly, environmental legislation is becoming increasingly demanding" ${ }^{738)}$, and "industrial countries are moving increasingly towards an electrical economy" ${ }^{739)}$. The reconsideration of the possibilities made available by electro-organic synthesis is useful when taking into account the actual situation. "It seems likely, indeed, that the one-generation future will bring an electro-chemical industry which will be more than half of chemical industry and indeed it seems likely to guess that in a two-generation future chemical industry will become largely electrochemical"; this forecast ${ }^{740}$ ) is very optimistic but should stimulate us to do everything possible in this field of application.

The advantages of electro-organic synthetic methods are obvious:

- pollution-free oxidation and reduction carried out without oxidizing or reducing agents and without catalysts;

- controlled reaction rates;

- high selectivity when the potential along the electrode surface is uniform ${ }^{741}$;

- fewer reaction steps;

- simplified product recovery and purification.

Reaction intermediates such as radicals, carbonium ions, carbanions, cation and anion radicals, dications and dianions can be produced. For example, six reversible

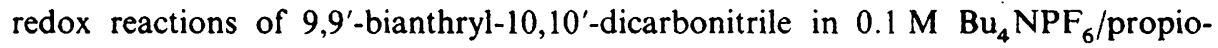
nitrile solution yield a spectrum of products ranging from the tetra-anion to the dication ${ }^{742)}$.

The energy to overcome the reaction barrier is introduced by electrical energy, which can be finely tuned, instead of thermal energy and thus can be applied at low temperatures to thermally-sensitive compounds ${ }^{739}$ ). The processes offer great ease in monitoring the reactions and are suitable for continuous and automatic operation ${ }^{743)}$. Spontaneous electrochemical reactions which produce chemicals and electric energy simultaneously, e.g. electrogenerative halogenation ${ }^{740,744)}$, and electro-initiated polymerizations ${ }^{746)}$ are further promising fields.

However, parameters concerning the electrode potential, electrode material, current density, electric field, conductance, and absorption must be controlled and optimized in addition to the usual ones, i.e. concentrations, temperature, pressure, and time ${ }^{738}$. 747.748). Scaling up of electrode reactions, which depend on the reactor surface instead of reactor volume as usual, is difficult and expensive ${ }^{736.738}$. Fabrication of appropriate electrodes and cell design require new technologies ${ }^{738)}$. Some typical examples are given for illustration.

Jansson and Tomov ${ }^{74}$ ) studied the dehydrodimerisation of diethyl malonate in Rl: AN using six types of ecll. The cell performance depends on the proper mixing for high $(>40 \%)$ conversion and on the choice of the electrolyte and solute concentrations at low $(<40 \%)$ conversion. The reduction of nitrobenzene yiclds nine products depending only on the electrolyte solution and the electrode material ${ }^{738)}$. Alkire and Gould ${ }^{741)}$ published an engineering model for continuous 
flow-through porous electrodes. They studied the multiple-reaction sequence (EEC) in the oxidation of 9,10-diphenylanthracene using $0.2 \mathrm{Et}_{4} \mathrm{NClO}_{4} / \mathrm{AN}$ as the electrolyte solution. The excellent agreement of $4 \%$ deviation of experience and model calculation shows the benefit of such models for estimating the influence of the reaction cell parameters and for scaling up the process. Further optimization calculations for electrochemical processes and cell design can be found in Refs. ${ }^{733}, 747,748,750-753$ ).

Recently numerous investigations have been carried out in non-aqueous solutions, many of them with mechanistical orientation, see $733,736,743,745,754-771$. The work devoted to the.study of fuel cells and high-energy batteries stimulated ${ }^{743)}$ electroorganic synthesis. Appropriate solvent properties for organic reactants and reaction products, the wide range of polarity which can be achieved, the large range of electrolytic inactivity (up to $> \pm 3 \mathrm{~V}$ ) far beyond that of water, fast electron transfer, and new and unusual types of reaction favour the use of non-aqueous solvents. For electro-activity ranges depending on the supporting electrolyte see Refs. ${ }^{41,759}$. ${ }^{772)}$; e.g., the use of supporting electrolytes with $\mathrm{BF}_{4}^{-}$and $\mathrm{PF}_{6}^{-}$anions in $\mathrm{AN}$ even permits the electrochemical study of allylic or tertiary $\mathrm{C}-\mathrm{H}$ bonds ${ }^{773)}$. Nonaqueous solvents can be selected for stabilizing reactive intermediates, for acting as a reactant or favouring a variety of desired reaction paths.

The main problems in industrial processes are the costs of highly purified solvents and the ohmic drop across the cell resulting in energy wastage. For example, the inactive range of a $0.1 \mathrm{M} \mathrm{DMSO}$ solution of $\mathrm{NaClO}_{4}$ (Pt-electrode) is diminished markedly by the residual water content ${ }^{774}$ ). The drawback due to poor conductivity could be overcome by the use of mixed solvents and weakly-associating electrolytes, cf. battery electrolytes (Sect. X). Comprehensive information can be found in monographs and reviews, Refs. ${ }^{733,735,736,743,745,754-758,760-764,766-771,775) \text {. }}$

\subsection{The Influence of Electrolyte Solutions on Reactions}

The general conditions for the choice of appropriate solvents and solvent mixtures concerning solvent classes, permittivity, viscosity, etc. are given in Section X. Supplementary conditions may result from requirements of solution structure near to the electrode or from the properties of intermediate reaction products as the new solutes in the solution. Solvation and ion-pair formation of these species depend strongly on the electrolyte solution, cf. Section VII, and control both reaction path and reaction rate. Some examples may illustrate these features.

The reaction rate of the electrohydrodimerization of 1,2-diactivated olefines in DMF solutions is significantly increased by adding alkali-metal salts ${ }^{776)}$ to a solution containing $\mathrm{Bu}_{4} \mathrm{NI}$ as a consequence of ion-pair formation with the intermediate radical anion. Formation of ion pairs and possibly of higher aggregates with the benzil radical anion is discussed in the electrochemical reduction of benzil in DMSO, DMF, and AN solutions containing $\mathrm{Bu}_{4} \mathrm{NClO}_{4}$ and alkali metal perchlorates ${ }^{777)}$; voltametric measurements show fast reversible association reactions of the benzil radical anion with the alkali metal ions whereas $\mathrm{Bu}_{4} \mathrm{~N}^{+}$exhibits only weak ionpair formation.

The cation plays an important role ${ }^{778}$ ) in the electrochemical formation of the commercially important mono- and disubstituted $\mathrm{N}$-alkyl formamides from $\mathrm{CO}$ in 
Josef Barthel et al.

$\mathrm{MeOH}$ and alkylamine solutions. The use of $0.2 \mathrm{M} \mathrm{Et}_{4} \mathrm{NBr}, \mathrm{Et}_{4} \mathrm{NBF}_{4}, \mathrm{Bu}_{4} \mathrm{NBr}$ or $\mathrm{NaBF}_{4}$ results in high yields $(1 \mathrm{~mol} / \mathrm{F})$, that of ammonium salts gives no yield at all. Alcoholate ions, which can be formed only in the presence of $\mathrm{R}_{4} \mathrm{~N}^{+}$and $\mathrm{Na}^{+}$, catalyze the reaction; the catalyst is believed to be highly concentrated in the diffusional electrical double layer, especially when $R_{4} N^{+}$are the cations.

The reductive cyclotetramerization of $\mathrm{CO}$ to squarate ions has been extensively. studied in DMF, HMPT, diglyme, THF, $\mathrm{NH}_{3}, \mathrm{AN}$ and DME using $\mathrm{Bu}_{4} \mathrm{NBr}$ as the supporting electrolyte, in DMF with $\mathrm{CaCl}_{2}, \mathrm{MgCl}_{2}, \mathrm{KBr}, \mathrm{LiCl}, \mathrm{NaN}_{3}$ and some $\mathrm{R}_{4} \mathrm{~N}^{+}$salts and in $\mathrm{DME}$ with $\mathrm{LiClO}_{4}$. It is another example where ionic effects occur ${ }^{779)}$ : large cations and anions give high yields, small cations and anions poor ones.

\subsection{Selected Examples from Actual Investigations}

Just as in the preceding sections, only a few examples from the recent literature will be given to illustrate the various types of research and application.

The electrochemical synthesis of tetraalkyl lead by the Nalco process ${ }^{733}, 736,760$. $780,781)$ is carried out in mixed ethers as a large-scale industrial process.

The potential shortage of hydrocarbons as raw materials may favour ${ }^{755,782}$. reactions with small molecules. Carbon dioxide is reduced to oxalic acid in aprotic solvents (DMF, AN, PC) containing tetraalkylammonium salts ${ }^{783-786)}$. Oxalate and succinate are obtained by electroreduction of $\mathrm{CO}_{2} / \mathrm{C}_{2} \mathrm{H}_{4}$ mixtures in DMF or HMPT at elevated pressure ${ }^{787}$. Carbon monoxide is reduced to squaric acid at high pressures in DMF, HMPT, and THF solutions of $\mathrm{Bu}_{4} \mathrm{NBr}^{788)}$. Organic carbonates at high pressure $(100 \mathrm{~atm})$ were synthesized by electrolysis of a solution of $\mathrm{CO}$ in the appropriate alcohol in the presence of various halides which also act as catalysts (e.g. $\left.\mathrm{NH}_{4} \mathrm{Br}\right)^{789)}$; these important solvents are thus available without the use of phosgene and the problem of the disposal of hydrochloric acid. For further use of $\mathrm{CO}$ as a starting material see ${ }^{778,779}$. Cyclic sulfones of high purity are produced by reduction of $\mathrm{SO}_{2}$ in $\mathrm{AN}$ solutions in presence of some dibromides ${ }^{790}$ ), symmetric $\mathrm{R}-\mathrm{SO}_{2}-\mathrm{R}^{791)}$ or non-symmetric $\mathrm{R}-\mathrm{SO}-\mathrm{R}^{\prime}{ }^{792)}$ sulfones in presence of alkyl halides or a mixtures of two alkyl halides, respectively.

Monomethoxylated amides, used for the preparation of vinylamides, were obtained in yields up to $100 \%$ by anodic oxidation of $\mathrm{N}, \mathrm{N}$-dialkylamides in methanol solutions of $\mathrm{Bu}_{4} \mathrm{NBF}_{4}{ }^{793)}$. $\mathrm{N}-\mathrm{N}$ coupling can be achieved by anodic oxidation, e.g., amide anions of secondary amines in $\mathrm{LiClO}_{4} / \mathrm{THF}$ yield tetrasubstituted hydrazines $^{794)}$; monosubstituted sulfamide anions in $\mathrm{MeOH}$ are oxidized to azo compounds which can be cathodically reduced to symmetrically-substituted hydrazines, and imidodisulfonate trisanions to hydrazine tetrasulfonate which can be converted to hydrazine.

Heterocyclic compounds (e.g. indazoles) have been synthesized ${ }^{795}$ ) by anodic oxidation of hydrazones, in $\mathrm{LiClO}_{4} / \mathrm{AN}$. Tetrazolium salts are obtained by oxidation of formazans in $\mathrm{Et}_{4} \mathrm{~N} \mathrm{ClO}_{4} / \mathrm{AN}$, sec ${ }^{746)}$.

Anodic coupling of vinyl ethers, phenols and phenol ethers is claimed to be promising ${ }^{7971}$ for the synthesis of natural products and medicaments, e.g. cyclization of methoxybibenzyls in $\mathrm{LiClO}_{4} / \mathrm{AN}^{798 .}{ }^{799}$ ). Dimethoxydihydrofuran, a sales product 
for disinfectants, can be produced without pollution by methoxylation of furan in $\mathrm{NH}_{4} \mathrm{Br} / \mathrm{MeOH}$. Nohe ${ }^{800}$ ) has made an economic comparison with the competing conventional route and the effect of cell design on this process is reported by Jansson and Fleischmann ${ }^{801}$ ). Lelandais ${ }^{754)}$ refers to acetimidation reactions in $\mathrm{LiClO}_{4} / \mathrm{AN}$ and $\mathrm{Et}_{4} \mathrm{NBF}_{4} / \mathrm{AN}^{802,803)}$ as a promising route to pharmaceutically active products. The trifluoroacetoxylation of chlorobenzene in $\mathrm{CF}_{3} \mathrm{COONa} /$ $\mathrm{CF}_{3} \mathrm{COOH}$ is carried out ${ }^{804)}$ with $94 \%$ product yield at $70 \%$ current efficiency. The products may be hydrolyzed to the corresponding phenol, resorcinol or pyrocatechol derivatives and hence can be used as a simple way to the technicallyinteresting 4-chlororesorcinol. Production of dimethylsebacate by the Kolbe synthesis in aqueous methanol is a further process which has reached the pilot stage ${ }^{733}, 736,800$ ). Studying the Kolbe-synthesis with $\mathrm{CF}_{3} \mathrm{COONa}, \mathrm{CF}_{2} \mathrm{ClCOONa}$ and $\mathrm{CF}_{2} \mathrm{BrCOONa}$ in $\mathrm{Bu}_{4} \mathrm{NPF}_{6} / \mathrm{AN}$ solutions Waefler and Tissot ${ }^{805}$ ) obtained the difluorocarbene as a by-product at room temperature from $\mathrm{CF}_{2} \mathrm{BrCOONa}$, the Kolbe synthesis being the main reaction.

A pilot process for production of dihydrophthalic acid used dioxane-water mixtures $736,738,800,806$ ). The influence of further organic co-solvents on yields is discussed by Nohe ${ }^{807)}$. Pletcher and Razaq have accomplished ${ }^{808)}$ the electrochemical reduction of 2,3,5-tribromothiophene to 3-bromothiophene, in $\mathrm{NaBr}$ solution, $0.2 \mathrm{M}$ in aqueous dioxane $(70 \%$ dioxane), with high current efficiencies. This process could replace the conventional reduction with a three-fold excess of $\mathrm{Zn}$, which leads to the disposal of waste containing $\mathrm{Zn}^{2+}$. Acetophenone may be electrochemically reduced to ethylbenzene in acidified $\left(\mathrm{HClO}_{4} / \mathrm{H}_{2} \mathrm{SO}_{4}\right)$ ethanol. This is a further example for avoiding the problems allied with the use of metal powders in reductions ${ }^{809)}$.

Aqueous $\mathrm{Bu}_{4} \mathrm{NBr} /$ trioxane solution proved to be an efficient medium for the reduction of benzene to cyclohexadiene ${ }^{810)}$. The advantage of trioxane when compared to dioxane results from the higher conductivity of its electrolyte solutions and the possibility of applying more negative potentials.

The use of solid polymer-electrodes is a new technique in electro-organic synthesis avoiding the supporting electrolyte and the side reactions caused by it. For example, Ogumi et al. ${ }^{811}$ hydrogenated olefine double bonds in EtOH, DEE, and hexane without supporting electrolyte.

The application of polymer-coated electrodes was already discussed for high energy batteries (doped polyacetylenes, Sect. X) and liquid junction solar cells (conducting polypyrrole films, Sect. XII). Further information on the application of polymermodified electrodes can be found in recent reviews ${ }^{812.821-823)}$.

Baizer has critically reviewed ${ }^{767)}$ the prospects for further application of organic electrosynthesis and has compiled a list of conditions for the successful use of this technique. The main suggestions were: use of electrochemical methods in oxidation or reduction processes, where stoichiometric concentrations of oxidants or reductants, especially exotic ones, cf. Refs. ${ }^{733.770 .806)}$, are needed in conventional synthesis; the use of an electro-organic synthesis where it is the only successful approach; finally in small-scale processes, e.g. the production of medicinals or fine chemicals. These and further suggestions may be found in Refs. ${ }^{733.754 .769 .770)}$. For further information, concerning other examples of electro-synthesis, the reader is referred to recent reviews published by Lelandais ${ }^{754)}$, Fioshin ${ }^{755)}$, Baizer ${ }^{767)}$, Köster 
Josef Barthel et al.

and Wendt ${ }^{806)}$, Pletcher ${ }^{760)}$, and Schäfer ${ }^{770}$ ), and the volume 75 of the American Chemical Engineers Symposium Series ${ }^{733}$ ).

\section{Further Promising Fields of Application}

Some applications of interest which cannot be subsumed under the headings of the previous sections are still to be mentioned.

\subsection{Processes Based on Solvating Properties}

Parker ${ }^{813)}$ developed the energy and capital-cost-saving "roast-leach-disproportionation process" for sulfide concentrates of $\mathrm{Cu}$ and $\mathrm{Ag}$. The process makes use of the different solvating powers of $\mathrm{AN}$ and $\mathrm{H}_{2} \mathrm{O}$, respectively. The equilibria

$$
\begin{aligned}
& \mathrm{Cu}+\mathrm{CuSO}_{4} \rightleftarrows \mathrm{Cu}_{2} \mathrm{SO}_{4} \\
& 2 \mathrm{Ag}+2 \mathrm{CuSO}_{4} \rightleftarrows \mathrm{Ag}_{2} \mathrm{SO}_{4}+\mathrm{Cu}_{2} \mathrm{SO}_{4}
\end{aligned}
$$

are shifted to $\mathrm{Cu}^{+}$and $\mathrm{Ag}^{+}$which are strongly solvated by $\mathrm{AN}$ when adding an acidified $\mathrm{AN} / \mathrm{H}_{2} \mathrm{O}$ solution. In contrast, pure water favours the $\mathrm{Cu}^{2+}$ ion and the pure metals. As a consequence materials containing impure copper or silver may be leached using acidified $\mathrm{CuSO}_{4} / \mathrm{H}_{2} \mathrm{O} / \mathrm{AN}$ solutions; subsequent distillation of $\mathrm{AN}$ from the solution yields the purified metal; the waste heat of the roast process can be advantageously used for carrying out the distillation. The energy saving $(>50 \%)$ and the reduction in capital cost $(>60 \%)$ of this process as compared to an electrolytic copper refinery are impressive.

Using the same principles, waste materials such as cement silver, silver halide residues and circuit boards can be recovered ${ }^{813)}$ using $\mathrm{CuCl}_{2}$ as the oxidant in $\mathrm{NaCl} / \mathrm{DMSO}$ solutions. The anions $\mathrm{CuCl}_{2}^{-}, \mathrm{AgCl}_{2}^{-}$and $\mathrm{AuCl}_{2}^{-}$are strongly solvated in DMSO in contrast to water.

$$
\begin{aligned}
& \mathrm{Ag}+\mathrm{CuCl}_{2}+2 \mathrm{NaCl} \rightleftarrows \mathrm{CuCl}_{2}^{-}+\mathrm{AgCl}_{2}^{-}+2 \mathrm{Na}^{+} \\
& \mathrm{Au}+3 \mathrm{CuCl}_{2}+4 \mathrm{NaCl} \rightleftarrows 3 \mathrm{CuCl}_{2}^{-}+\mathrm{AuCl}_{4}^{-}+4 \mathrm{Na}^{+} .
\end{aligned}
$$

Addition of water to these solutions yields gold metal or silver chloride precipitates, because the $\mathrm{Cl}^{-}$ion is strongly solvated in water. It should be mentioned that these processes do not involve pyrometallurgical steps.

The two-phase battery $\mathrm{Zn} / \mathrm{ZnBr}_{2},\left(\mathrm{H}_{2} \mathrm{O}\right) / \mathrm{Zn}\left(\mathrm{Br}_{3}\right)_{2}$, (dipolar aprotic solvent)/ insoluble electrode is a further example ${ }^{813)}$ using the stronger solvation of halide ions by dipolar aprotic solvents when compared to water. As a further advantage of different solvent solvation powers the $\mathrm{Br}_{2}$ is kept away from the $\mathrm{Zn}$ electrode. The battery with an overall efficiency of about $60 \%$ at $20 \mathrm{~mA} / \mathrm{cm}$ charge-discharge 
current densities and an open-circuit voltage of $1.76 \mathrm{~V}$ is claimed to have some promise for load-levelling applications.

For further aspects of solvating properties which have been used technically see Ref. ${ }^{813)}$ and literature quoted there.

\subsection{Electropolishing}

Electropolishing is a technique where non-aqueous solutions are applied to even out surface irregularities. A bath for polishing $\mathrm{Mo}, \mathrm{V}, \mathrm{Al}, \mathrm{Fe}$, and $\mathrm{U} / \mathrm{V}$ alloys consists of a $1 \mathrm{M} \mathrm{H}_{2} \mathrm{SO}_{4} / \mathrm{MeOH}$ solution $\left.{ }^{814}\right) ; \mathrm{HClO}_{4}(5-20 \%) / \mathrm{MeOH}$ can be used for $\mathrm{Al}$, $\mathrm{Cu}, \mathrm{Pb}, \mathrm{Sn}$, and $\mathrm{Fe}^{815)}$.

\subsection{Anodic Oxidation of Semiconductors}

Anodic oxidation is used commercially in the production of metal-oxide semiconductor (MOS) devices on $\mathrm{GaAs}^{816,817)}$. The production of $\mathrm{As}_{2} \mathrm{O}_{3} / \mathrm{Ga}_{2} \mathrm{O}_{3}$ films is best carried out with glycol/water or propane-1,2-diol as the solvents. The resulting stable oxide films exhibit $10^{5}$ to $10^{8}$ times higher resistivities than those from aqueous anodization. Glycol can be replaced by other protic solvents, e.g. N-methylacetamide ${ }^{818)}$.

Electrochemical etching and electropolishing of semiconductors are further techniques which should be mentioned. The reader is referred to Ref. ${ }^{819}$.

\section{Acknowledgements}

We are very grateful to the Herbert Quandt Stiftung who sponsored our investigations by a grant and to the DECHEMA, Projekt: Entwicklung computergestützter Rechnungsmethoden für Stoffdaten, which is financially supported by the Bundesministerium für Forschung und Technologie.

\section{Appendices}

\section{A Solvent and Electrolyte Data}

\section{A.1 Properties of Organic Solvents}

Reliable data of organic solvents are needed for the control of purity as well as for the parameters in the equations expressing the concentration dependence of the properties of electrolyte solutions. Table A-I contains a selection of currently used solvents which are arranged in classes according to the principles given in Section II, cf. also Table l. Data are given for $25^{\circ} \mathrm{C}$ if not indicated otherwise.

Improvements of the purification processes and new methods of purity control have provided data which often deviate significantly from the traditionally used ones. As far as we are aware of trustworthy new data these are given in Table A-I. 
$\bar{N}$ Table A-l. Properties of organic solvents

\begin{tabular}{|c|c|c|c|c|c|c|c|c|c|}
\hline Solvent & $\begin{array}{l}\text { Abbrevi- } \\
\text { ation }\end{array}$ & $\frac{\theta_{\mathrm{F}}}{{ }^{\circ} \mathrm{C}}$ & $\frac{\theta_{\mathrm{B}}}{{ }^{\circ} \mathrm{C}}$ & $\varepsilon$ & $\frac{\eta}{c P}$ & $\frac{\mathrm{Q}}{\mathrm{g} \mathrm{ml}^{-1}}$ & 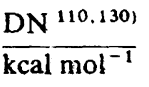 & $\frac{E_{\tau}{ }^{111}}{\mathrm{kcal} \mathrm{mol}^{-1}}$ & $\mathrm{AN}^{112-114,130)}$ \\
\hline \multicolumn{10}{|c|}{ 1. Amphiprotic ${ }^{1031}$ hydroxylic ${ }^{104)}$ solvents } \\
\hline $\begin{array}{l}\text { Methanol } \\
\text { Ethanol } \\
\text { 1-Propanol } \\
\text { 2-Propanol } \\
\text { 1-Butanol } \\
\text { 2-Butanol } \\
\text { 1,2-Ethanediol } \\
\text { Glycerol } \\
\text { Diethylene glycol } \\
\text { Triethylene glycol } \\
\text { 2-Methoxyethanol } \\
\text { Cyclohexanol } \\
\text { Benzylalcohol }\end{array}$ & $\begin{array}{l}\mathrm{MeOH} \\
\text { EtOH } \\
\text { PrOH } \\
\text { i-PrOH } \\
\text { BuOH } \\
\text { i-BuOH } \\
\text { EG } \\
\text { DEG } \\
\text { TEG } \\
\text { MOE }\end{array}$ & $\begin{array}{l}-97.68^{1.21} \\
-114.15^{1.10)} \\
-126.2^{1.21} \\
-87.90^{101} \\
-88.62^{11} \\
-114.7^{1,21} \\
-13^{11} \\
18.18^{11} \\
-6.5^{11} \\
-4.3^{11} \\
-85.1^{11} \\
25.15^{11} \\
-15.3^{11} \\
\end{array}$ & $\begin{array}{r}64.515^{31} \\
78.293^{111} \\
97.151^{111} \\
82.242^{111} \\
117.725^{11} \\
99.52^{111} \\
197.3^{11} \\
290.0^{11} \\
244.8^{11} \\
288.0^{11} \\
124.6^{11} \\
161.1^{11} \\
205.45^{11}\end{array}$ & $\begin{array}{l}32.63^{4-71} \\
24.35^{4,121} \\
20.33_{5}^{4,14)} \\
19.40^{7,17)} \\
17.43^{141} \\
16.7^{1,21)} \\
40.8^{23)} \\
42.5^{11} \\
31^{23,26)} \\
23.4^{26)} \\
17.0^{7,28)} \\
15.0^{11} \\
13.27^{301}\end{array}$ & $\begin{array}{l}0.542^{4,71} \\
1.087^{12,13)} \\
1.96_{8}^{7,15,16)} \\
2.08^{18.19)} \\
2.61^{15,20)} \\
3.18^{11} ; 30^{\circ} \mathrm{C} \\
16^{24,6^{25,101)}} \\
945^{1)} \\
17.4^{271} ; 30^{11} \\
49.0^{11} ; 20^{\circ} \mathrm{C} \\
1.53_{5}^{7,29)} \\
41.067^{11} \\
4.650^{11} ; 30^{\circ} \mathrm{C}\end{array}$ & $\begin{array}{l}0.7863_{6}{ }^{8.9)} \\
0.7849_{5}^{8.9)} \\
0.7995^{7,8.9 .16)} \\
0.7809_{7}^{9.18,191} \\
0.8057_{5}^{9,20)} \\
0.8023_{9}^{9,22)} \\
1.109_{5}^{24,25,101)} \\
1.2551^{11} ; 30^{\circ} \mathrm{C} \\
1.11_{6}^{23.27)} \\
1.1235^{17} ; 20^{\circ} \mathrm{C} \\
0.9601_{4}^{71} \\
0.9684^{11} \\
1.0424^{31)}\end{array}$ & $\begin{array}{l}19.1 \\
19.6\end{array}$ & $\begin{array}{l}55.5 \\
51.9 \\
50.7 \\
48.6 \\
50.2 \\
47.1 \\
56.3 \\
\\
53.8 \\
53.5 \\
52.3 \\
46.9 \\
50.8\end{array}$ & $\begin{array}{l}41.5 \\
37.9 \\
37.3 \\
33.6 \\
36.8 \\
\\
(42.8) \\
(44.3)\end{array}$ \\
\hline \multicolumn{10}{|c|}{ 2. Amphiprotic protogenic ${ }^{1031}$ solvents } \\
\hline Acetic Acid & & $16.66^{11} \quad 1$ & $117.90^{11}$ & $\begin{array}{l}6.20^{34)} \\
20^{\circ} \mathrm{C}\end{array}$ & $1.13_{5}^{32.331}$ & $1.0436^{1.33)}$ & & 51.2 & 52.9 \\
\hline \multicolumn{10}{|c|}{ 3. Protophilic ${ }^{103 /} \mathrm{H}$-bond donor ${ }^{104 /}$ solvents } \\
\hline $\begin{array}{l}\text { Formamide } \\
\text { N-Methylformamide } \\
\text { N-Methylacetamide }\end{array}$ & $\begin{array}{l}\text { FA } \\
\text { NMF } \\
\text { NMA }\end{array}$ & $\begin{array}{c}2.5_{s}{ }^{1.381} \\
-5.4^{38,} \\
30.56^{44)} \\
11.3^{11}\end{array}$ & $\begin{array}{l}218^{381} \\
180-185^{1.381} \\
206^{11} \\
117.26^{11}\end{array}$ & $\begin{array}{l}109.5^{36.37)} \\
186.9^{42)} \\
171.7^{451} \\
35^{\circ} \mathrm{C} \\
\quad 1.54^{11}\end{array}$ & 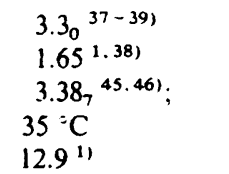 & $\begin{array}{l}1.129_{3}{ }^{35,38,40,41)} \\
0.998244^{43)} \\
0.94553^{46)} ; \\
35^{\circ} \mathrm{C} \\
0.8922^{601}\end{array}$ & 1) 24 & $\begin{array}{l}56.6 \\
54.1 \\
52.0 \\
\\
42.0\end{array}$ & $\begin{array}{c}39.8 \\
32.1 \\
(33.7)\end{array}$ \\
\hline
\end{tabular}




\begin{tabular}{|c|c|c|c|c|c|c|c|c|c|}
\hline \multirow{3}{*}{$\begin{array}{l}\text { 2-Pyrrolidinone } \\
\text { 2-Aminoethanol } \\
\text { Morpholine }\end{array}$} & & \multirow{3}{*}{$\begin{array}{c}25^{11} \\
10.53^{11} \\
-\quad 3.1^{\prime \prime}\end{array}$} & \multirow{3}{*}{$\begin{array}{l}245^{11} \\
170.95^{11} \\
128.94^{11}\end{array}$} & \multirow{3}{*}{$\begin{array}{l}33^{601} \\
37.72^{11} \\
7.42^{11}\end{array}$} & \multirow{3}{*}{$\begin{array}{l}13.3^{11} \\
19.346^{11} \\
1.792^{11} ; 30^{\circ} \mathrm{C}\end{array}$} & \multicolumn{2}{|l|}{$1.107^{11}$} & \multirow{3}{*}{51.8} & \multirow{3}{*}{$\begin{array}{l}33.7 \\
17.5\end{array}$} \\
\hline & & & & & & $1.01159^{11}$ & & & \\
\hline & & & & & & $0.99547^{11}$ & - & & \\
\hline \multicolumn{10}{|c|}{ 4. Aprotic protophilic ${ }^{1031}$ solvents } \\
\hline Dimethylformamide & DMF & $-60.44^{47)}$ & $153.0^{11}$ & $36.71^{11}$ & $0.793_{9}^{48)}$ & $0.9438_{7}^{40.48)}$ & 26.6 & 43.8 & 16.0 \\
\hline Diethylformamide & DEF & & $178.3^{1061}$ & $28.4^{421}$ & $1.139^{105)}$ & $0.9017^{105,42)}$ & 30.9 & & \\
\hline Dimethylacetamide & DMA & $-20^{11}$ & $166.1^{1)}$ & $37.78^{11}$ & $0.927^{1051}$ & $0.9350^{105)}$ & 27.8 & 43.7 & 13.6 \\
\hline Diethylacetamide & DEA & & $184^{106)}$ & $30.4^{42)}$ & $1.226^{105)}$ & $0.904^{105,42)}$ & 32.3 & & \\
\hline $\begin{array}{l}\text { 1-Methyl-2-pyr- } \\
\text { rolidinone }\end{array}$ & NMP & $-24.4^{\prime \prime}$ & $202^{11}$ & $32.0^{11}$ & $1.663^{105)}$ & $1.0286^{105)}$ & 27.3 & 42.2 & 13.3 \\
\hline $\begin{array}{l}\text { Hexamethylphosphoric } \\
\text { triamide }\end{array}$ & HMPT & $7.20^{13}$ & $233^{11}$ & $29.649-511$ & $3.22_{4}^{50.52)}$ & $1.0201^{49.52)}$ & 38.8 & 40.9 & 10.6 \\
\hline Pyridine & PY & $-41.55^{11}$ & $115.256^{11}$ & $\begin{array}{l}12.4^{11} \\
21^{\circ} \mathrm{C}\end{array}$ & $0.884^{11}$ & $0.97824^{11}$ & 33.1 & 40.2 & 14.2 \\
\hline Tetramethylurea & TMU & $-1.2^{13}$ & $175.2^{1)}$ & $23.533,107)$ & $1.39_{8}^{53,107)}$ & $0.9619^{53,107)}$ & 29.6 & 41.0 & $(9.8)$ \\
\hline Dimethylsulfoxide & DMSO & $18.54^{\prime \prime}$ & $189.0^{11}$ & $46.554-57)$ & $1.99_{2}^{54.56-58)}$ & $1.0955^{41,55-57)}$ & 29.8 & 45.0 & 19.3 \\
\hline \multicolumn{10}{|c|}{ 5. Aprotic protophobic ${ }^{103)}$ solvents } \\
\hline Acetonitrile & AN & $-48.835^{11}$ & $81.60^{11}$ & $35.95^{7,59,61)}$ & $0.341^{5.59 .61)}$ & $0.7767_{5} 5.7 .59 .611$ & 14.1 & 46.0 & 18.9 \\
\hline Propionitrile & PN & $-92.78^{11}$ & $97.35^{11}$ & $27.2^{11}$ & $\begin{array}{l}0.389^{11} \\
30^{\circ} \mathrm{C}\end{array}$ & $0.77682^{11}$ & 16.1 & 43.7 & \\
\hline Benzonitrile & $\mathrm{BN}$ & $-12.75^{11}$ & $191.10^{11}$ & $25.20^{11}$ & $1.237^{62)}$ & $1.0006^{11}$ & 11.9 & 42.0 & 15.5 \\
\hline Acetone & & $-94.7^{11}$ & $56.29^{11}$ & $20.56^{16.55)}$ & $0.303^{16,55,63)}$ & $0.7843_{s}{ }^{16,55.63)}$ & 17.0 & 42.2 & 12.5 \\
\hline 2-Butanone & MEK & $-86.69^{11}$ & $79.64^{11}$ & $18.04_{5}^{7)}$ & $0.368^{7}$ & $0.7996_{6}^{71}$ & & 41.3 & \\
\hline 3-Pentanone & & $-38.97^{\prime \prime}$ & $101.99^{11}$ & $\begin{array}{l}17.00^{11} \\
20^{\circ} \mathrm{C}\end{array}$ & $0.442^{11}$ & $0.80945^{11}$ & & 39.3 & \\
\hline Acetophenone & & $19.62^{11}$ & $202.0^{11}$ & $17.48^{641}$ & $1.511^{11} ; 30^{\circ} \mathrm{C}$ & $1.02382^{11}$ & & 41.3 & \\
\hline Nitromethane & NM & $-28.55^{11}$ & $101.20^{11}$ & $38.0^{651}$ & $0.62^{1,651}$ & $1.131^{1.65)}$ & 2.7 & 46.3 & 20.5 \\
\hline Nitrobenzene & NB & $5.76^{11}$ & $210.80^{\prime \prime}$ & $34.82^{1.661}$ & $1.818^{67)}$ & $1.1985^{67.68)}$ & 4.4 & 42.0 & 14.8 \\
\hline Sulfolane & TMS & $28.45^{11}$ & $287.3^{1)}$ & $\begin{array}{l}43.3_{0}^{56.69)} \\
30^{\circ} \mathrm{C}\end{array}$ & $\begin{array}{l}10.28_{7}^{1,56.69)} ; \\
30^{\circ} \mathrm{C}\end{array}$ & $\begin{array}{l}1.261_{9}^{56,69,70 ;} ; \\
30^{\circ} \mathrm{C}\end{array}$ & 14.8 & 44.0 & 19.2 \\
\hline
\end{tabular}


Table A-l. (continued)

\begin{tabular}{|c|c|c|c|c|c|c|c|c|c|}
\hline Solvent & $\begin{array}{l}\text { Abbrevi- } \\
\text { ation }\end{array}$ & $\frac{\theta_{\mathrm{F}}}{{ }^{\circ} \mathrm{C}}$ & $\frac{\theta_{\mathrm{B}}}{{ }^{\circ} \mathrm{C}}$ & $\varepsilon$ & $\frac{\eta}{c P}$ & $\frac{\mathrm{Q}}{\mathrm{gml^{-1 }}}$ & $\frac{\mathrm{DN}^{110,130)}}{\mathrm{kcal} \mathrm{mol}^{-1}}$ & $\frac{E_{\mathcal{T}}{ }^{111}}{\mathrm{kcal}^{\mathrm{mol}}{ }^{-1}}$ & $\mathrm{AN}^{112-114,130)}$ \\
\hline Ethylene carbonate & EC & $36.5^{711}$ & $238^{11}$ & $\begin{array}{l}90.36^{72,73)} \\
40^{\circ} \mathrm{C}\end{array}$ & $\begin{array}{l}1.9^{71,73,74)} \\
40^{\circ} \mathrm{C}\end{array}$ & $\begin{array}{l}1.321_{4}^{71-74)} \\
40^{\circ} \mathrm{C}\end{array}$ & 16.4 & & \\
\hline $\begin{array}{l}\text { Propylene carbonate } \\
\gamma \text {-Butyrolactone } \\
\text { Acetic anhydride }\end{array}$ & $\begin{array}{l}\text { PC } \\
\gamma-\mathrm{BL}\end{array}$ & $\begin{array}{l}-54.53^{75)} \\
-43.53^{11} \\
-73.1^{11}\end{array}$ & $\begin{array}{l}242^{60)} \\
204^{\prime \prime} \\
140.0^{11}\end{array}$ & $\begin{array}{l}64.9_{\mathrm{s}}{ }^{7.76)} \\
39.1^{78)} \\
20^{79)} \\
30^{\circ} \mathrm{C}^{\circ}\end{array}$ & $\begin{array}{l}2.51_{2}^{7.771} \\
1.7315^{781} \\
0.8^{79)} \\
30^{\circ} \mathrm{C}^{\circ}\end{array}$ & $\begin{array}{l}1.199_{6}^{7,77)} \\
1.1242^{78)} \\
1.0686^{79)} \\
30^{\circ} \mathrm{C}\end{array}$ & $\begin{array}{l}15.1 \\
10.5\end{array}$ & $\begin{array}{l}46.6 \\
43.9\end{array}$ & $\begin{array}{c}18.3 \\
(18.6)\end{array}$ \\
\hline Tributylphosphate & TBP & $<-80^{\prime \prime}$ & $289^{11}$ & $\begin{array}{l}7.959^{11} \\
30^{\circ} \mathrm{C}\end{array}$ & $3.39^{11}$ & $0.9760^{11}$ & 23.7 & & 9.9 \\
\hline \multicolumn{10}{|c|}{ 6. Low permittivity-electron donor ${ }^{104)}$ solvents } \\
\hline $\begin{array}{l}\text { Diethyl ether } \\
\text { Diisopropyl ether } \\
\text { 1,4-Dioxane } \\
\text { Tetrahydrofuran } \\
\text { 1,2-Dimethoxyethane } \\
\text { Diglyme }\end{array}$ & $\begin{array}{l}\text { DEE } \\
\text { DI } \\
\text { THF } \\
\text { DME } \\
\text { DG }\end{array}$ & $\begin{array}{l}-116.3^{11} \\
-85.5^{11} \\
11.80^{11} \\
-108.5^{11} \\
-58^{11} \\
-64^{1081}\end{array}$ & $\begin{array}{l}34.55^{11} \\
68.3^{11} \\
101.320^{11} \\
65.965^{851} \\
84.50^{911} \\
163^{931}\end{array}$ & $\begin{array}{l}4.33^{80)} \\
3.88^{11} \\
2.21^{1.81)} \\
7.4^{86-88)} \\
7.07_{5}^{92)} \\
7.2^{109)}\end{array}$ & $\begin{array}{l}0.242^{11} ; 20^{\circ} \mathrm{C} \\
0.379^{11} \\
1.20_{4}^{82,83)} \\
0.45_{9}^{86-88)} \\
0.40_{7}^{7,92)} \\
1.06^{94)}\end{array}$ & $\begin{array}{l}0.70760^{11} \\
0.7182^{11} \\
1.0280_{5}^{67,82,84)} \\
0.8819^{89.90)} \\
0.8612_{2}^{7,92)} \\
0.9440^{11}\end{array}$ & $\begin{array}{l}19.2 \\
14.8 \\
20.0\end{array}$ & $\begin{array}{l}34.6 \\
34.0 \\
36.0 \\
37.4 \\
38.2 \\
38.6\end{array}$ & $\begin{array}{r}3.9 \\
\\
10.8 \\
8.0 \\
10.2 \\
9.9\end{array}$ \\
\hline \multicolumn{10}{|l|}{ 7. Inert Solvents } \\
\hline $\begin{array}{l}\text { Dichloromethane } \\
\text { Trichloroethylene }\end{array}$ & & $\begin{array}{l}-95.14^{11} \\
-86.4^{11}\end{array}$ & $\begin{array}{l}39.75^{11} \\
87.19^{\prime \prime}\end{array}$ & $\begin{array}{r}8.93^{11} \\
3.42^{11} \\
\sim 16^{\circ} \mathrm{C}\end{array}$ & $\begin{array}{l}0.413^{95)} \\
0.532^{11}\end{array}$ & $\begin{array}{l}1.31678^{11} \\
1.4514^{11} \\
30^{\circ} \mathrm{C}\end{array}$ & & 35.9 & 20.4 \\
\hline Benzene & & $5.533^{11}$ & $80.0^{1,96)}$ & $\begin{array}{r}2.274 \\
1,97.98)\end{array}$ & $0.6028^{1.991}$ & $0.87360^{100)}$ & 0.1 & 34.5 & 8.2 \\
\hline Cyclohexane & & $6.544^{11}$ & $80.725^{11}$ & $2.023^{\prime \prime}$ & $0.898^{11}$ & $0.77374^{102)}$ & & 31.2 & \\
\hline
\end{tabular}


Table A-II. Radii of ions $X_{i}$ and distance parameters $s$

\begin{tabular}{|c|c|c|c|c|c|c|c|c|c|c|c|}
\hline Ion & $\frac{a_{i}}{n m}$ & Ion & $\frac{a_{i}}{n m}$ & Ion & $\frac{a_{i}}{n m}$ & Ion & $\frac{a_{i}}{n m}$ & Ion & $\frac{a_{i}}{n m} 1211$ & solvent & $\frac{\mathrm{s}}{\mathrm{nm}}^{(24)}$ \\
\hline $\begin{array}{l}\mathrm{Li}^{+} \\
\mathrm{Na}^{+} \\
\mathrm{K}^{+} \\
\mathrm{Rb}^{+} \\
\mathrm{Cs}^{+} \\
\mathrm{Cu}^{+} \\
\mathrm{Ag}^{+} \\
\mathrm{NH}_{4}^{+}\end{array}$ & $\begin{array}{l}(0.078) \\
0.098 \\
0.133 \\
0.149 \\
0.165 \\
0.095 \\
0.113 \\
0.137^{121)}\end{array}$ & $\begin{array}{l}\mathrm{Be}^{2+} \\
\mathrm{Mg}^{2+} \\
\mathrm{Ca}^{2+} \\
\mathrm{Sr}^{2+} \\
\mathrm{Ba}^{2+} \\
\mathrm{Zn}^{2+} \\
\mathrm{Cd}^{2+} \\
\mathrm{Hg}^{2+} \\
\mathrm{Pb}^{2+} \\
\mathrm{Mn}^{2+} \\
\mathrm{Co}^{2+} \\
\mathrm{Ni}^{2+} \\
\mathrm{Cu}^{2+}\end{array}$ & $\begin{array}{l}(0.034) \\
0.078 \\
0.106 \\
0.127 \\
0.143 \\
0.069 \\
0.103 \\
0.093 \\
0.117 \\
0.091 \\
0.082 \\
0.068 \\
0.072\end{array}$ & $\begin{array}{l}\mathrm{Me}_{4} \mathbf{N}^{+} \\
\mathrm{Me}_{2} \mathbf{R}_{2} \mathrm{~N}^{+} \\
\mathrm{Et}_{4} \mathbf{N}^{+} \\
\mathrm{Pr}_{4} \mathbf{N}^{+} \\
\mathrm{n}-\mathrm{Bu}_{4} \mathbf{N}^{+} \\
\mathrm{n}-\mathrm{Am}_{4} \mathbf{N}^{+} \\
\mathrm{AsPh}_{4}^{+}\end{array}$ & $\begin{array}{c}0.347^{116)} \\
0.347^{116)} \\
0.400^{116} \\
0.452^{116)} \\
0.494^{116)} \\
0.529^{116} \\
(0.42)^{118}\end{array}$ & $\begin{array}{l}\mathrm{F}^{-} \\
\mathrm{Cl}^{-} \\
\mathrm{Br}^{-} \\
\mathrm{I}^{-} \\
\mathrm{BF}_{4}^{-} \\
\mathrm{CO}_{4}^{-} \\
\mathrm{CN}^{-} \\
\mathrm{OH}^{-} \\
\mathrm{BPh}_{4}^{-}\end{array}$ & $\begin{array}{l}0.133 \\
0.181^{\prime} \\
0.196^{2} \\
0.220 \\
0.232^{121)} \\
0.240^{121)} \\
0.191^{121)} \\
0.133^{121} \text { ) } \\
0.48^{124)}\end{array}$ & $\begin{array}{l}\mathrm{CO}_{3}^{2-}- \\
\mathrm{CrO}_{4}^{2-} \\
\mathrm{SO}_{4}^{2-} \\
\mathrm{SeO}_{4}^{2-} \\
\mathrm{SiF}_{6}^{2-}\end{array}$ & $\begin{array}{l}0.178 \\
0.256 \\
0.258 \\
0.249 \\
0.259\end{array}$ & \begin{tabular}{l}
$\mathrm{OH}_{2}$ \\
$\mathrm{MeOH}$ \\
EtOH \\
PrOH \\
$\mathrm{AN}$ \\
$\mathrm{PC}$ \\
$\mathrm{NM}$ \\
$\mathrm{NB}$ \\
$(: \mathrm{OH})$ \\
\multicolumn{1}{l}{$\quad$}
\end{tabular} & $\begin{array}{l}0.28 \\
0.47 \\
0.57 \\
0.69 \\
0.58 \\
0.65 \\
0.52 \\
0.77 \\
0.28\end{array}$ \\
\hline
\end{tabular}


Josef Barthel et al.

If more than one reliable value was found in the recent literature the table contains their mean value; the number of decimal places indicates their agreement. In the case that no recent determination of data was found which is based on thoroughly purified solvents and established precision methods we preferred to quote the data from Ref. "). The compilation corresponds to the actual state of the ELDAR data bank ${ }^{115}$ ). It may also be helpful in finding new purification methods, new precise measuring equipment and new precision methods for the determination of data.

\section{A.2 Ion Distance Parameters}

The chemical model, Section 4.2., when used to provide data of electrolyte solutions by computer-assisted methods, presupposes the knowledge of the distance parameters a and $\mathbf{R}$. These are needed in the appropriate equations as the characteristic distances of the bare or solvated single ions and of the adjacent solvent molecules. Solvent molecules may be orientated either by free electrons, by $\mathrm{H}$-bonds or by their dipole moments, depending on the nature of the ions and the solvent molecule itself.

Ionic radii depend on the method of their determination. Various systems can be found and are compared in the literature, cf. ${ }^{116-123)}$ and literature quoted there. Table A-II shows a selection of values which have proved to be compatible with one another ${ }^{115,124)}$. Goldschmidt's ionic radii were taken when not indicated otherwise. The distances s due to solvent molecules were calculated from bond lengths, bond angles and van der Waals volumes of functional groups ${ }^{125,126)}$. For their use in the chemical model see Section 4.2., cf. also Ref. ${ }^{124)}$.

\section{B Electrostatic Potential around a Particle with an Arbitrary Charge Distribution}

The electrostatic potential around a particle $\mathrm{i}$, ion or molecule, in solution is obtained by the resolution of a system of differential equation, e.g.

$$
\begin{array}{lll}
\nabla^{2} \psi_{i}^{(1)}(\mathrm{r}, \theta, \varphi)=0 & \mathrm{a} \leqq \mathrm{r} \leqq \mathrm{R}_{1} & (\mathrm{~B}-1 \mathrm{a}) \\
\nabla^{2} \psi_{\mathrm{i}}^{(2)}(\mathrm{r}, \theta, \varphi)=0 & \mathrm{R}_{1} \leqq \mathrm{r} \leqq \mathrm{R}_{2} & (\mathrm{~B}-1 \mathrm{~b}) \\
\nabla^{2} \psi_{\mathrm{i}}^{(3)}(\mathrm{r}, \theta, \varphi)=-\frac{\mathrm{Q}^{(3)}(\mathrm{r}, \theta, \varphi)}{\varepsilon_{0} \varepsilon} & \mathrm{R}_{2} \leqq \mathrm{r} \leqq \infty & (\mathrm{B}-1 \mathrm{c})
\end{array}
$$

if the space around the appropriate charge distribution of the ion or molecule, situated in a sphere of radius a, is subdivided into three parts:

region (1): $a \leqq r \leqq R_{1}$. relative permittivity $\varepsilon_{1}$ and free of single charges (ions), i.c. $e^{(1)}(r, 0, \varphi)=0$. 
region (2): $R_{1} \leqq r \leqq R_{2}$, relative permittivity $\varepsilon_{2}$ and free of single charges (ions), $\mathrm{Q}^{(2)}(\mathrm{r}, \theta, \varphi)=0$,

region (3): $\mathrm{R}_{2} \leqq \mathrm{r} \leqq \infty$, relative permittivity $\varepsilon$ of the bulk solution and charge density $\mathrm{Q}^{(3)}(\mathrm{r}, \theta, \varphi)=-\varepsilon_{0} \varepsilon \mathcal{X}^{2} \psi_{i}^{(3)}(\mathrm{r}, \theta, \varphi)$ [for $x$ see table II]

The appropriate boundary conditions for Eqs. (1) are

$$
\begin{array}{lll}
\lim _{R_{1} \rightarrow \infty} \psi_{i}^{(1)}=\psi_{i}^{(0)}(r, \theta, \varphi) & (\mathrm{B}-2 \mathrm{a}) & \psi_{i}^{(2)}\left(\mathrm{R}_{2}\right)=\psi_{i}^{(3)}\left(\mathrm{R}_{2}\right) \\
\psi_{i}^{(1)}\left(\mathrm{R}_{1}\right)=\psi_{i}^{(2)}\left(\mathrm{R}_{1}\right) & (\mathrm{B}-2 \mathrm{~b}) & \varepsilon_{2}\left(\frac{\partial \psi_{i}^{(2)}}{\partial r}\right)_{\mathrm{R}_{2}}=\varepsilon\left(\frac{\partial \psi_{i}^{(3)}}{\partial r}\right)_{R_{2}} \\
\varepsilon_{1}\left(\frac{\partial \psi_{i}^{(1)}}{\partial r}\right)_{R_{1}}=\varepsilon_{2}\left(\frac{\partial \psi_{i}^{(2)}}{\partial r}\right)_{R_{1}}(\mathrm{~B}-2 \mathrm{c}) & \lim _{\mathrm{r} \rightarrow \infty} \psi_{i}^{(3)}=0
\end{array}
$$

where $\psi_{i}^{(0)}(r, \theta, \varphi)$ means the potential of the isolated molecular or ionic charge distribution, which is placed in a homogeneous and isotropic medium of relative permittivity $\varepsilon_{1}$, in terms of Legendre polynomials

$$
\begin{aligned}
& \psi_{i}^{(0)}=\sum_{j=0}^{\infty} \sum_{m=-j}^{m=+j} b_{j}^{(m)} \times \frac{1}{r^{j+1}} \times P_{j}^{(m)}(\cos \theta)^{i m \varphi} \\
& b_{j}^{(m)}=\frac{1}{4 \pi \varepsilon_{0} \varepsilon_{1}} b_{j}^{\prime(m)} .
\end{aligned}
$$

The coefficients $b_{j}^{(m)}$ are calculated from bond lengths, bond angles and charges of the ion or molecule, cf. Ref. ${ }^{128}$. The system of differential equations is resolved by usual methods yielding ${ }^{127}$ )

$$
\begin{aligned}
& \psi_{i}^{(1)}(r, \theta, \varphi)=\sum_{j=0}^{\infty} \sum_{m=-j}^{m=+j}\left[A_{j}^{(m)} \times r^{j}+B_{j}^{(m)} \times \frac{1}{r^{j+1}}\right] \times P_{j}^{(m)}(\cos \theta) \times e^{i m \varphi} \\
& \psi_{i}^{(2)}(r, \theta, \varphi)=\sum_{j=0}^{\infty} \sum_{m=-j}^{m=+j}\left[C_{j}^{(m)} \times r^{j}+D_{j}^{(m)} \times \frac{1}{r^{j+1}}\right] \times P_{j}^{(m)}(\cos \theta) \times e^{i m \varphi} \\
& \psi_{i}^{(3)}(r, \theta, \varphi)=\sum_{j=0}^{\infty} \sum_{m=-j}^{m=+j}\left[E_{j}^{(m)} \times e^{x r} \sum_{n=0}^{j} \frac{\alpha_{n}^{(j)}}{r^{n+1}}+F_{j}^{(m)} \times e^{-x r} \sum_{n=0}^{j} \frac{\beta_{n}^{(j)}}{r^{n+1}}\right] \times \\
& \times P_{j}^{(m)}(\cos \theta) \times e^{i m \varphi}
\end{aligned}
$$

with the coefficients $\alpha_{n}^{(j)}$ and $\beta_{n}^{(j)}$ of Eq. (4c) oblained from the recursion formulac

$$
\begin{array}{ll}
{[n(n+1)-j(j+1)] \alpha_{n}^{(j)}-2 x(n+1) \alpha_{n+1}^{(j)}=0 ;} & \alpha_{0}^{(j)}=1 \\
{[n(n+1)-j(j+1)] \beta_{n}^{(j)}+2 x(n+1) \beta_{n+1}^{(j)}=0 ;} & \beta_{0}^{(j)}=1
\end{array}
$$


Josef Barthel et al.

Combining Eqs. (3), (4) and (5) gives

$$
\begin{aligned}
& A_{j}^{(m)}=-\frac{(j+1)(1-\eta) X_{j}-[j(1+\eta)+\eta] Q^{2 j+1} Y_{j}}{[j(1+\eta)+1] X_{j}-j(1-\eta) Q^{2 j+1} Y_{j}} \times \frac{1}{R_{1}^{2 j+1}} \times b_{j}^{(m)} \\
& B_{j}^{(m)}=b_{j}^{(m)} \\
& C_{j}^{(m)}=\frac{\eta(B-6 a)}{[j(1+\eta)+1] X_{j}-j(1-\eta) Q^{2 j+1} Y_{j}} \times \frac{1}{R_{2}^{2 j+1}} \times b_{j}^{(m)} \\
& D_{j}^{(m)}=\frac{\eta(2 j+1) X_{j}}{[j(1+\eta)+1] X_{j}-j(1-\eta) Q^{2 j+1} Y_{j}} \times b_{j}^{(m)} \\
& E_{j}^{(m)}=0 \\
& F_{j}^{(m)}=\frac{\eta(2 j+1)^{2} \times \exp \left(x R_{2}\right)}{[j(1+\eta)+1] X_{j}-j(1-\eta) Q^{2 j+1} Y_{j}} \times b_{j}^{(m)}
\end{aligned}
$$

with $\eta=\left(\varepsilon_{1} / \varepsilon_{2}\right)$ and $Q=\left(R_{1} / R_{2}\right)$. The $X_{j}$ and $Y_{j}$ are polynomials

$$
\begin{aligned}
& X_{j}=\sum_{n=0}^{j}\left[\frac{\varepsilon}{\varepsilon_{2}}\left(1+n+x R_{2}\right)+j\right] R_{2}^{j-n} \beta_{n}^{(j)} \\
& Y_{j}=-\sum_{n=0}^{j}\left[\frac{\varepsilon}{\varepsilon_{2}}\left(1+n+x R_{2}\right)-(j+1)\right] R_{2}^{j-n} \beta_{n}^{(j)}
\end{aligned}
$$

A tabular survey for $\mathrm{j}=0$ to $\mathrm{j}=3$ is given in tables B-I and B-II

Table B-I: Polynomials $\mathrm{X}_{\mathrm{j}}$

$$
\begin{aligned}
\varepsilon_{2} X_{0} & =\varepsilon\left(1+x R_{2}\right) \\
x \varepsilon_{2} X_{1} & =\varepsilon\left(2+2 x R_{2}+x^{2} R_{2}^{2}\right)+\varepsilon_{2}\left(1+x R_{2}\right) \\
x^{2} \varepsilon_{2} X_{2} & =\varepsilon\left(9+9 x R_{2}+4 x^{2} R_{2}^{2}+x^{3} R_{2}^{3}\right)+2 \varepsilon_{2}\left(3+3 x R_{2}+x^{2} R_{2}^{2}\right)
\end{aligned}
$$

Table B-II : Polynomials $Y_{j}$

$$
\begin{aligned}
\varepsilon_{2} Y_{0} & =-\varepsilon\left(1+x R_{2}\right)+\varepsilon_{2} \\
x \varepsilon_{2} Y_{1} & =-\varepsilon\left(2+2 x R_{2}+x^{2} R_{2}^{2}\right)+2 \varepsilon_{2}\left(1+x R_{2}\right) \\
x^{2} \varepsilon_{2} Y_{2} & =-\varepsilon\left(9+9 x R_{2}+4 x^{2} R_{2}^{2}+x^{3} R_{2}^{3}\right)+3 \varepsilon_{2}\left(3+3 x R_{2}+x^{2} R_{2}^{2}\right)
\end{aligned}
$$


The electrostatic parts $W_{i j}^{e 1}(r)$ of the ion-ion interaction potentials in Table II

$$
W_{i j}^{e l}=e_{0} z_{j} \psi_{i}^{(2)} \quad(a \leqq r \leqq R) \quad \text { and } \quad W_{i j}^{e l}=e_{0} z_{j} \psi_{i}^{(3)} \quad(r \geqq R)
$$

are obtained by setting

$\mathrm{b}_{j}^{\prime(m)}=\mathrm{b}_{0}^{\prime(0)}=\mathrm{e}_{0} \mathrm{z}_{\mathrm{i}}$ (spherical charge symmetry of the ion i). Local permittivities are not considered $\left(\varepsilon_{1}=\varepsilon_{2}=\varepsilon\right)$ and $R_{1}=R_{2}=R$, i.e. $\psi_{i}^{(1)}=\psi_{i}^{(2)}$.

The kinetic solvent effect, Section VIII, presupposes vanishing ional concentrations $\left(R_{2} \rightarrow \infty ; \varepsilon_{2}=\varepsilon\right)$. The parameter $R_{1}$ is the distance of the reactants, $i$ and $j$, in the activated complex $\left(R_{1}=r_{0}\right) ; \varepsilon_{1}=1$ for a non-polarisable particle. The use of first order approximations, i.e. single charge $\left(b_{j}^{(m)}=b_{0}^{\prime(0)}=e_{0} z_{i}\right)$ or point dipole $\left(b_{j}^{\prime(m)}=b_{1}^{\prime(0)}=\mu_{j}\right)$, for the ion or polar molecule, respectively, yields the Equations (51) and (52) of Section 8.2.

\section{Electrostatic Potential around a Polarisable Apolar Particle}

A polarisable apolar molecule can be represented by a dielectric sphere of radius a and relative permittivity $\varepsilon_{i}$ bearing no charge distribution which can produce singularities for $\mathrm{r} \leqq \mathrm{a}$. An ion or polar molecule situated in the vicinity of this sphere give rise to an induced dipole moment in and hence to an electrostatic field around the dielectric sphere. The solvent around the apolar molecule is considered as a homogeneous medium of relative permittivity $\varepsilon$.

The appropriate potential equations are

$$
\begin{aligned}
& \psi_{i}^{(1)}=\sum_{j=0}^{\infty} \sum_{m=-j}^{m=+j}\left[A_{j}^{(m)} \times r^{j}+B_{j}^{(m)} \times \frac{1}{r^{j+1}}\right] \times P_{j}^{(m)}(\cos \theta) \times e^{i m \varphi} \quad r \leqq a \\
& \psi_{i}^{(2)}=\sum_{j=0}^{\infty} \sum_{m=-j}^{m=+j}\left[C_{j}^{(m)} \times r^{j}+D_{j}^{(m)} \times \frac{1}{r^{j+1}}\right] \times P_{j}^{(m)}(\cos \theta) \times e^{i m \varphi} \quad r \geqq a .
\end{aligned}
$$

with the boundary conditions ${ }^{129}$

$$
\begin{array}{lll}
\lim _{r \rightarrow 0} \psi_{i}^{(1)}=\text { finite } & (\mathrm{C}-2 \mathrm{a}) & \varepsilon_{\mathrm{i}}\left(\frac{\partial \psi_{i}^{(1)}}{\partial \mathrm{r}}\right)_{\mathrm{a}}=\varepsilon\left(\frac{\partial \psi_{i}^{(2)}}{\partial \mathrm{r}}\right)_{a} \\
\psi_{i}^{(1)}(\mathrm{a})=\psi_{i}^{(2)}(\mathrm{a}) & \text { (C-2 b) } \quad \lim _{\mathrm{r} \rightarrow \infty} \varphi_{i}^{(2)}=0
\end{array}
$$

with

$$
\begin{aligned}
& \varphi_{i}^{(2)}(P)=\psi_{i}^{(2)}(P) \cdots \psi^{(0)}(P) \\
& \psi^{(0)}(P)=\sum_{j=0}^{\infty} \sum_{m=-j}^{m=+j} C_{j}^{(m)} \times r^{j} \times P_{j}^{(m)}(\cos \theta) \times e^{i m \varphi}
\end{aligned}
$$


Josef Barthel et al.

$\psi^{(0)}(\mathrm{P})$ is that potential which would exist at point $\mathrm{P}(\mathrm{r}, \theta, \varphi)$ if the dielectric sphere of relative permittivity $\varepsilon_{\mathrm{i}}$ would be replaced by the dielectric medium of relative permittivity $\varepsilon$

A single charge (ion) situated at a distance $d$ from the center of the dielectric sphere yields a potential

$$
\psi^{(0)}(P)=\frac{e_{0}}{4 \pi \varepsilon_{0} \varepsilon} \sum_{j=0}^{\infty} \frac{r^{j}}{d^{j+1}} P_{j}(\cos \theta)
$$

This special case is the basic model of Section 7.2. for the reaction between halides and olefines. The appropriate potentials are

$$
\begin{aligned}
& \psi_{i}^{(1)}=\frac{e_{0}}{4 \pi \varepsilon_{0} \varepsilon} \sum_{j=0}^{\infty} \frac{(2 j+1) \varepsilon}{(j+1) \varepsilon+j \varepsilon_{i}} \frac{r^{j}}{d^{j+1}} P_{j}(\cos \theta) \quad r \leqq a \\
& \psi_{i}^{(2)}=\frac{e_{0}}{4 \pi \varepsilon_{0} \varepsilon} \sum_{j=0}^{\infty}\left[\frac{r^{j}}{d^{j+1}}+\frac{\left(\varepsilon-\varepsilon_{i}\right) j}{(j+1) \varepsilon+j \varepsilon_{i}} \times \frac{a^{2 j+1}}{(r \times d)^{j+1}}\right] P_{j}(\cos \theta) \quad r \geqq a
\end{aligned}
$$

From Eqs. (C-4) and (C-5) the following field and dielectric displacement vectors are obtained

$$
\vec{E}_{1}^{(0)}=-\operatorname{grad} \psi^{(0)} ; \quad \vec{D}_{1}^{(0)}=\varepsilon_{0} \varepsilon \vec{E}_{1}^{(0)} \quad 0 \leqq r \leqq \infty
$$

and

$$
\begin{array}{lll}
\overrightarrow{\mathrm{E}}_{2}^{(1)}=-\operatorname{grad} \psi_{\mathrm{i}}^{(1)} ; & \overrightarrow{\mathrm{D}}_{2}^{(1)}=\varepsilon_{0} \varepsilon_{\mathrm{i}} \overrightarrow{\mathrm{E}}_{2}^{(1)} & 0 \leqq \mathrm{r} \leqq \mathrm{a} \\
\overrightarrow{\mathrm{E}}_{2}^{(2)}=-\operatorname{grad} \psi_{\mathrm{i}}^{(2)} ; & \overrightarrow{\mathrm{D}}_{2}^{(2)}=\varepsilon_{0} \varepsilon \overrightarrow{\mathrm{E}}_{2}^{(2)} & \mathrm{a} \leqq \mathrm{r} \leqq \infty
\end{array}
$$

Eq. (C-6) represents the situation before and Eqs. (C-7) after the dielectric sphere is brought from infinite distance to a distance $d$ from the ion. Hence, the energy for building the latter configuration is

$$
\Delta G=\frac{N_{A}}{2} \iiint\left(\vec{E}_{2} \vec{D}_{2}-\vec{E}_{1} \vec{D}_{1}\right) d V
$$

Eq. $(C-8)$ can be transformed ${ }^{129)}$ to give

$$
\begin{aligned}
\Delta G & =N_{A} \frac{\varepsilon-\varepsilon_{i}}{2} \iiint \vec{E}_{1} \vec{E}_{2} d V \\
& =N_{A} c_{10}^{2} \times \frac{\varepsilon-\varepsilon_{i}}{8 \pi \varepsilon_{0} \varepsilon} \times \frac{1}{d} \sum_{j=0}^{\infty} \frac{j}{(j+1) \varepsilon+j \varepsilon_{i}}\left(\frac{d}{d}\right)^{2 j+1} .
\end{aligned}
$$

Eq. $(C-9)$ is an ill converging series if $d \approx a$ as it is required for building the activated complex of the reaction between an apolar molecule and an ion. 


\section{Symbols and Abbreviations}

\section{D.1 Fundamental Constants ${ }^{131)}$}
$\mathrm{N}_{\mathrm{A}}$ : Avogadro constant
$(6.022045 \pm 0.000031) \times 10^{23} \mathrm{~mol}^{-1}$
F: Faraday constant
$(9.648456 \pm 0.000027) \times 10^{4} \mathrm{C} \mathrm{mol}^{-1}$
h: Planck constant
$(6.626176 \pm 0.000036) \times 10^{-34} \mathrm{~J} \mathrm{~s}$
k: Boltzmann constant
$(1.380662 \pm 0.000044) \times 10^{-23} \mathrm{~J} \mathrm{~K}^{-1}$
$\mathrm{e}_{0}$ : charge of proton
$(1.602189 \pm 0.000005) \times 10^{-19} \mathrm{C}$
$\varepsilon_{0}$ : permittivity of vacuum
$(8.854188 \pm 0.000000) \times 10^{-12} \mathrm{~J}^{-1} \mathrm{C}^{2} \mathrm{~m}^{-1}$

\section{D.2 Generally Used Superscripts and Subcripts}

\section{D.2.1 Superscripts}

\begin{tabular}{|c|c|}
\hline $\begin{array}{l}\text { pure substance also: non- } \\
\text { Coulombic part of a quantity } \\
\text { infinite dilution } \\
\text { standard } \\
\text { reference solvent } \\
\text { (Section VIII) } \\
\text { solvent S (Section VIII) }\end{array}$ & $\begin{array}{l}\text { *: activated complex } \\
\text { el: Coulombic part of a quantity } \\
\text { free particles } \\
\text { also: final state (Section V) } \\
\text { (c): molar scale } \\
\text { (m): molal scale } \\
\text { (i): component i }\end{array}$ \\
\hline
\end{tabular}

\section{D.2.2 Subscripts}

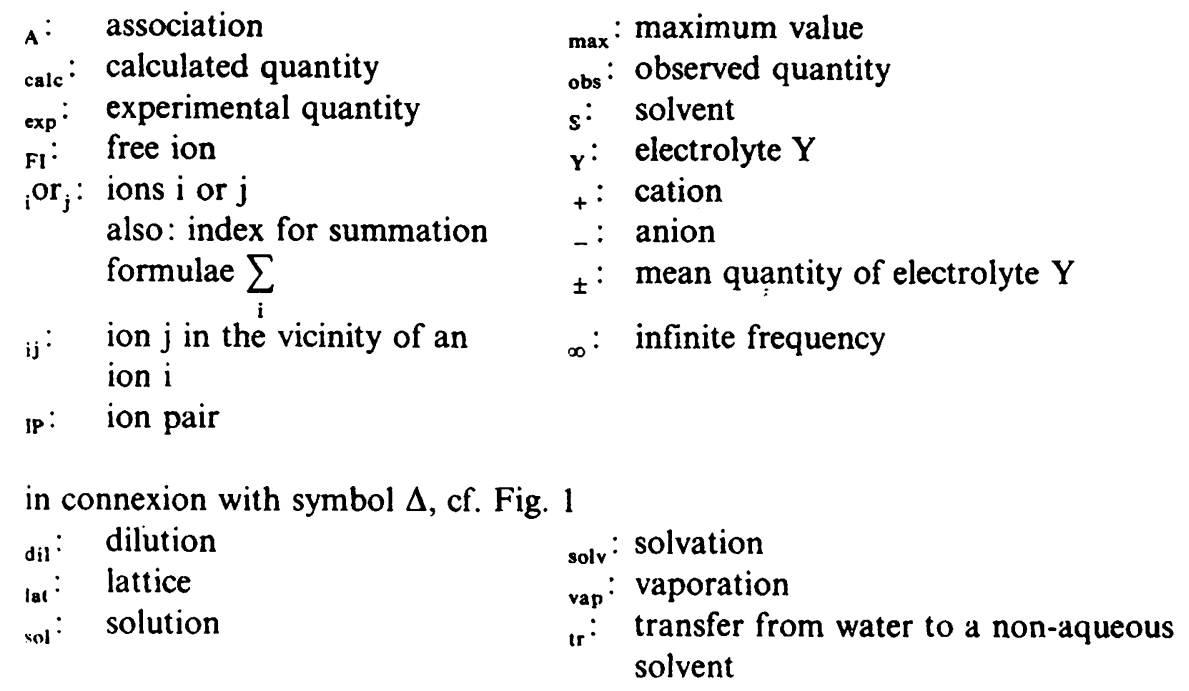


Josef Barthel et al.

\section{D.3 Symbols}

* means a superscript or subscript, see Section D.2.

$\mathrm{a}, \mathrm{a}_{*}$ : $\quad$ ion size parameter

$c, c_{*}, c^{*}: \quad$ molarity $\left[\mathrm{mol} \mathrm{dm}^{-3}\right]$

$\mathrm{E}, \mathrm{E}^{*}$ : $\quad$ property (general) of an electrolyte solution (Sect. V)

$f, f_{s}$ also: e.m.f (Sect. V)

$\mathrm{f}_{\mathrm{ij}}, \mathrm{f}_{\mathrm{ji}}$ : two-particle distribution function

$\mathrm{g}_{\mathrm{ij}}, \mathrm{g}_{\mathrm{ji}}$ : pair-correlation function

$\Delta \mathrm{G}_{*}, \Delta \mathrm{G}^{*}, \Delta_{*} \mathrm{G}:$ Gibbs energy

$\Delta \mathrm{H}_{*}^{*}, \Delta \mathrm{H}^{*}, \Delta_{*}^{*} \mathrm{H}$ : enthalpy

$\mathrm{K}, \mathrm{K}_{*}$ :

equilibrium constant

$\mathrm{k}, \mathrm{k}_{*}, \mathrm{k}^{*}$ :

$\mathrm{m}, \mathrm{m}_{*}, \mathrm{~m}^{*}$ :

rate constant, exception see D.1

molality [mol kg-1]

also: mass of particle (Sect. IV)

$\mathrm{M}$ : $\quad \mathrm{mol} \mathrm{dm}^{-3}$

$\mathrm{n}_{\mathbf{s}}, \mathrm{n}_{\mathrm{Y}}: \quad$ amount of substance (number of moles)

$\mathrm{N}_{*}$ : $\quad$ particle density [particles per $\mathrm{cm}^{-3}$ ], exception see D.1

p: $\quad$ pressure

q: $\quad$ Bjerrum parameter, see Eq. (19b)

$\mathrm{R}, \mathrm{R}_{*}$ : $\quad$ distance parameter, see Figs. 2 and 3

$R \quad$ also: gas constant

$\mathrm{r}, \mathrm{r}_{*}, \overrightarrow{\mathrm{r}}, \overrightarrow{\mathrm{r}}_{*}: \quad$ distance variable

$\Delta \mathrm{S}^{*}, \Delta \mathrm{S}_{*}, \Delta_{*} \mathrm{~S}: \quad$ entropy

$\mathrm{t}_{*}, \mathrm{t}^{*}:$ transference number

$\mathrm{t}^{*}$ also: time

$\mathrm{T}, \mathrm{T}_{*}: \quad$ temperature $[\mathrm{K}]$

$\mathrm{V}, \Delta \mathrm{V}^{*}, \Delta \mathrm{V}_{*}: \quad$ volume

$\mathrm{W}_{*}, \mathrm{~W}^{*}$ : $\quad$ mean-force potential

$\mathrm{x}, \mathrm{x}_{*}, \mathrm{x}^{*}$ : $\quad$ mole fraction

$y, y_{*}, y^{*}: \quad$ activity coefficient (molar scale)

$\mathrm{z}, \mathrm{z}_{*}: \quad$ valency

$\mathrm{Z}, \mathrm{Z}_{*}, \mathrm{Z}^{*}, \Delta \mathrm{Z}_{*}, \Delta \mathrm{Z}^{*}, \Delta_{*} \mathrm{Z}$ : thermodynamic property (general), see Fig. 1

$\alpha$ : degree of dissociation

$(1-\alpha)$ : degree of association

$\bar{\alpha}: \quad \quad$ cubic expansion coefficient (Section V)

$\gamma_{*}, \gamma^{*}: \quad$ activity coefficient (molal scale)

${ }_{m} \gamma_{*}: \quad$ transfer activity coefficient

$\Gamma: \quad$ ional concentration, see Table II

$\delta, \delta_{*}: \quad$ chemical shift

$\varepsilon, \varepsilon_{*}, \varepsilon^{*}: \quad$ relative permittivity, exception see D.1

$\eta:$

$\theta, \theta_{*}$ :

$x$ :

viscosity

temperature $\left[{ }^{\circ} \mathrm{C}\right]$

$x, x_{*}:$

Debye parameter, see Table II

$\Lambda, \Lambda^{*}$ :

also: electrolytic conductivity $\left[\Omega^{-1} \mathrm{~cm}^{-1}\right]$

equivalent conductance $\left[\Omega^{-1} \mathrm{~mol}^{-1} \mathrm{~cm}^{2}\right]$ 
$\lambda_{*}, \lambda^{*}: \quad$ single ion conductance $\left[\Omega^{-1} \mathrm{~mol}^{-1} \mathrm{~cm}^{2}\right]$

$\mu_{*}, \mu^{*}: \quad$ chemical potential

$v_{\mathrm{i}} v_{\mathrm{i}}^{\mathrm{m}}: \quad$ stoichiometric number

$\mathrm{Q}: \quad$ density $\left[\mathrm{g} \mathrm{cm}^{-3}\right]$

$\omega$ : $\quad$ circular frequency

Remark: Symbols used only at single places with special meaning, which may also deviate from the meaning of the above list, are explained in the text.

\section{References (Part A and B)}

1. Parker, A. J.: Electrochim. Acta 2l, 671 (1976)

2. Friedman, H. L.: Faraday Discuss. Chem. Soc. 64, 7 (1977)

3. Barthel, J.: Ber. Bunsenges. Phys. Chem. 83, 252 (1979)

4. Barthel, J.: Pure Appl. Chem. 51, 2093 (1979)

5. Bjerrum, N.: Math.-Fys. Medd. Kon. Dan. Vidensk. Selsk. 7,1 (1926)

6. Kosower, E. M.: J. Amer. Chem. Soc. 80, 3253 (1958)

7. Kosower, E. M.: J. Chim. Phys. Phys.-Chim. Biol. 6I, 230 (1964)

8. Dimroth, K., Reichardt, C., Siepmann, T. and Bohlmann, F.: Liebigs Ann. Chem. 66I, 1 (1963)

9. Reichardt, C.: Solvent Effects in Organic Chemistry, Weinheim: Verlag Chemie 1979

10. Gutmann, V. and Wychera, E.: Inorg. Nucl. Chem. Lett. 2, 257 (1966)

11. Gutmann, V.: The Donor-Acceptor Approach to Molecular Interactions, New York: Plenum 1978

12. Grunwald, E. and Winstein, S.: J. Amer. Chem. Soc. 70, 846 (1948)

13. Gielen, M. and Nasielsky, J.: J. Organomet. Chem. 1, 173 (1963)

14. Gielen, M. and Nasielsky, J.: J. Organomet. Chem. 7, 273 (1967)

15. Mayer, U., Gutmann, V. and Gerger, W.: Monatsh. Chem. 106, 1235 (1975)

16. Mayer, U.: Coord. Chem. Rev. 21, 159 (1976)

17. Berson, J. A., Hamlet, Z. and Mueller, W. A.: J. Amer. Chem. Soc. 84, 297 (1962)

18. Reichardt. C.: Angew. Chem. 77, 30 (1965)

19. Burgess, J.: Metal Ions in Solution, Chichester: Ellis Horwood 1978

20. Dack, M. R. J. in: Dack, M. R. J. (ed.): Techniques of Chemistry, Vol. 8, Solutions and Solubilities (Part I1), p. 95, New York: Wiley 1976

21. Jensen, W. B.: The Lewis Acid-Base Concepts, New York: Wiley 1980

22. Debye, P. and Hückel, E.: Phys. Z. 24, 185 (1923)

23. Pimentel, G. C. and McClellan, A. L.: The Hydrogen Bond, San Francisco: Freeman 1960

24. Craver, J. K.: J. Appl. Polym. Sci. 14, 1755 (1970)

25. Godfrey, N. B. : Chem. Techn. 1972, 359

26. Kolthoff, I. M. in: Marchon, J. C. (ed.): Non Aqueous Electrochemistry, p. 312, London: Butterworths 1971

27. Bates, R. G. in: Coetzee, J. F. and Ritchie, C. D. (eds.): Solute-Solvent Interactions, Vol. 1, p. 45. New York: Dekker 1969

28. Kratochvil. B.: Rec. Chem. Prog. 27, 253 (1966)

29. Brönsted. J. N.: Chem. Ber. 61, 2049 (1928)

30. Fuoss, R. M. and Accascina, F.: Electrolytic Conductance, New Yurh: Interscience 1959

31. Kortüm. (i.: Lehrbuch der Elektrochemie (4th ed.) Weinheim: Verlag Chemic 1966 
Josef Barthel et al.

32. Kolthoff, I. M. and Bruckenstein, S.: J. Amer. Chem. Soc. 78, 1 (1956)

33. Bruckenstein, S. and Kolthoff, I. M.: J. Amer. Chem. Soc. 78, 10 (1956)

34. Bruckenstein, S. and Kolthoff, I. M.: J. Amer. Chem. Soc. 78, 2974 (1956)

35. Hantzsch, A.: Z. Phys. Chem. A134, 406 (1928)

36. Barthel, J.: Ionen in nichtwäBrigen Lösungen, Darmstadt: Steinkopff 1976

37. Staveley, L. A. K. (ed.): The Characterization of Chemical Purity. Organic Compounds, London: Butterworths 1971

38. Zief, M. (ed.): Purification of Inorganic and Organic Materials, New York: Dekker 1969

39. Zief, M. and Speights, R. (eds.): Ultrapurity Methods and Techniques, New York: Dekker 1972

40. Perrin, D. D., Armarego, W. L. F. and Perrin, D. R.: Purification of Laboratory Chemicals (2nd ed), Oxford: Pergamon 1980

41. Mann, C. K. in: Bard, A. J. (ed.): Electroanalytical Chemistry, Vol. 3, New York: Dekker 1969

42. Riddick, J. A. and Bunger, W. B. in: Weissberger, A. (ed.): Techniques of Chemistry, Vol. 2 (3rd ed.): Organic Solvents, New York: Wiley 1970

43. Kirkwood, J. G. and Oppenheim, I.: Chemical Thermodynamics, New York: McGraw-Hill 1961

44. Robinson, R. A. and Stokes, R. H.: Electrolyte Solutions (2nd ed.), London: Butterworths 1970

45. Onsager, L.: Phys. Z. 28, 277 (1927)

46. Falkenhagen, H.: Theorie der Elektrolyte (2nd ed.), Stuttgart: S. Hirzel 1971

47. Harned, H. S. and Owen, B. B.: The Physical Chemistry of Electrolytic Solutions (3rd ed.), New York: Reinhold 1958

48. Résibois, P. M. V.: Electrolyte Theory, New York: Harper and Row 1968

49. Friedman, H. L.: Ionic Solution Theory, New York: Interscience 1962

50. Petrucci, S. (ed.): Ionic Interactions, Vol. 1, Vol. 2, New York: Academic Press 1971

51. Kelbg, G.: Z. Phys. Chem. (Leipzig) 214, 8 (1960)

52. Falkenhagen, H. and Ebeling, W. in: Ref. [50], Vol. 1, p. 1; Falkenhagen, H., Ebeling. W. and Kraeft, W. D. in: Ref. [50], Vol. 1, p. 61

53. Falkenhagen, H. and Kelbg, G. in: Bockris, J. O'M. (ed.): Modern Aspects of Electrochemistry, Vol. 2, p. 1, London: Butterworths 1959

54. Conway, B. E. and Barradas, R. G. (eds.): Chemical Physics of lonic Solutions, New York: Wiley 1966

55. Covington, A. K. and Dickinson, T. (eds.): Physical Chemistry of Organic Solvent Systems, London: Plenum 1973

56. Rasaiah, J. C. and Friedman, H. L.: J. Phys. Chem. 72, 3352 (1968); J. Chem. Phys. 50, 3965 (1969)

57. Rasaiah, J. C.: J. Chem. Phys. 52, 704 (1970); 56, 3071 (1972)

58. Rasaiah, J. C.: J. Solution Chem. 2, 301 (1973)

59. Friedman, H. L. and Larsen, B.: J. Chem. Phys. 70. 92 (1979)

60. Friedman, H. L.: Annu. Rev. Phys. Chem. 32, (1981)

61. Friedman, H. L.: Pure Appl. Chem. 53, 1277 (1981)

62. Fuoss, R. M.: Proc. Natl. Acad. Sci. USA 75, 16 (1978)

63. Ebeling, W. and Grigo, M.: Ann. Phys. (Leipzig) 36, 21 (1980)

64. Ebeling, W. and Künstner, H. (eds.): Theorie elektrolytischer Flüssigkeiten, Rostocker Physikalische Manuskripte, Heft 4, 1979

65. Justice, M.-C. and Justice, J.-C.: J. Solution Chem. 5, 543 (1976); 6, 819 (1977)

66. Justice, J.-C.: J. Solution Chem. 7, 859 (1978)

67. Justice, J.-C. and Ebeling, W.: J. Solution Chem. 8, 809 (1979)

68. Justice, J.-C. and Justice, M.-C.: Pure Appl. Chem. 51, 1681 (1979)

69. Justice. J.-C.. Justice, M.-C. and Micheletti, C.: Pure Appl. Chem. 53, 1291 (1981)

70. Herty, H. (i. : Electrohenistry. $\wedge$ Reformulation of the Basic Principles (1.ceture Notes in ('hemistry. Vol. 17) Heidelberg: Springer 1980

71. European Federation of Chemical Engineering (ed.): Phase Equilibria and Fluid Propertics in the Chemical Industry, Vol. 2, Frankfurt: DECHEMA 1980

72. Barthel, J.: in Ref. [71], p. 497

73. Onsager, L.: quoted after Ref. [52] 
74. Barthel, J.: Chem.-Ing.-Techn. 50, 259 (1978)

75. Barthel, J., Wachter, R. and Gores, H.-J.: Faraday Discuss. Chem. Soc. 64, 285 (1977)

76. Barthel, J., Wachter, R. and Gores, H.-J. in: Conway, B. E. and Bockris, J. O'M. (eds.): Modern Aspects of Electrochemistry, Vol. 13, p. 1, New York: Plenum 1979

77. Wachter, R. and Riederer, K.: Pure Appl. Chem. 53, 1301 (1981)

78. Barthel, J. and Schmeer, G. in: Bak, T. (ed.): Kemisk Forening 100 Års Jubilaeum: Kopenhagen (in press)

79. Wachter, R. and Barthel, J.: Ber. Bunsenges. Phys. Chem. 83, 634 (1979)

80. Barthel, J., Schmeer, G., Strasser, F. and Wachter, R.: Rev. Chim. Minérale 15, 99 (1978)

81. Schwitzgebel, G., Lührs, C. and Barthel, J.: Ber. Bunsenges. Phys. Chem. 84, 1220 (1980)

82. Barthel, J., Ströder, U., Iberl, L. and Hammer, H.: Ber. Bunsenges. Phys. Chem. 86, 636 (1982)

83. Barthel, J., Popp, H. and Schmeer, G.: Data Bank ELDAR (Electrolyte Data Bank Regensburg): DECHEMA project

84. Wachter, $R$. et al.: in preparation

85. Abraham, M. H., Danil de Namor, A. F. and Schulz, R. A.: J. Solution Chem. 6, 491 (1977)

86. Abraham, M. H., Danil de Namor, A. F. and Schulz, R. A.: J. Solution Chem. 5, 529 (1976)

87. Abraham, M. H.: J. Chem. Soc., Faraday Trans. 169,1375 (1973)

88. Wölbl, J.: Dissertation, Regensburg (1982)

89. Pasztor, A. J. and Criss, C. M.: J. Solution Chem. 7, 27 (1978)

90. Choi, Y.-S. and Criss, C. M.: Faraday Discuss. Chem. Soc. 64, 204 (1977)

91. Dack, M. R. J., Bird, K. J. and Parker, A. J.: Aust. J. Chem. 28, 955 (1975)

92. Millero, F. J.: J. Phys. Chem. 72,3209 (1968)

93. Millero, F. J.: J. Phys. Chem. 73, 2417 (1969)

94. Gopal, R., Agarwal, D. K. and Kumar, R.: Bull. Chem. Soc. Japan 46, 1973 (1973)

95. Zana, R., Lage, G. A. and Criss, C. M.: J. Solution Chem. 9, 667 (1980)

96. Smid, J. and Grotens, A. M.: J. Phys. Chem. 77, 2377 (1973)

97. Chang, S. and Criss, C. M.: J. Solution Chem. 2, 457 (1973)

98. Libuś, W., Meçik, M. and Strzelecki, H.: J. Solution Chem. 9, 723 (1980)

99. Choi, Y.-S. and Criss, C. M.: J. Chem. Eng. Data 22, 297 (1977)

100. Shin, C. and Criss, C. M.: J. Solution Chem. 7, 205 (1978)

101. Bennetto, H. P. and Spitzer, J. J.: J. Chem. Soc., Faraday Trans. 1 73, 1066 (1977)

102. Bennetto, H. P. and Spitzer, J. J.: J. Chem. Soc., Faraday Trans. 1 72, 2108 (1976)

103. Spitzer, J. J.: J. Chem. Soc., Faraday Trans. 1 74, 756 (1978)

104. Pitzer, K. S.: Acc. Chem. Res. 10, 371 (1977)

105. Picker, P., Jolicoeur, C. and Desnoyers, J. E.: J. Chem. Thermodyn. I, 469 (1969)

106. Wadsö, I.: Acta Chem. Scand. 22, 927 (1968)

107. Monk, P. and Wadsö, I.: Acta Chem. Scand. 22, 1842 (1968)

108. Born, M. and Mayer, J. E.: Z. Phys. 75, 1 (1932)

109. Ladd, M. F. C. and Lee, W. H.: in Reiss, H. (ed.): Progress in Solid State Chemistry, Vol. 1, p. 37, Oxford: Pergamon 1964

110. Morris, D. F. C.: Struct. Bonding (Berlin) 4, 63 (1968)

111. Criss, C. M. and Salomon, M.: in Ref. [55], p. 253

112. Krishnan, C.V. and Friedman, H. L. in: Coetzee, J. F. and Ritchie, C. D. (eds.): SoluteSolvent Interactions, Vol. 2, p. 1, New York: Dekker 1976

113. Janz, G. J. and Tomkins, R. P. T.: Nonaqueous Electrolytes Handbook, Vol. 2, New York: Academic Press 1973

114. Popovych, O. in: Kolthoff, I. M. and Elving, P. J. (eds.): Treatise on Analytical Chemistry (2nd ed.), Vol. 1 (1), p. 711, New York: Wiley 1978

115. Trémillon. B. and Coetzee, J. F.: Pure Appl. Chem. 50, 587 (1978)

116. Popovych, O.: Anal. Chem. 38, 558 (1966)

117. Ben-Naim, A.: J. Phys. Chem. 82, 792 (1978)

118. Kim, J. I., Duschner, H., Born, H.-J. and Hashimoto, T.: Z. Phys. Chem. N.F. 103, 15 (1976)

119. Marcus, Y.: Rev. Anal. Chem. 5, 53 (1980)

120. Coetzee, J. F. and Istone, W. K.: Anal. Chem. 52, 53 (1980) 
Josef Barthel et al.

121. Coetzee, J. F. and Martin, M. W.: Anal. Chem. 52, 2412 (1980)

122. Born, M.: Z. Phys. 1, 45 (1920)

123. Hepler, L. G. : Aust. J. Chem. 17, 587 (1964)

124. Stiles, P. J.: Aust. J. Chem. 33, 1389 (1980)

125. Latimer, W. M., Pitzer, K. S. and Slansky, C. M.: J. Chem. Phys. 7. 108 (1939)

126. Stokes, R. H.: J. Amer. Chem. Soc. 86, 979 (1964)

127. Dogonadze, R. R. and Kornyshev, A. A.: J. Chem. Soc., Faraday Trans. 2 70, 1121 (1974)

128. Bernal, J. D. and Fowler, R. H.: J. Chem. Phys. 1, 515 (1933)

129. Frank, H. S. and Wen, W.-Y.: Faraday Discuss. Chem. Soc. 24, 133 (1957)

130. Nemethy, G. and Scheraga, H. A.: J. Chem. Phys. 36. 3382 (1962)

131. Cox, B. G., Hedwig, G. R., Parker, A. J. and Watts, D. W.: Aust. J. Chem. 27, 477 (1974)

132. Covington, A. K. and Newman, K. E.: Pure Appl. Chem. 51, 2041 (1979)

133. Schneider, H.: Topics in Current Chemistry 68, 103 (1976)

134. Kim, J. I.: Z. Phys. Chem. N.F. 121, 1 (1980)

135. Kim, J. I. and Duschner, H.: J. Inorg. Nucl. Chem. 39, 471 (1977)

136. Kim, J. I.: J. Phys. Chem. 82, 191 (1978)

137. de Valera, E., Feakins, D. and Waghorne, W. E.: J. Chem. Soc., Faraday Trans. $176,560(1980)$

138. Buckingham, A. D.: Faraday Discuss. Chem. Soc. 24, 151 (1957)

139. Muirhead-Gould, J. S. and Laidler, K. J.: Trans. Faraday Soc. 63, 944 (1967)

140. Morf, W. E. and Simon, W.: Helv. Chim. Acta 54, 794 (1971)

141. Izmailov, N. A.: Dokl. Akad. Nauk SSSR 126, 1033 (1959)

142. Izmailov, N. A.: Zh. Fiz. Khim. 34, 2414 (1960)

143. Feakins, D. and Watson, P.: J. Chem. Soc. 1963,4734

144. Alfenaar, M. and De Ligny, C. L.: Recl. Trav. Chim. Pays-Bas 86, 929 (1967)

145. De Ligny, C. L. and Alfenaar, M.: Recl. Trav. Chim. Pays-Bas 84, 81 (1965)

146. De Ligny, C. L., Denessen, H. J. M. and Alfenaar, M.: Recl. Trav. Chim. Pays-Bas $9(1), 1265$ (1971)

147. Pleskov, V. A.: Usp. Khim. 16, 254 (1947)

148. Köpp, H.-M., Wendt, H. and Strehlow, H.: Z. Electrochem. 64, 483 (1960)

149. Parker, A. J. and Alexander, R.: J. Amer. Chem. Soc. 90, 3313 (1968)

150. Alexander, R. and Parker, A. J.: J. Amer. Chem. Soc. 89, 5549 (1967)

151. Grunwald, E., Baughman, G. and Kohnstam, G. : J. Amer. Chem. Soc. 82, 5801 (1960)

152. Fuchs, R., Bear, J. L. and Rodewald, R. F.: J. Amer. Chem. Soc. 9l, 5797 (1969)

153. Kolthoff, I. M. and Chantooni, M. K.: J. Phys. Chem. 76, 2024 (1972)

154. Millero, F. J.: J. Phys. Chem. 75, 280 (1971)

155. Kim, J. I., Cecal, A., Born, H.-J. and Gomaa, E. A. : Z. Phys. Chem. N.F. 110, 209 (1978)

156. Kim, J. I.: Z. Phys. Chem. N.F. 113, 129 (1978)

157. Coetzee, J. F. and Sharpe, W. R.: J. Phys. Chem. 75, 3141 (1971)

158. Treiner, C. : Can. J. Chem. 55, 682 (1977)

159. Pierotti, R. A.: Chem. Rev. 76, 717 (1976)

160. Parker, A. J.: Electrochim. Acta 21,671 (1976)

161. Alexander, R., Parker, A. J., Sharp, J. H. and Waghorne, W. E. : J. Amer. Chem. Soc. 94, 1148 (1972)

162. Owensby, D. A., Parker. A. J. and Diggle, J. W.: J. Amer. Chem. Soc. 96. 2682 (1974)

163. Lam, S. Y., Louis, C. and Benoit, R. L.: J. Amer. Chem. Soc. 98, 1156 (1976)

164. Mayer, U.: Monatsh. Chem. 108, 1479 (1977)

165. Marcus, Y., Pross, E. and Hormadaly, J.: J. Phys. Chem. 84, 2708 (1980)

166. Pitzer, K. S.: J. Phys. Chem. 77, 268 (1973)

167. Pitzer, K. S. and May.orga, G.: J. Phys. Chem. 77, 2300 (1973)

168. Pitzer, K. S. and Mayorga, G.: J. Solution Chem. 3, 539 (1974)

169. Pitzer, K. S. and Kim, J. J.: J. Amer. Chem. Soc. 96, 5701 (1974)

170. Pitzer, K. S., Roy, R. N. and Silvester, L. F.: J. Amer. Chem. Soc. 99, 4930 (1977)

171. Pitzer, K. S. in: Pytkowicz, R. M. (ed.): Activity Cocfficients in Electrolyte Solutions, Vol. I. p. 157, Boca Raton: CRC Press 1979

172. Cruz., J. L. and Renon, H.: AlChE J. 24. 817 (1978)

173. Cruz. J. L. and Renon. 11.: Ind. Eng. Chem. Fundament. 18. 168 (1979)

174. Renoll, H.: in Ref. 1711, p. 509 
175. Smedly, S. I.: The Interpretation of Ionic Conductivity in Liquids, New York: Plenum 1980

176. Franck, E. U.: Pure Appl. Chem. 53, 1401 (1981)

177. Quist, A. S. and Marshall, W. L.: J. Phys. Chem. 72, 684 (1968)

178. Quist, A. S., Franck, E. U., Jolley, H. R. and Marshall, W. L.: J. Phys. Chem. 67, 2453 (1963)

179. Quist, A. S. and Marshall, W. L.: J. Phys. Chem. 70, 3714 (1966)

180. Quist, A. S. and Marshall, W. L.: J. Phys. Chem. 72, 1545 (1968)

181. Quist, A. S. and Marshall, W. L.: J. Phys. Chem. 72, 2100 (1968)

182. Quist, A. S. and Marshall, W. L.: J. Phys. Chem. 72, 3122 (1968)

183. Dunn, L. A. and Marshall, W. L.: J. Phys. Chem. 73, 723 (1969)

184. Franck, E. U.: Z. Phys. Chem. N.F. 8, 92 (1956)

185. Franck. E. U.: Z. Phys. Chem. N.F. 8, 107 (1956)

186. Ritzert, G. and Franck, E. U.: Ber. Bunsenges. Phys. Chem. 72, 798 (1968)

187. Mangold, K. and Franck, E. U.: Ber. Bunsenges. Phys. Chem. 73, 21 (1969)

188. Heger, K., Uematsu, M. and Franck, E. U.: Ber. Bunsenges. Phys. Chem. 84, 758 (1980)

189. Fernandez-Prini, R.: in Ref. [55], p. 525

190. Spiro, M.: in Ref. [55], p. 615,635

191. Barthel, J.: Angew. Chem. 80, 253 (1968); Int. Ed. Engl. 7, 260 (1968)

192. Janz, G. J. and Tomkins, R. P. T.: Nonaqueous Electrolytes Handbook, Vol. 1, New York: Academic Press (1972)

193. Justice, J.-C. and Justice, M.-C.: Faraday Discuss. Chem. Soc. 64, 265 (1977)

194. Perié, J., Perié, M. and Justice, J.-C.: J. Solution Chem. 9, 395 (1980); Justice, J.-C., Perié, J. and Perié, M.: J. Solution Chem. 9, 583 (1980)

195. Barthel, J., Justice, J.-C. and Wachter, R.: Z. Phys. Chem. N.F. 84, 100 (1973)

i96. Fuoss, R. M.: J. Solution Chem. 7, 771 (1978); J. Phys. Chem. 79, 525, 1983 (1975); 82, 2427 (1978)

197. Ebeling, W., Feistel, R., Kelbg, G. and Sändig, R. : J. Nonequil. Thermodyn. 3,11 (1978)

198. Turq, P., Orcil, L., Chemla, M. and Barthel, J.: Ber. Bunsenges. Phys. Chem. 85, 535 (1981); Turq, P., Orcil, L., Chevalet, J., Mills, R. and Chemla, M.: in press

199. Hubbard, J. B. and Onsager, L.: J. Chem. Phys. 67, 4850 (1977); Hubbard, J. B. : J. Chem. Phys. $68,1649(1978)$

200. Pikal, M. J. : J. Phys. Chem. 75, 663 (1971)

201. Chen, M.-S. and Onsager, L.: J. Phys. Chem. 81, 2017 (1977); Chen, M.-S.: J. Solution Chem. $7,675(1978) ; 8,165,509$ (1979)

202. Quint. J. and Viallard, A.: J. Solution Chem. 7, 137, 525, 533 (1978)

203. Lee, W. H. and Wheaton, R. J.: J. Chem. Soc., Faraday Trans. 2 74, 743, 1456 (1978); 75,1128 (1979)

204. Pethybridge, A. D. and Taba, S. S.: Faraday Discuss. Chem. Soc. 64, 274 (1977); J. Chem. Soc., Faraday Trans. 176,368 (1980); 78, 1331 (1982)

205. Onsager, L.: Phys. Z. 27, 388 (1926)

206. Fuoss, R. M. and Hirsch, E.: J. Amer. Chem. Soc. 82, 1013 (1960)

207. Brown. A. M. and Fuoss, R. M.: J. Phys. Chem. 64, 1341 (1960)

208. Coetzee, J. F. and Cunningham, G. P.: J. Amer. Chem. Soc. 87, 2529 (1965)

209. Evans, D. F. and Gardam, P.: J. Phys. Chem. 72, 3281 (1968)

210. Krumgalz, B.: Russ. J. Phys. Chem. (Engl. Transl.) 47. 528 (1973)

211. Kay, R. L. and Dye, J. L.: Proc. Nat. Acad. Sci. USA 49, 5 (1963); Vidulich, G. A., Cunningham, G. P. and Kay, R. L.: J. Solution Chem. 2, 23 (1973)

212. Moynihan, C. T.: in Ref. [50], Vol. 1, p. 261

213. Angell, C. A. and Bressel, R. D.: J. Phys. Chem. 76, 3244 (1972)

214. Angell, C. A.: J. Phys. Chem. 70, 3988 (1966)

215. Adam, G. and Gibbs, J. H.: J. Chem. Phys. 43, 139 (1965)

216. Cohen. M. H. and Turnbull, D.: J. Chem. Phys. 31, 1164 (1959)

217. Angell, ('. A., Sare, J. M. and Sare, E. J.: J. Phys. Chem. 82, 2622 (1978)

218. Angell. C'. A. and Tucker, J. C.: J. Phys. Chem. 78. 278 (1974)

219. Brumo, P. and Della Monica, M.: Electrochim. Acta 20, 179 (1975): J. Phys. ('hem. 76,3034 (1972)

220. Brumo. P.. (iatti, ('. and Della Monica, M.: Electrochim. Acta 20, 533 (1975) 
Josef Barthel et al.

221. Spiro, M. and King, F. in: Inman, D. and Lovering, D. G. (eds.): Ionic Liquids, p. 57, New York: Plenum 1981

222. Harrison, G.: The Dynamic Properties of Supercooled Liquids, New York: Academic Press 1976

223. Copeland, J. L.: Transport Properties of Ionic Liquids, Ch. 4, New York: Gordon and Breach 1974

224. Anderson, P. W. in: Balian, R., Maynard, R. and Toulouse, G. (eds.): Ill-Condensed Matter, Les Houches, Session XXXI, 3. Juillet - 18 Aout. 1978, Amsterdam: North Holland 1979

225. Leist, M.: Z. Phys. Chem. (Leipzig) 205, 16 (1955)

226. Wishaw, B. F. and Stokes, R. H.: J. Amer. Chem. Soc. 76, 2065 (1954)

227. Gores, H.-J. and Barthel, J.: J. Solution Chem. 9, 939 (1980)

228. Ebeling, W., Geisler, D., Kraeft, D. and Sändig, R.: Wiss. Z. Univ. Rostock, Math.-Naturwiss Reihe 23, 903 (1974)

229. Jasinski, R.: High-Energy Batteries, New York: Plenum 1967

230. Jasinski, R. in: Tobias, C. W. (ed.): Advances in Electrochemistry and Electrochemical Engineering, Vol. 8, p. 253, New York: Wiley 1971

231. Casteel, J. F. and Amis, E. S.: J. Chem. Eng. Data 17, 55 (1972)

232. Barthel, J., Gores, H.-J. and Schmeer, G.: Ber. Bunsenges. Phys. Chem. 83, 911 (1979)

233. Barthel, J., Gerber, R. and Gores, H.-J.: in preparation

234. Fuoss, R. M. and Kraus, C. A.: J. Amer. Chem. Soc. 55, 2387 (1933)

235. Peled, E., Brand, M. and Gileadi, E.: J. Electrochem. Soc. 128, 1697 (1981)

236. Reger, A., Peled, E. and Gileadi, E.: J. Phys. Chem. 83, 873 (1979)

237. Reger, A., Peled, E. and Gileadi, E.: J. Phys. Chem. 83,869 (1979)

238. Gorenbein, E. Y.: Russ. J. Phys. Chem. (Engl. Transl.) 20, 547 (1946)

239. Rubinstein, I. and Gileadi, E.: J. Electrochem. Soc. 126, 1368 (1979)

240. Barthel, J. and Wittmann, H.-J.: in preparation

241. Neilson, G. W. and Enderby, J. E.: Annual Reports C, p. 185, London: The Royal Chemical Society 1979

242. Enderby, J. E. and Neilson, G. W.: Adv. Phys. 29, 323 (1980)

243. Ohtaki, H. and Johansson, G.: Pure Appl. Chem. 53, 1357 (1981)

244. Stern, E. A.: Contemp. Phys. 19, 289 (1978)

245. Sandstrom, D. R. and Lytle, F. W.: Annu. Rev. Phys. Chem. 30, 215 (1979)

246. Eisenberger, P. and Kincaid, B. M.: Chem. Phys. Lett. 36, 134 (1975)

247. Fontaine, A., Lagarde, P., Raoux, D., Fontana, M. P., Maisano, G. Migliardo, P. and Wanderlingh, F.: Phys. Rev. Lett. 41, 504 (1978)

248. Sandstrom, D. R.: J. Chem. Phys. 71, 2381 (1979)

249. Sandstrom, D. R., Dodgen, H. W. and Lytle, F. W.: J. Chem. Phys. 67, 473 (1977)

250. Barthel, J. (ed.): 7th International Conference on Non-Aqueous Solutions, Vol. 1, Vol. 2 , Regensburg 1980

251. Goulon, J. and Chabanel, M.: in Ref. [250], Vol. I, p. Cl

252. Kosower, E. M.: J. Amer. Chem. Soc. 80, 3261 (1958)

253. Libuś, W.: Pure Appl. Chem. 53, 1345 (1981)

254. Symons, M. C. R. in: Kevan, L. and Webster, B. C. (eds.): Electron-Solvent and Anion-Solvent Interactions, p. 311, Amsterdam: Elsevier 1976

255. Hogen-Esch, T. E. and Smid, J.: J. Amer. Chem. Soc. 87, 669 (1965)

256. Hogen-Esch, T. E. and Smid, J.: J. Amer. Chem. Soc. 88, 307, 318 (1966)

257. Chang, C. J., Kiesel, R. F. and Hogen-Esch, T. E. : J. Amer. Chem. Soc. 97, 2805 (1975)

258. Hogen-Esch, T. E. in: Gold, V. and Bethell, D. (eds.): Advances in Physical Organic Chemistry, Vol. 15. p. 153, New York: Academic Press 1977

259. Dubois, J.-E., Goetz, E. and Bienvenüe, A.: Spectrochim. Acta 20, 1815 (1964); Dubois, J.-E and Bienvenüe. A.: J. Chim. Phys. Phys.-Chim. Biol. 65, 1259 (1968)

260. Kamlet. M. J., Abboud, J. L. M. and Taft, R. W. in: Taft, R. W. (ed.): Progress in Physical Organic Chemistry, Vol. 13, p. 485, New York: Wiley 1981

261. Ahmed, W.: J. Chem. Educ. 56, 795 (1979)

262. Irish, D. E. and Brooker, M. H. in: Clark, R. J. H. and Hester, R. E. (eds.): Advances in Infrared and Raman Spectroscopy, Vol. 2, p. 212, London: Heyden 1976 
263. Bulmer, J. T. and Shurvell, H. F.: J. Phys. Chem. 77, 256, 2085 (1973); Bulmer, J. T. and Shurvell, H. F.: Can. J. Chem. 53, 1251 (1975)

264. Bulmer, J. T., Irish, D. E., Grossman, F. W., Herriot, G., Tseng, M. and Weerheim, A. J.: Appl. Spectrosc. 29, 506 (1975)

265. Gans, P.: Computers and Chemistry l, 291 (1977)

266. Gans, P. and Gill, J. B.: Appl. Spectrosc. 31, 451 (1977)

267. Gans, P.: Proc. Anal. Div. Chem. Soc. 17, 133 (1980)

268. Edgell, W. F., Schmidlin, E. and Balk, M. W.: Appl. Spectrosc. 34, 420 (1980)

269. Kauppinen, J. K., Moffatt, D. J., Mantsch, H. H. and Cameron, D. G.: Appl. Spectrosc. 35, $271(1981)$

270. Freeman, J. J., Heaviside, J., Hendra, P. J., Prior, J. and Reid, E. S.: Appl. Spectrosc. 35, 196 (1981)

271. Martin, A. E. in: Durig, J. R. (ed.): Vibrational Spectra and Structure, Vol. 8: Infrared Interferometric Spectrometers, Amsterdam: Elsevier 1980

272. Coetzee, J. F. and Sharpe, W. R.: J. Solution Chem. 1, 77 (1972)

273. Perelygin, I. S. and Klimchuk, M. A.: Russ. J. Phys. Chem. (Engl. Transl.) 47, 1138 (1973)

274. Perelygin, I. S. and Klimchuk, M. A.: Russ. J. Phys. Chem. (Engl. Transl.) 47, 1402 (1973)

275. Perelygin, I. S. and Klimchuk, M. A.: Russ. J. Phys. Chem. (Engl. Transl.) 48, 363 (1974)

276. Perelygin, I. S., Klimchuk, M. A. and Beloborodowa, N. N.: Russ. J. Phys. Chem. (Engl. Transl.) $54,1703(1980)$

277. Chang, T. G. and Irish, D. E.: J. Solution Chem. 3, 161 (1974)

278. Sze, Y.-K. and Irish, D. E.: J. Solution Chem. 8, 395 (1979)

279. Janz, G. J. and Müller, M. A.: J. Solution Chem. 4, 285 (1975)

280. Kabisch, G.: Abh. Sächs. Akad. Wiss. Leipzig, Math.-Naturwiss. Klasse, 54, 71 (1979)

281. Tsatsas, A. T., Stearns, R. W. and Risen, Jr., W. M. : J. Amer. Chem. Soc. 94,5247 (1972)

282. Rannou, J. and Chabanel, M.: J. Chim. Phys. Phys.-Chim. Biol. 77, 201 (1980)

283. Edgell, W. F. and Harris, D.: J. Solution Chem. 9, 649 (1980)

284. Roberts, J. H., Lemley, A. T. and Lagowski, J. J.: Spectrosc. Lett. S, 271 (1972)

285. Lemley, A. T., Roberts, J. H., Plowman, K. R. and Lagowski, J. J.: J. Phys. Chem. 77, 2185 (1973)

286. Plowman, K. R. and Lagowski, J. J.: J. Phys. Chem. 78, 143 (1974)

287. Lemley, A. T. and Lagowski, J. J.: J. Phys. Chem. 78, 708 (1974)

288. Gill, J. B.: Pure Appl. Chem. 53, 1365 (1981)

289. Gans, P., Gill, J. B., Griffin, M. and Cahill, P. C.: J. Chem. Soc., Dalton Trans. 1981, 968

290. Symons, M. C. R.: Pure Appl. Chem. 5l, 1671 (1979)

291. Lees, A. J., Stroughan, B. P. and Gardiner, D. J.: J. Mol. Struct. 71, 61 (1981)

292. Bukowska, J. and Miaskiewicz, K.: J. Mol. Struct. 74, 1 (1981)

293. Barthel, J., Behret, H. and Schmithals, F.: Ber. Bunsenges. Phys. Chem. 75, 305 (1971)

294. Badiali, J.-P., Cachet, H. and Lestrade, J.-C.: Pure Appl. Chem. 53, 1383 (1981)

295. Chabanel, M., Ménard, C. and Guihéneuf, G.: C.R. Acad. Sci. (Paris) 272C. 253 (1971)

296. Paoli, D., Luçon, M. and Chabanel, M.: Spectrochim. Acta 35 A, 593 (1979)

297. Edgell, W. F., Hegde, S. and Barbetta, A.: J. Amer. Chem. Soc. 100, 1406 (1978)

298. Edgell. W. F. and Chanjamsri, S.: J. Amer. Chem. Soc. 102, 147 (1980)

299. Barker, C. and Yarwood, J.: J. Chem. Soc., Faraday Trans. 271,1322 (1975)

300. Riddell, J. D., Lockwood, D. J. and Irish, D. E.: Can. J. Chem. 50, 2951 (1972)

301. Pease, L. G., Baron, D., Easwaran, K. R. K. and Blout, E. R. in: Ananchenko, S. N. (ed.) Front. Bioorg. Chem. Mol. Biol. Proc. Int. Symp. 1978, p. 81, Oxford: Pergamon 1980

302. Hertz, H. G.: in Ref. [46], p. 479

303. von Goldammer, E. in: Bockris, J. O'M. and Conway, B. E. (eds.): Modern Aspects of Electrochemistry, Vol. 10, p. 1, New York: Plenum 1975

304. Popov, A. I.: Pure Appl. Chem. 51, 101 (1979)

305. Harris, R. K. and Mann, B. E. (eds.): NMR and the Periodic Table, New York: Academic Press 1978

306. Briggs, R. W., Metz, K. R. and Hinton, J. F.: J. Solution Chem. 8, 479 (1979)

307. Metz, K. R. and Hinton, J. F.: J. Solution Chem. 10, 21 (1981)

308. Symons, M. C. R. in: Kevan, L. and Webster, B. C. (eds.): Electron-Solvent and Anion-Solvent Interactions, p. 327, Amsterdam: Elsevier 1976 
Josef Barthel et al.

309. Greenberg, M. S., Bodner, R. L. and Popov, A. 1.: J. Phys. Chem. 77, 2449 (1973)

310. Cahen, Y. M., Handy, P. R., Roach, E. T. and Popov, A. I.: J. Phys. Chem. 79, 80 (1975)

311. Dewitte, W. J., Schoening, R. C. and Popov, A. I. : Inorg. Nucl. Chem. Lett. 12, 251 (1976)

312. Dewitte, W. J., Liu, L., Mei, E., Dye, J. L. and Popov, A. I. : J. Solution Chem. 6, 337 (1977)

313. Shih, J. S. and Popov, A. I.: Inorg. Nucl. Chem. Lett. 13, 105 (1977)

314. Heubel, P.-H. and Popov, A. I.: J. Solution Chem. 8. 283 (1979)

315. Rahimi, A. K. and Popov, A. I.: J. Magn. Res. 36, 351 (1979)

316. Farmer, R. M. and Popov, A. 1.: Inorg. Nucl. Chem. Lett. 17, 51 (1981)

317. Buckson, R. L. and Smith, S. G.: J. Phys. Chem. 68, 1875 (1964)

318. Cahen, Y. M., Dye, J. L. and Popov, A. I. : J. Phys. Chem. 79, 1289 (1975)

319. Melendres, C. A. and Hertz, H. G.: J. Chem. Phys. 6l, 4156 (1974)

320. Geiger, A. and Hertz, H. G.: Adv. Mol. Relaxation Processes 9, 293 (1977)

321. Weingärtner, H. and Hertz, H. G.: Ber. Bunsenges. Phys. Chem. 81, 1204 (1977)

322. Singer, J. R.: J. Phys. E: Sci. Instr. 11, 281 (1978)

323. Holz, M. and Müller, C.: Ber. Bunsenges. Phys. Chem. 86, 141 (1982)

324. Sharp, J. H. and Symons, M. C. R. in: Szwarc, M. (ed.): Ions and Ion Pairs in Organic Reactions, Vol. 1, p. 177, New York: Wiley 1972

325. Hill, N. E., Vaughan, W. E., Price, A. H. and Davies, M.: Dielectric Properties and Molecular Behaviour, London: Van Nostrand Reinhold 1969

326. Barthel, J. and Feuerlein, F.: in preparation

327. Lestrade, J.-C., Badiali, J.-P. and Cachet, H. in: Davies, M. (ed.): Dielectric and Related Molecular Processes (Spec. Period. Rep.), Vol. 2, p. 106, London: The Chemical Society 1975

328. Davies, M. and Johansson, G.: Acta Chem. Scand. 18, 1171 (1964)

329. Barthel, J., Schmithals, F. and Behret, H.: Z. Phys. Chem. N.F. 71, 115 (1970): Behret, H., Schmithals, F. and Barthel, J.: Z. Phys. Chem. N.F. 96, 73 (1975)

330. Barthel, J., Krüger, J. and Schollmeyer, E.: Z. Phys. Chem. N.F. 104, 59 (1977)

331. Barthel, J. and Kaukal, B. in: Ref. [250], Vol. II, p. 36; Kaukal, B.: Dissertation, Regenshurg 1982

332. Brot, C. in: Davies, M. (ed.): Dielectric and Related Molecular Processes (Spec. Period. Rep.). Vol. 2, p. 1, London: The Chemical Society 1975

333. Hill, N. E.: Proc. Phys. Soc. 82, 723 (1963)

334. Edgell, W. F., Watts, A. T., Lyford, J. and Risen, Jr., W. M.: J. Amer. Chem. Soc. 88, 181 (1966)

335. Maxey, B. W. and Popov, A. I.: J. Amer. Chem. Soc. 89, 2230 (1967); Popov, A. I. : Pure Appl. Chem. 41, 275 (1975)

336. Edgell, W. F. in: Szwarc, M. (ed.): Ions and Ion Pairs in Organic Reactions, Vol. 1, p. 153, New York: Wiley 1972

337. Falkenhagen, H.: in Ref. [46], p. 168

338. Ebeling, W. and Justice, J.-C. in: Ref. [64], p. 133

339. van Beek, W. M.: Dissertation, Leiden 1975

340. Irish, D. E., Chang, T. G., Tang, S.-Y. and Petrucci, S. : J. Phys. Chem. 8.5, 1686 (1981)

341. Strehlow, H. and Knoche, W.: Fundamentals of Chemical Relaxations. Weinheim: Verlag Chemie 1977

342. Eigen, M. and Tamm, K.: Z. Elektrochem. 66, 93, 107 (1962)

343. Alexander, R., Ko, E. C. F., Parker, A. J. and Broxton, T. J. : J. Amer. Chem. Soc. 90, 5049 (1968)

344. Makosza, M. and Wawrzyniewicz, M.: Tetrahedron Lett. 1969,4659

345. Boden, R. M.: Synthesis 1975,784

346. Parker, A. J., Clare, B. W. and Smith, R. P.: Hydrometallurgy 4, 233 (1979)

347. Livingston, R.: J. Chem. Educ. 7, 2887 (1930)

348. Scatchard, G.: Chem. Rev. 10, 229 (1932)

349. Perlmutter-Hayman, B. in: Jennings, K. R. and Cundall, R. B. (cds.): Progress in Reaction Kinetics, Vol. 6, p. 239, Oxford: Pergamon 1971

350. Marshall, Jr., E. K. and Acree, S. F.: J. Phys. (hem. 19, 589 (1915)

351. Brändström. A.: Ark. Kcmi 11,527 (1957)

352. Brïndström, A.: Ark. Kemi $/ 1,567$ (1957)

353. Beronius, P., Nilsson, A.-M. and Wikander, G. : Acta ('hem. Scand. 24, 2826 (1970)

354. Barthel, J. Bäder, (;. and Ratach-Lenz, M. : Z. Phys. ('hem. N.I: 11).3. 1.35 (1976) 
355. Barthel, J. and Raach-Lenz, M.: Z. Phys. Chem. N.F. 103, 149 (1976)

356. Cayzergues, J., Georgoulis, C. and Papanastasiou, G.: J. Chim. Phys. Phys.-Chim. Biol. 74, $1103,1112(1977)$

357. Cayzergues, J., Georgoulis, C. and Mathieu, G.: J. Chim. Phys. Phys.-Chim. Biol. 77, 401 (1980)

358. Dubois, J.-E. and Barthel, J.: C.R. Acad. Sci. (Paris) 245, 1531 (1957)

359. Parker, A. J.: Chem. Rev. 69, I (1969)

360. Johnson, S. L. in: Gold, V. (ed.): Advances in Physical Organic Chemistry, Vol. 5, p. 235. New York: Academic Press 1967

361. Abraham, M. H.: J. Chem. Soc., Perkin Trans. 2 1972, 1343

362. von Halban, H.: Z. Phys. Chem. (Leipzig) 67, 129 (1909)

363. Menschutkin, N.: Z. Phys. Chem. (Leipzig) 6, 41 (1890)

364. Menschutkin, N.: Z. Phys. Chem. (Leipzig) 34, 157 (1900)

365. Yamamura, K. and Murahashi, S.: Tetrahedron Lett. 1977, 4429

366. Hughes, E. D. and Whittingham, D. J.: J. Chem. Soc. 1960, 806

367. Gleave. J. L.; Hughes, E. D. and Ingold, C. K.: J. Chem. Soc. 1935, 236

368. Watts, D. W.: Pure Appl. Chem. 51, 1713 (1979)

369. Bender, M. L.: Chem. Rev. 60, 53 (1960)

370. Kirby, A. J. in: Bamford, C. H. and Tipper, C. F. W. (eds.): Comprehensive Chemical Kinetics, Vol. 10, p. 156, Amsterdam: Elsevier 1972

371. Kirby, A. J. : in Ref. [370], p. 162

372. Hughes, E. D. and Wilby, J.: J. Chem. Soc. 1960, 4094

373. DePuy, C. H. and Bishop, C. A.: J. Amer. Chem. Soc. 82, 2532 (1960)

374. Dubois, J.-E., Huynh, X. Q. and Viellard, H.: C.R. Acad. Sci. Paris 260, 3057 (1965)

375. Garnier, F. and Dubois, J.-E.: Bull. Soc. Chim. Fr. 1968, 3797

376. Barthel, J. and Schmeer, G. in: Dubois, J.-E. (ed.): Reaction Transition States, p. 211, New York: Gordon and Breach 1972

377. Laidler, K. J. and Landskroener, P. A.: Trans. Faraday Soc. 52, 200 (1956)

378. Amis, E. S. and Hinton, J. F.: Solvent Effects on Chemical Phenomena, Vol. 1, New York: Academic Press 1973

379. Hiromi, K.: Bull. Chem. Soc. Japan 33, 1251, 1264 (1960)

380. Reynaud, R.: Bull. Soc. Chim. Fr. 1968, 2279

381. Ingold, C. K.: Structure and Mechanism in Organic Chemistry (2nd ed.), Ithaca: Cornell University Press 1969

382. Schmeer, G. and Barthel, J.: to be published

383. Caldin, E. F.: Pure Appl. Chem. 51, 2067 (1979)

384. Ritchie. C. D.: Pure Appl. Chem. 5l, 153 (1979)

385. Svirbely. W. J. and Kuchta, A. D.: J. Phys. Chem. 65, 1333 (1961)

386. Tommila, E.: Suom. Kemistil. B37, 117 (1964)

387. Goitein, R. and Bruice, T. C.: J. Phys. Chem. 76, 432 (1972)

388. Balakrishnan, M.; Rao, G. V. and Venkatasubramanian. N.: J. Chem. Soc.. Perkin Trans. 2 1974. 6

389. Simmons, E. L. in: Jennings, K. R. and Cundall, R. B. (eds.): Progress in Reaction Kinetics, Vol. 8, p. 161, Oxford: Pergamon 1977

390. Ritchie. C. D., Skinner, G. A. and Badding, V. G.: J. Amer. Chem. Soc. 89, 2063 (1967)

391. Koppel. I. A. and Palm, V. A. in: Chapman, N. B. and Shorter, J. (eds.): Advances in Linear Free Energy Relationships, p. 203, New York: Plenum 1972

392. Wold, S. : Chemica Scripta 5, 97 (1974)

393. Wold. S. and Sjöström, M. in: Chapman, N. B. and Shorter, J. (cds.): Correlation Analysis in Chemistry, p. 1, New York: Plenum 1978

394. Fainberg, A. H. and Winstein, S.: J. Amer. Chem. Soc. 78, 2770 (1956)

395. Smith, S. G. Fainberg, A. H. and Winstein, S.: J. Amer. Chem. Soc. 83, $618(1961)$

396. Lassau, C. and Jungers, J.-C.: Bull. Soc. Chim. Fr. 1968, 2678

397. Drougard, Y. and Decroocq. D.: Bull. Soc. Chim. Fr. 1969, 2972

398. Parker. A. J., Mayer, U.. Schmid, R. and Gutmann, V.: J. Org. Chem. 4.3, 1843 (197x)

399. Krygowski, T. M. and Faweett, W. R.: J. Amer. Chem. Soc. 97, 2143 (1975)

400. Fawelt, W. R. and Krygowski. T. M.: Aust. J. Chem. 28. 2115 (1975) 
Josef Barthel et al.

401. Mayer, U.: Pure Appl. Chem. 51, 1697 (1979)

402. Ehrenson, S.: J. Amer. Chem. Soc. 103, 6036 (1981)

403. Kolling, O. W.: Anal. Chem. 54, 260 (1982)

404. Kamlet, M. J., Carr, P. W., Taft, R. W. and Abraham, M. H.: J. Amer. Chem. Soc. 103, 6062 (1981)

405. Dubois, J.-E.: Pure Appl. Chem. 53, 1313 (1981)

406. Dubois, J.-E.: Entropie 27, 1 (1969)

407. Fredenslund, A., Michelsen, M. L. and Sörensen, J. M. : in Ref. [71], p. 433

408. Rasmussen, P. and Skjold-Jørgensen, S.: in Ref. [71], p. 419

409. Eckermann, R.: in Ref. [71], p. 741

410. Scholz, A. G. R.: in Ref. [71], p. 761

411. Onken, U., Gmehling, J. and Arlt, W.: in Ref. [71], p. 781

412. Buck, E.: in Ref. [71], p. 771

413. Brändström, A. in: Gold, V. and Bethell, D. (eds.): Advances in Physical Organic Chemistry, Vol. 15, p. 267, London: Academic Press 1977

414. Weber, W. P. and Gokel, G. W.: Phase Transfer Catalysis in Organic Synthesis, Berlin: Springer 1977

415. Starks, C. M. and Liotta, C.: Phase Transfer Catalysis, Principles and Techniques, New York: Academic Press 1978

416. Dehmlow, E. V. and Dehmlow, S. S.: Phase Transfer Catalysis, Weinheim: Verlag Chemie 1980

417. Starks, C. M.: CHEMTECH 10,110 (1980)

418. Reuben, B. and Sjöberg, K.: CHEMTECH 11, 315 (1981)

419. Dehmlow, E. V.: Chimia 34, 12 (1980)

420. Lindblom, L. and Elander, M.: Pharm. Technol. 4 (10), 59 (1980)

421. Dehmlow, E. V., Slopianka, M. and Heider, J.: Tetrahedron Lett. 1977, 2361

422. Juliá, S., Ginebrada, A., Guixer, J., Masana, J., Tomás, A. and Colonna, S. : J. Chem. Soc., Perkin Trans. 1 1981, 574

423. Haase, R., Sauermann, P.-F. and Drücker, K.-H.: Z. Phys. Chem. N.F. 47, 224 (1965)

424. Haase, R. and Drücker, K.-H.: Z. Phys. Chem. N.F. 46, 141 (1965)

425. Barthel, J. et al.: unpublished results

426. Mamantov, G. in: Murphy, D. W., Broadhead, J. and Steele, B. C. H. (eds.): Materials for Advanced Batteries, p. 111, New York: Plenum 1980

427. Carpio, R. A., King, L. A., Lindstrom, R. E., Nardi, J. C. and Hussey, C. L.: J. Electrochem. Soc. 126,1644 (1979)

428. Johnson, W. B. and Worrell, W. L.: Solid State Ionics 5, 367 (1981)

429. Rea, J. R., Kelsey, G. S., Kuo, H. C. and Kallianidis, M. : Solid State Ionics 3/4, 267 (1981)

430. Liang, C. C. and Bro, P.: J. Electrochem. Soc. 116, 1322 (1969)

431. Owens, B. B.: Solid State Ionics 3/4, 273 (1981)

432. von Alpen, U. and Bell, M. F.: Solid State Ionics 3/4, 259 (1981)

433. Stakem, D.: Electr. Prod. Mag., Nov. (1979), p. 75

434. Graham, R. W.: Rechargeable Batteries, Advances since 1977, Chem. Techn. Rev. No. 160, Energy Techn. Rev. No. 55, Park Ridge N. J.: Noyes Data Corp. (1980)

435. Newman, G. H. and Klemann, L. P.: J. Electrochem. Soc. 127, 2097 (1980)

436. Klemann, L. P. and Newmann, G. H.: J. Electrochem. Soc. 129, 230 (1982)

437. Saito, T., Ikeda, H., Matsuda, Y. and Tamura, H.: J. Appl. Electrochem. 6, 85 (1976)

438. Jasinski, R. : Electroanal. Chem. 26, 189 (1970)

439. Eckert, J. and Gálovà, M.: Z. Chemie 20, 194 (1980)

440. Matsuda, Y., Ouchi, Y. and Tamura, H.: J. Appl. Electrochem. 4. 53 (1974)

441. Takahashi, S. and Koura, N.: J. Electrochem. Soc. 128, 710 (1981)

442. Staniewicz, R. J.: J. Electrochem. Soc. 127, 782 (1980)

443. Scrosati, B.: Electrochim. Acta 26, 1559 (1981)

444. Besenhard, J. O. and Heydecke, J. in: von Stumm, F. (ed.): Elektrochenie und Elektronik, p. 189, DECHEMA Monographien, Vol. 90, Weinheim: Verlag Chemie 1980

445. Murphy, D. W., Broadhead, J. and Steele, B. C. H. (eds.): Materials for Advanced Batteries, New York: Plenum 1980

446. Vissers, D. R.: in Ref. [445], p. 47 
Non-Aqueous Electrolyte Solutions in Chemistry and Modern Technology

447. Huggins, R. A.: in Ref. [445], p. 91

448. Roberts, R. in: Ouellette, R. P.; Ellerbusch, F. and Cheremisinoff, P. N. (eds.): Electrotechnology, Vol. 2, p. 335, Ann Arbor: Ann Arbor Science 1978

449. Steunenberg, R. K. in: Vashishta, P., Mundy, J. N. and Shenoy, G. K. (eds.): Fast Ion Transport in Solids, p. 23, New York: North Holland 1979

450. Dell, R. M. and Bones, R. J. in: Vashishta, P., Mundy, J. N. and Shenoy, G. K. (eds.): Fast Ion Transport in Solids, p. 29, New York: North Holland 1979

451. Asher, J. A. in: Vashishta, P., Mundy, J. N. and Shenoy, G. K. (eds.): Fast Ion Transport in Solids, p. 39, New York: North Holland 1979

452. Liang, C. C. and Holmes, C. F.: in Ref. [465], p. 27

453. Greatbatch, W.: in Ref. [465], p. 3

454. Kennedy, J. H. in: Bockris, J. O'M., Conway, B. E., Yeager, E. and White, R. E. (eds.): Comprehensive Treatise of Electrochemistry, Vol. 3, p. 279, New York: Plenum 1981

455. Owens, B. B. and Skarstad, P. M. in: Vashishta, P., Mundy, J. N. and Shenoy, G. K. (eds.): Fast Ion Transport in Solids, p. 61, New York: North Holland 1979

456. Armand, M. B., Chabagno, J. M. and Duclot, M. J. in: Vashishta, P., Mundy, J. N. and Shenoy, G. K. (eds.): Fast Ion Transport in Solids, p. 131, New York: North Holland 1979

457. Kronenberg, M. L. and Blomgren, G. E. in: Bockris, J. O'M, Conway, B. E., Yeager, E. and White, R. E. (eds.): Comprehensive Treatise of Electrochemistry, Vol. 3, p. 247, New York: Plenum 1981

458. Sprengel, D.: Symposium Lithium Batterien, Kelkheim/Taunus 1980

459. Fiordiponti, P., Pistoia, G. and Temperoni, C.: J. Electrochem. Soc. 125, 14 (1978)

460. Barthel, J., Gores, H.J. and Utz, M.: in preparation

461. Olmstead, W. N.: J. Electrochem. Soc. 127, 344C (1980)

462. Venkatasetty, H. V. (ed.): Proceedings of the Symposium on Lithium Batteries, Pennington N.J.: The Electrochem. Soc. 1981

463. Olmstead, W. N.: in Ref. [462], p. 144

464. Angres, I. A.: J. Electrochem. Soc. 127, 344C (1980); Angres, I. A. and James, S. D. in Ref. [465], p. 332

465. Owens, B. B. and Margalit, N. (eds.): Proceedings of the Symposia on Power Sources for Biomedical Implantable Applications and Ambient Temperature Lithium Batteries, Princeton: The Electrochemical Society 1980

466. Margalit, N. and Canning, H. J. : J. Electrochem. Soc. 127, 344C (1980)

467. Venkatasetty, H. V., Saathoff, D. J. and Patel, B. K.: J. Electrochem. Soc. 127, 344C (1980); Ref. [462], p. 155

468. Kronenberg, M. L.: U.S. Pat. 3,871,916 (1975); 3,951,685 (1976); Ger. Pat. 2,516,035 (1977)

469. Lehmann, G. and Gabano, J. P.: Ger. Pat. 2,154,092 (1972)

470. Whitney, T. A. and Klemann, L. P.: Ger. Offen. 2,828,628 (1979); U.S. Pat. 4,117,213 (1978); U.S. Pat. 4,104,450 (1978)

471. Klemann, L. P., Newman, G. H. and Stogryn, E. L.: U.S. Pat. 4,139,681 (1979)

472. Klemann, L. F. and Newman, G. H.: J. Elecirochern. Soc. 128, 13 (1981)

473. Newman, G. H., Francis, R. W., Gaines, L. H. and Rao, B. M. L.: J. Electrochem. Soc. 127, $2025(1980)$

474. Matsuda, Y., Nakashima, H., Morita, M. and Takasu, Y.: J. Electrochem. Soc. 128, 2552 (1981)

475. Matsuda, Y. and Satake, H.: J. Electrochem. Soc. 127, 877 (1980)

476. Yeager, E. B., Schumm Jr., B., Blomgren, B., Blankenship, D. R., Leger, V. and Akridge, J. (eds.): Lithium Nonaqueous Battery Electrochemistry, Pennington: The Electrochemical Society 1980

477. Werblan, L. and Lesinski, J.: Pol. J. Chem. 53, 2571 (1979)

478. Kedrinskii, 1. A., Morozov, S. V., Sukhova, G. I. and Sokolov, L. A.: Sov. Electrochem. 12. 1094 (1977)

47\%. Sclim, R. and Bro, P.: J. Hlectrochem. Soc. 121, 1457 (1974)

480. Dey, A. N. and Sullivan, B. P.: J. Electrochem. Soc. 117, 222 (1970)

481. Eichinger, G.: J. Electroanal. Chem. Interfacial Electrochem. 74, 183 (1976)

482. Dousek, F. P., Jansta, J. and Ríha, J.: J. Electroanal. Chem. Interfacial Electrochem. 46, 281 (1973)

483. Dey, A. N.: Thin Solid Films 43, 131 (1977) 
Josef Barthel et al.

484. Epelboin, I., Froment, M.. Gazreau, M., Thevenin. J. and Warin, D. : J. Electrochem. Soc. 127. $2100(1980)$

485. Seiger, H. N., Lyall, A. E. and Chair. R. C. in: Collins, D. H. (ed.): Power Sources, Vol. 2, Proc. 6th Intern. Symp. Brighton, Sept. 1968, Oxford: Pergamon 1970

486. Dey, A. N. and Holmes, R. W.: J. Electrochem. Soc. 127, 1877 (1980)

487. Dousek, F. P. and Jansta, J.: J. Electroanal. Chem. Interfacial Electrochem. 74, 195 (1976)

488. Caiola, A.. Fadou, J. Y. and Sohm, J. C.: Electrochim. Acta 17, 1401 (1972)

489. Caiola, A., Guy, H. and Sohm, J. C.: Electrochim. Acta 15, 555 (1970)

490. Dey, A. N.: J. Electrochem. Soc. 127, 1886 (1980)

491. Peled, E.: J. Electrochem. Soc. 126, 2047 (1979)

492. Brummer, S. B., Koch, V. R. and Rauh, R. D. : in Ref. [445], p. 123

493. Clincspoor, C. C.: Dissertation, Bonn 1970

494. Lautié, R.: Bull. Soc. Chim. Fr. 118, 508 (1947)

495. Kruger, F. J.: Symposium Lithium Batterien, Kelkheim (Taunus), 1980

496. Rasmussen, R. M.: Microtechniques, Symp. Intern. 23.-24. 4. 1981, Mulhouse (France)

497. Kruger, F. J.: Microtechniques, Symp. Intern. 23.- 24. 4. 1981, Mulhouse (France)

498. Ideka, H., Narukawa, S., Inokudi, H. and Nakaido, S.: Microtechniques, Symp. Intern. 23.--24. 4. 1981, Mulhouse (France)

499. Datenblatt VARTALITH, VARTA-Batterie, AG, D-3000 Hannover 21, Postfach 210540 (1980)

500. Linden, D. and McDonald, B.: J. Power Sources 5, 35 (1980)

501. Schlaikjer, C. R., Goebel, F. and Marincic, N.: J. Electrochem. Soc. 126, 513 (1979)

502. Dey, A. N. and Schlaikjer, C. R.: Proc. of the 26th Power Sources Conference, Atlantic City. N.J. (1974)

503. Datenblatt Silberkraft, Leichtakkumulatoren GmbH, D-4100 Duisburg. Meidericher Str. 6.8 (1981)

504. Collins, D. H. (ed.): Power Sources, Vol. 5, Proc. 9th Intern. Symp., Brighton September 1974, London: Academic Press 1975

505. Bro, P., Holmes, R. W., Marincic, N. and Taylor, H.: in Ref. [504], p. 703

506. Gardner, C. L., Fouchard, D. T. and Fawcett, W. R.: J. Electrochem. Soc. 128,2337 (1981)

507. Gardner, C. L., Fouchard, D. T. and Fawcett, W. R. : J. Electrochem. Soc. I28, 2345 (1981)

508. Dey, A. N. and Holmes, R. W. : J. Electrochem. Soc. 126, 1637 (1979)

509. Dey, A. N. and Holmes, R. W.: J. Electrochem. Soc. 127, 775 (1980)

510. Dey, A. N.: J. Electrochem. Soc. 127, 1000 (1980)

511. Blomgren, G. E. and Kronenberg, M. L.: Ger. Offen. 2,262,256 (1973)

512. Behl, W. K., Christopulos, J. A., Ramirez, M. and Gilman, S.: J. Electrochem. Soc. 120,1619 (1973)

513. Auborn, J. J., French, K. W., Lieberman, S. I., Shah, V. K. and Heller. A.: J. Electrochem. Soc. $120,1613(1973)$

514. Datenblatt 1102, Sonnenschein Accumulatorenfabrik, D-6470 Büdingen, Thicrgarten

515. Bowden, W. L. and Dey. A. N. : J. Electrochem. Soc. 127, 1419 (1980)

516. Bowden, W. L. and Dey, A. N.: J. Electrochem. Soc. 126, 2035 (1979)

517. Abraham. K. M. and Mank, R. M.: J. Electrochem. Soc. 127, 2091 (1980)

518. Venkatasetty, H. V. and Saathoff, D. J.: J. Electrochem. Soc. 128, 773 (1981)

519. Salomon, M.: J. Electrochem. Soc. 128, 233 (1981)

520. Klinedinst. K. A. and Domeniconi, M. J.: J. Electrochem. Soc. 127, 539 (1980)

521. Dey, A. N. and Miller, J.: J. Electrochem. Soc. 126, 1445 (1979)

522. Ohzuku. T., Wakamatsu, H., Takehara, Z. and Yoshizawa. S.: Electrochim. Acta 24, 723 (1979)

523. Gilman, S. and Wade Jr., W.: J. Electrochem. Soc. 127, 1427 (1980)

524. Rauh, R. D., Abraham, K. M., Pearson, G. F., Surprenant, J. K. and Brunimer, S. B.: J. Electrochem. Soc. 126. 523 (1979)

525. Rauh, R. D., Shuker, F. S., Marston, J. M. and Brummer, S. B.: J. Inorg. Nucl. Chem. 39. 1761 (1977)

526. Whittingham, M. S.: Science 192, 1126 (1976) 
527. Koch, V. R. and Young, J. H.: Science 204, 499 (1979)

528. Holleck, G. L., Abraham, K. M. and Brummer, S. B. in: Ref. [465], p. 384

529. Journé, J. and Tobias, C. W.: J. Appl. Electrochem. 5, 279 (1975)

530. Rauh, R. D. and Brummer, S. B.: Electrochim. Acta 22, 75 (1977)

531. Dampier, F. W. and Brummer, S. B.: Electrochim. Acta 22, 1339 (1977)

532. Koch, V. R. and Brummer, S. B.: Electrochim. Acta 23, 55 (1978)

533. Rauh, R. D. and Brummer, S. B.: Electrochim. Acta 22, 85 (1977)

534. Gunther, R. G.: U.S. Pat. 3.928,070 (1975); Ger. Offen. 2,502,497 (1975)

535. Broadhead, J. and Trumbore, F. A.: in Ref. [504], p. 661

536. Soffer, A.: U.S. Pat. 4,132,837 (1979)

537. Koch, V. R. and Young, J. H.: J. Electrochem. Soc. 125, 1371 (1978)

538. Koch, V. R.: J. Electrochem. Soc. 126, 181 (1979)

539. Koch, V. R.: U.S. Pat. 4,118,550 (1978)

540. Goldman, J. L., Mank, R. M., Young, J. H. and Koch, V. R.: J. Electrochem. Soc. 127, 1461 (1980)

541. Carjaval, C., Tölle, K. J., Smid, J. and Szwarc, M.: J. Amer. Chem. Soc. 87, 5545 (1965)

542. Nichols. D., Sutphen, C. and Szwarc, M.: J. Phys. Chem. 72, 1021 (1968)

543. Abraham, K. M., Goldman, J. L. and Dempsey, M. D.: J. Electrochem. Soc. 128, 2493 (1981)

544. Koch, V. R., Goldman, J. L., Mattos, C. J. and Mulvaney, M.: J. Electrochem. Soc. 129, 1 (1982)

545. Koch, V. R.: U.S. Pat. 4,252,876 (1981)

546. Whittingham, M. S.: Progr. Solid State Chem. 12, 41 (1978)

547. Armand, M. B.: in Ref. [445], p. 145

548. Holleck, G. L. and Driscoll, J. R.: Electrochim. Acta 22, 647 (1977)

549. Thompson, A. H. and Symon, C. R.: Solid State Ionics, 3/4, 175 (1981)

550. Rao, B. M. L. and Klemann, L. P.: J. Electrochem. Soc. 127, 761 (1980)

551. Murphy, D. W., Christian, P. A., DiSalvo, F. J. and Carides, J. N.: J. Electrochem. Soc. 126, 497 (1979)

552. Spurdens. P. C.. Drennan, J., Owen, J. R., Steele, B. C. H., Gonzales-Calbet, J. M. and Jefferson. D. A.: Solid State Ionics 5, 335 (1981)

553. Dickens, P. G. and Reynolds, G. J.: Solid State Ionics 5, 331 (1981)

554. Jacobson. A. J.: Solid State Ionics 5, 65 (1981)

555. Christian, P. A., Carides, J. N., DiSalvo, F. J. and Waszczak, J. V.: J. Electrochem. Soc. 127,2315 (1980)

556. Mizushima, K., Jones, P. C., Wiseman, P. J. and Goodenough, G. J.: Solid State Ionics 3/4. 171 (1981)

557. Whittingham, M. S. and Newman, G. H.: J. Electrochem. Soc. 128, 706 (1981)

558. Moshtev, R. V., Manev, V., Nassalevska, A., Pistoia, G. and Icovi, M.: J. Electrochem. Soc. $128,1399(1981)$

559. Cava. R. J., Santoro, A., Murphy, D. W., Zahurak, S. and Roth, R. S.: Solid State Ionics 5 , $323(1981)$

560. Eisenberg, M.: J. Electrochem. Soc. 127, 2382 (1980)

561. Eisenberg, M.: Electrochim. Acta 26, 955 (1981)

562. Eisenberg, M.: U.S. Pat. 4,136,223 (1979)

563. Jacobson. A. J. and Rich, S. M.: J. Electrochem. Soc. 127, 779 (1980)

564. Jacobson, A. J., Chianelli, R. R. and Whittingham, M. S.: J. Electrochem. Soc. 126, 2277 (1979)

565. Jacobson, A. J., Chianelli, R. R., Rich, S. M. and Whittingham, M. S.: Mat. Res. Bull. 14. 1437 (1979)

566. Jacobson, A. J., Whittingham, M. S. and Rich, S. M.: J. Electrochem. Soc. 126, 887 (1979)

567. Lazzari, M. and Scrosati, B.: J. Electrochem. Soc. 127, 773 (1980)

568. MacDiarmid, A. G. and Heeger, A. J.: Synth. Met. $I, 101$ (1979/1980)

569. MacInnes. Jr., D.. Druy, M. A., Nigrey, P. J., Nairns, D. P., Macliarmid, A. G. and Hecger, A. J.: J. ('hem. Soc. Chem. Commun. 1981, 317

570. Nigrey, P. J., MacDiarmid, A. G. and Heeger, A. J.: J. Chem. Soc. ('hem. Commun. 1979. 594 
Josef Barthel et al.

571. Nigrey, P. J., MacInnes, Jr., D., Nairns, D. P., MacDiarmid, A. G. and Heeger, A. J.: J. Electrochem. Soc. 128, 1651 (1981)

572. Thompson, J. (edł): Power Sources, Vol. 7, Proc. 11th Intern. Symp., Brighton Sept. 1978 London: Academic Press 1979

573. Collins, D. H. (ed.): Power Sources, Vol. 6, Proc. 10th Intern. Symp., Brighton September 1976, London: Academic Press 1977

574. Besenhard, J. O. and Eichinger, G.: J. Electroanal. Chem. Interfacial Electrochem. 68, 1 (1976)

575. Eichinger, G. and Besenhard, J. O.: J. Electroanal. Chem. Interfacial. Electrochem. 72, 1 (1976)

576. Beghi, G. (ed.): Energy Storage and Transportation, Dordrecht: Reidel 1981

577. Popovych, O. and Tomkins, R. P. T.: Nonaqueous Solution Chemistry, New York: Wiley 198

578. Graham, R. W.: Primary Batteries, Recent Advances, Chem. Techn. Rev. No. 105, Energy Techn. Rev. No. 25, Park Ridge, N. J.: Noyes Data Corp. 1978

579. Graham, R. W.: Secondary Batteries, Recent Advances, Chem. Techn. Rev. No. 106, Energy Techn. Rev. No. 26, Park Ridge, N. J.: Noyes Data Corp. 1978

580. "Gottesfeld, S. and McIntyre, J. D. E.: J. Electrochem. Soc. 126, 742 (1979)

581. Novotny, V. and Hopper, M. A.: J. Electrochem. Soc. 126, 2211 (1979)

582. Camlibel, I., Singh, S., Stocker, H. J., VanUitert, L. G. and Zydzik, G. J.: Appl. Phys. Lett. 33, 793 (1978)

583. Beni, G.: Solid State Ionics 3/4, 157 (1981)

584. Deb, S. K.: Phil. Mag. 27, 801 (1973)

585. Faughnan, B. W., Crandall, R. S. and Heyman, P. M.: RCA Rev. 36, 177 (1975)

586. Chang, I. F., Gilbert, B. L. and Sun, T. I.: J. Electrochem. Soc. 122, 955 (1975)

587. Hersh, H. N., Kramer, W. E. and McGee, J. H.: Appl. Phys. Lett. 27, 646 (1975)

588. Faughnan, B. W., Crandall, R. S. and Lampert, M. A.: Appl. Phys. Lett. 27, 275 (1975)

589. Crandall, R. S. and Faughnan, B. W.: Appl. Phys. Lett. 28, 95 (1976)

590. Faughnan, B. W. and Crandall, R. S.: Appl. Phys. Lett. 31, 834 (1977)

591. Mohapatra, S. K.: J. Electrochem. Soc. 125, 284 (1978)

592. Reichmann, B. and Bard, A. J.: J. Electrochem. Soc. 126, 583 (1979)

593. Randin, J. P.: J. Electron. Mat. 7, 47 (1978)

594. Reichmann, B. and Bard, A. J.: J. Electrochem. Soc. 126, 2133 (1979)

595. Ho, C., Raistrick, I. D. and Huggins, R. A.: J. Electrochem. Soc. 127, 343 (1980)

596. Dautremont-Smith, W. C., Green, M. and Kang, K. S.: Electrochim. Acta 22, 751 (1977)

597. Zeller, H. R. and Beyeler, H. U.: Appl. Phys. 13, 231 (1977)

598. Dickens, P. G., Moore, J. H. and Neild, D. J.: Solid State Chem. 7, 241 (1973)

599. Faughnan, B. W. and Crandall, R. S. in: Pankove, J. I. (ed.): Topics in Applied Physics, Vol. 40, Display Devices, Berlin: Springer 1980

600. Freller, H. and Mund, K. in : von Stumm, F. (ed.): Elektrochemie und Elektronik, DECHEMAMonographien, Vol. 90, p. 107, Weinheim: Verlag Chemie 1981

601. McIntyre, J. D. E., Basu, S., Peck, Jr., W. F., Brown, W. L. and Augustyniak, W. M.: Solid State Ionics 5, 359 (1981)

602. Burke, L. D. and O'Sullivan, E. J. M.: J. Electroanal. Chem. Interfacial Electrochem. 111 . $383(1980)$

603. Gottesfeld, S.: J. Electrochem. Soc. 127, 272 (1980)

604. Reichmann, B. and Bard, A. J.: J. Electrochem. Soc. 127, 241 (1980)

605. Gottesfeld, S., McIntyre, J. D. E., Beni, G. and Shay, J. L.: Appl. Phys. Letl. 33, 208 (1978)

606. Beni, (3. and Shay, J. 1.: Appl. Phys. Lett. 33, 567 (1978)

607. Shay, J. L., Beni, G. and Schiavone, L. M.: Appl. Phys. Lell. 33, 942 (1978)

608. Schiavone, L. M., Dautremont-Smith, W. C., Beni, G. and Shay, J. L.: Appl. Phys. Lett. 35,823 (1979)

609. Corker, G. A., Grant, B. and Clecak, N. J.: J. Electrochem. Soc. 126, 1339 (1979)

610. Walton, D., Ely, B. and Elliott, G.: J. Electrochem. Soc. 128, 2479 (1981)

611. Barna, G. G.: J. Electrochem. Soc. 127, 1317 (1980) 
612. Matsumoto, S., Kato, H. and Tomura, S.: Jpn. Kokai Tokkyo Kohu 76,160,573; C.A. 93 , P $58277 \mathrm{~g}(1980)$

613. Miyamura, M., Tomura, S., Imai, A. and Inomata, S.: Solid State Ionics $3 / 4,149$ (1981)

614. Green, M. and Kang, K.: Solid State Ionics 3/4, 141 (1981)

615. Kmetz, A. R. in: Kmetz, A. R. and von Willisen, F. K. (eds.): Nonemissive Electrooptic Displays, p. 261, New York: Plenum 1976

616. Beni, G.: J. Electrochem. Soc. 127, 467C (1980)

617. Bogenschütz, A. F. and Krusemark, W.: Elektrochemische Bauelemente, Weinheim: Verlag Chemie 1976

618. Dalisa, A. L.: Proc. Soc. Inf. Displ. 18, 43 (1977)

619. Dalisa, A. L. in: Pankove, J. I. (ed.): Topics in Applied Physics, Vol. 40, Display Devices, p. 213, Berlin: Springer 1980

620. Novotny, V. and Hopper, M. A.: J. Electrochem. Soc. 126, 925 (1979)

621. Chang, I. F. in: Kmetz, A. R. and von Willisen, F. K. (eds.): Nonemissive Electrooptic Displays, p. 155, New York: Plenum 1976

622. Pankove, J. I. in: Pankove, J. I. (ed.): Topics in Applied Physics, Vol. 40, Display Devices, p. 1, Berlin: Springer 1980

623. Matsuhiro, K. and Masuda, Y.: SID Digest 1979, quoted after Ref. [583]

624. Raistrick, I. D., Mark, A. J. and Huggins, R. A.: Solid State Ionics 5, 351 (1981)

625. Schiavone, L. M., Dautremont-Smith, W. C., Beni, G. and Shay, J. L.: Appl. Phys. Lett. 35, 823 (1979)

626. McIntyre, J. D. E., Peck, W. F. and Nakahara, S. : J. Electrochem. Soc. 127, 1264 (1980)

627. Dautremont-Smith, W. C., Beni, G., Schiavone, L. M. and Shay, J. L. in: Vashishta, P., Mundy, J. N. and Shenoy, G. K. (eds.): Fast Ion Transport in Solids, p. 99, New York: North Holland 1979

628. Morrison, S. R. : Electrochemistry at Semiconductor and Oxidized Metal Electrodes, New York: Plenum 1980

629. Johnston, Jr., W. D.: Solar Voltaic Cells, New York: Dekker 1980

630. Kazmerzki, L. in: Murr, L. E. (ed.): Solar Materials Science, p. 525, New York: Academic Press 1980

631. Photoelectrochemistry, Faraday Discuss. Chem. Soc. 70 (1981)

632. Ang, P. G. P. and Sammells, A. F.: in Ref. [631], p. 207

633. Gerischer, H.: in Ref. [631], p. 137

634. Gerischer, H.: in Seraphin, B. O. (ed.): Topics in Applied Physics, Vol. 31, Solar Energy Conversion, p. 115, Berlin: Springer 1979

635. Tributsch, H.: in Ref. [631], p. 189

636. Bockris, J. O'M.: in Ref. [631], p. 429

637. Cheremisinoff, P. N. and Regino, T. C.: Principles and Applications of Solar Energy, Ann. Arbor: Ann. Arbor Science 1978

638. Weaver, N. L., Singh, R., Rajeshwar, K., Singh, P. and Dubow, J.: Solar Cells 3, 221 (1981)

639. Park, S. M. and Barber, M. E.: J. Electroanal. Chem. Interfacial Electrochem. 99, 67 (1979)

640. Wilson, J. R. and Park, S.-M.: J. Electrochem. Soc. 129, 149 (1982)

641. Gerischer, H.: J. Electroanal. Chem. Interfacial Electrochem. 82, 133 (1977)

642. Gerischer, H.: J. Vac. Sci. Technol. 15, 1422 (1978)

643. Bard, A. J. and Wrighton, M. S.: J. Electrochem. Soc. 124, 1706 (1977)

644. Kohl, P. A. and Bard, A. J.: J. Electrochem. Soc. 126, 603 (1979)

645. Langmuir, M. E., Hoenig, P. and Rauh, R. P.: J. Electrochem. Soc. 128, 2357 (1981)

646. Kohl, P. A. and Bard, A. J.: J. Electrochem. Soc. 126, 598 (1979)

647. Curran, J. S.: in Ref. [631]. p. 259

648. Cardon, F., Gomes, W. P.. VanDen Kerchove, F., Vanmeakelbergh, D. and Van Overmeire, F.: in Ref. |631], p. 153

649. Kawai, T., Tributsch, H. and Sakata, T.: Chem. Phys. Lett. 69, 336 (1980)

650. Fan, F.-R. F.. White, H. S. Wheeler, B. and Bard, A. J.: J. Electrochem. Soc. 127, 518 (1980)

651. Kline, G., Kam, K., Canfield, D. and Parkinson, B. A.: Sol. Energy Mater. 4, 301 (1981)

652. Ang, P. G. P. and Sammells, A. F.: J. Electrochem. Soc. 129, 233 (1982) 
Josef Barthel et al.

653. Ginley, D. S., Biefeld, R. M., Parkinson, B. A. and Keung-Kam, K.: J. Electrochem. Soc. $129,145(1982)$

654. Tenne, R.: J. Electrochem. Soc. 129, 143 (1982)

655. Tributsch, H.: Ber. Bunsenges. Phys. Chem. 81, 361 (1977)

656. Tributsch, H.: Ber. Bunsenges. Phys. Chem. 82, 169 (1978)

657. Bard, A. J.: J. Phys. Chem. 86, 172 (1982)

658. Noufi, R. and Tench, D.: J. Electrochem. Soc. 127, 188 (1980)

659. Noufi, R., Tench, D. and Warren, L. F.: J. Electrochem. Soc. 127, 2709 (1980)

660. Noufi, R., Tench, D. and Warren, L. F.: J. Electrochem. Soc. 128,2363 (1981)

661. Laser, D. and Bard, A. J.: J. Phys. Chem. 80, 459 (1976)

662. Kohl, P. A. and Bard, A. J.: J. Electrochem. Soc. 126, 59 (1979)

663. Kohl, P. A. and Bard, A. J.: J. Amer. Chem. Soc. 99, 7531 (1977)

664. Noufi, R., Tench, D. and Warren, L. F.: J. Electrochem. Soc. 127, 2310 (1980)

665. Noufi, R., Tench, D. and Warren, L. F.: J. Electrochem. Soc. 128, 2596 (1981)

666. Diaz, A. F., Kanazawa, K. K. and Gardini, G. P.: J. Chem. Soc. Chem. Commun. 1979, 635

667. Kanazawa, K. K., Diaz, A. F., Geiss, R. H., Gill, W. D., Kwak, J. F., Logan, J. A., Rabolt, J. F. and Street, G. B.: J. Chem. Soc. Chem. Commun. 1979, 854

668. Diaz, A. F. and Castillo, J. I.: J. Chem. Soc. Chem. Commun. 1980, 397

669. Neville, R. C.: Solar Energy Conversion: The Solar Cell, Amsterdam: Elsevier 1978

670. Heller, A. (ed.): Semiconductor Liquid Junction Cells, Pennington N.J.: The Electrochemical Society 1977

671. Seraphin, B. O. (ed.): Topics in Applied Physics, Vol. 31, Solar Energy Conversion, Berlin: Springer 1979

672. Brenner, A. in: Tobias, C. W. (ed.): Advances in Electrochemistry and Electrochemical Engineering, Vol. 5, p. 205, New York: Wiley 1967

673. Lowenheim, F. A. in: Vossen, J. L. and Kern, W. (eds.): Thin Film Processes, p. 209, New York: Academic Press 1978

674. Takei, T.: Surf. Techn. $8,543(1979)$

675. Couch, D. E.: Plating 49, 363 (1962)

676. Beach, J. G. and Faust, C. L.: J. Electrochem. Soc. 106, 654 (1959)

677. Yoshio, M. and Ishibashi, N.: J. Appl. Electrochem. 3, 321 (1973)

678. Roethlein, R. J.: J. Electrochem. Soc. 117, 931 (1970)

679. Schmidt, F. J. and Hess, I. J.: Plating 53, 229 (1966)

680. Gaugin, R. and Nury, G.: Bull. Soc. Fr. Electriciens, $7^{\mathfrak{e}}$ série, 8,733 (1958)

681. Takei. T.: Surf. Techn. 9, 285 (1979)

682. Elwell, D.: J. Cryst. Growth 52,741 (1981)

683. Isserlis, G. in: Kuhn, A. T. (ed.): Industrial Electrochemical Processes, p. 376, Amsterdam: Elsevier 1971

684. Couch, D. E. and Brenner, A.: J. Electrochem. Soc. 99, 234 (1952)

685. Connor, J. H. and Brenner, A.: J. Electrochem. Soc. 103, 657 (1956)

686. Beach, J. G., McGraw, L. D. and Faust, C. L.: Plating 55, 936 (1968)

687. Ishibashi, N. and Yoshio, M.: Electrochim. Acta 17, 1343 (1972)

688. Yoshio, M., Ishibashi, N., Waki, W. and Seiyama, T.: J. Inorg. Nucl. Chem. 34, 24.39 (1972)

689. Eckert, J. and Gálovà, M.: Electrochim. Acta 26, 1169 (1981)

690. Gálovà, M., Lux, L. and Eckert, J.: Z. Phys. Chem. (Leipzig) 263, 377 (1982)

691. Peled, E., Mitavski, A., Reger, A. and Gileadi, E.: J. Electroanal. Chem. Interlacial Electrochem. 75. 677 (1977)

692. Peled. E. and Gileadi, E.: Plating 62, 342 (1975)

693. Peled, L:. and (jileadi, L.: J. Electrochem. Soc. 123, 15 (1976)

694. Pcled, E., Mitavski, A. and Gileadi, E.: Z. Phys. Chem. N.F. 98. 111 (1975)

695. Reger, A., Peled, E. and Gileadi, E.: J. Electrochem. Soc. 123, 638 (1976)

696. Ziegel, S., Peled, E. and Gileadi, E.: Electrochim. Acta 23, 363 (1978)

697. Yoshio, M., Nakamura, H., Nogouchi, N. and Nagamatsu. M.: in Ref. [25()]. p. 1: 3

698. Anonymous: Chem. Eng. News, 57, May 14, p. 8, 1979 
699. Barbier, M. and Bovarnick, B. in: Ouelette, R. P., Ellerbusch, F. and Cheremisinoff, P. N. (eds.): Electrotechnology, Vol. 2, p. 259, Ann Arbor: Ann Arbor Science 1978

700. Biallozor, S. and Lisowska, A.: Electrochim. Acta 25, 1209 (1980)

701. Reid, Jr., W. E., Bish, J. M. and Brenner, A.: J. Electrochem. Soc. 104, 21 (1957)

702. Santos, F. and Dyment, F.: Plating 60, 821 (1973)

703. Fischer, H. W. and Schwabe, K.: Korrosion (Dresden) 11,105 (1980)

704. Agrawal. A. K. and Austin, A. E.: J. Electrochem. Soc. 128, 2292 (1981)

705. Rama Mohan, T. R. and Kroeger, F. A.: Electrochim. Acta 27, 371 (1982)

706. Bernard, W. J. in: Hampel, C. A. (ed.): Encyclopedia of Electrochemistry, p. 140, New York: Reinhold 1964

707. Morley, A. R. and Campbell, D. S. : Radio Electron. Eng. 43, 421 (1973)

708. Campbell, D. S.: Radio Electron. Eng. 41, 5 (1971)

709. Vijh, A. K. in: Diggle, J. W. (ed.): Oxides and Oxide Films, Vol. 2, New York: Dekker 1973

710. Campbell, D. S. in: Chapman, B. N. and Anderson, J. C. (eds.): Science and Technology of Surface Coating. p. 87, London: Academic Press 1974

711. Lacour, H. R.: Elektronische Bauelemente, Vol. 1, Stuttgart: Berliner Union 1978

7.12. Wood, G. C. in: Diggle, J. W. (ed.): Oxide and Oxide Films, Vol. 2, New York: Dekker 1973

713. Westwood, W. D., Waterhouse, N. and Wilcox, P. S.: Tantalum Thin Films, London: Academic Press 1975

714. Young, L.: Can. J. Chem. 38, 1141 (1960)

715. Hagihara, M. H. and Takimoto, S. M.: Ger. Pat. 1,614,166 (1973)

716. Höft, H.: Passive Elektronische Bauelemente, Heidelberg: Hüthig 1977

717. Taketani. Y. D. and Niwa, S.: Ger. Offen, 2,508,904 (1978)

718. Pringuet. M. G.: Ger. Pat. 2,449,282 (1975)

719. Jackson, N. F. and Sethi, R. S.: Brit. Pat. 1,445,894 (1976)

720. Mallory, P. R.: Ger. Offen. 2,646,500 (1977)

721. Anderson, D. J.: U.S. Pat. 3,812,038 (1974)

722. Zinke, O.: Widerstände, Kondensatoren, Spulen und ihre Werkstoffe, Berlin: Springer 1965

723. Burger. F. J. and Young, L.: Progress in Dielectrics 5, I (1962)

724. Vermileya, D. A. in: Delahay, P. (ed.): Advances in Electrochemistry and Electrochemical Engineering, Vol. 3, p. 211, New York: Wiley 1963

725. Burger. F. J. and Wu, J. C.: J. Electrochem. Soc. 1/8, 2039 (1971)

726. Yahalom, J. and Hoar, T. P.: Electrochim. Acta 15, 877 (1970)

727. Ikonopisov, S. : Electrochim. Acta 22, 1077 (1977)

728. Ikonopisov, S., Girginov, A. and Machkova, M.: Electrochim. Acta 22, 1283 (1977)

729. Ikonopisov, S., Girginov, A. and Machkova, M.: Electrochim. Acta 24, 451 (1979)

730. Tajima, S.: Electrochim. Acta 22, 995 (1977)

731. Mund, K. and Richter, R. in: von Stumm, F. (ed.): DECHEMA-Monographien, Vol. 90, Elektrochemie und Elektronik, p. 173, Weinheim: Verlag Chemie 1981

732. Sanada, K. and Hosokawa, M.: NEC-Res. and Development 55, 21 (1979)

733. Krumpelt. M., Weissmann, E. Y. and Alkire, R. C. (eds.): Electro-organic Synthesis Tuchnology, AlChE Symp. Ser. No. 185, Vol. 75, AIChE National Meeting, Atlanta, USA, 26. 2.-1. 3. 1978. New York: AIChE 1979

734. Swann, Jr.. S. and Alkire, R. C.: in Ref. [733], p. 61

735. Swann, Jr.. S. and Alkire, R. C.: Bibliography of Electro-Organic Synthesis 1801-1975, Princet on: The Electrochemical Society 1980

736. Danly, D. in: The Kirk-Othmer Encyclopedia of Chemical Technology, Vol. 8 (3rd cd.), p. 696, New York: Wiley 1979

737. Beck. T. R.. Alkire, R. C. and Weinberg, N. L.: J. Electrochem. Soc. 126. 136 ( (1979)

738. Weinberg. N. L..: in Ref. [733], p. 31

739. Fitzjohn. J. L.: in Ref. [733]. p. 65

740. Bockris, J. O'M. in: Bockris, J. O’M., Rand, D. A. J. and Welch, B. J. (eds.): Trends in Lilectrochemistry, New York: Plenum 1977

741. Alkirc, R. C. and Gould, R. M.: J. Electrochem. Soc. 127, 605 (1980)

742. Heinze, I.: Angew. ('hem. 93. 186 (1981) 
Josef Barthel et al

743. Rifi, M. R. and Covitz, F. H.: Introduction to Organic Electrochemistry, New York: Dekker 1974

744. Pietsch, S. J. and Langer, S. H.: in Ref. [733], p. 51

745. Weinberg, N. L. (ed.) in: Weissberger, A. (ser. ed.): Techniques of Chemistry, Vol. 5. Technique of Electro-organic Synthesis, Part I (1974), Part II (1975), Part III (1982) New York: Wiley

746. Funt, B. L. and Tanner, J. in Ref. [745], Part II, p. 559

747. Houghton, R. W. and Kuhn, A. T.: J. Appl. Electrochem. 4, 173 (1974)

748. Newman, J. S. and Tiedemann, W. in: Gerischer H. and Tobias, C. W. (eds.): Advances in Electrochemical Engineering, Vol. 11, p. 353, New York: Wiley 1978

749. Jansson, R. E. W. and Tomov, N. R.: Electrochim. Acta 25, 497 (1980)

750. Ibl, N.: Electrochim. Acta 22, 465 (1977)

751. Keller, R.: Electrochim. Acta 25, 303 (1980)

752. Gallone, P.: Electrochim. Acta 22, 913 (1977)

753. Beck, T. R. in: Yeager, E. and Salkind, A. J. (eds.): Techniques of Electrochemistry, Vol. 3, p. 1, New York: Wiley 1978

754. Lelandais, D.: Labo-Pharma.-Probl. Techn. 283, 43 (1979)

755. Fioshin, M. Y.: Sov. Electrochem. 13, 1 (1977)

756. Fleischmann, M. and Pletcher, D.: Chem. Brit. 11, 50 (1975)

757. Grimshaw, J. in: Thirsk, H. R. (sen. rep.): Electrochemistry (Spec. Period. Rep.), Vol. 7, London: The Chemical Society 1980

758. Brown, O. R. in: Thirsk, H. R. (sen. rep.): Electrochemistry (Spec. Period. Rep.), Vol. 6. London: The Chemical Society 1978

759. Sawyer, D. T. and Roberts, Jr., J. L. : Experimental Electrochemistry for Chemists, New York: Wiley 1974

760. Pletcher, D.: Industrial Electrochemistry, London: Chapman and Hall 1982

761. Brown, O. R. in: Thirsk, H. R. (sen. rep.): Electrochemistry (Spec. Period. Rep.), Vol. 5, London: The Chemical Society 1975

762. Peover, M. E. in: Hush, N. S. (ed.): Reactions of Molecules at Electrodes, p. 259, London: Wiley 1971

763. Fleischmann, M. and Pletcher, D. in: Hush, N. S. (ed.): Reaction of Molecules at Electrodes, p. 347, London: Wiley 1971

764. Fleischmann, M. and Pletcher, D. in: Gold, V. (ed.): Advances in Physical Organic Chemistry, Vol. 10, London: Academic Press 1973

765. Prescott, J. H.: Chem. Eng. 72, 238 (1965)

766. Baizer, M. M. (ed.): Organic Electrochemistry, New York: Dekker 1973

767. Baizer, M. M.: J. Appl. Electrochem. 10, 285 (1980)

768. Beck, F.: Elektroorganische Chemie, Weinheim: Verlag Chemie 1973

769. Kyriacou, D. K.: Basis of Electroorganic Synthesis, New York: Wiley 1981

770. Schäfer, H. J.: Angew. Chem. 93, 978 (1981)

771. Miller, L. L.: Pure Appl. Chem. 51, 2125 (1979)

772. Eberson, L. and Weinberg, N. L.: Chem. Eng. News 49 (4), 40 (1971)

773. Fleischmann, M. and Pletcher, D.: Tetrahedron Lett. 1968, 6255

774. Badoz-Lambling, J. and Cauquis, G. in: Nürnberg, H. W. (ed.): Electroanalytical Chemistry, London: Wiley 1974

775. Beck, F.: Chem. Ing. Techn. 42, 153 (1970)

776. Hazelrigg, Jr., M. J. and Bard, A. J.: J. Electrochem. Soc. 122, 211 (1975)

777. Ryan, M. D. and Evans, D. H.: J. Electroanal. Chem. Interfacial Electrochem. 67, 333 (1976)

778. Cipris, D.: J. Electrochem. Soc. 127, 1045 (1980)

779. Silvestri, G., Gambino, S., Filardo, G., Spadaro, S. and Palmisano, L. : Electrochim. Acta 23, $4 ! 3(1978)$

780. Braithwite, D. G.: U.S. Pat. 3,256,161 (1966)

781. Braithwite, D. G. and Bott, L. L.: U.S. Pat. 3,380,899 (1968)

782. Johnson. J. W. in: Bloom, H. and Gutmann, F. (eds.): Electrochemistry. The Past Thirty and the Next Thirty Years, New York: Plenum 1977

783. Kaiser, U. and Heitz, E.: Ber. Bunsenges. Phys. Chem. 77, 818 (1973)

784. Skarlos, L.: U.S. Pat. 3,720,591 (1973) 
785. Heitz, E. and Kaiser, U.: Ger. Offen. 2,301,032 (1974)

786. Amatore, C. and Savéant, J. M.: J. Amer. Chem. Soc. 103, 5021 (1981)

787. Gambino, S. and Silvestri, G.: Tetrahedron Lett. 1973, 3025

788. Silvestri, G., Gambino, S., Filardo, G., Guianazzi, M. and Ercoli, R.: Gazz. Chim. Ital. 102, 818 (1972)

789. Cipris, D. and Mador, I. L.: J. Electrochem. Soc. 125, 1954 (1978)

790. Knittel, D. and Kastening, B.: Ger. Offen. 2,328,196 (1974)

791. Knittel, D. and Kastening, B. : J. Appl. Electrochem. 3, 291 (1973)

792. Knittel, D. and Kastening, B.: Ber. Bunsenges. Phys. Chem. 77, 833 (1972)

793. Nyberg, K., Malmberg, M. and Servin, R.: in Ref. [733], p. 36

794. Bauer, R. and Wendt, H.: in Ref. [733], p. 56

795. Barbey, G., Delahaye, D., Lamant, M. and Caullet, C.: Electrochim. Acta 25, 1273 (1980)

796. Lácan, M., Tabaković, I. and Cehović, Ž. : Tetrahedron 30, 2911 (1974)

797. Miller, L. L., Kariv, E. and Behling, J. R. in: Clarke, F. H. (ed.): Annu. Rep. Med. Chem., Vol. 12, p. 309, New York: Academic Press 1977

798. Ronlan. A., Hammerich, O. and Parker, V. D.: J. Amer. Chem. Soc. 95, 7132 (1973)

799. Falck, J. R., Miller, I. L. and Stermitz, F. R.: J. Amer. Chem. Soc. 96, 2981 (1974)

800. Nohe, H. : in Ref. [733], p. 69

801. Jansson, R. E. W. and Fleischmann, M.: in Ref. [733], p. 2

802. Becker, J. Y., Byrd, L. R., Miller, L. L. and Ying-Huong, S.: J. Amer. Chem. Soc. 97, 853 (1975)

803. Vincent, F., Tardivel, R. and Mison, P.: Tetrahedron Lett. 1975, 603

804. Bockmair, G., Fritz, H. P. and Gebauer, H.: Electrochim. Acta 23, 21 (1978)

805. Waefler, J. P. and Tissot, P.: Electrochim. Acta 23, 899 (1978)

806. Koester, H. and Wendt, H. in: Bockris, J. O'M., Conway, B. E., Yeager, E. and White, R. A. (eds.): Comprehensive Treatise of Electrochemistry, Vol. 2, p. 251, New York: Plenum 1981

807. Nohe, H.: Chem.-Ing.-Techn. 46, 594 (1974)

808. Pletcher, D. and Razaq, M.: J. Appl. Electrochem. 10, 575 (1980)

809. Pletcher, D. and Razaq, M.: Electrochim. Acta 26, 819 (1981)

810. Hatayama, T., Hamano, Y., Udo, K. and Yamamoto, T.: Japan. Pat. 7,441,192 (1974)

811. Ogumi, Z., Nishio, K. and Yoshizawa, S.: Electrochim. Acta 20, 1779 (1981)

812. Merz, A.: Nachr. Chem. Techn. Lab. 30, $16(1982)$

813. Parker, A. J.: Pure Appl. Chem. 53, 1437 (1981)

814. Toušek, J.: Electrochim. Acta 22, 47 (1977)

815. Gabe, D. R.: Metallography 5, 415 (1972)

816. Breeze, P. A., Hartnagel, H. L. and Sherwood, P. M. A.: J. Electrochem. Soc. 127, 454 (1980)

817. Hasegawa, H. and Hartnagel, H. L.: J. Electrochem. Soc. 123, 713 (1976)

818. Müller, H., Eisen, F. H. and Mayer, J. W.: J. Electrochem. Soc. 122, 651 (1975)

819. Turner, D. R. and Pankove, J. I. in: Yeager, E. and Salkind, A. J. (eds.): Techniques of Electrochemistry, Vol. 3, p. 105, New York: Wiley 1978

820. Binder, M., Gilman, S. and Wade, Jr., W.: J. Electrcchem. Scc. 129, 897 (1982)

821. Murray, R. W.: Acc. Chem. Res. 13, 135 (1980)

822. Andrieux, C. P., Dumas-Bouchat, J. M. and Savéant, J. M.: J. Electroanal. Chem. Interfacial Electrochem. 131, 1 (1982)

823. Snell, K. D. and Keenan, A. G.: Chem. Soc. Rev. 1979, 259

\section{References (Appendices A, B, C and D)}

1. Riddick, J. A. and Bunger, W. B.: Organic Solvents in: Weissberger, A. (ed.), Techniques of Chemistry, Vol. 2, 3rd ed. New York: Wiley 1970

2. Wilhoit, R. C. and Zwolinski, B. J.: Physical and Thermodynamic Properties of Aliphatic Alcohols. New York: Amer. Chem. Soc. 1973

3. Alm, K. and Ciprian, M.: J. Chem. Eng. Data 25, 100 (1980)

4. Srinivasan, K. R. and Kay, R. L.: J. Solution Chem. 4, 299 (1975)

5. Cunningham, G. P., Vidulich, G. A. and Kay, R. L.: J. Chem. Eng. Data 12, 336 (1967) 
Josef Barthel et al.

6. D'Aprano, A., Donato, I. D. and Caponetti, E.: J. Solution Chem. 3, 371 (1974)

7. Barthel, J. et al.: unpublished data

8. Benson, G. C. and Kiyohara, O.: J. Solution Chem. 9, 791 (1980)

9. Hales, J. L. and Ellender, J. H.: J. Chem. Thermodyn. 8, 1177 (1976)

10. Brown, Jr., G. N. and Ziegler, W. T.: J. Chem. Eng. Data 24, 319 (1979)

11. Ambrose, D. and Sprake, C. H. S.: J. Chem. Thermodyn. 2, 631 (1970)

12. Kay, R. L. and Broadwater, T. L.: J. Solution Chem. 5, 57 (1976)

13. Barthel, J., Schmeer, G., Strasser, F. and Wachter, R.: Rev. Chim. Miner. 15, 99 (1978)

14. D'Aprano, A., Donato, I. D. and Caponetti, E.: J. Solution Chem. 8. 135 (1979)

15. D'Aprano, A., Donato, I. D., Caponetti, E. and Agrigento, V.: J. Solution Chem. 8, 793 (1979)

16. Evans, D. F., Thomas, J., Nadas, J. A. and Matesich, M. A.: J. Phys. Chem. 75, 1714 (1971)

17. Dannhauser, W. and Bahe, L. W.: J. Chem. Phys. 40, 3058 (1964)

18. Matesich, M. A., Nadas, J. A. and Evans, D. F.: J. Phys. Chem. 74, 4568 (1970)

19. Evans, D. F. and McElroy, M. I.: J. Solution Chem. 4, 413 (1975)

20. Evans, D. F. and Gardam, P.: J. Phys. Chem. 73, 158 (1969)

21. Taniewska-Osińska, St. and Witkowski, St.: Acta Univ. Lodz, Ser. 2, 24, 3 (1978)

22. Subrahmanyam, S. V. and Moorthy, N. M.: J. Solution Chem. 4, 347 (1975)

23. Kalidas, C. and Sivaprasad, P. in: Furter, W. F. (ed.): Thermodynamic Behaviour of Electrolytes in Mixed Solvents, Vol. 2, p. 345, Washington: American Chemical Society 1979

24. DeSieno, R. P., Greco, P. W. and Mamajek, R. C.: J. Phys. Chem. 75, 1722 (1971)

25. Hayduk, W. and Malik, V. K.: J. Chem. Eng. Data 16, 143 (1971)

26. Douhéret, G. and Morénas, M.: Can. J. Chem. 57, 608 (1979)

27. Blokhra, R. L. and Sehgal, Y. P.: J. Solution Chem. 5, 399 (1976)

28. Merken, G. V., Thun, H. P. and Verbeek, F.: Electrochim. Acta 21, 11 (1976)

29. Barker, B. J., Rosenfarb, J. and Mullin, T.: J. Solution Chem. 6, 513 (1977)

30. Dulić, N. and Horváth, L.: Acta Phys. Chem. 24, 451 (1978)

31. Abraham, T., Bery, V. and Kudchadker, P.: J. Chem. Eng. Data 16, 355 (1971)

32. Vitagliano, V., Zagari, A. and Sartorio, R.: J. Chem. Eng. Data 18, 370 (1973)

33. Hafez, M. and Hartland, S.: J. Chem. Eng. Data 21, 179 (1976)

34. Ratkovics, F., Salamon, T. and László, M.: Acta Chim. Acad. Sci. Hung. 66, 259 (1970)

35. Thomas, J. and Evans, D. F.: J. Phys. Chem. 74, 3812 (1970)

36. Della Monica, M. and Bufo, S.: Electrochim. Acta 22, 1213 (1977)

37. Bruno, P. and Della Monica, M.: Electrochim. Acta 20, 179 (1975)

38. Reid, D. S. and Vincent, C. A.: J. Electroanal. Chem. 18, 427 (1968)

39. Kozlowski, Z., Kinart, C. and Bald, A.: Rocz. Chem. 51, 1471 (1977)

40. Dack, M. R. J.: Aust. J. Chem. 28, 1643 (1975)

41. Hamilton, D. and Stokes, R. H.: J. Solution Chem. I, 213 (1972)

42. Rohdewald, P. and Moldner, M.: J. Phys. Chem. 77, 373 (1973)

43. de Visser, C., Pel, P. and Somsen, G.: J. Solution Chem. 6, 571 (1977)

44. Kreis, R. W. and Wood, R. H.: J. Chem. Thermodyn. I, 523 (1969)

45. Kortüm, G. and Hebestreit, Ch.: Z. Phys. Chem. N.F. 93, 235 (1974)

46. Thompson, P. T., Durbano, M., Turner, J. L. and Wood, R. H.: J. Solution Chem. 9. $955(1980)$

47. Moellmer. J. F., Ott, J. B., Goates, J. R. and Farrell, D. W.: J. Chem. Eng. Data 21, 317 (1976)

48. Aoyagi, K. and Albright, J. G.: J. Solution Chem. 6, 635 (1977)

49. Atlani, Ch. and Justice, J.-C.: J. Solution Chem. 4, 955 (1975)

50. Bollinger, J.-C., Yvernault, G. and Yvernault, Th.: J. Solution Chem. 7, 317 (1978)

51. Hanna, E. M., Pethybridge, A. D., Prue, J. E. and Spiers, D. J.: J. Solution Chem. 3, 563 (1974)

52. Sacco, A., Petrella, G., Della Monica, M. and Castagnolo, M.: J. Chem. Soc., Faraday Trans. I 73,1936 (1977)

53. Okpala, Ch., Guiseppi-Elie, A. and Maharajh, D. M.: J. Chem. Eng. Data 25, 384 (1980)

54. Yao. N.-P. and Bennion, D. N.: J. Electrochem. Soc. 118, 1097 (1971)

55. Schiavo, S. Fuoss, R. M., Marrosu, G. and Guida, G.: J. Solution Chem. 8, 557 (1979)

56. Casteel. J. F. and Sears, P. G.: J. Chem. Eng. Data 19, 196 (1974)

57. Cooke, C., McCallum, C., Pethybridge, A. D. and Prue, J. E.: Flectrochim. Acta 20, 591 (1975) 
58. Bicknell, R. T. M., Lawrence, K. G. and Feakins, D.: J. Chem. Soc. Faraday Tranis. 1, $76,637(1980)$

59. D'Aprano, A.: J. Solution Chem. 3, 363 (1974)

60. Covington, A. K. and Dickinson, T. (eds.): Physical Chemistry of Organic Solvent Systems, p. 5, London: Plenum 1973

61. Srinivasan, K. R. and Kay, R. L.: J. Solution Chem. 6, 357 (1977)

62. Akhmetkarimov, K. A., Mai, I. I. and Muldakhmetov, Z. M.: J. General. Chem. USSR (Engl. Transl.) 43, 460 (1973)

63. Hafez, M. and Hartland, S.: J. Chem. Eng. Data 21, 179 (1976)

64. Niki, E., Kamiya, Y. and Ohta, N.: Bull. Chem. Soc. Jpn. 42, 3578 (1969)

65. Shkodin, A. M., Podolyanko, V. A. and Mikhailova, E. N.: Sov. Electrochem. (Engl. Transl.) 10,399 (1974)

66. Pirson, D. J. and Huyskens, P. L.: J. Solution Chem. 3, 503 (1974)

67. Aelenei, N.: Bull. Inst. Politeh. Iasi, Sect. 2: Chim. Ing. Chim. 25, 41 (1979)

68. Miller, L. P., Wachter, H. N. and Fried, V.: J. Chem. Eng. Data 20, 417 (1975)

69. Petrella, G., Castagnolo, M., Sacco, A. and De Giglio, A.: J. Solution Chem. 5, 621 (1976)

70. Ashcroft, St. J., Clayton, A. D. and Shearn, R. B. : J. Chem. Eng. Data 24, 195 (1979)

71. Sears, P. G., Stoeckinger, Th. M. and Dawson, L. R.: J. Chem. Eng. Data 16, 220 (1971)

72. D'Aprano, A.: Gazz. Chim. Ital. 104, 91 (1974)

73. Boerner, B. R. and Bates, R. G.: J. Solution Chem. 7, 245 (1978)

74. Petrella, G. and Sacco, A.: J. Chem. Soc., Faraday Trans. 1 74, 2070 (1978)

75. Jones, A. R. and Aikens, D. A.: J. Chem. Eng. Data 27, 24 (1982)

76. Payne, R. and Theodorou, I. E.: J. Phys. Chem. 76, 2892 (1972)

77. Jansen, M. L. and Yeager, H. L.: J. Phys. Chem. 77, 3089 (1973)

78. Werblan, L. and Lesiński, J.: Pol. J. Chem. 54, 507 (1980)

79. Islam, N., Islam, M. R. and Ahmad, M.: Indian J. Chem. 17A, 126 (1979)

80. Tommila, E. and Lindell, E.: Suom. Kemistil. B42, 93 (1969)

81. Tommila, E. and Yrjövuori, R.: Suom. Kemistil. B42, 90 (1969)

82. Mussche, M. J. and Verhoeye, L. A.: J. Chem. Eng. Data 20, 46 (1975)

83. Kay, R. L. and Broadwater, T. L.: Electrochim. Acta 16, 667 (1971)

84. Fratiello, A. and Kay, R. L.: J. Solution Chem. 3, 857 (1974)

85. Scott, D. W.: J. Chem. Thermodyn. 2, 833 (1970)

86. Hogen-Esch, T. E. and Smid, J.: J. Amer. Chem. Soc. 88, 318 (1966)

87. Carvajal, C., Tölle, K. J., Smid, J. and Szwarc, M.: J. Amer. Chem. Soc. 87, 5548 (1965)

88. Comyn, J., Dainton, F. S. and Ivin, K. J.: Electrochim. Acta 13, 1851 (1968)

89. Hayduk. W., Laudie, H. and Smith, O. H.: J. Chem. Eng. Data 18, 373 (1973)

90. Jagodzinski, P. and Petrucci, S.: J. Phys. Chem. 78, 917 (1974)

91. Kusano, K.: J. Chem. Eng. Data 23, 141 (1978)

92. Renard, E. and Justice, J.-C.: J. Solution Chem. 3, 633 (1974)

93. Takenaka, N. and Arakawa, K.: Bull. Chem. Soc. Jpn. 47, 566 (1974)

94. Canters, G. W.: J. Amer. Chem. Soc. 94,5230 (1972)

95. Phillips, T. W. and Murphy, K. P.: J. Chem. Eng. Data 15, 304 (1970)

96. Wade, J. C. and Taylor, Jr., Z. L.: J. Chem. Eng. Data 18, 424 (1973)

97. Badiali, J.-P., Cachet, J., Cyrot, A. and Lestrade, J.-C.: J. Chem. Soc., Faraday Trans. 2 69, 1339 (1973)

98. Tommila, E. and Autio, T.: Soum. Kemistil. B42, 107 (1969)

99. Paljk, S. and Klofutar, C.: J. Chem. Soc., Faraday Trans. 1 74, 2159 (1978)

100. Hales, J. L. and Townsend, R.: J. Chem. Thermodyn. 4, 763 (1972)

101. Fernández-Prini, R. and Urrutia, G.: J. Chem. Soc., Faraday Trans. 1 72, 637 (1976)

102. Kiyohara, O. and Benson, G.: J. Chem. Eng. Data 26, 263 (1981)

103. Kolthoff, I. M. in: Marchon, J. C. (ed.): Non Aqueous Electrochemistry, p. 312, London: Butterworths 1971

104. Dack, M. R. J. in: Solutions and Solubilities, Part II, in: Weissberger, A. (ser. ed.): Techniques of Chemistry, Vol. 8, p. 95, New York: Wiley 1976

105. Assarsson, P. and Eirich, F. R.: J. Phys. Chem. 72, 2710 (1968)

106. Ioffe, B. V.: Zh. Obsh. Khim. 25, 902 (1955)

107. Barker, B. J. and Caruso, J. A.: J. Amer. Chem. Soc. 93, 1341 (1971) 